\title{
Extracción y bioconversión del ácido clorogénico de la yerba mate en químicos finos
}

\author{
Tesis de Doctorado
}

Ama Oaula Outiuk

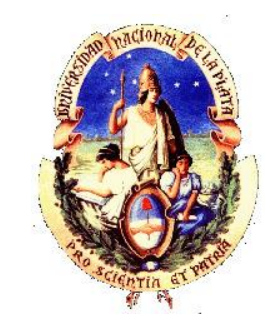

Presentada ante la Facultad de Ingeniería de la

Universidad Nacional de La Plata

como requisito para la obtención del grado académico de

\section{DOCTOR EN INGENIERÍA}

Dirección de Tesis:

Director: Dr. Roque Alberto Hours

Co-director: Dra. María Alicia Martos

Jurado de Tesis:

Dra. Noemi Zaritzky

Dr. Luis A. Brumovsky

Dr. Dr. Javier Breccia

Fecha de la defensa oral y pública: 04 de Marzo de 2016, La Plata, Argentina 
A mamá

A Nanda, Danita y Anita

A mi ángel...mi abuelito..

A Dúbu... 
Extracción y bioconversión del ácido clorogénico de la yerba mate en químicos finos

El presente trabajo de tesis, para optar al título de Doctor de la Facultad de Ingeniería, fue realizado en el Laboratorio de Microbiología y Biotecnología de los Alimentos, Facultad de Ciencias Exactas, Químicas y Naturales, Universidad Nacional de Misiones en colaboración con el Centro de Investigaciones y Desarrollo en Fermentaciones Industriales (CINDEFI), Facultad de Ciencias Exactas, Universidad Nacional de la Plata, con el financiamiento del Consejo Nacional de Investigaciones Científicas y Técnicas (CONICET) y el Instituto Nacional de la Yerba Mate (INYM).

Tesista: Ing. Ana Paula Butiuk

Director: Dr. Roque Alberto Hours

Co-director: Dra. María Alicia Martos 


\section{Agradecimientos:}

A Dios porque he llegado a comprender que sin él nada es posible, por la fuerza que me diste y me das cada hora de mi vida para superar cada problema, cada tristeza, cada fracaso y cada obstáculo. Por la perseverancia y el esfuerzo que pusiste en mi mente desde el primer instante que empecé este recorrido.

A Alicia, mi Co-directora de tesis, mi consejera, mi segunda mamá, por su apoyo, por haber aceptado dirigirme y ser parte de este desafío. Principalmente por su infinito aliento en tiempos donde todo parecía imposible, por hacerme ver que nada era imposible, por estar junto a mí en cada segundo de mi tesis y de mi vida, por dejarme formar parte de su vida.

A mi Director de Tesis, Dr. Roque Hours por su apoyo, por haber aceptado dirigirme, por su estímulo e interés en el éxito de mi trabajo, y principalmente por la confianza durante todo este trabajo.

Al Dr. Osao Adachi el principal motor de este camino, al ideólogo de este trabajo a quien aprecio muchísimo y tuve el honor de conocerlo y el privilegio de tenerlo como maestro. Eternamente agradecida por su paciencia, dedicación y empeño en enseñarme cada técnica, cada detalle de las experiencias, por responder todas mis dudas y consultas a pesar de los kilómetros de distancia. Gracias Sensei por haber sido parte de este camino.

Al Dr. Carlos Mignone un agradecimiento muy especial, por su asesoría y su gran aporte en todo este trabajo, a quien lo recuerdo con gran estima.

A la Ing. Silvana Andrea Maidana por tantas horas de trabajo compartidas, por estar siempre dispuesta, por su aliento en todo momento y su apoyo incondicional. Gracias Silvana por las horas de terapia compartidas, por prestarme tu oído cuando lo necesité, por acompañarme en este viaje.

A Teresita, mi amiga, mi compañera, mi consejera, inmensamente agradecida a Dios por haberte conocido y por poner a una persona maravillosa en mí camino. Gracias por estar siempre, por haberme aguantado en tiempos donde todo parecía imposible y haberme dado palabras de aliento.

Al Dr. Claudio Voget, por prestar su tiempo en brindarme asesoría y aportes en tiempos que lo necesité, pero fundamentalmente por los largos consejos recibidos y los gratos momentos que compartimos.

A los chicos que trabajaron junto a mi este tiempo, por la paciencia interminable, por las largas horas de trabajo compartidas, por su alegría en el laboratorio, en particular a Andre, Emilce, Leo, Ceci y Betina.

A mis amigos de siempre, por ser parte de mi vida y darme el apoyo en todo momento, por tantas andanzas compartidas, a Fer, Sole, Ro, Cami, Caro, Bety, Mari, Gaby, Aldo y Lucas. 
A las chicas de la peluquería, Romi y Cintia, por su incesante aliento y apoyo en el momento más duro de la carrera, por incentivarme en tener cada día más fé en Dios y en mí misma.

A mi abuelo Roberto, mi ejemplo a seguir, mi angelito que me mira desde el cielo y me da fuerzas para seguir siempre adelante. A mi abuela Celia, mi otro angelito, por el apoyo incondicional durante muchas etapas de mi vida, por su fortaleza en todo. Ambos por confiar hasta lo último en mí...

A Anita, mi mamá espiritual, doy gracias a Dios por haberla conocido ya que sin ella no podría haber escrito estas palabras. Por su amor incondicional, su apoyo, su aliento, en los momentos más duros de mi vida. Por prestarme su tiempo y su vida para poder mejorar la mía. Por hacerme ver que detrás de la oscuridad siempre brilla la luz. Por enseñarme que nada es imposible para Dios. Por ayudarme a hacer un cambio en mi vida...

A mi hermana, Nanda, quien me apoyó y alentó en cada momento de mi vida, con quien comparto cada sentimiento, cada emoción, cada alegría. Por caminar juntas de la mano en este camino.

A mi mamá, por haberme criado y logrado lo que hoy soy. Gracias por tu apoyo incondicional, tus palabras de aliento en momentos donde todo parecía oscuro, pero más que nada por tu confianza en mí. Por estar cada segundo de mi vida a mi lado, por escucharme y levantarme en cada tropiezo o fracaso. Por estar conmigo en cada momento.

A Dibu, mi amor, eternamente agradecida por haber conocido a un compañero de vida. Por su apoyo incondicional, su aliento en cada momento de mi vida, por levantarme, por darme amor pero más que nada por su inmensa paciencia en los momentos más duros de mi vida. Gracias mi Dibu por caminar de la mano hacia un mismo destino, hacia un mismo sueño... 
Nuestra recompensa se encuentra en el esfuerzo y no en el resultado...

un esfuerzo total

es una victoria completa...

Mahatma Gandhi 


\section{Publicaciones derivadas de este trabajo de tesis}

\section{Presentaciones a Congresos}

- V Encuentro Regional de Biocatálisis y Biotransformaciones. CCT-La Plata, Buenos Aires, Argentina, 2012.

- Extracto acuoso de yerba mate: novedoso sustrato para la cuantificación de clorogenato hidrolasa. Formato: Póster.

- La yerba mate: un importante inductor de la actividad clorogenato hidrolasa. Formato: Póster.

- XIV Congreso Argentino de Ciencia y Tecnología de Alimentos. Rosario, Argentina, 2013.

- Optimización de la producción de clorogenato hidrolasa de Aspergillus niger utilizando yerba mate como inductor. Formato: Póster y trabajo compelto.

- Preparación de un biocatalizador fúngico con actividad clorogenato hidrolasa utilizando yerba mate. Formato: Póster y trabajo completo.

- VIII Encuentro latinoamericano y del Caribe de biotecnología. Mar del Plata, Argentina, 2013.

- Thermostability of Free and Immobilized Aspergillus niger chlorogenate hydrolase. Formato: Póster.

- An immobilized fungal chlorogenate hydrolase for the production of quinic and caffeic acids from yerba mate extract. Formato: Póster.

- VI Congreso Sudamericano de la Yerba Mate. Montevideo, Uruguay, 2014.

- Optimización de la actividad clorogenato hidrolasa de Aspergillus niger AKU 3302 para su utilización en la bioconversión de ácido 
clorogénico contenido en extractos de yerba mate. Formato: Póster, trabajo completo y presentación oral.

- Caracterización de una clorogenato hidrolasa de Aspergillus niger AKU 3302 inducida con extractos de yerba mate. Formato: Póster y trabajo completo.

- Chlorogenic acid form yerba mate. Formato: Póster.

- V Congreso Internacional de Ciencia y Tecnología de Alimentos. Córdoba, Argentina, 2014.

- Variación del contenido de ácido clorogénico durante el procesamiento de la yerba mate (Ilex paraguariensis). Formato: Póster y trabajo completo.

- $3^{\circ}$ Simposio Argentino de Procesos Biotecnológicos. Santa Fé, Argentina, 2014.

- Caracterización de clorogenato hidrolasa naturalmente inmovilizada en micelio no viable de Aspergillus niger AKU 3302. Formato: Póster y presentación oral.

- IV Congreso Latinoamericano de Ingeniería y Ciencias Aplicadas a la Industria. San Rafael, Mendoza, 2015.

- Extracción de ácido clorogénico a partir de yerba mate (Ilex paraguariensis). Formato: Póster, trabajo completo y presentación oral.

- Modelado de la extracción acuosa de ácido clorogénico a partir de yerba mate (Ilex paraguariensis). Formato: póster.

\section{Publicaciones científicas}

- Yerba mate as a novel inducer for fungal chlorogenate hydrolase production. Butiuk, A.P.; Osao, A. and Hours, R.A. Biocatalysis and Agricultural Biotechnology. Manuscript BAB-D-15-00037. Accepted (June 03, 2015).

- Study of the chlorogenic acid content in yerba mate (Ilex paraguariensis St. Hil.): effect of plant fraction, industrialization step and harvesting 
season. Butiuk, A.P.; Martos, M.A.; Osao, A. and Hours, R.A. Journal of Applied Research on Medicinal and Aromatic Plants. Accepted (December 16, 2015). 


\section{ÍNDICE DE CONTENIDOS}

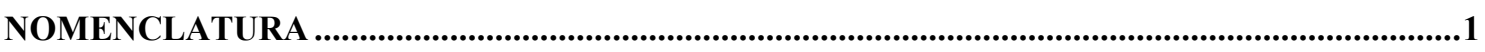

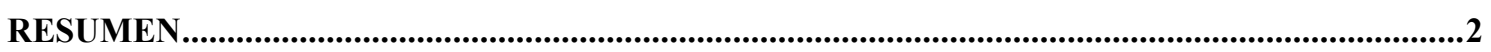

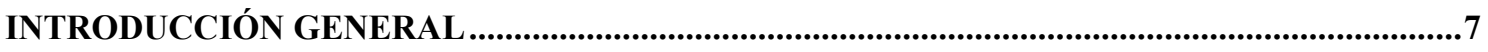

CAPÍTULO 1: LA YERBA MATE (ILEX PARAGUARIENSIS).................................................11

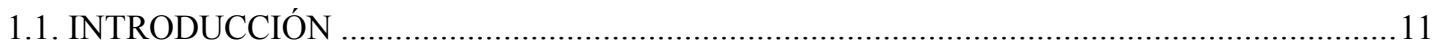

1.2. ASPECTOS HISTÓRICOS SOBRE EL CULTIVO DE LA YERBA MATE ...............................13

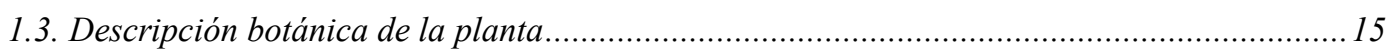

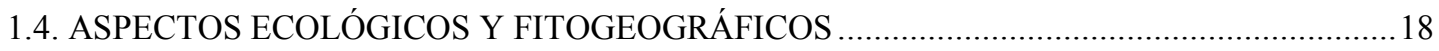

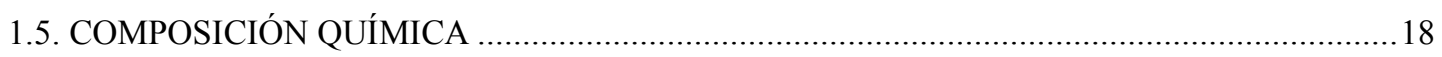

1.5.1. La importancia de los compuestos fenólicos y metilxantinas en yerba mate.........................19

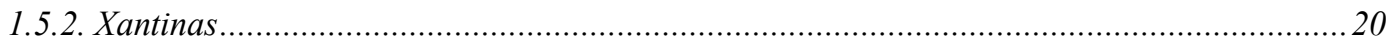

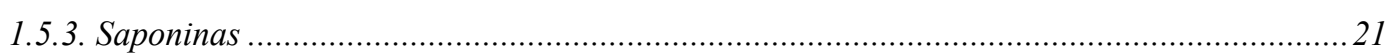

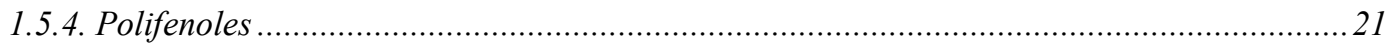

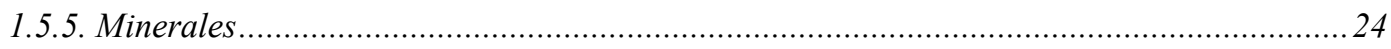

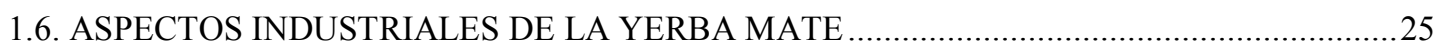

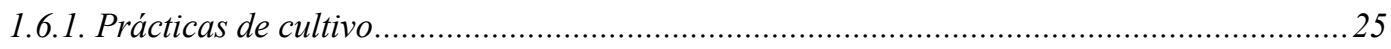

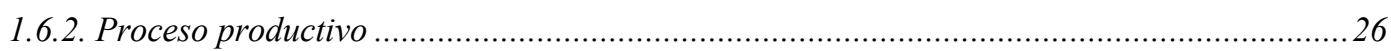

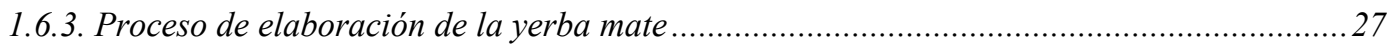

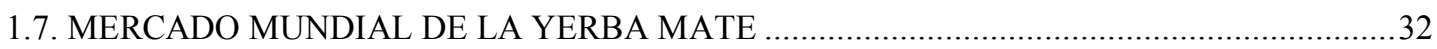

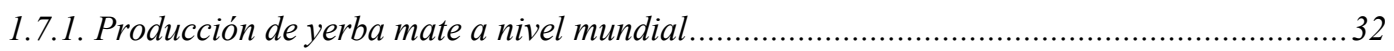

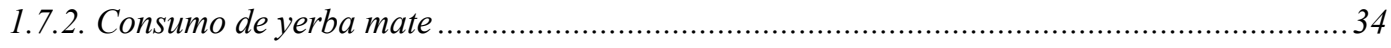

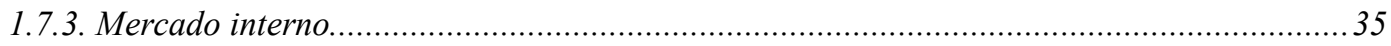

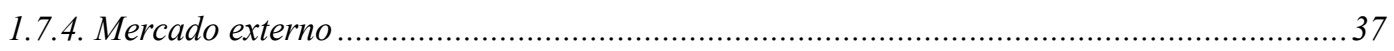

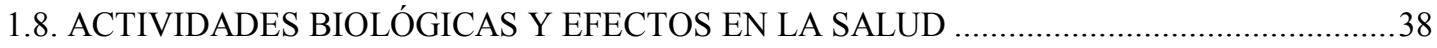

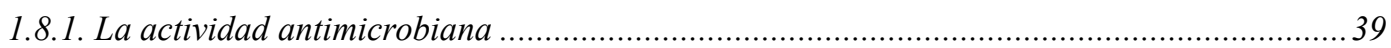

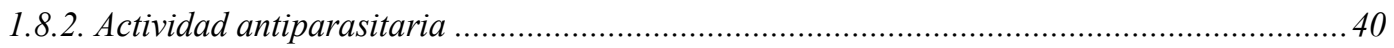

1.8.3. Capacidad antioxidante ............................................................................................. 40

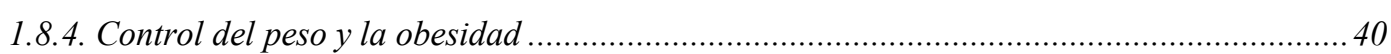

1.8.5. Actividades contra el cáncer .................................................................................. 41

1.9. PRODUCTOS ELABORADOS CON YERBA MATE ……………....................................42

CAPÍTULO 2: EXTRACCIÓN DE ÁCIDO CLOROGÉNICO DE YERBA MATE (ILEX PARAGUARIENSIS): EFECTO DE LA FRACCIÓN VEGETAL, ETAPA DE

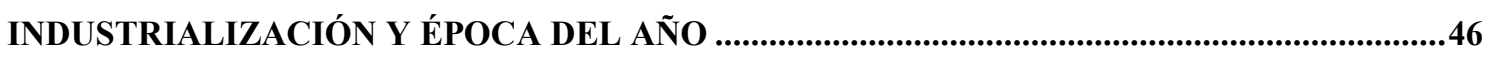

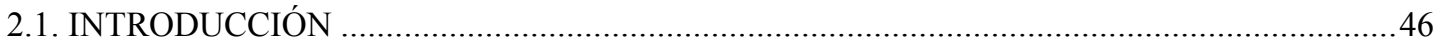

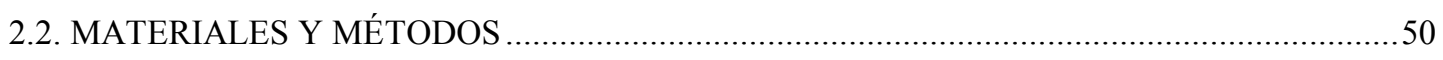

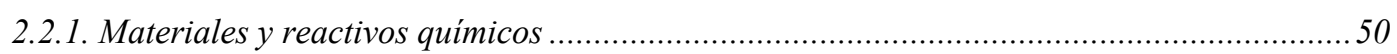

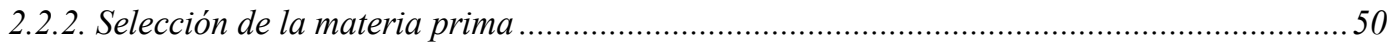


2.2.3. Determinación del contenido de humedad de las muestras ...............................................52

2.2.4. Preparación de los extractos de yerba mate .........................................................................52

2.2.5. Identificación y cuantificación de ácido clorogénico en los extractos de yerba mate ..........53

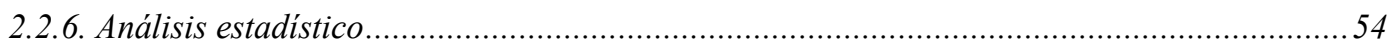

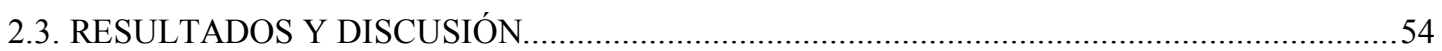

2.3.1. Determinación del contenido de humedad de las muestras ................................................54

2.3.2. Identificación y cuantificación de ácido clorogénico en los extractos de yerba mate ..........55

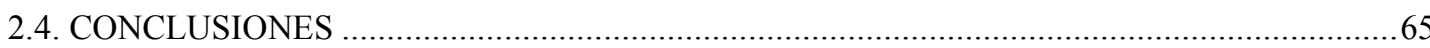

CAPÍTULO 3: OPTIMIZACIÓN Y MODELADO DE LA EXTRACCIÓN ACUOSA DE ÁCIDO

CLOROGÉNICO A PARTIR DE PALOS VERDES DE YERBA MATE (ILEX

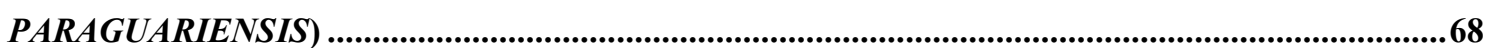

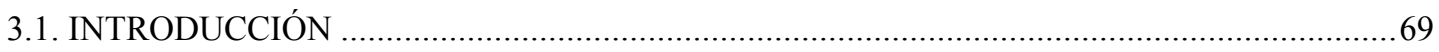

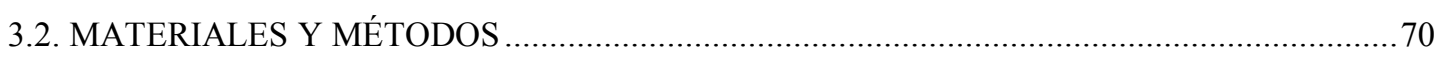

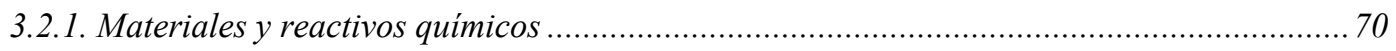

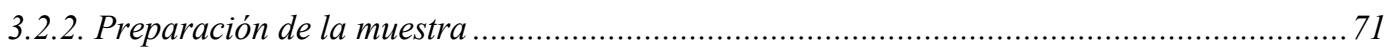

3.2.3. Preparación de los extractos .......................................................................................... 71

3.2.4. Selección de variables relevantes y rangos experimentales............................................ 72

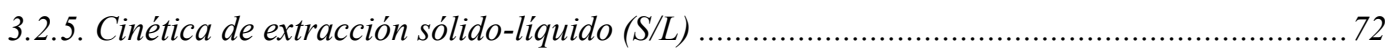

3.2.6. Diseño experimental: Metodología de superficie de respuesta (MSR).............................73

3.2.7. Determinación del contenido de ácido clorogénico en los extractos de yerba mate ............74

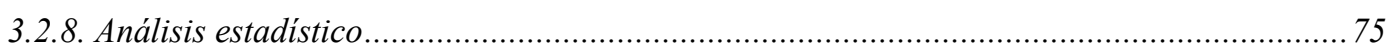

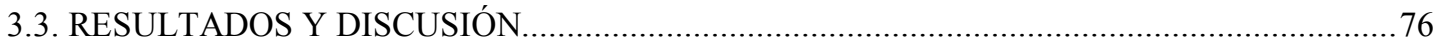

3.3.1. Selección de variables relevantes y rangos experimentales.............................................. 76

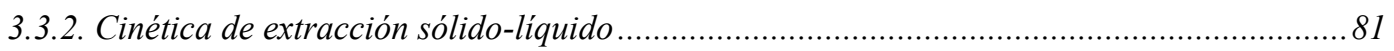

3.3.3. Optimización de la extracción mediante metodología de superficie de respuesta................85

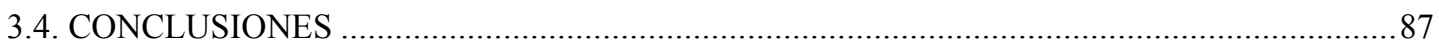

CAPÍtULO 4: PRODUCCIÓN DE CLOROGENATO HIDROLASA POR HONGOS

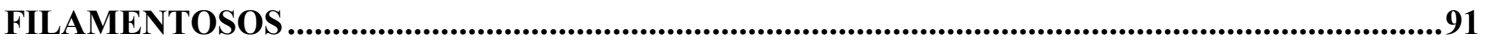

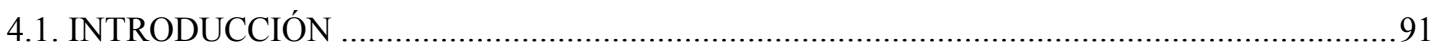

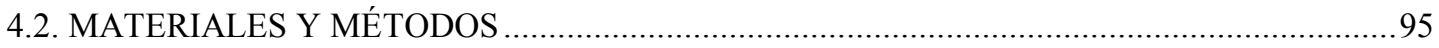

4.2.1. Selección de hongos filamentosos como fuentes potenciales de CHasa ..............................95

4.2.2. Efecto de diferentes muestras de yerba mate (Ilex paraguariensis) como inductores de

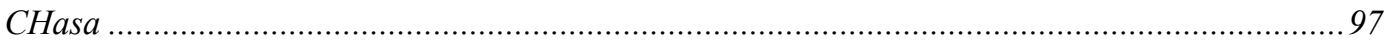

4.2.3. Efecto de la concentración del inductor sobre la producción de CHasa ............................99

4.2.4. Condiciones óptimas para la producción de CHasa mediante un diseño experimental .......99

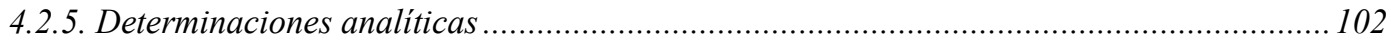

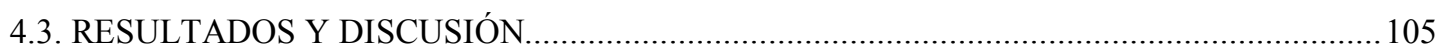

4.3.1. Preselección de hongos filamentosos como fuentes potenciales de CHasa....................... 105 
4.3.2. Efecto de diferentes muestras de yerba mate (Ilex paraguariensis) como inductores de

CHasa por A. niger AKU 3302 .

4.3.3. Efecto de la concentración del extracto concentrado de yerba mate sobre la producción de

CHasa por A. niger AKU 3302 .

4.3.4. Efecto combinado de la concentración de extracto de yerba mate y del tiempo de inducción sobre la producción de CHasa por A. niger AKU 3302. 114

4.4. CONCLUSIONES

CAPÍTULO 5: CLOROGENATO HIDROLASA DE $A$. NIGER AKU 3302: CARACTERIZACIÓN Y APLICACIÓN EN LA HIDRÓLISIS DEL ÁCIDO CLOROGÉNICO CONTENIDO EN UN

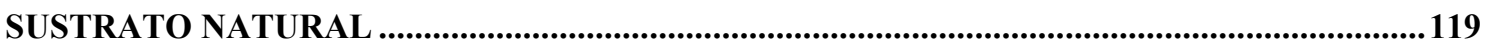

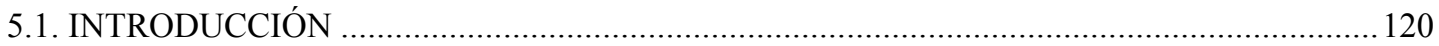

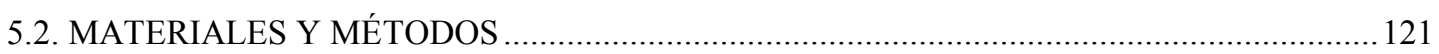

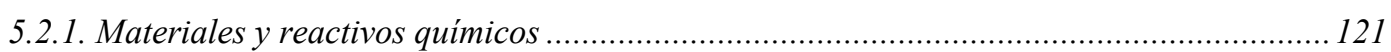

5.2.2. Obtención del extracto enzimático................................................................. 122

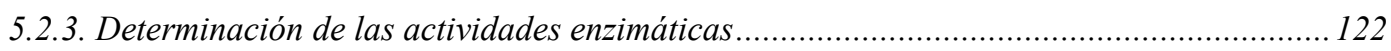

5.2.4. Caracterización de la actividad CHasa .......................................................................... 124

5.2.5. Ensayos de hidrólisis enzimática de ácido clorogénico en el extracto concentrado de yerba

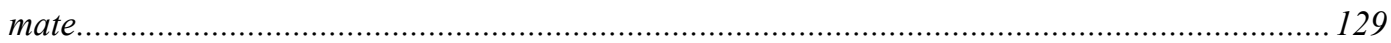

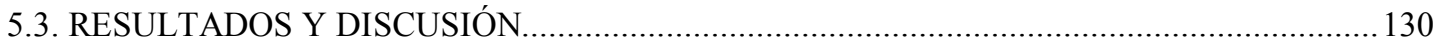

5.3.1. Caracterización parcial de actividades enzimáticas ................................................. 130

5.3.2. Caracterización parcial de la actividad CHasa .............................................................. 131

5.3.3. Ensayos de hidrólisis de ácido clorogénico en el extracto concentrado de yerba mate ..... 141

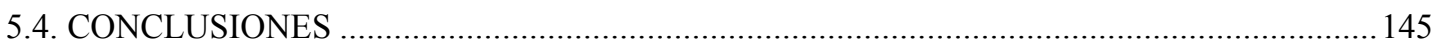

CAPÍTULO 6: PRODUCCIÓN Y CARACTERIZACIÓN DE UN MICELIO INMOBILIZADO DE $A$. NIGER AKU 3302 CON ACTIVIDAD CLOROGENATO HIDROLASA ..........................148

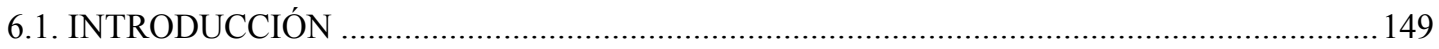

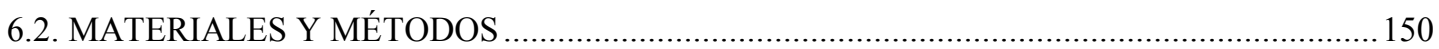

6.2.1. Producción de micelio de Aspergillus niger AKU 3302 con actividad CHasa..................150

6.2.2. Preparación de micelio no viable con actividad CHasa naturalmente inmovilizada

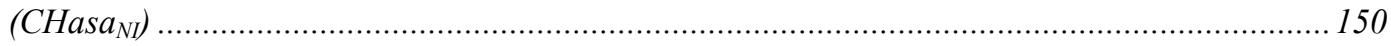

6.2.3. Efecto de la velocidad de agitación y la carga del catalizador sobre la hidrólisis del ACG

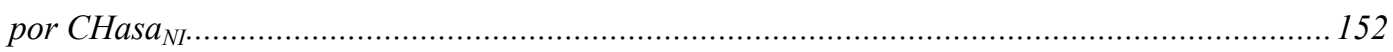

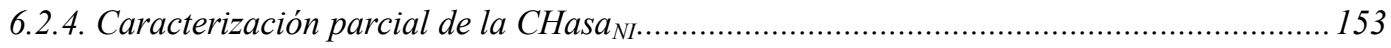

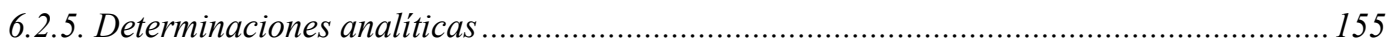

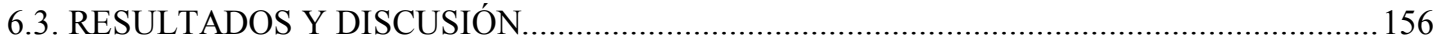

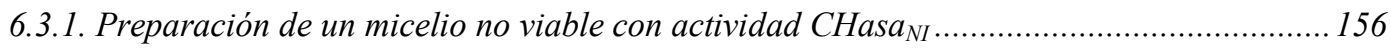

6.3.2. Efecto de la velocidad de agitación y la carga del catalizador sobre la hidrólisis del ACG

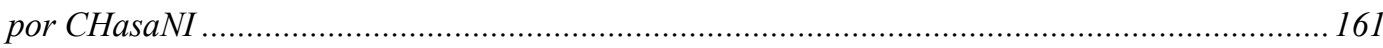

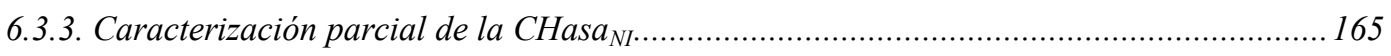


6.4. CONCLUSIONES

CAPÍTULO 7: BIOCONVERSIÓN DEL ÁCIDO CLOROGÉNICO DE LA YERBA MATE A ÁCIDOS QUÍNICO Y CAFEICO EN UN BIORREACTOR DE LECHO EMPAQUETADO .....180

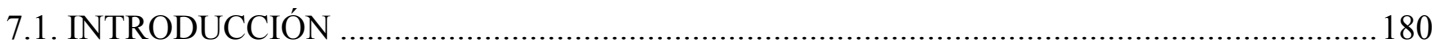

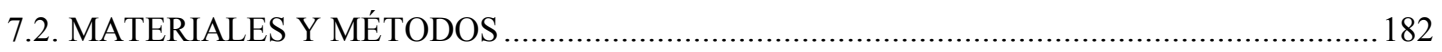

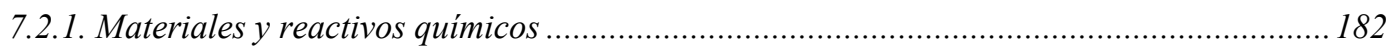

7.2.2. Preparación de CHasa naturalmente inmovilizada $\left(\mathrm{CH} \mathrm{Had}_{\mathrm{NI}}\right)$..................................... 182

7.2.3. Obtención del extracto de yerba mate con elevado contenido de ACG............................. 182

7.2.4. Determinación de la actividad clorogenato hidrolasa .................................................. 183

7.2.5. Operación del reactor de lecho empaquetado para la producción de $A Q$ y AC................ 183

7.2.6. Identificación de los productos de reacción ................................................................... 185

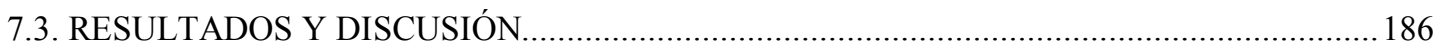

7.3.1. Bioconversión de ACG en $A C$ y $A Q$ mediante un BLE a un caudal fijo............................ 186

7.3.2. Efecto del tiempo de residencia sobre la bioconversión de ACG en el BLE ..................... 191

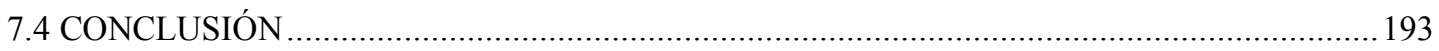

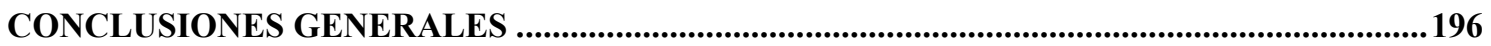

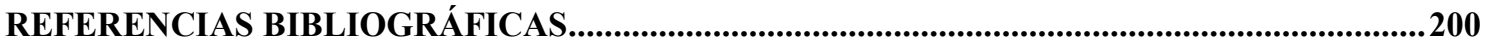




\section{NOMENCLATURA}

AC: ácido cafeico

ACG: ácido clorogénico

ACM: agar Czapek modificado

AQ: ácido quínico

ASK: ácido siquímico

BLE: biorreactor de lecho empaquetado

BFS: buffer fosfato de sodio

BTMG: buffer Tris-Mes-Glicina

CHasa: clorogenato hidrolasa

CHasa $_{N I}$ : clorogenato hidrolasa naturalmente inmovilizada

CLM: Czapek líquido modificado

EE: extracto enzimático

EYM: extracto concentrado de yerba mate

-MD: mate cocido instantáneo sin malto dextrina

+MD: mate cocido instantáneo con malto dextrina

PD: polvo de yerba mate (residuo de la elaboración de yerba mate)

PPO: polifenoloxidasa

$\mathbf{P V}_{\mathbf{Y M}}$ : palos verdes de yerba mate

VM: viabilidad del micelio 


\section{RESUMEN}

\section{$1^{\circ}$ Etapa}

Se analizó el contenido de ácido clorogénico (ACG) en muestras de yerba mate (Ilex paraguariensis) obtenidas de dos plantas de procesamiento ubicadas al Sur de la provincia de Misiones-Argentina, a lo largo de las diferentes etapas de procesamiento y en dos épocas del año. El contenido total de ACG (expresado en base seca) varió desde 4,58 $\pm 0,04$ a 8,08 $\pm 0,10 \mathrm{~g}$ ACG/100 g hojas, y de 3,16 $\pm 0,06$ a 7,89 $\pm 0,53 \mathrm{~g} \mathrm{ACG/100}$ g palos, a lo largo de las diferentes etapas de industrialización. El contenido de ACG decreció a lo largo de las diferentes etapas de industrialización. El análisis cuantitativocomparativo indicó que el mayor contenido de ACG fue encontrado en las muestras de yerba mate recién cosechada: hoja y palo verde. No hubo diferencias significativas ( $\mathrm{p}<$ $0,05)$ en el contenido de ACG entre estas muestras. El contenido de ACG al inicio de la época de zafra fue sustancialmente mayor al obtenido al final de la época de zafra, tanto para las hojas como para los palos verdes.

Se evaluó el método de extracción acuosa sólido-líquido más adecuado, para obtener un extracto rico en ACG, a partir de muestras de palo verde de yerba mate ( $\left.\mathrm{PV}_{\mathrm{YM}}\right)$, material vegetal previamente seleccionado debido a su elevado contenido en ACG. La relación sólido/líquido $(\mathrm{S} / \mathrm{L})$ óptima fue de 1:20 (p/v), a mayor relación disminuyó la extracción de ACG debido a la saturación del extracto. El ACG extraído en las dos primeras etapas de extracción representó el 98,5 \% del contenido total de ACG de las tres etapas. A partir de la relación $\mathrm{S} / \mathrm{L}$ óptima se evaluó la cinética de extracción a $80^{\circ} \mathrm{C}$ para los dos tamaños de partículas. El tiempo de extracción tuvo influencia significativa únicamente para las partículas de mayor tamaño $(1 \times 5 \mathrm{~mm}<$ tamaño de partícula $<2,5$ $\times 5 \mathrm{~mm})$, mientras que la mayor concentración de ACG (1,05 g ACG/1) fue extraída con partículas de menor tamaño $(\varnothing$ partícula $<500 \mu \mathrm{m}$ ), siendo en este caso el proceso de extracción prácticamente instantáneo.

Se realizó un estudio cinético con las partículas de mayor tamaño, el mismo indicó que la extracción de ACG aumentó con el tiempo de extracción hasta los 30 min para todas las temperaturas evaluadas. Así mismo la extracción de ACG aumentó con la temperatura de extracción hasta $\operatorname{los} 80^{\circ} \mathrm{C}$; sin embargo, un incremento adicional de la temperatura $\left(100^{\circ} \mathrm{C}\right)$ condujo a una disminución de la extracción. La cinética de 
extracción acuosa de ACG se ajustó adecuadamente dos modelos matemáticos $\left(\mathrm{R}^{2}>\right.$ $0,90)$ y los resultados obtenidos con el diseño de superficie de respuesta indicaron que los valores óptimos para tiempo y temperatura de extracción fueron 25-30 min y 80-90 ${ }^{\circ} \mathrm{C}$, respectivamente, alcanzando en este caso una concentración de ACG de 0,43 g ACG/1.

\section{$2^{\circ}$ Etapa}

Se analizó la producción de la enzima clorogenato hidrolasa (EC 3.1.1.42, CHasa) por varias cepas fúngicas utilizando materiales derivados del procesamiento de la yerba mate como inductores de la actividad enzimática. Todas las cepas fúngicas ensayadas presentaron actividad CHasa. Sin embargo, la CHasa fue altamente inducida en los micelios de Aspergillus niger AKU 3302, observándose las manchas más intensas de ácido cafeico en el TLC con las concomitantes reducciones en ACG, y el valor de actividad más elevado $(6,49 \mathrm{UE} / \mathrm{ml})$. Todas las muestras de yerba mate produjeron actividad CHasa, pero el extracto concentrado de yerba mate (EYM) fue seleccionado como el inductor más conveniente. El diseño experimental reveló que la producción óptima de CHasa ( $\approx 12 \mathrm{UE} / \mathrm{ml})$ se alcanza a largos tiempos de inducción $(\geq 25 \mathrm{~h}) \mathrm{y}$ bajas concentraciones de inductor $(0,1-0,2 \% \mathrm{p} / \mathrm{v}$, en base seca).

Se realizó la producción de CHasa de A. niger AKU 3302 en medio Czapek líquido modificado, a escala frascos agitados $(180 \mathrm{rpm})$ y a $30{ }^{\circ} \mathrm{C}$, al cual se le adicionó un EYM al final de la etapa exponencial de crecimiento.

En el extracto enzimático no se detectó actividad polifenoloxidasa. La CHasa presentó mayor actividad a pHs ligeramente neutros y fue estable en un rango de $\mathrm{pH}$ entre 2,0 a 9,0 y hasta $50{ }^{\circ} \mathrm{C}$. El diseño experimental reveló que la actividad CHasa óptima se alcanza a una temperatura de $45^{\circ} \mathrm{C}$. Los valores de $\mathrm{K}_{\mathrm{m}}$ para la CHasa estimados a partir de la gráfica de Lineweaver-Burk y la gráfica de Eadie-Hofstee fueron de 0,257 y 0,229 $\mathrm{g} / \mathrm{l}$, respectivamente. Mientras que los valores de $\mathrm{V}_{\text {máx }}$ obtenidos con cada gráfica fueron de 1,996 y 1,901 $\mu \mathrm{mol} / 1$.min, respectivamente. El coeficiente de temperatura fue de 1,5 y la energía de activación $\left(\mathrm{E}_{\mathrm{a}}\right)$ de $6,38 \mathrm{kcal} / \mathrm{mol}$. Se demostró la capacidad de la CHasa para hidrolizar el ACG contenido en sustratos naturales como el EYM.

Se preparó un micelio no viable de A. niger AKU 3302 con actividad CHasa naturalmente inmovilizada $\left(\mathrm{CHasa}_{\mathrm{NI}}\right)$. La relación óptima entre inactivación térmica del 
micelio y elevada actividad CHasa fue observada luego de un tratamiento térmico a 55 ${ }^{\circ} \mathrm{C}$ por 60 min, reteniendo bajo estas condiciones cerca del $90 \%$ de la actividad inicial. Se determinaron las condiciones óptimas de operación de la $\mathrm{CHasa}_{\mathrm{NI}}$, así como sus parámetros cinéticos y termodinámicos a fin de establecer las condiciones apropiadas para su utilización en la hidrólisis del ACG presente en sustratos naturales. Las condiciones óptimas de operación para la $\mathrm{CHasa}_{\mathrm{NI}}$ naturalmente fueron: $50{ }^{\circ} \mathrm{C}, \mathrm{pH} 6,5 \mathrm{y}$ una velocidad de agitación de 100 golpes/min. Los valores de $\mathrm{K}_{\mathrm{m}}$ para la enzima $\mathrm{CHasa}_{\mathrm{NI}}$ estimados a partir de la gráfica de Lineweaver-Burk y la gráfica de EadieHofstee fueron de 0,48 y 0,50 g/l, respectivamente. Mientras que los valores de $\mathrm{V}_{\text {máx }}$ obtenidos con cada gráfica fueron de 4,149 y 4,414 $\mu$ mol/l.min, respectivamente. $\mathrm{CHasa}_{\mathrm{NI}}$ fue estable en un rango de $\mathrm{pH}$ entre 2,0 - 9,0 y hasta $50{ }^{\circ} \mathrm{C}$ durante $8 \mathrm{~h}$. Los cationes que produjeron una disminución de la actividad CHasa fueron $\mathrm{Fe}^{+3} \mathrm{y} \mathrm{Zn}^{+2}$. Los resultados obtenidos demuestran la aplicación potencial de los pellets del micelio de A. niger AKU 3302 como un biocatalizador naturalmente inmovilizado con actividad CHasa. Las propiedades y la estabilidad de la enzima exhibieron características interesantes que pueden ser adecuadas para su aplicación futura en la bioconversión del ACG. Además, la alta estabilidad operacional de la CHasa naturalmente inmovilizada propicia su aplicabilidad para la hidrólisis continua de este sustrato presente en extractos naturales.

\section{$3^{\circ}$ Etapa}

La obtención de un extracto acuoso con elevado contenido de ACG a partir de los palos de yerba mate $\left(1^{\circ}\right.$ Etapa) y la utilización de la $\mathrm{CHasa}_{\mathrm{NI}}$ como biocatalizador enzimático capaz de hidrolizar el ACG en AC y AQ (2 ${ }^{\circ}$ Etapa), constituyen la fuente y el proceso necesarios para la obtención de los metabolitos de interés, respectivamente.

Con el fin de desarrollar una producción más práctica de estos metabolitos, se propuso la utilización de un biorreactor del tipo lecho empaquetado conteniendo la CHasa $\mathrm{NI}$ como relleno del biorreactor a través del cual se hizo circular en forma ascendente una solución de $\mathrm{PV}_{\mathrm{YM}}$. El ACG inicialmente presente en el extracto de $\mathrm{PV}_{\mathrm{YM}}$ fue completamente convertido en $\mathrm{AC}$ y $\mathrm{AQ}$ al circular a través de un biorreactor de lecho empaquetado, alcanzándose rendimientos del $100 \%$ de conversión al trabajar a un caudal de 13,6 ml/h. Se confirmó la eficacia de la CHasa ${ }_{N I}$ como biocatalizador 
inmovilizado estable con actividad CHasa, y su estabilidad para usos repetidos durante varias veces $(\sim 12 \mathrm{~h})$ sin pérdida apreciable de la actividad catalítica. Se alcanzaron conversiones de AC y AQ mayores al 100\%, lo cual se podría deber a que tanto el AC como el AQ fueron liberados a partir de otros ésteres diferentes al ACG por la acción de otras esterasas intracelulares (además de CHasa). Se confirmó la eficacia de la inactivación térmica del micelio de $A$. niger AKU 3302 ya que no se observó formación de gas $\left(\mathrm{CO}_{2}\right)$ por respiración al hacer circular una solución de ACG a través del biorreactor de lecho empaquetado. 
Introduceión General 


\section{INTRODUCCIÓN GENERAL}

El ácido clorogénico (ACG) es una sustancia formada por un resto de ácido quínico (AQ) unido mediante unión éster en la posición 5, a otro ácido carboxílico, el ácido cafeico (AC). El ACG se encuentra naturalmente presente en altas concentraciones en diferentes vegetales (pulpa de remolacha, papa, batata, salvado de trigo, manzana, pera) y principalmente en los frutos del café, sobre todo en los granos de café verde, siendo este último la principal fuente natural de ACG, hasta la fecha (Clifford, 1999; Clifford, 2000).

La hidrólisis del ACG produce cantidades estequiométricas de AQ y AC. El AC, ampliamente utilizado debido a su reconocida capacidad antioxidante, es obtenido a partir de vegetales ricos en compuestos polifenólicos (Chen y Ho, 1997). Por otro lado, el AQ comercial se obtiene en muy bajas cantidades a partir de corteza de quina, granos de café y otros productos vegetales. Menor atención se le ha dado a la producción de $\mathrm{AQ}$, respecto a la de $\mathrm{AC}$, debido a su limitada utilización. Sin embargo, el AQ es considerado un intermediario clave en la síntesis de nuevos fármacos. Se ha reportado que el AQ es fácilmente convertido a ácido siquímico (ASK) vía 3-dehidroquinato y 3dehidrosiquimato (Fig. A), mediante la acción de enzimas de bacterias acéticas (Adachi y col., 2006a, b, c; Adachi y col., 2008b). El ASK es un precursor directo de la síntesis química de la droga antiviral Oseltamivir, el principio activo del Tamiflú ${ }^{\mathrm{MR}}$ (Enserink, 2006). Por lo tanto, resulta importante desarrollar un proceso alternativo para la producción competitiva de AQ para su posterior conversión en químicos finos valiosos, como el ASK.

Una alternativa a la producción de AQ lo constituye el tratamiento ácido de vegetales ricos en ACG. Este método produce, además del $\mathrm{AC}$ y $\mathrm{AQ}$, una proporción relativamente alta de sub-productos, siendo necesario un proceso adicional de aislamiento y purificación muy laborioso y costoso, además de generar residuos altamente contaminantes difíciles de ser tratados adecuadamente antes de su disposición final. Por lo tanto, resulta conveniente desarrollar un método alternativo para la obtención de AQ a partir del ACG contenido en materiales vegetales ricos en este compuesto, que resulte en una producción más limpia y competitiva respecto a la hidrólisis ácida. 
La clorogenato hidrolasa (CHasa, EC 3.1.1.42) es el nombre sistemático de una enzima que cataliza la hidrólisis del ACG, formando AQ y AC. Esta enzima pertenece a la familia de las hidrolasas, específicamente a aquellas que actúan sobre los enlaces éster carboxílicos. Otros nombres de uso común incluyen clorogenasa y esterasa de ácido clorogénico. La CHasa es una enzima intracelular, inducible, producida por diferentes especies de Aspergillus cultivados en medios suplementados con materiales vegetales ricos en ACG (Okamura y Watanabe, 1982b; Asther y col., 2005; Adachi y col., 2008). El uso del micelio del hongo desarrollado en medio líquido, en forma de pellets, puede ser utilizado como biocatalizador naturalmente inmovilizado (Romano y col., 2005) para la hidrólisis de ACG contenido en extractos vegetales. Esta es una tecnología innovadora capaz de reducir los problemas de contaminación ambiental que se generan con la hidrólisis química en condiciones ácidas. Con los procesos de inmovilización enzimática se han podido superar los inconvenientes de inhibición enzimática (por sustrato y/o productos). A la vez, se presenta la posibilidad de la reutilización del catalizador, permitiendo que el proceso biotecnológico sea económicamente rentable. Asimismo el uso de células enteras con actividad biocatalítica evita las etapas de purificación necesarias en el caso de enzimas con el concomitante riesgo de inactivación y aumento de costos.

Estudios recientes han reportado que la yerba mate (Ilex paraguarienses), un recurso natural y autóctono de la Provincia de Misiones, Argentina, posee un alto contenido de ACG, superior al encontrado en los derivados del café (Marques y Farah, 2009; Isolabella y col., 2010; Pagliosa y col., 2010). Además, el contenido en sustancias lipídicas y compuestos polifenólicos coloreados de la yerba mate es bajo, lo cual redunda en mayores facilidades y menores costos en las etapas de extracción, bioconversión y purificación de productos (intermedios y finales).

El uso potencial de un sistema de enzima inmovilizada con actividad CHasa podría ser de considerable importancia económica para la hidrólisis enzimática del ACG contenido en extractos de yerba mate, para la obtención de $\mathrm{AC}$ y $\mathrm{AQ}$, siendo este último un intermediario clave en la síntesis de químicos finos (ASK). 


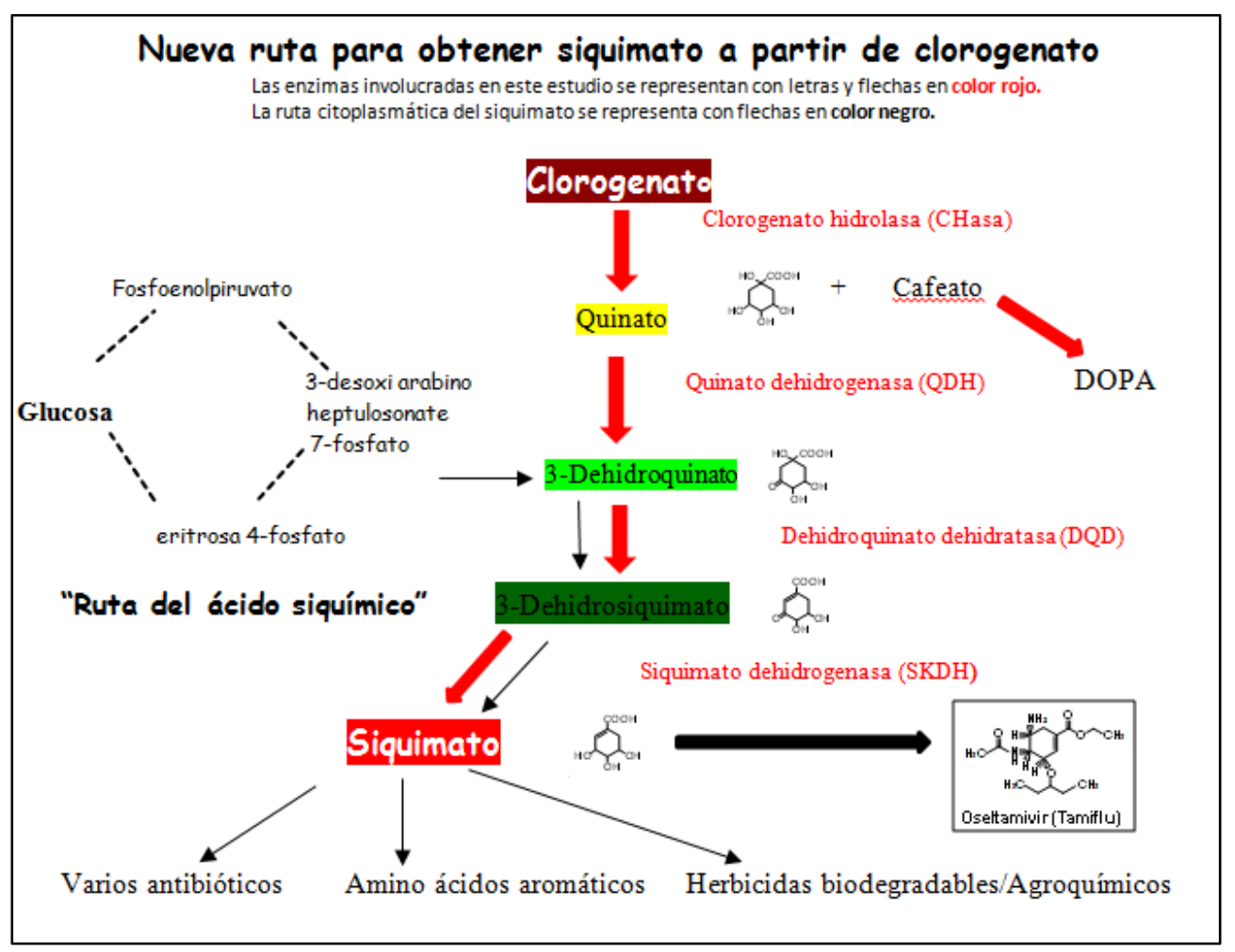

Figura A: Ruta propuesta para la obtención de ácido siquímico a partir de ácido clorogénico.

HIPÓTESIS: El ácido clorogénico de la yerba mate es la materia prima para obtener ácido siquímico.

OBJETIVO GENERAL: Desarrollar una tecnología innovadora, que permita contribuir a la valorización de la yerba mate, como fuente novedosa de ácido clorogénico para su biotransformación en químicos finos.

\section{OBJETIVOS ESPECÍFICOS:}

$\checkmark$ Obtención de un extracto acuoso de yerba mate con elevado contenido de ácido clorogénico (ACG).

$\checkmark$ Producción de la enzima clorogenato hidrolasa (CHasa) a partir de hongos filamentosos y determinación de sus condiciones óptimas de operación.

$\checkmark$ Aplicación de la enzima CHasa en la hidrólisis enzimática del ACG contenido en un extracto de yerba mate. 


\section{Capítulo 1}

Laa yerba mate ( Hex paraguariensis) 


\section{CAPÍTULO 1 \\ La yerba mate (Ilex paraguariensis)}

\subsection{INTRODUCCIÓN}

La yerba mate (Ilex paraguariensis St. Hil., Aquifoliaceae) es una planta autóctona de la región central del MERCOSUR, cuyas hojas y ramas más jóvenes se consumen convenientemente procesadas. La producción anual en la región es de aproximadamente 806.324 ton, de las cuales el $90 \%$ se comercializa localmente y el resto se exporta a otros países, principalmente al Medio Oriente

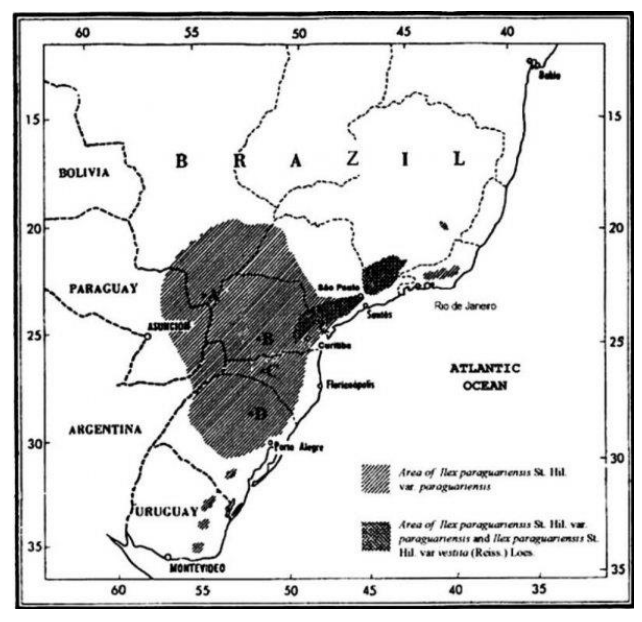
(Instituto Nacional de la Yerba Mate, 2015).

El Código Alimentario Argentino en su Artículo 1193 (Resolución Conjunta SPRyRS y SAGyPA N $\mathrm{N}^{\circ}$ 41/2006 y $\mathrm{N}^{\circ}$ 641/2006) dice: “Con la denominación de Yerba Mate o Yerba se entiende el producto formado por las hojas desecadas, ligeramente tostadas y desmenuzadas, de Ilex paraguariensis Saint Hilaire (Aquifoliácea) exclusivamente, mezcladas o no con fragmentos de ramas secas jóvenes, pecíolos y pedúnculos florales".

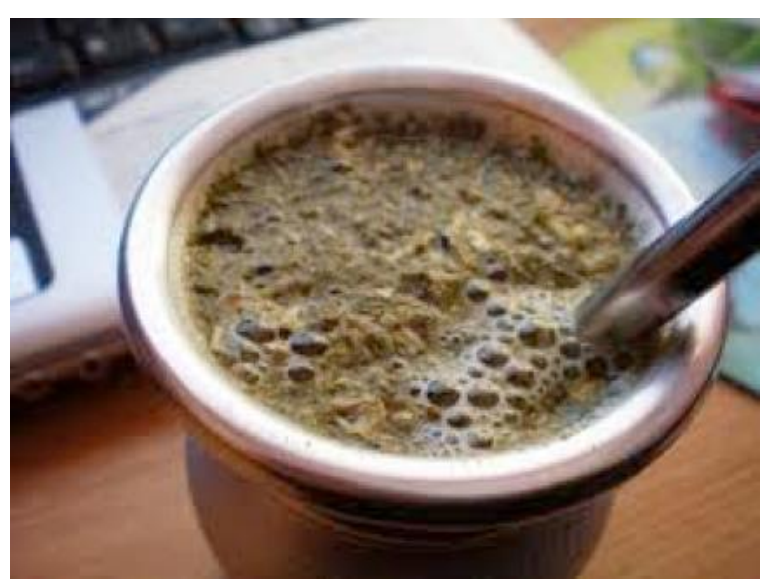
El consumo de la yerba mate, por lo general, se lleva a cabo en la forma denominada "mate". En esta forma de consumo se coloca una porción de 30 a $50 \mathrm{~g}$ de yerba mate en un recipiente $\mathrm{y}$ sobre el mismo se vierten porciones de aproximadamente $20 \mathrm{ml}$ de agua, succionándose por medio de una bombilla. En general se emplean entre 0,5 y 1 L por cada porción de yerba mate.

En el denominado "mate caliente", el agua vertida tiene una temperatura entre 70 y 85 ${ }^{\circ} \mathrm{C}$. En algunas zonas cálidas de la región y principalmente en los meses cálidos, se consume con agua fría $\left(5-10^{\circ} \mathrm{C}\right)$, denominándose a esta forma de consumo mate frío o “tereré" (Ramallo et al., 1998). La modalidad del consumo del mate varía en los diferentes países del MERCOSUR. Las preferencias argentinas son hacia la yerba mate 
con molienda gruesa y mucho tiempo de estacionamiento. En Brasil se prefiere la yerba mate de molienda fina y sin estacionamiento mientras que en Uruguay se prefiere la yerba mate estacionada y con un grado de molienda mayor que el argentino en tanto que en Paraguay las preferencias de consumo son similares a la Argentina.

Una segunda modalidad de consumo es en forma de infusión, en la que la yerba mate (a granel o en saquitos) se consume en forma similar al té con agua a temperaturas cercanas a la de

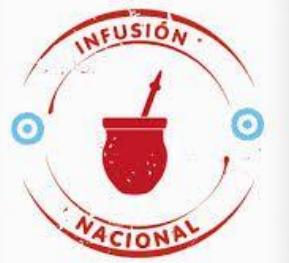
ebullición. Es frecuente encontrar esta modalidad de consumo en el desayuno o a media tarde.

En los últimos años, aparecen otras dos formas de consumo: como bebida carbonatada o como "soluble en forma sólida" con la que se preparan bebidas calientes. Estos dos productos no están aún muy expandidos. Además, existen otros usos de la yerba mate que serán mencionados en el punto correspondiente.

En la Figura 1 se detalla el así denominado "circuito de la yerba mate" donde se resumen las diferentes etapas que van desde la planta hasta su uso.

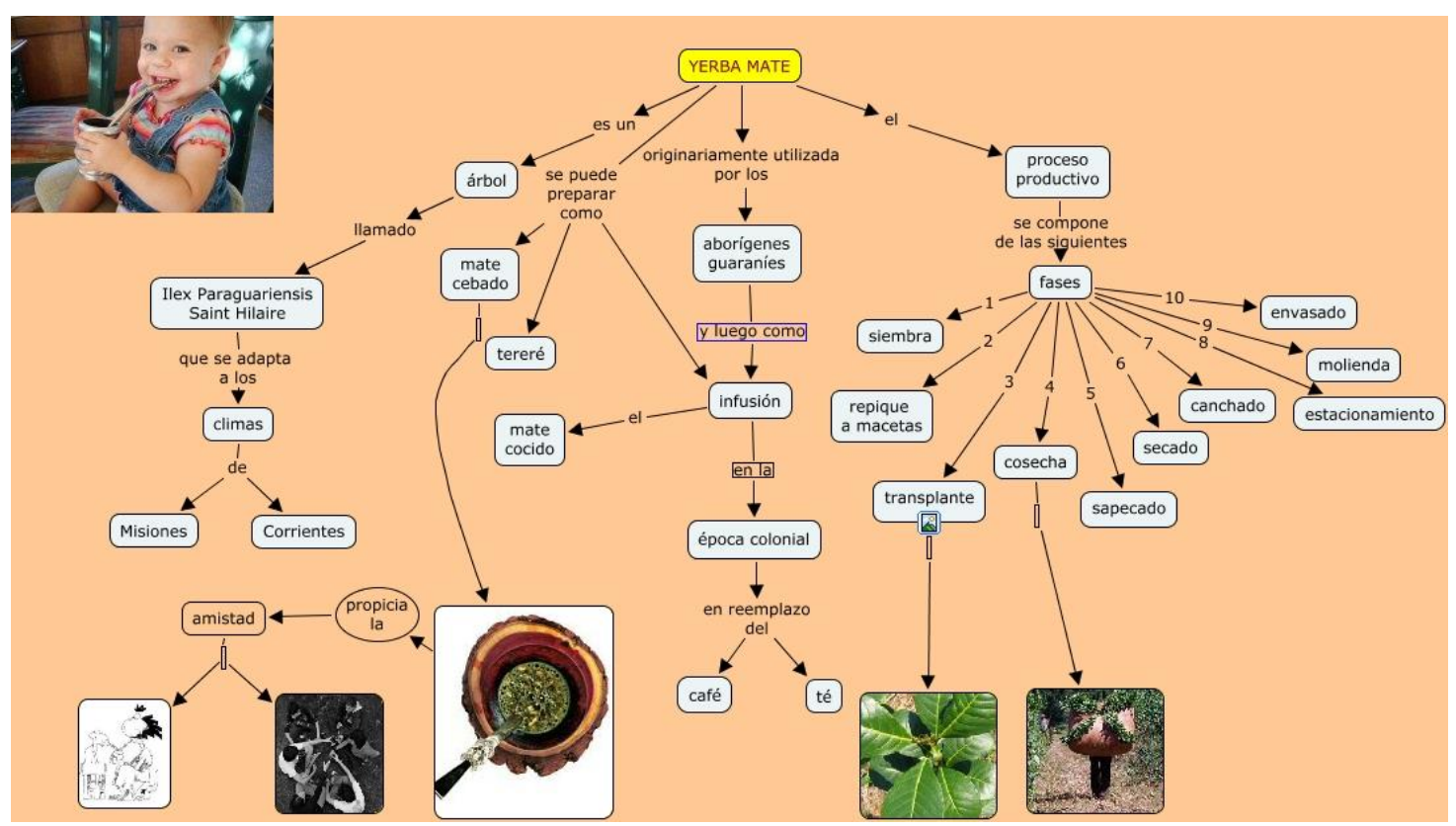

Figura 1.1: Circuito de la yerba mate.

El Gobierno argentino oficializó el 02 de agosto de 2013 la ley 26871- aprobada en julio de 2013- que declara al mate como "infusión nacional", con el objetivo de impulsar su 
promoción en el mundo. El texto de dicha ley define al mate como "la infusión preparada en base al alimento de yerba mate, que colocada en un recipiente y mojada con agua caliente, es bebida mediante una bombilla". Además, se menciona en la norma que: "En eventos y actividades culturales, sociales o deportivas de carácter oficial, debe preverse la presencia de la expresión y logotipo de 'Mate Infusión Nacional', y la promoción de dicha bebida y sus tradiciones".

\subsection{ASPECTOS HISTÓRICOS SOBRE EL CULTIVO DE LA YERBA MATE}

El origen del nombre de la yerba mate, alimento de los indios guaraníes, proviene del término "caá" que significa en guaraní "planta o hierba", en tanto que "mate" se supone que deriva de la palabra quichua "mati", que era la calabaza que usaban para tomar mate. Para su consumo, los indios guaraníes utilizaban bombillas hechas de cañas.

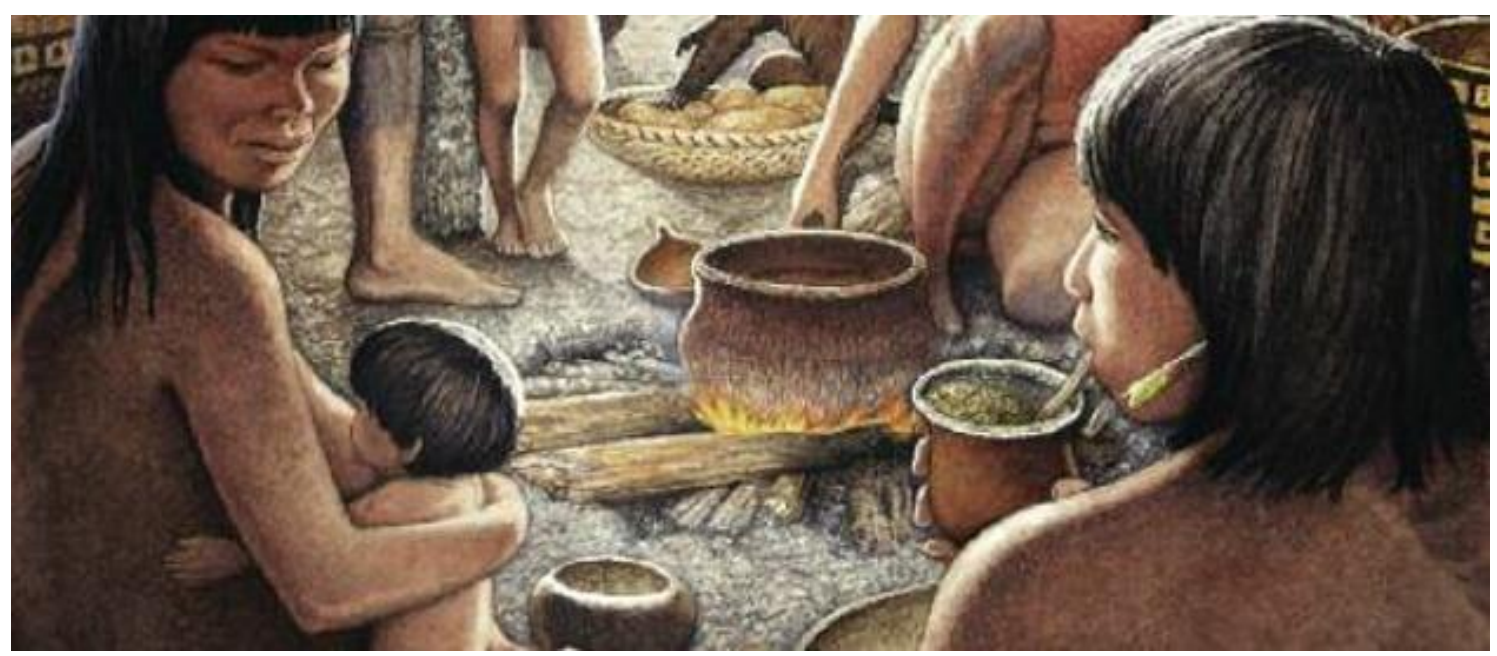

El descubrimiento de la yerba mate por parte de los españoles fue realizado por Ruiz Díaz de Guzmán, en 1592. Este había encontrado polvo de yerba mate en los sacos de algunos indios que había tomado prisioneros. La costumbre de tomar mate se expandió rápidamente entre los mestizos que habitaban el Virreinato del Río de la Plata.

A comienzos del siglo XVII, a fin de evitar las grandes distancias que separaban los lugares de consumo de los de producción, introdujeron el cultivo en algunas reducciones jesuíticas distribuidas en Corrientes, Misiones y Paraguay. Con su expulsión, en 1769, se abandonaron sus yerbales y con esto se pierde también la tradición de su cultivo. La superficie cultivada en ese momento era de 504 ha. 
Posteriormente en 1901, luego de muchos fracasos, se vuelve a cultivar la yerba mate en Colonia "Nueva Germania" del Paraguay. Muy poco después, en el año 1903, se realizó la primera plantación de importancia en nuestro país en San Ignacio, Misiones.

En la década del 20 comenzaron a impulsarse en forma masiva el cultivo de yerbales en el país. Los molinos existentes en ese momento molían yerba mate canchada proveniente de Brasil y Paraguay. Al comenzar a producir estos yerbales, principalmente en manos de inmigrantes recién llegados, se tuvo inconvenientes en la comercialización debido al cambio de gusto que presentaba y a que los molinos instalados en la Argentina preferían utilizar yerba mate de sus cultivos en el Paraguay. Como consecuencia de esta crisis decide intervenir el estado Argentino, creando en el año 1935 por ley 12.236 la Comisión Reguladora de la Producción y el Comercio de la Yerba Mate (CRYM) y el Mercado Consignatario. Este organismo prohíbe la implantación de la yerba mate en la Argentina y en el año 1937, autoriza cosechar únicamente el $40 \%$ de la producción. De esta manera se crea un conflicto, ya que la importación del Paraguay y Brasil era libre (Navajas Artaza, 1995). No obstante a pesar de que en los años siguientes se mantuvo esta política con ciertas flexibilizaciones, como contrapartida estos organismos garantizaban un precio para la yerba mate, manteniéndose además la estructura minifundista existente.

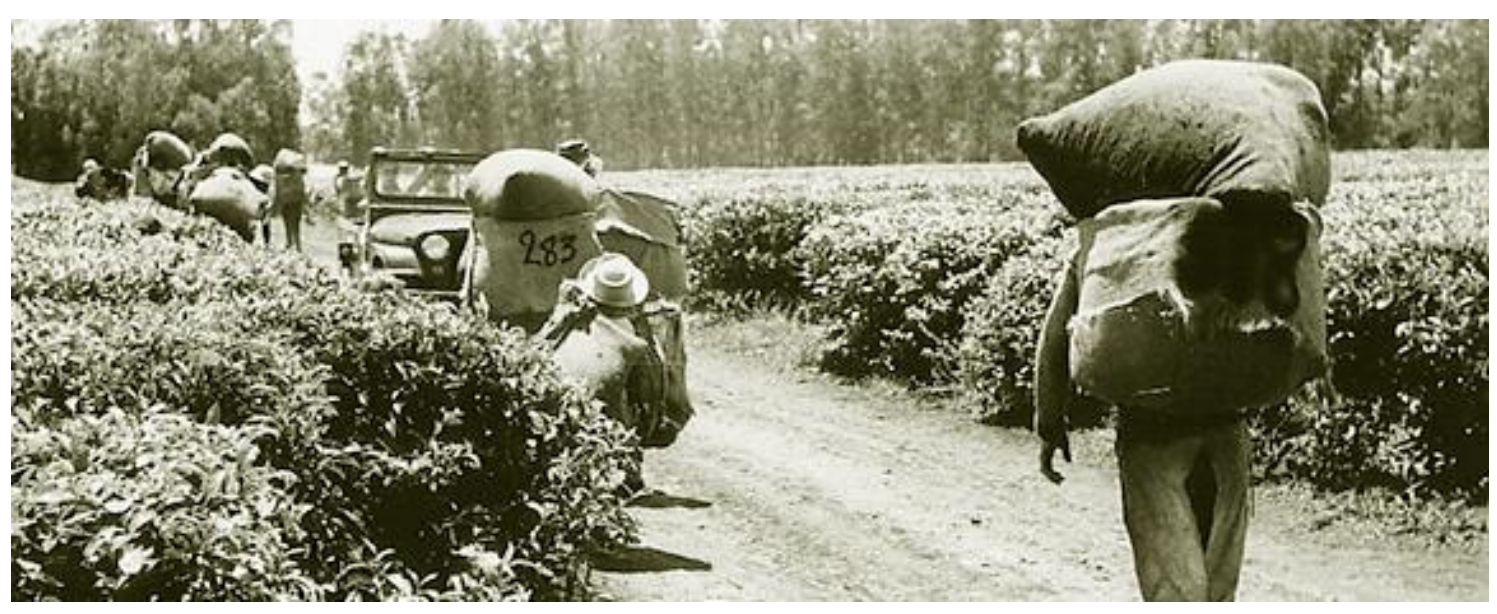

Luego, a mediados de la década del 40, se reemplaza a la CRYM por otro organismo, que reemplazó la regulación de la actividad por una política de precios. Como había controlado el cultivo imponiendo un alto impuesto a las nuevas plantaciones, se generó una crisis de escasez a mediados de los años 50. En los años 1953 y 1954 se establecen 
decretos eliminando los impuestos para la plantación, pero poniendo límites en la densidad de la plantación.

En 1956 se vuelve a crear la CRYM debido a la sobreoferta por la entrada en producción de los nuevos yerbales implantados. Esto impulsó nuevamente nuevos cupos y limitaciones de cosecha que se extendió hasta los primeros años de la década del 60 , llegándose en el año 1966 a prohibirse totalmente la cosecha.

A partir del año siguiente se fijan cupos crecientes hasta liberarlo completamente en el año 1977. En el año 1973 se había autorizado la renovación parcial de los yerbales y para realizar su control se crea un Comité de Investigaciones (Coninmate) en el que participó el INTA. En 1984 se autoriza el cultivo de 20.000 ha y en el año 1987 se incorporan otras 7.000 ha. Debido a la escasez de yerba mate (en coincidencia con la fijación de precios máximos del plan Austral) se introducen las mejoras tecnológicas desarrolladas por el Coninmate-INTA, con el consiguiente aumento de la producción. En el año 1991 (Decreto 2284/91) se elimina la CRYM y con ello la regulación de la actividad yerbatera. Esto lleva a un incremento de la producción que, en el período de los años 1992/99 fue del orden del 50 \%. Como consecuencia, salen de producción yerbales con bajos rendimientos, principalmente de pequeños y medianos productores (De Bernardi y Prat Krikum, 2001). De esta manera se llega al año 2001, donde la sobreoferta estimada es de un $30 \%$ con la consecuente reducción del precio que se le paga al productor. En el año 2002, y como consecuencia de la presión ejercida por los productores yerbateros, se crea por ley 25.564 el Instituto Nacional de la Yerba Mate (INYM), que tiene como objetivos principales la regulación del precio de la yerba mate, la promoción de su

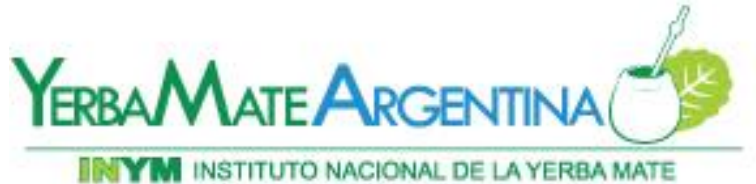
consumo y la búsqueda de nuevas alternativas en su uso. Participan en este Instituto representantes de los agricultores, industrializadores primarios y molineros, consumidores y los Gobiernos Provincial y Nacional.

\subsection{Descripción botánica de la planta}

La yerba mate se obtiene de las hojas y ramas jóvenes del Ilex paraguariensis. Según Giberti (1989), se conoció la planta de la yerba mate en Europa desde el principio del siglo XIX con la denominación de "Ilex theazans" dada por Bonpland en 1821. Sin 
embargo, Saint Hilaire, en 1812, la denominó "Ilex paraguariensis" en las "Memoire du Museúm d'historie Naturale" y en su "Historie de Plantees Plus" que se encontraba en Curitiba, usando esa denominación de especie en razón de que los antiguos historiadores españoles usaban para el gentilicio "paraguayo" la palabra latina "paraguariensis". Tal denominación ha prevalecido sobre las de "Ilex paraguayensis", "Ilex mate", "Ilex paraguariensis Lambert", "Ilex paraguariensis undeer", "Ilex curitibensis" y muchísimas otras con las que se le ha descrito.

El Ilex paraguariensis pertenece a la clase de las dicotiledóneas, familia de las aquifoliáceas, y al género Ilex que comprende casi toda la familia (175 de las 181 especies) dispersas en toda Sudamérica. Es un árbol perennifolio dioico de porte erecto y copa redondeada, nativo de las regiones subtropicales de Argentina, Brasil, Paraguay y Uruguay. La Figura 1.2 A muestra las principales regiones donde es nativa la planta.

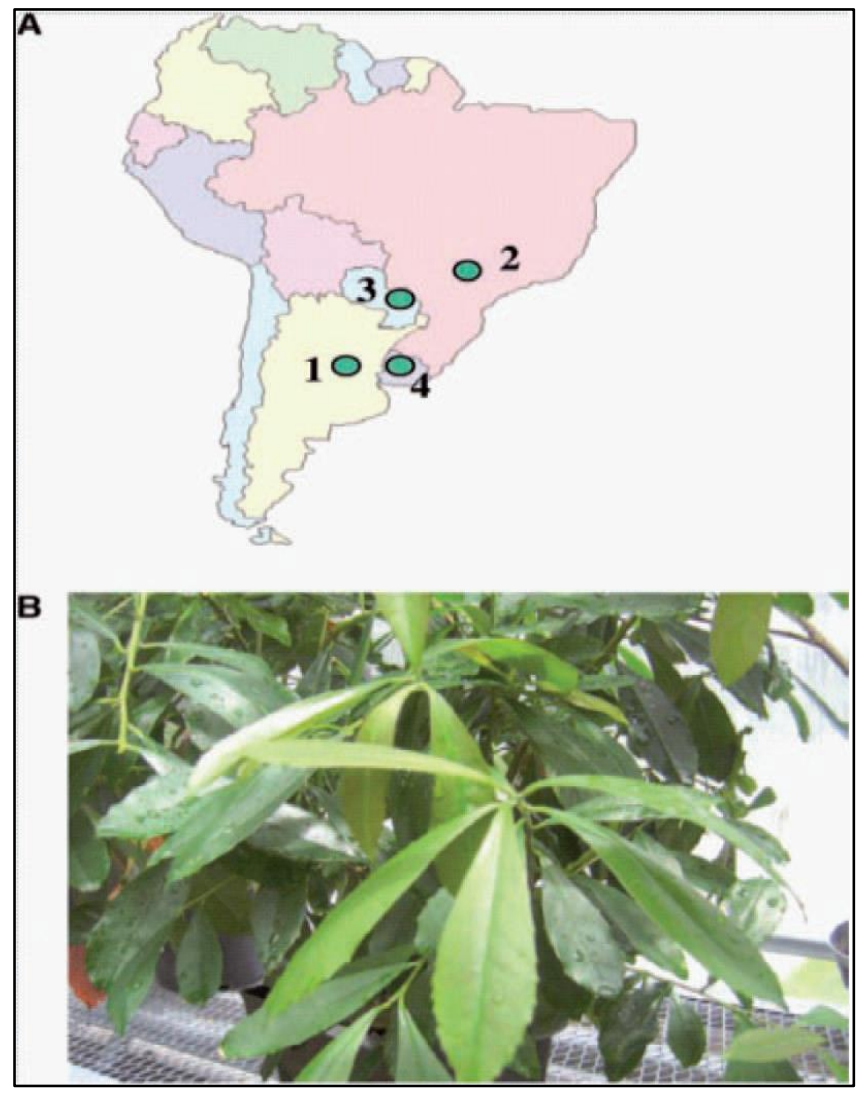

Figura 1.2: (A) Mapa de América del Sur que muestra las regiones de cultivo de la Yerba mate (Ilex paraguariensis), 1 Argentina, 2 Brasil, 3 Paraguay, 4 Uruguay. (B) La planta de yerba mate.

El área de distribución natural de la especie es muy restringida, sólo prospera en la zona delimitada por el océano Atlántico al este y por el río Paraguay al oeste, entre los 18 y 30 grados de latitud sur, presenta follaje persistente compuesto por hojas gruesas y 
coriáceas. En su hábitat natural puede alcanzar un desarrollo de hasta $18 \mathrm{~m}$ de altura en estado salvaje, aunque bajo cultivo se realizan podas para que tome un porte arbustivo de 3 a $6 \mathrm{~m}$ de altura, facilitando la labor de la cosecha. Tiene un fuste recto y cilíndrico, de hasta $30 \mathrm{~cm}$ de diámetro, cubierto de una fina corteza pardo-grisácea acanalada. Las ramas brotan del árbol en ángulo recto, dando lugar a una copa apicada. La raíz es pivotante. Las hojas son alternas, obovadas, con el margen dentado y el ápice obtuso como se observa en la Figura 1.2 B, de unos $11 \mathrm{~cm}$ de largo y $5 \mathrm{~cm}$ de ancho, coriáceas; no presentan nunca pelos ni estomas por el haz, de color verde oscuro y estomas pequeños en el envés. Las nervaduras primarias y secundarias son de color amarillento y muy marcadas. Perduran unos tres años en la planta.

Entre octubre y noviembre, la época de floración, produce inflorescencias en forma de haces corinboides de 40 a 50 flores, que se desarrollan axilarmente. Es dioica, los ejemplares masculinos presentan dicasios de entre 3 y 11 flores mientras que en los femeninos aparecen solitarias o en grupos de tres a lo sumo. Las flores son simples, pequeñas, polígamas, de color blancuzco; el cáliz y la corola suelen ser tetrámeros o excepcionalmente pentámeros. Entre los pétalos presenta igual número de estambres.

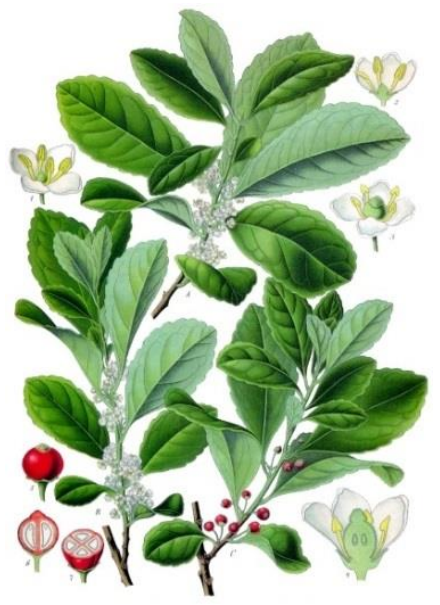
La polinización es entomófila, siendo tanto abejas como dípteros los vehículos de la fecundación. Entre los meses de enero y marzo madura el fruto, una núcula indehiscente de unos $7 \mathrm{~mm}$ de diámetro, de color violáceo, rojizo o negruzco cuando madura, con un estigma poco prominente. Contiene 4 a 8 propágulos rugosos, de color amarillo. La diseminación se produce por lo general endozoicamente, siendo las aves sus principales vectores.

La ubicación sistemática de la planta es la siguiente:

Reino: Plantae - Plantas.

Subreino: Tracheobionta - Plantas vasculares.

Superdivisión: Spermatophyta - Plantas con semilla.

División: Magnoliophyta - Plantas con flores.

Clase: Magnoliopsida - Dicotiledóneas.

Orden: Aquifoliales. 
Familia: Aquifoliaceae.

Género: Ilex.

Especie: I. paraguariensis.

Nombre científico: Ilex paraguariensis St. Hil.

Nombre común: yerba mate

\subsection{ASPECTOS ECOLÓGICOS Y FITOGEOGRÁFICOS}

Entre los requerimientos ecológicos de esta especie subtropical se destacan los de tipo climático, en especial la precipitación media anual y una distribución pareja de las lluvias a lo largo del año. Estas no deben ser inferiores a $1200 \mathrm{~mm}$ anuales, y durante el trimestre más seco — que en la región es el invierno — el mínimo debe ser de $250 \mathrm{~mm}$. $\mathrm{Su}$ área de distribución silvestre está siempre libre de déficit hídrico. La temperatura media anual es de aproximadamente 21 $22{ }^{\circ} \mathrm{C}$. Las temperaturas mínimas absolutas no son inferiores a $-6{ }^{\circ} \mathrm{C}$, si bien las nevadas invernales son frecuentes en mesetas y serranías al sur de Brasil y este de Misiones. Los suelos

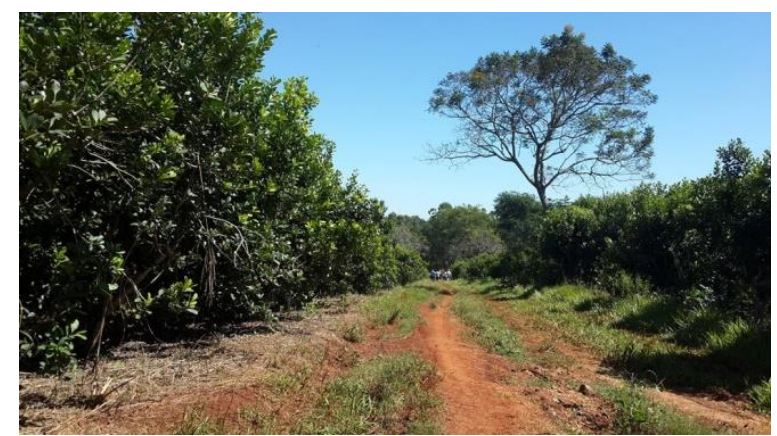
son lateríticos, ácidos (pH entre 5,8 y 6,8) y de textura media a fina (Giberti, 1989).

\subsection{COMPOSICIÓN QUÍMICA}

Al revisar la composición química, es importante distinguir entre la investigación realizada en las hojas frescas o conservadas de I. paraguariensis, y la yerba mate que se ha sido sometida a un proceso industrial que implica secado y tostado, dos procesos muy drásticos que pueden producir cambios significativos en la composición química original. También hay una gran cantidad de trabajos realizados en las infusiones de la yerba mate, donde la cantidad de sustancia vegetal, la temperatura, tipo de extracción y disolvente no siempre es clara. Todos estos factores conducen a una variedad de resultados, muchos de los cuales son contradictorios como se verá más adelante.

Los principales metabolitos secundarios de I. paraguariensis pertenecen a tres grupos fitoquímicos: alcaloides derivados de purinas (metilxantinas), saponinas $\mathrm{y}$ fenilpropanoides. El contenido en minerales también es remarcable. 


\subsubsection{La importancia de los compuestos fenólicos y metilxantinas en yerba mate}

Los compuestos fenólicos y las metilxantinas son metabolitos secundarios, con funciones importantes tales como la protección contra los herbívoros y patógenos y, además, con potencial como alelopáticos y como atractantes de los insectos polinizadores (Taiz y col., 2004).

En los alimentos, los fenoles pueden contribuir al amargor, astringencia, pigmentación, sabor, olor y estabilidad oxidativa de los productos (Shahidi y col., 2004).

Bajo condiciones de estrés, algunas plantas tienen la capacidad de aumentar su producción de alcaloides, como la cafeína y teobromina, actuando como defensa contra insectos y hongos y contra la pérdida de hojas. Mazzafera y col. (1996) consideran la cafeína como un aportante de nitrógeno, que contiene cuatro átomos de nitrógeno en su molécula. Sin embargo, de acuerdo a una revisión por parte de Ashihara y Suzuki (2004), el papel de la cafeína en las plantas es aún incierto.

Hay dos escenarios posibles: la defensa química para proteger el tejido de los jóvenes depredadores como larvas de insectos y/o la función autotóxica como alelopáticos, inhibiendo la germinación de las semillas de otros.

Además de la composición química rica en saponinas y metilxantinas, los compuestos cafeoilquínicos comprenden hasta el $12 \%$ del peso seco de la yerba mate, lo que indica su posible importancia para determinar el sabor del producto final. Esto también puede estar influenciado por factores extrínsecos tales como el método de secado y estacionamiento. Además, la percepción de la astringencia al beber yerba mate se ha correlacionado positivamente con el contenido de polifenoles totales.

Una gran parte de los beneficios atribuidos al consumo de la infusión de yerba mate están relacionados con los compuestos fenólicos, que actúan como antioxidantes (Bravo y col, 2006). Filip y col. (2000) correlacionaron la actividad antioxidante de la infusión de mate con el contenido de rutina, quercetina, canferol y derivados cafeoilquínicos, a los cuales se les reconoce una actividad antioxidante en la salud humana (Silva y col., 2008).

Además de los compuestos fenólicos, se ha demostrado que las metilxantinas son también responsables de efectos observados en el sistema nervioso central, cardiovascular, renal y digestivo. La teobromina y la teofilina contribuyen al aumento 
del flujo de filtración glomerular y la sangre renal, lo que refuerza su actividad diurética (Simoes y col., 2004).

\subsubsection{Xantinas}

Estos son los metabolitos secundarios más característicos y significativos que se han detectado en I. paraguariensis. Los tres alcaloides derivados de la purina más comunes son la cafeína, la teobromina y la teofilina (Fig. 1.3). De ellos, la teobromina (3,7dimetilxantina) y la cafeína (1,3,7-trimetilxantina) (Athayde y col., 2000) están presentes en grandes cantidades en las hojas de I. paraguariensis y en la yerba mate. La cafeína se encuentra en mayor concentración seguida por la teobromina, estando presentes principalmente en las hojas de la planta y en los tallos leñosos en pequeñas concentraciones que a menudo están presentes en el producto.

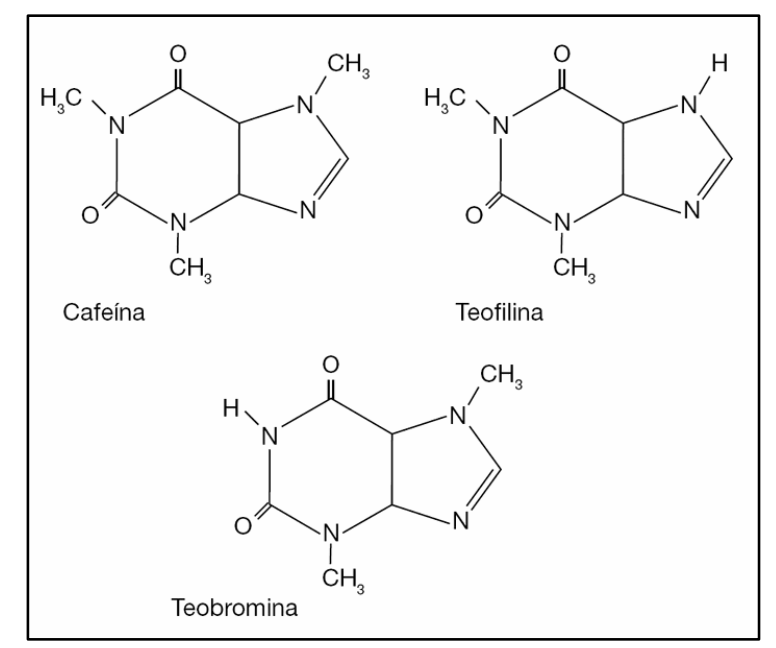

Figura 1.3: Estructura de las xantinas cafeína, teofilina y teobromina.

Se ha sugerido que el proceso de secado de la yerba mate puede afectar significativamente la concentración de cafeína, así como el color y el contenido de clorofila de las hojas. Schmalko y col. (2001) examinaron el contenido de cafeína y el color de la clorofila de las hojas de mate después de tres etapas de secado. La primera etapa es el escaldado y sapecado con una temperatura de 500 a $550{ }^{\circ} \mathrm{C}$ durante $2-4$ min. La segunda y tercera etapa son las etapas de secado con una temperatura de aproximadamente $110{ }^{\circ} \mathrm{C}$ donde se observó la disminución de la concentración de cafeína como así también del color verde de la clorofila. 
Otro factor determinante en la concentración de metilxantinas es el momento de la cosecha (Schubert y col., 2006).

A diferencia de la teobromina y la cafeína, la presencia de teofilina es controvertida apareciendo en unos pocos trabajos. La teofilina parece ser un intermediario en el catabolismo de la cafeína en la planta. Se cree que la principal vía del metabolismo de la teofilina implica la conversión a 3-metilxantina, que es desmetilado a xantina antes de entrar en la vía del catabolismo de las purinas y se degrada a través de la ruta xantina $\rightarrow$ ácido úrico $\rightarrow$ alantoína $\rightarrow$ acido alantoideo $\rightarrow \mathrm{CO}_{2}+\mathrm{NH}_{3}$. El catabolismo de la cafeína se ha estudiado mediante el uso de $\mathrm{C}_{14}$ marcado (Suzuki y Waller, 1984).

Según el Código Alimentario Argentino (armonizado con los demás países del Mercosur respecto del Codex) existen básicamente dos tipos comerciales de yerba mate: la que contiene hasta un $35 \%$ de los tallos (yerba mate elaborada con palo) y otra que sólo puede contener $10 \%$ de los tallos y que deben tener no menos del 0,6 \% de cafeína. Según la Farmacopea Nacional Argentina (VII Ed.) la yerba mate está constituida por hojas y tallos jóvenes procesados, desecados y fragmentados de Ilex paraguariensis A. St. Hil. var. paraguariensis (Aquifoliaceae). Debe contener no menos de 0,8\% de cafeína, calculado sobre la sustancia seca, y no más del 10,0\% de tallos.

\subsubsection{Saponinas}

Las saponinas son compuestos amargos y muy solubles en agua que se encuentran en muchos tipos de plantas y que se cree que son uno de los factores que contribuyen al distintivo sabor del mate. No solo juegan un papel en el sabor, sino también se le atribuyen propiedades antiinflamatorias e hipocolesterolemiantes (Gnoatto y col., 2005). Varios de estos compuestos, es decir saponinas triterpénicas derivadas de los ácidos ursólico y oleanólico, han sido aislados de las hojas de yerba. Las saponinas identificadas derivadas del ácido ursólico son las matesaponinas 1, 2, 3, 4 y 5 (Gosmann y col., 1995). Es la única especie del género Ilex que tiene saponinas derivadas del ácido ursólico.

\subsubsection{Polifenoles}

Los compuestos fenólicos son biosintetizados en las plantas por diferentes rutas siendo un grupo muy heterogéneo. Las dos vías metabólicas básicas son: la ruta del ácido 
malónico y el ácido siquímico, este último participa en la biosíntesis de la mayoría de los fenoles en las plantas (Taiz y Zeiger, 2004).

En general, la estructura se compone de un anillo aromático con uno o más sustituyentes hidroxilo, pudiendo ser desde moléculas fenólicas simples hasta compuestos altamente polimerizados. La mayoría de los compuestos fenólicos se encuentran ligados a carbohidratos (mono y polisacáridos), proteínas y otros componentes de la planta (Robbins, 2003), lo que resulta en una gran variedad de compuestos fenólicos en la naturaleza, que se clasifican en clases, siendo los ácidos fenólicos, los flavonoides y taninos considerados como los compuestos fenólicos principales (Balasundram y col., 2006).

La yerba mate no contiene una gran cantidad de flavonoides representando menos de un $5 \%$ del contenido total de polifenoles (Bravo y col., 2006). La rutina se ha detectado inequívocamente en todas las muestras de I. paraguariensis y en la yerba mate (Heck y col., 2008; Bravo y col., 2006; Carini y col., 1998; Filip y col., 2000). La quercetina y su aglicón no siempre han sido detectados. Carini y col. (1998) y Heck y col. (2008) reportaron sólo rutina y un diglicósido de luteolina.

Sin embargo, con respecto a la identidad de los flavonoides en mate desde un estudio publicado por Rostagno y col. (2011) confirmó la presencia de rutina, pero detectó kaempferol-3-O-glucósido y quercetina-3-O-glucopiranósido y no detecta luteolina-3$O$-glucósido.

Además la yerba mate contiene ácidos hidroxicinámicos, los más comunes son los llamados ácidos clorogénicos, que son una familia de ésteres formados entre el ácido quínico y uno o más residuos de algunos ácidos tales como el trans-cinámico, $p$ cumárico, ferúlico y cafeico. El ácido 5-cafeoilquínico (ACG) está presente como compuesto mayoritario en el mate y es un éster del ácido quínico con ácido cafeico (Clifford, 1985) (Fig. 1.4).

El contenido de rutina, ácido cafeico y ACG en la yerba mate ha sido determinado por diversos autores utilizando el método de HPLC, obteniéndose valores de 0,60 a 13,00 $\mathrm{mg} / \mathrm{g}, 0,14$ a $0,55 \mathrm{mg} / \mathrm{g}$ y 5,70 a 28,00 mg/g, respectivamente, sobre base seca (López y col., 2006; Cardozo y col., 2007). Además de éstos compuestos monocafeoilquínicos, en la yerba mate se encuentran los ácidos dicafeoilquínicos (DCQ) (Fig. 1.3), tales como los isómeros 3,4-; 3,5-y 4,5-dicafeoilquínico, con contenidos que van 0,11 a 8,55 
$\mathrm{mg} / \mathrm{g}, 0,35$ a 30,40 mg/g y 2,60 a 28,90 mg/g, respectivamente (Filip y col., 2001). El contenido de estos compuestos en la yerba mate varía aún para el mismo componente, dependiendo de la ubicación y sistema de cultivo del I. paraguariensis (Da Croce, 2002) empleados en el procesamiento e industrialización (Zanoelo y col., 2006).

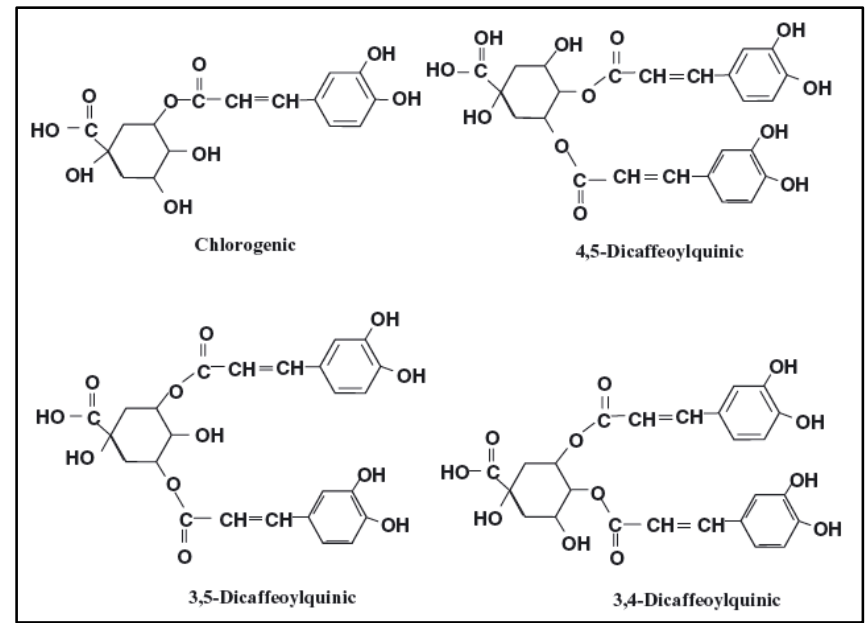

Figura 1.4: Estructura del ácido clorogénico y los ácidos dicafeoilquínicos.

El método de extracción utilizado para la obtención de los extractos analizados varía de acuerdo al objetivo del estudio. La infusión acuosa se utiliza para emular el consumo de la yerba mate como alimento. El método analítico más utilizado es el HPLC, principalmente con gradiente de elución para optimizar la separación de las diferentes clases de componentes debido a la heterogeneidad en sus características químicas.

Se realizó un estudio comparativo sobre el contenido de ácidos clorogénicos y flavonoides en diferentes especies de diversas especies del género Ilex (I. dumosa, I. argentina, I. brevicuspis) que crecen en la misma región que I. paraguariensis utilizando HPLC/UV. Los resultados mostraron que I. paraguariensis contenía la mayor cantidad de ácido clorogénico (2,8 \%), ácido cafeico $(0,023 \%)$ y los tres isómeros del ácido isoclorogénico (3,4-DCQ, 3,5-DCQ y 4,5-DCQ) (Filip y col. 2001). En otro trabajo, también determinaron el contenido total de ácido clorogénico de estas especies, utilizando un método espectrofotométrico. Se determinó que I. paraguariensis contenía $10,71 \%$ (sobre base seca) referido al ácido clorogénico mientras que las otras especies de Ilex variaron entre 0,96 y 4,26 \% (Filip y col., 2000).

En un estudio realizado por Carini y col. (1998), se identificaron 10 compuestos en la yerba mate verde comercial usando LC/MS, incluyendo los 3 isómeros del ácido 
monocafeoilquínico (ACG), los ácidos neoclorogénico, clorogénico y criptoclorogénico, como así también los tres isómeros del ácido dicafeoilquínico, la rutina (quercetina-3rutinósido), un derivado diglicosilado de luteolina, el ácido cafeico y 2 isómeros glucósidos. Además, todos los isómeros del ACG se cuantificaron utilizando un DAD (detector de arreglo de diodos) para adquirir y analizar los datos. El contenido total del extracto metanólico fue de 17,7 \% (como ACG) de los cuales 5,1 \% correspondió a 3ACG (ácido neoclorogénico, neo-ACG); 8,2 \% a 5-ACG (ácido clorogénico, ACG) y 4,4 \% a 4-ACG (ácido criptoclorogénico, cripto-ACG), lo que corresponde, a aproximadamente $1,17 \%$ neo-ACG, $1,85 \%$ ACG y $0,99 \%$ cripto-ACG.

Bastos y col. (2007) utilizaron espectrometría de masas con electrospray directo (ESIMS) para identificar los principales compuestos fenólicos en extractos acuosos, etanólicos y etéreos de yerba mate verde y tostada. En los extractos acuosos y etanólicos de yerba mate verde se detectó ácidos cafeico y quínico, glucosa, ácido cafeoilquínico, ácido feruloilquínico, el ácido dicafeoilquínico y rutina. En los extractos de yerba mate tostada se detectó además ácidos cafeoilsiquímico y dicafeoilsiquímico.

La información más completa sobre los polifenoles en la yerba mate fue publicada por Jaiswal y col. (2010), quienes informaron de la detección y caracterización de 42 derivados hidroxicinámicos por LC-MSn, de los cuales 24 nunca habían sido publicados. El material utilizado para esta determinación fueron hojas de yerba mate verde y tostada (presumiblemente yerba mate comercial).

\subsubsection{Minerales}

Las hojas de la yerba mate tienen un alto contenido de minerales, concentrados principalmente en la lámina y no en los tallos. Un estudio realizado en el producto comercial reveló la presencia de $\mathrm{K}, \mathrm{P}, \mathrm{Mg}, \mathrm{Ca}, \mathrm{S}, \mathrm{B}, \mathrm{Cu}, \mathrm{Fe}, \mathrm{Mn}, \mathrm{Ni}, \mathrm{Al}, \mathrm{Cr}, \mathrm{Co}$ y $\mathrm{Na}$ (por absorción atómica) y nitrógeno (por Kjeldahl) de los cuales los más abundantes resultaron ser $\mathrm{K}, \mathrm{Mg}$ y $\mathrm{Mn}$ (un micronutriente) representando un 1,2, 0,4 y 0,06 \% en peso seco, respectivamente. El contenido de Mn detectado es por lo menos cinco veces mayor que lo detectada en café o chocolate. Los metales pesados tales como $\mathrm{Cd}$ y $\mathrm{Pb}$ no se detectaron en contraste con los informes anteriores, lo que implica que la presencia de estos metales depende de la proximidad a zonas industriales o centros urbanos (Heinrichs y col., 2001). Los metales más abundantes son el $\mathrm{K}$ y Mg, seguido por otros 
elementos tales como $\mathrm{S}$ y $\mathrm{Mn}$. En todos los casos, no se detectaron $\mathrm{Pb}$ ni $\mathrm{Cd}$ y el $\mathrm{Al}$ se detectó en cantidades muy bajas. Esto confirmó los resultados obtenidos por Sanz y Torija (1991) mediante absorción atómica, previa digestión en $\mathrm{HNO}_{3} / \mathrm{HCl}$, que mostró a la yerba mate como una buena fuente de $\mathrm{Mg}, \mathrm{K}$ y Mn. Otro estudio reciente confirmó estos resultados usando espectrometría de absorción atómica electrotérmica, previa digestión ácida en $\mathrm{HNO}_{3} / \mathrm{HClO}_{4}$, donde se encontró que la yerba mate comercial contenía pequeñas cantidades de $\mathrm{Al}(369 \mu \mathrm{g} / \mathrm{g}$, equivalente a $0,037 \%)$ y de $\mathrm{Mn}(2223$ $\mu \mathrm{g} / \mathrm{g}, 0,2 \%), 48,1 \%$ de los cuales estaba disponible en la infusión de estas hojas (Wrobel y col., 2000).

\subsection{ASPECTOS INDUSTRIALES DE LA YERBA MATE}

\subsubsection{Prácticas de cultivo}

En la variada y amplia área de producción económica de yerba mate, las prácticas de cultivo o de explotación de los yerbales naturales varían considerablemente en cuanto a sus aspectos técnicos, lo que resulta en rendimientos por hectárea disímiles.

Se pueden distinguir tres modalidades de producción, que se ordenarán de menor a mayor, en función del empleo de técnicas y de sus rendimientos:

- Explotación extractiva del monte natural (forestal). Aprovecha la riqueza de yerbales naturales. La cosecha no está mecanizada y el sistema de poda es en general incorrecto. Esta forma de producción está difundida principalmente en Brasil.

- Sistema mixto o de enriquecimiento del monte natural. Consiste en incrementar el número de ejemplares del yerbal nativo y en la reposición de los que se han perdido. En Brasil, donde se practica más comúnmente esta modalidad, se llama adensar el yerbal. Como por lo general esta técnica se acompaña con otras que incrementan el rendimiento, tales como cuidados culturales y mejoras en formas de poda, se compensa el mayor costo de producción.

- Yerbales cultivados. Sin duda el mejor sistema, generalizado en Argentina hacia 1915. A pesar de tener más altos costos, el rendimiento por hectárea crece mucho. Complementado con medidas tales como mejoras en el diseño de las plantaciones (que han evolucionado desde el tresbolillo, con plantas espaciadas que usaban los jesuitas, hasta el cultivo según curvas de nivel de alta densidad 
por hectárea y "corte mesa"), con podas en el momento oportuno, labores culturales y cosecha, ha permitido que la producción argentina superase a la brasileña, a pesar de realizarse la primera en un área más reducida e incluso fuera de los ambientes más aptos para la yerba. El sistema de poda y conducción de las plantas denominado corte mesa no solamente aumenta el rendimiento sino que se adapta mejor a la cosecha mecánica. La plantación siguiendo curvas de nivel, el uso de cubiertas verdes naturales o implantadas (colza, leguminosas, etc.), la fertilización (N, P, K), el control de malezas (mecánico y/o utilizando herbicidas), tratamientos fitosanitarios oportunos y la cosecha realizada racionalmente mejoran los rendimientos. Las experiencias relacionadas tienen bastantes años de vigencia, pero lamentablemente sus resultados no se han generalizado. La introducción al cultivo de cultivares mejorados es mucho menos difundida.

\subsubsection{Proceso productivo}

El cultivo de la yerba mate comienza con la siembra, realizada entre los meses de febrero y marzo. La germinación es dificultosa ya que el $80 \%$ de la semilla está constituida por tegumentos y sólo el resto por el endosperma y la radícula. Luego de aproximadamente seis meses se seleccionan las plantas mejor

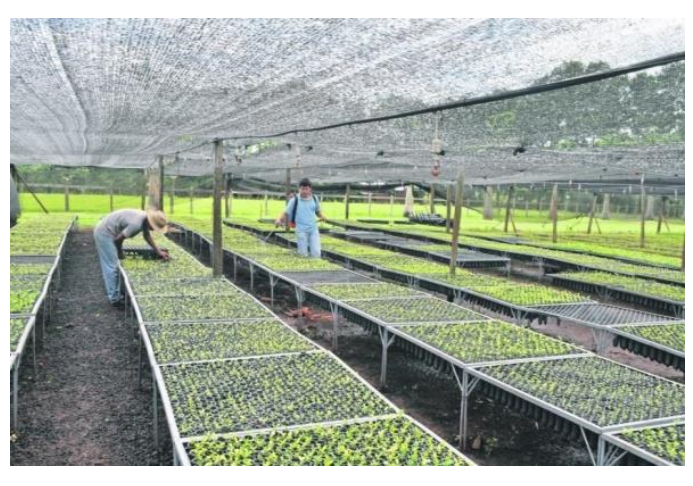
desarrolladas y se las repica a macetas entre octubre y noviembre. El trasplante definitivo a

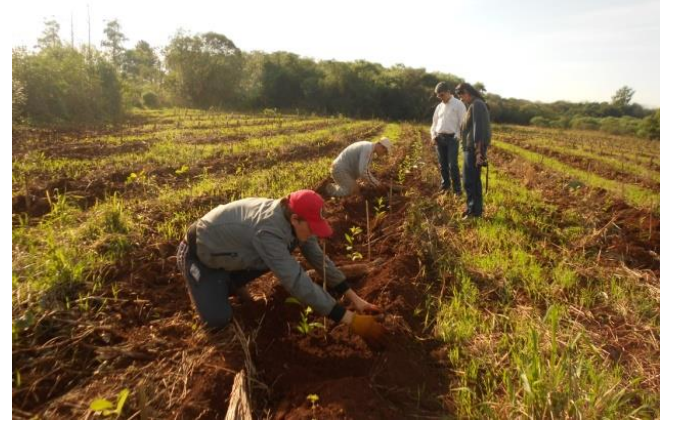
campo se realiza en la temporada otoñoinvernal. Las pequeñas plantas requieren de protección contra la intensa insolación y los vientos, lográndose con estructuras colocadas alrededor de las plantitas llamadas "ponchos" realizadas con diversos materiales, como cañas o tablitas. En general, pueden plantarse con 3 a 4 m entre líneas y con 2 a 3 m entre plantas, según la densidad buscada. Respecto de los manejos culturales, se realiza una 
pasada de rastra de disco entre líneas para el control de malezas y una carpida manual entre plantas tanto en primavera como en otoño, fuera de la época de cosecha. Se aconseja una fertilización cada tres años aproximadamente con $\mathrm{N}, \mathrm{P}$ y $\mathrm{K}$, teniendo en cuenta mantener una relación 4:1:1 y 2:1:1.

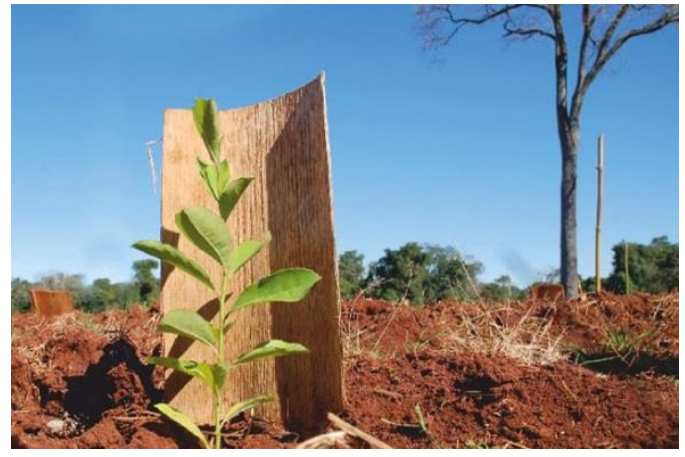

En Argentina, se trabaja con yerba cultivada con baja densidad de sombraje, en áreas

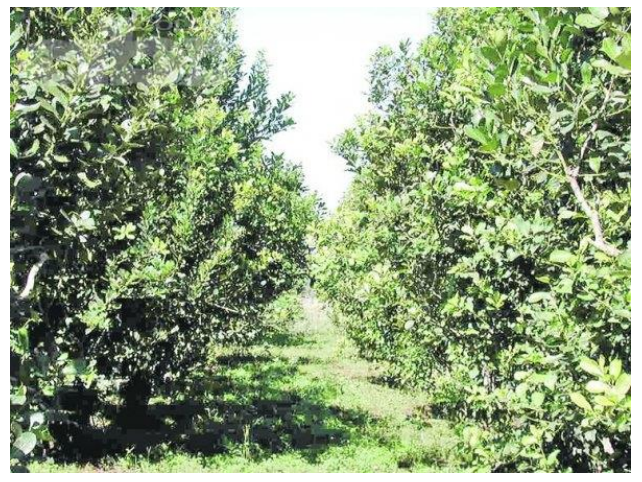
con 500 árboles de 40 a 50 especies nativas. En Paraguay, la yerba se cultiva en vivero y luego es trasladada al terreno, donde hay más de 1600 plantas por hectáreas. En Brasil, la yerba mate es nativa, no cultivada, dispuesta bajo la sombra de Araucarias y otras especies.

Las condiciones de crecimiento juegan un papel importante en la química de la planta, específicamente, en la producción de fitoquímicos. Incluso, el exceso de luz ultravioleta puede promover la producción de determinados compuestos que tienen como objetivo la protección de la planta (Meyer y col., 2006). Con frecuencia, estos compuestos son compuestos fenólicos, y muchos han demostrado poseer propiedades antioxidantes en otros sistemas de vida (Manach y col., 2004).

\subsubsection{Proceso de elaboración de la yerba mate}

El proceso de elaboración comienza con la cosecha, considerada como último eslabón del proceso productivo y como primero del de elaboración. Le sigue un conjunto de pasos cuya finalidad es la reducción del contenido de humedad del producto, constituido por el sapecado y el secado, para finalizar con el canchado (molienda grosera). El material producto del canchado es la materia prima que ingresa al molino yerbatero.

El procesamiento de la yerba mate comprende cinco etapas: 1) Zapecado o Escaldado; 2) Secado; 3) Molienda Gruesa o Canchado; 4) Estacionamiento y 5) Molienda Fina, Tipificación y Envasado. Las tres primeras etapas se llevan a cabo en establecimientos denominados "secaderos" y la quinta etapa en establecimientos industriales 
denominados "molinos". El estacionamiento se realiza indistintamente en los secaderos o en los molinos. En general, los molinos procesan yerba mate proveniente de diferentes secaderos, ya sean propios o de otras empresas. En Brasil, el procesamiento de la yerba mate no incluye la etapa de estacionamiento.

\section{Cosecha:}

La cosecha comienza durante los meses de abril y mayo extendiéndose hasta octubre, período durante el cual la planta disminuye la circulación de su savia y en que cuenta con un mayor porcentaje de hojas maduras. Consiste en el cuidadoso corte de las ramas, cargadas de hojas,

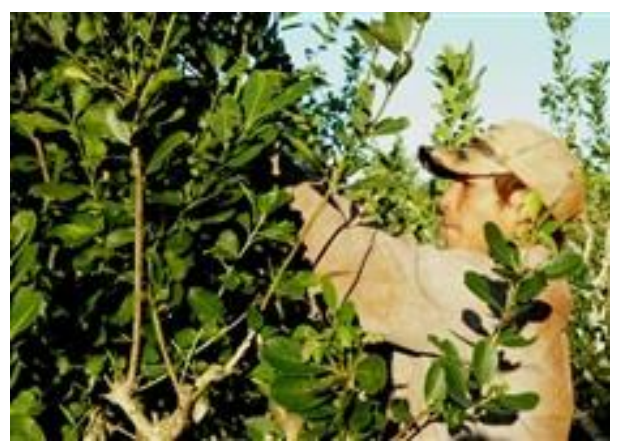
mediante tijera, machete o serrucho, según lo requiera el grosor de las ramas a cortar.

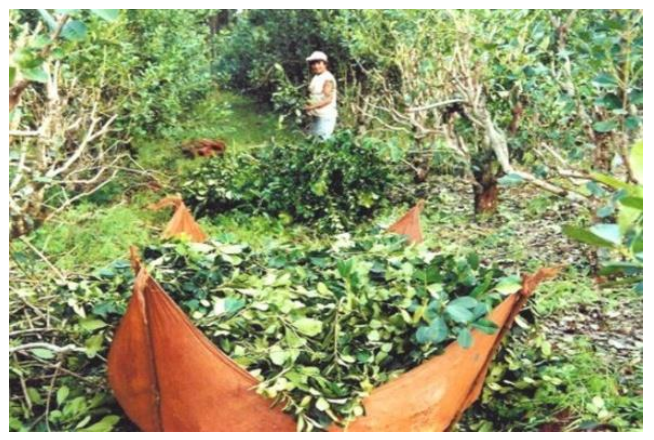

La primera cosecha de escaso rendimiento suele realizarse entre el $4^{\circ}$ y $5^{\circ}$ año de implantación. Si bien ésta puede realizarse anualmente el manejo racional del cultivo indica realizar la cosecha, también denominada "tarefa", año por medio. Hay que considerar que cosechas demasiado intensas generan desequilibrios en la estructura y fisiología de la planta, aconsejándose dejar en las plantas alrededor del $25 \%$ de su follaje, con cierta proporción de ramas medianamente gruesas con hojas.

Cosechadas las ramas, se procede a la "quiebra"

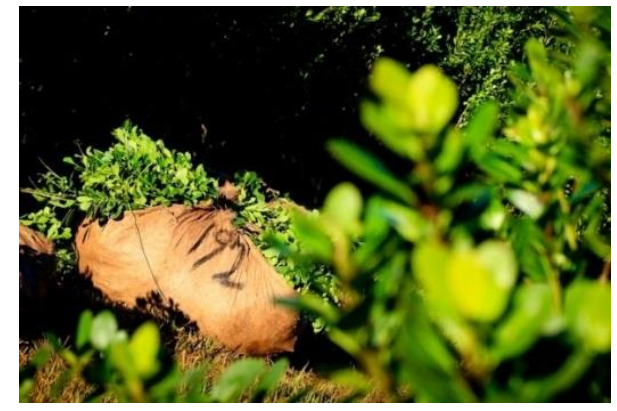
eliminando las más gruesas de otras menores y de las hojas aisladas. Las ramas ya

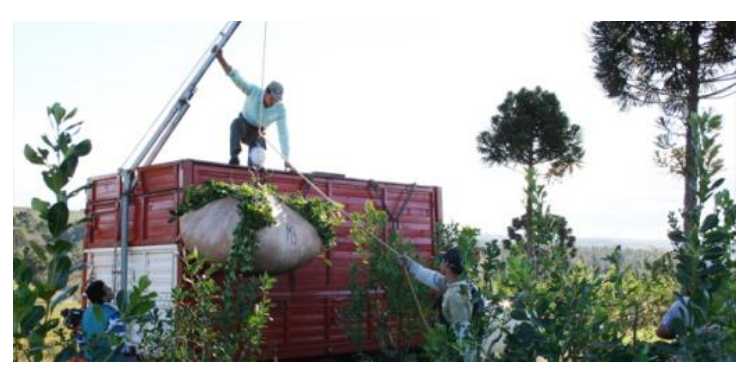
quebradas se acondicionan sobre amplios lienzos de arpillera "ponchadas" recogidas y atados sus cuatro extremos, constituyendo el "raído". Esta tarea se realiza para disminuir el volumen del material cosechado y para colaborar con 
un transporte más eficiente.

Sapecado: El sapecado consiste en un secado muy rápido, con duración de 20 a 30 s, a la acción directa de la llama del fuego. Este proceso debe ser concretado dentro de las $24 \mathrm{~h}$ de realizada la cosecha. Durante esta exposición, se genera vapor de agua en

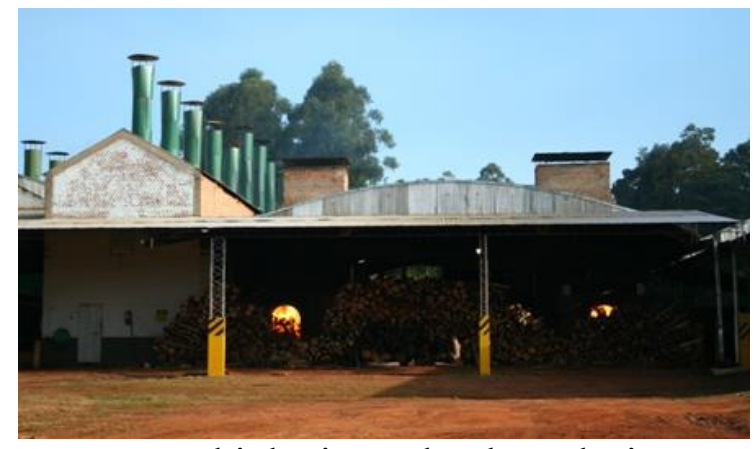

procesos biológicos de degradación. Esto impide la oxidación de las sustancias tánicas contenidas en la hoja, asegurando la conservación de su color verde. Durante el sapecado la yerba mate adquiere su característico aroma y pierde el sabor a hoja verde o tisana.

\section{Secado:}

Dentro de las $24 \mathrm{~h}$ siguientes al sapecado, el material debe ser sometido a un proceso de secado para reducir su contenido en humedad, hasta un valor que oscila entre $3 \%$ y $6 \%$, trayendo aparejado una disminución de peso. De acuerdo a referentes del sector, el punto óptimo de secado se produce cuando

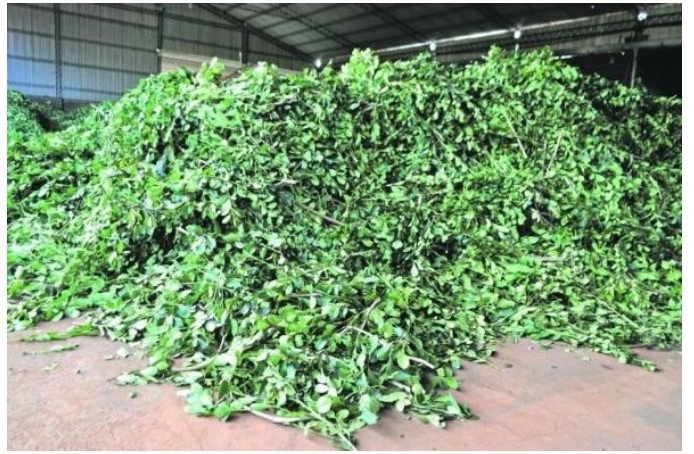

el parénquima foliar, formando pequeñas ampollas que rompen la epidermis de las hojas con un ligero crepitar. Este proceso también inactiva el protoplasma, destruyendo las enzimas responsables de los
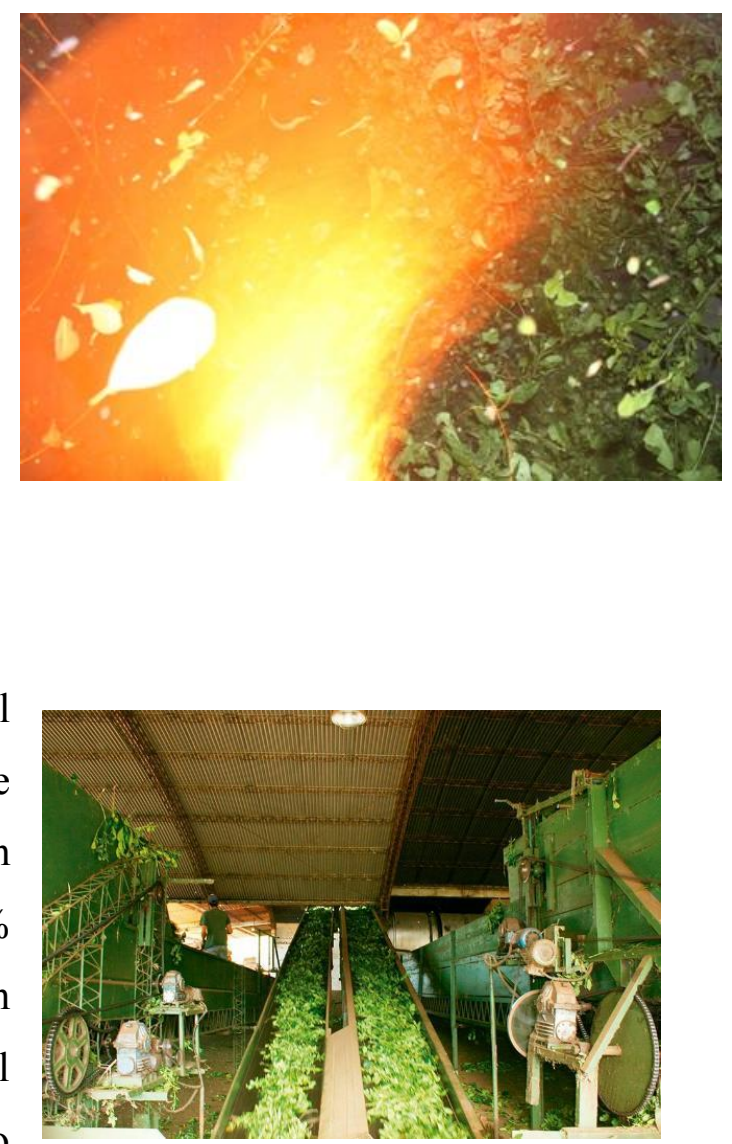
"la fracción de palo (ramitas) se quiebra con facilidad". Puede secarse directamente el material zapecado o bien realizar previamente una separación, obteniendo una fracción de hoja y otra de palo, para luego efectuar mezclas de las mismas.

Existen varios tipos de secaderos, según el nivel tecnológico de la empresa:

- Secaderos Barbacuá: son sencillas estructuras tubulares que suelen construirse de cañas tacuaras, en cuyo interior se coloca la yerba mate. El proceso es largo, con duración de un mínimo de $8 \mathrm{~h}$. Este proceso se realiza tradicionalmente durante la noche.

- Secaderos de Cinta: estructuras de mayor nivel tecnológico, consisten en una serie de cintas móviles que reciben calor desde su parte inferior. La yerba mate circula por tales cintas, perdiendo humedad en todo el circuito. Este proceso es más rápido con duración aproximada de $5 \mathrm{~h}$.

- Secaderos de Tubos Rotativos: estos equipos producen una secanza rápida, con duración menor a $1 \mathrm{~h}$.

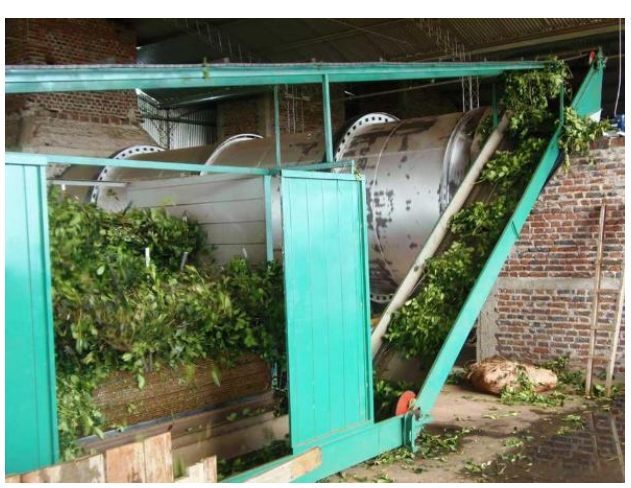

\section{Canchado:}

Secada la yerba, se somete al canchado, siendo un proceso de trituración grosero. La yerba mate se fracciona en trozos de aproximadamente un centímetro cuadrado. La finalidad es facilitar su embolsado y transporte. En general, se guarda una relación de 3 a 1 en volumen entre la hoja verde y la yerba mate canchada. Es de destacar que durante el canchado se genera la dispersión de gran cantidad de polvo. Antiguamente esta operación se realizaba esparciendo la yerba sobre un lugar plano, recubierto de arpilleras, a las que denominaban "canchas", de allí deriva este término de "canchado". Era una operación similar a la primitiva trilla del trigo, en la cual se golpeaba manualmente la yerba mate, mediante espadones o machetes de madera dura.

\section{Estacionamiento:}

Después del proceso de canchado, la yerba es colocada en bolsas de arpillera de 40-50 $\mathrm{kg}$ donde se somete a un período de estacionamiento. Este proceso puede ser natural o 
acelerado. En el primero se mantiene la yerba mate canchada almacenada por un lapso de tiempo adecuado, aproximadamente 6 a 24 meses en depósito, para que se sucedan los procesos de transformación espontánea, y la yerba mate adquiera las distintas características de sabor, aroma y color requeridas por los

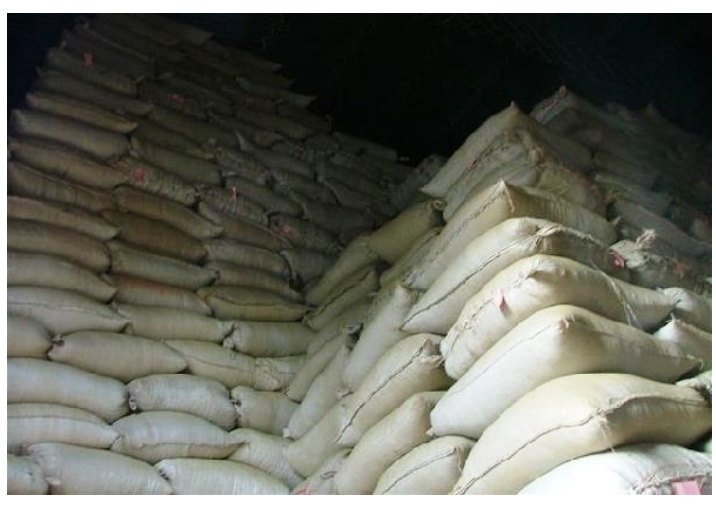
consumidores. En el proceso acelerado se almacena por un período de 30 a 60 días, en un depósito con regulación de temperatura, humedad y circulación de aire, para que la yerba mate adquiera características organolépticas similares a las generadas por el estacionamiento natural.

\section{Molienda:}

La yerba mate canchada y estacionada es la materia prima de la industria molinera. La molienda consiste en sucesivas operaciones de trituración, zarandeo y mezcla, dando como resultado final yerba mate adecuada al gusto de cada región. La materia prima es
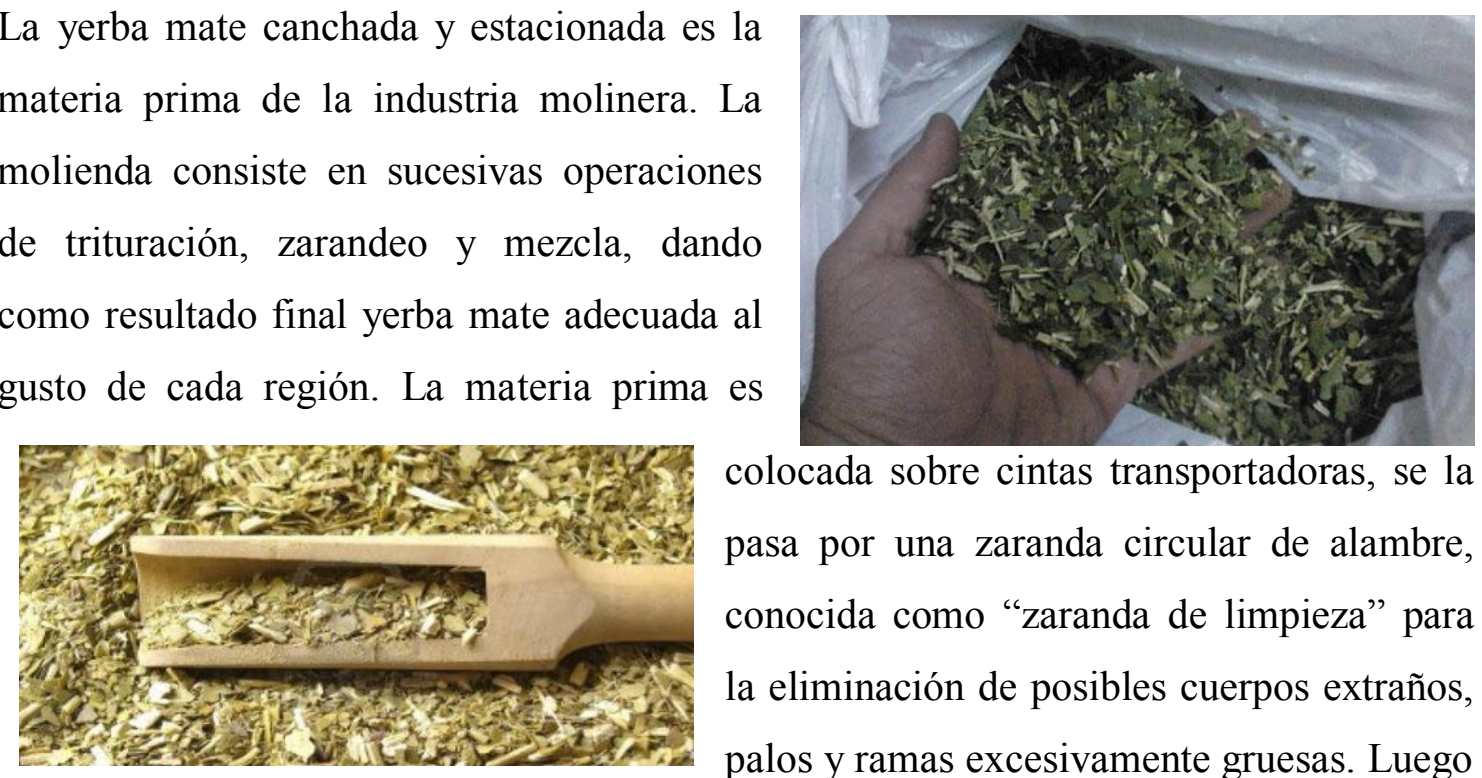

colocada sobre cintas transportadoras, se la pasa por una zaranda circular de alambre, conocida como "zaranda de limpieza" para la eliminación de posibles cuerpos extraños, palos y ramas excesivamente gruesas. Luego

se somete a un zarandeo primario de clasificación en el que se separan las hojas muy grandes y el palo. Estas hojas se someten a una trituración más o menos intensa en un molino o bien en el "trapiche" (tanque de hierro en el que giran dos pesados rodillos de

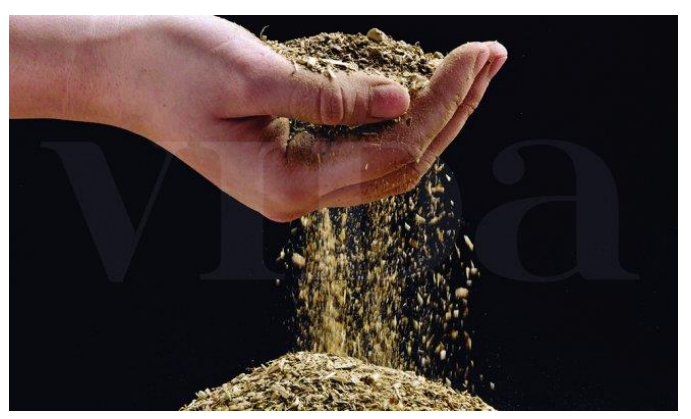
hierro, de forma cónica truncada y superficie estriada) para luego ser zarandeadas 
nuevamente. Se utilizan zarandas vibradoras para obtener distintos productos según grado de trituración, que se almacenan en silos especiales conocidos como "percheles". Una vez terminada la clasificación se puede proceder a una mezcla con "palos", cortados previamente en trozos uniformes mediante un "corta palos", en distintas proporciones, según características deseadas de acuerdo a calidad, origen y sabor, entre otras. Del proceso y de la granulometría de la mezcla depende el sabor diferenciando las distintas yerbas.

\section{Envasado:}

Una vez finalizada la molienda, clasificación y mezcla, se procede al envasado del producto final. Los envases presentan varias capas de diversos materiales para preservar las características organolépticas de la yerba mate.
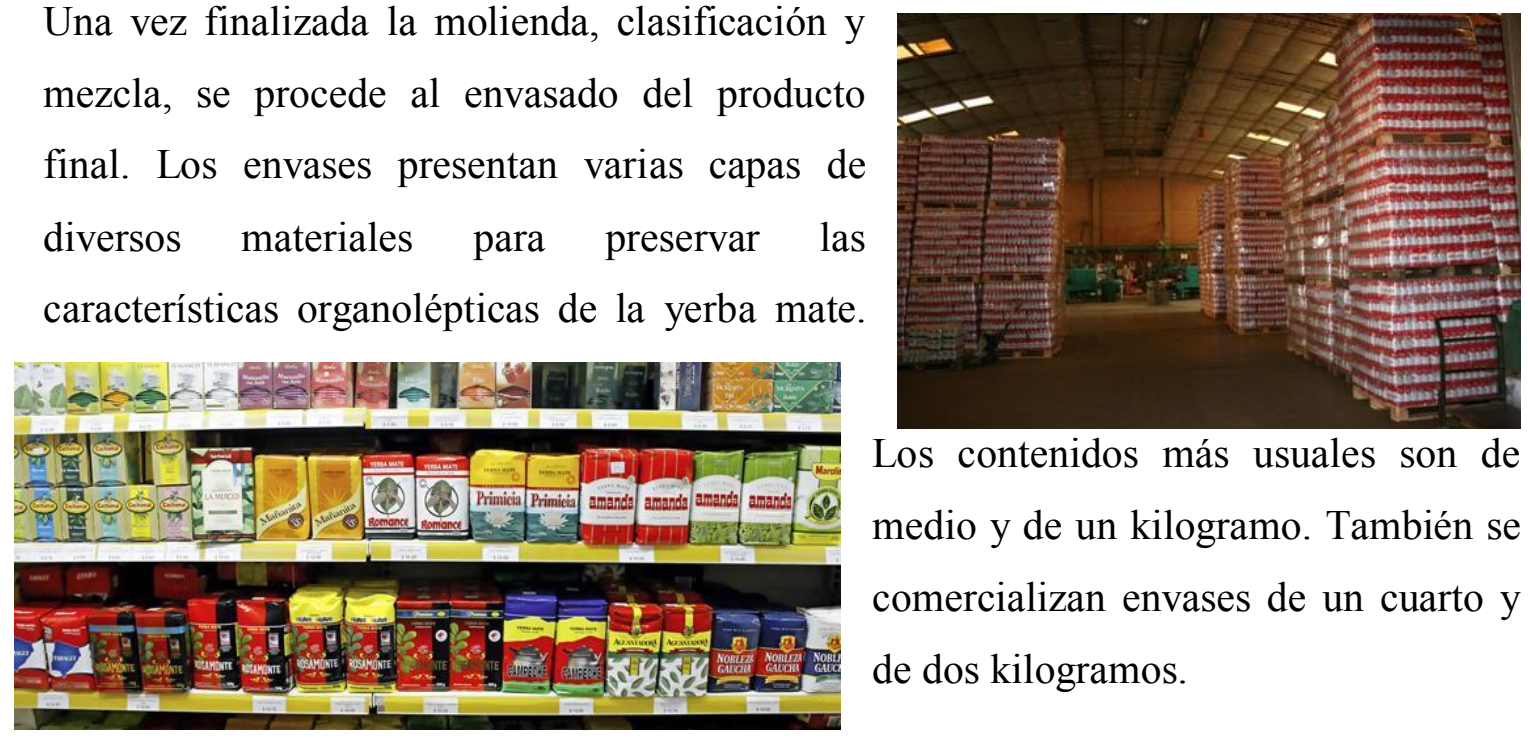

Los contenidos más usuales son de medio y de un kilogramo. También se comercializan envases de un cuarto y de dos kilogramos.

\subsection{MERCADO MUNDIAL DE LA YERBA MATE}

\subsubsection{Producción de yerba mate a nivel mundial}

Hoy, la Argentina es el principal productor de yerba mate en el mundo y el segundo consumidor detrás de Uruguay. Argentina produce cerca del $60 \%$ del total mundial de yerba mate canchada, encontrándose en el segundo puesto Brasil, y en el tercero, con yerbales muy heterogéneos, Paraguay

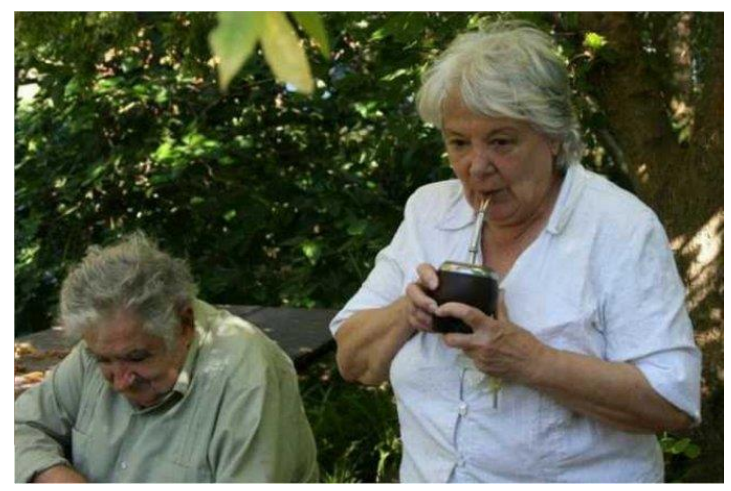
(Figura 1.5). 


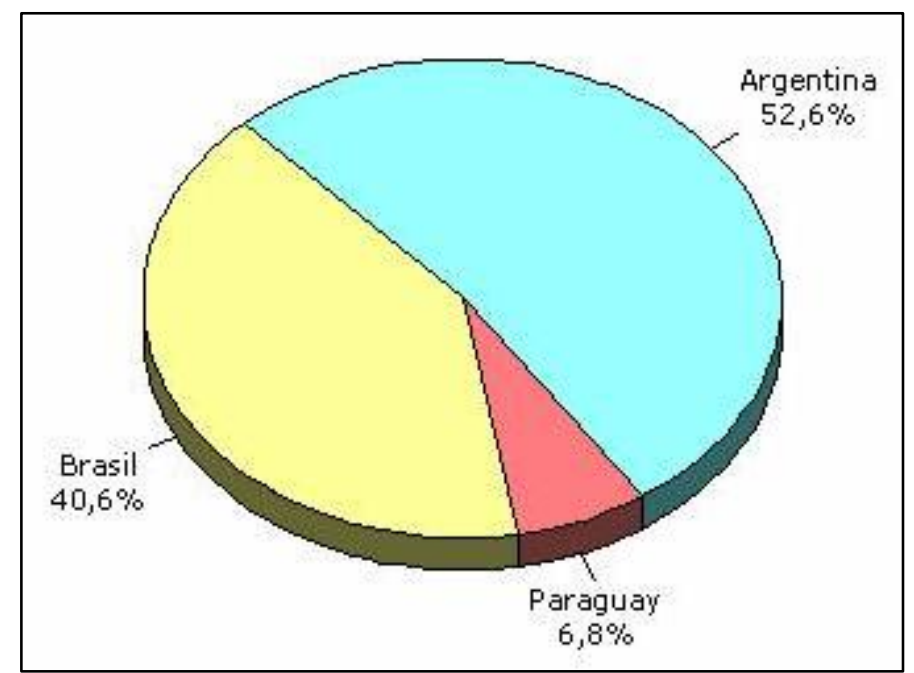

Figura 1.5: producción mundial de yerba mate. (Fuente: Dirección de Alimentos de Argentina, 2008)

En nuestro país, la única región donde se puede desarrollar la planta de la yerba mate, abarca la totalidad de la provincia de Misiones y la zona Norte de Corrientes, (departamentos de Santo Tomé e Ituzaingó). Esta zona reúne características agroecológicas únicas que le permiten alcanzar una producción potencial de más de 900.000 ton anuales de hojas de yerba mate. Dicho volumen es la cantidad equivalente para obtener unas 300.000 ton de yerba mate canchada que procesa el canal industrial. Como puede observarse en la Figura 1.6, del total de la superficie plantada, Misiones posee la mayor parte respecto del total, con datos actualizados al año 2013, la superficie total para esta provincia es de 190.629,99 ha, siendo los departamentos más destacados: Oberá, Cainguás, San Ignacio, Apóstoles, General Manuel Belgrano, Guaraní y Gral. San Martin, los cuales constituyen más del $50 \%$ del total de hectáreas cultivadas en toda la provincia. Por otro lado, la provincia de Corrientes posee su mayor concentración en el departamento de Santo Tomé con 12.996,64 ha cultivadas, haciendo un total para la provincia de 20.722,52 ha cultivadas. En conclusión existen 211.352,51 ha productoras de yerba mate que constituyen la oferta nacional de este primer sector. En Brasil, se cultiva solamente en 5 Estados: Mato Grosso do Sul, Sao Paulo, Paraná, Santa Catarina y Río Grande do Sul, encontrándose más del $80 \%$ del área cultivada en los últimos tres. Por su parte, Paraguay, al igual que los anteriores, tiene un importante nivel de consumo local, pero es el país de menor producción de los tres. Su cultivo se localiza principalmente en los departamentos de Amambay, Canindeyú, San Pedro, Guayrá, Alto Paraná e Itapuá. 


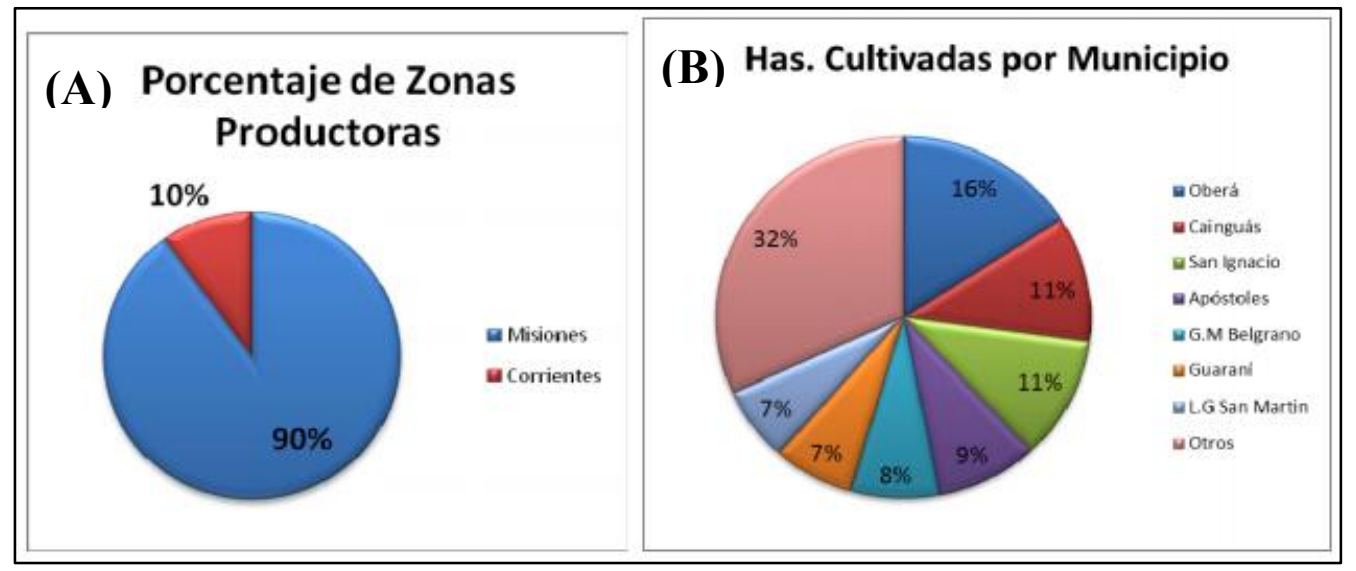

Figura 1.6: Porcentaje de zonas productoras de yerba mate en la Argentina (A) y hectáreas cultivadas con yerba mate en los municipios de la provincia de Misiones (B). (Fuente: Instituto Nacional de la Yerba mate (INYM); Ministerio del Agro y la Producción de la Provincia de Misiones; Subsecretaría de Desarrollo y Producción Vegetal - Dirección Gral. De Yerba mate y Té).

\subsubsection{Consumo de yerba mate}

La yerba mate presenta un elevado índice de consumo doméstico a nivel de su región de origen natural y genera importantes ingresos por ventas al exterior. Es un producto que moviliza a los sectores productivo, industrial y comercial, siendo un cultivo estratégico

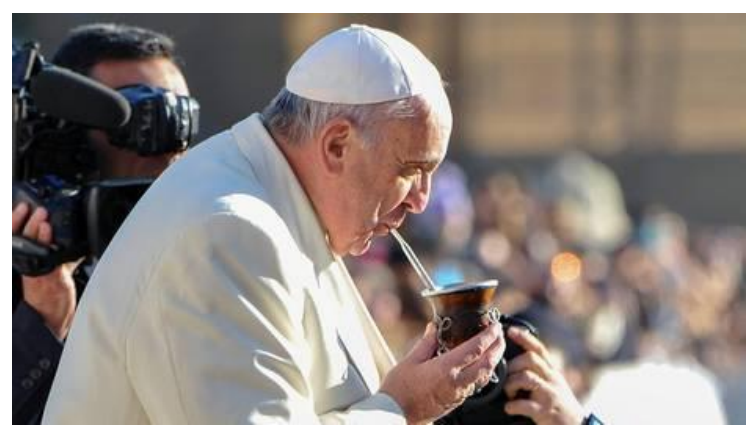
desde el punto de vista de la ocupación de mano de obra. Actualmente, los países productores procuran expandir el consumo de este vegetal a diversos países, así como ampliar sus usos, como por ejemplo, el empleo de sus principios activos con fines terapéuticos.

Hay tres formas básicas de consumir la yerba mate, que reciben distintos nombres:

- La forma más común es el mate, una infusión que se prepara en un recipiente (también denominado "mate") o -si el recipiente es de la variante de boca ancha se le llama

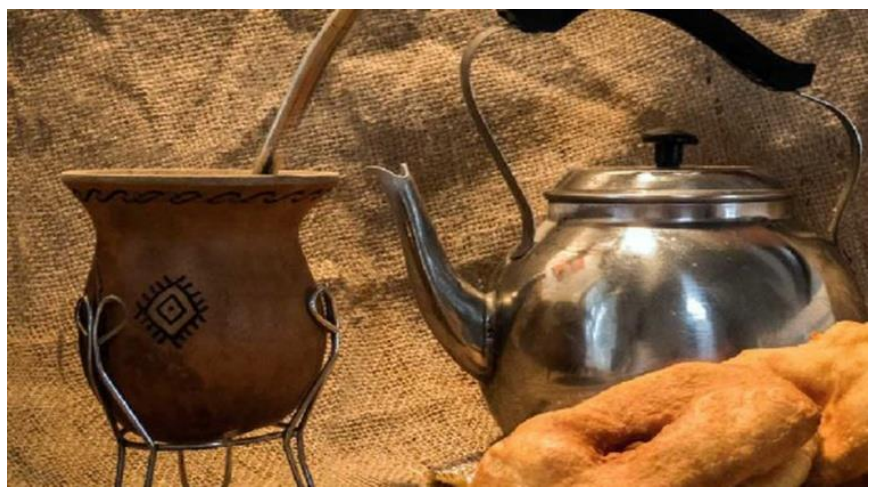


“porongo"- en donde se vierte agua entre 75 y 82 grados de temperatura, que se succiona por medio de una bombilla.

- El tereré es similar al mate, pero se lo prepara con agua bien fría, su consumo es constante sin importar la época o temperatura. Se le suele agregar mezcla de yerbas medicinales como la menta (Mentha arvensis), el cedrón (Lippia

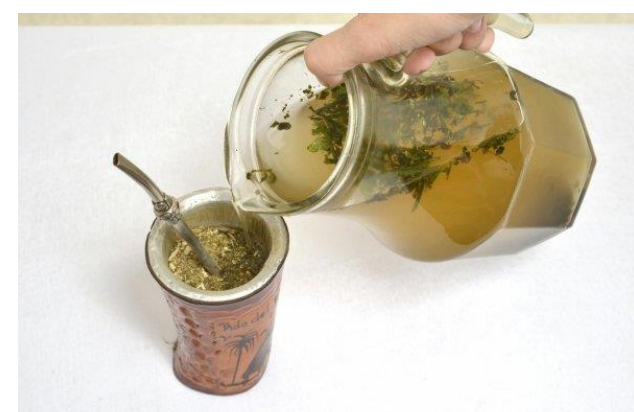
citriodora), menta peperina, y otras. Es propio de Paraguay, oeste de Mato Grosso y de São Paulo, y en el litoral argentino.

- El mate cocido es una infusión. Para prepararlo primero se calienta agua, se le agrega yerba mate antes de hervir (muchas veces "quemada" previamente con azúcar) y posteriormente se cuela y se sirve en una taza. Hoy, esta forma de preparar el mate cocido, ha sido en algunos lugares desplazada por el mate cocido preparado en bolsitas de papel, similares a las del té común y por el concentrado en polvo. El mate cocido fue conocido en los siglos XVII y XVIII como té de los jesuitas, por ser éstos quienes popularizaron su uso, a imitación del té.
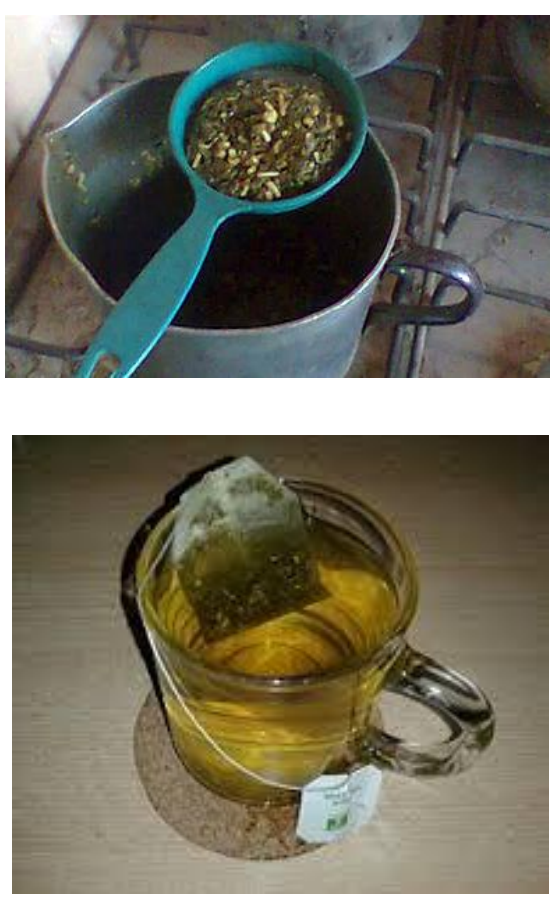

\subsubsection{Mercado interno}

\subsubsection{El precio de la hoja verde y la yerba canchada}

El Instituto Nacional de la Yerba Mate (INYM) es quien fija los precios de la hoja verde y canchada semestralmente (Ley 25.564). En los últimos años intervino también el Ministerio de Agricultura, Ganadería y pesca de la Nación. En la Tabla 1.1 se puede observar la evolución de los precios de la hoja verde y canchada por un período de diez años. 
Tabla 1.1: Evolución de los precios de la hoja verde y canchada por un período de doce años. (Fuente: Instituto Nacional de la Yerba mate (INYM); Ministerio del Agro y la Producción de la Provincia de Misiones; Subsecretaría de Desarrollo y Producción Vegetal - Dirección Gral. de Yerba Mate y Té).

\begin{tabular}{lcc}
\hline Año & $\begin{array}{c}\text { Hoja verde } \\
(\$ \text { por kg })\end{array}$ & $\begin{array}{c}\text { Yerba mate } \\
\text { canchada }(\$ \text { por kg })\end{array}$ \\
\hline 2003 & 0,17 & 0,70 \\
\hline 2004 & 0,27 & 0,91 \\
\hline 2005 & 0,35 & 1,51 \\
\hline 2006 & 0,43 & 1,77 \\
\hline 2007 & 0,48 & 1,85 \\
\hline 2008 & 0,52 & 2,01 \\
\hline 2009 & 0,63 & 2,31 \\
\hline 2010 & 0,69 & 2,42 \\
\hline 2011 & 0,90 & 3,15 \\
\hline 2012 & 2,10 & 6,15 \\
\hline 2013 & 3,00 & 8,20 \\
\hline 2014 & 3,60 & 13,30 \\
\hline 2015 & 3,95 & 14,60 \\
\hline
\end{tabular}

\subsubsection{Análisis del consumo nacional}

Para estimar el consumo interno se puede analizar la yerba mate salida de molino, este es un buen indicador. Se estima que el consumo interno fue de aproximadamente 256.157 ton de yerba mate para el período enero-diciembre 2014 (incluye la salida de molino hasta el mes de octubre) mientras que solamente 25.120 ton

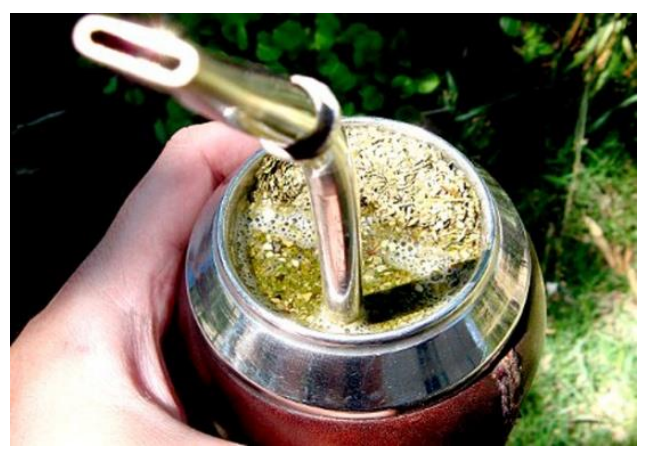
corresponde a exportación para el mismo periodo. Es llamativo observar lo arraigada que está a la población el consumo de yerba mate a través de las distintas modalidades de consumo prevaleciendo el "Mate" por sobre todos ellos. Según un informe realizado por el Ministerio de Agricultura, Ganadería y Pesca de la Nación, se revela que el 76 \% de la población consume mate, y ese consumo per cápita es aproximadamente de $6,0 \mathrm{~kg}$ anuales de yerba mate, equivalente a aproximadamente 100 litros de mate. Siendo así la bebida que más se consume, por encima de los vinos, cervezas, gaseosas, agua, etc. 


\subsubsection{Análisis de ventas según formato}

En cuanto a los formatos, los envases de medio kilo son los preferidos por los consumidores. Los datos provenientes de las declaraciones juradas indican que durante el mes de diciembre de 2014 los paquetes de medio kilo representan aproximadamente el $58 \%$ del total de yerba mate a la salida del molino, le siguen los paquetes de kilo con el $35 \%$ sobre el total. El $2 \%$ prefiere envases de dos kilos y el $1 \%$ a paquetes de un cuarto y otros formatos.

\subsubsection{Mercado externo}

\subsubsection{Exportación de yerba mate}

En la provincia de Misiones, la economía de la yerba mate, es uno de los pilares básicos de la economía. El esfuerzo que han hecho todos los actores de esta economía (Estado

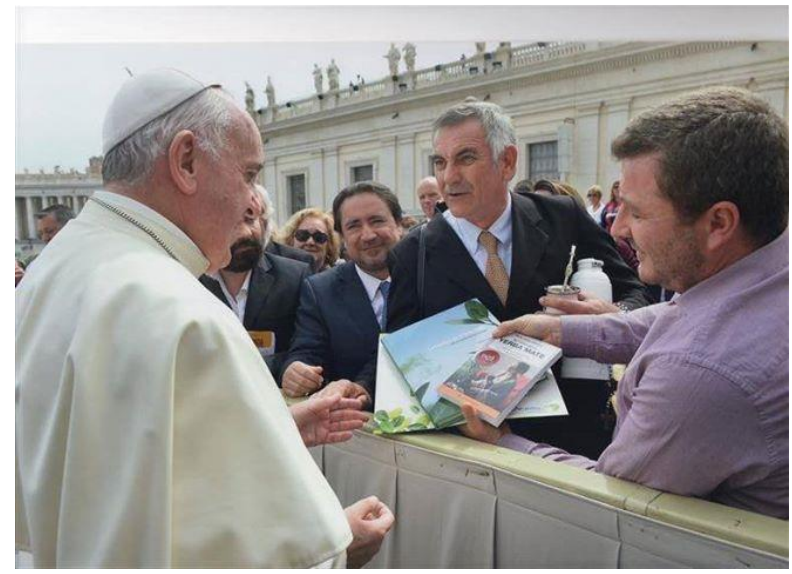

Unidos.

provincial, productores, empresarios, etc.) a lo largo de los últimos 20 años, fue recompensado con la conquista de muchos y variados mercados, algunos tradicionalmente consumidores como Chile y Brasil, y otros no tradicionales, como Siria y Líbano y últimamente la Comunidad Europea y los Estados

En los primeros siete meses del año 2014 se declararon exportaciones argentinas de yerba mate estacionada y molida a granel por 18.035 toneladas a un valor promedio ponderado de 2,78 u\$s/kg, lo cual implicó más de 50 millones de dólares (precios FOB).

A continuación se exponen los principales destinos exportadores de yerba mate, la Tabla 1.2 y la Figura 1.7 muestran los primeros veinte países importadores del producto y el porcentaje correspondiente respecto del total exportado para el año 2013.

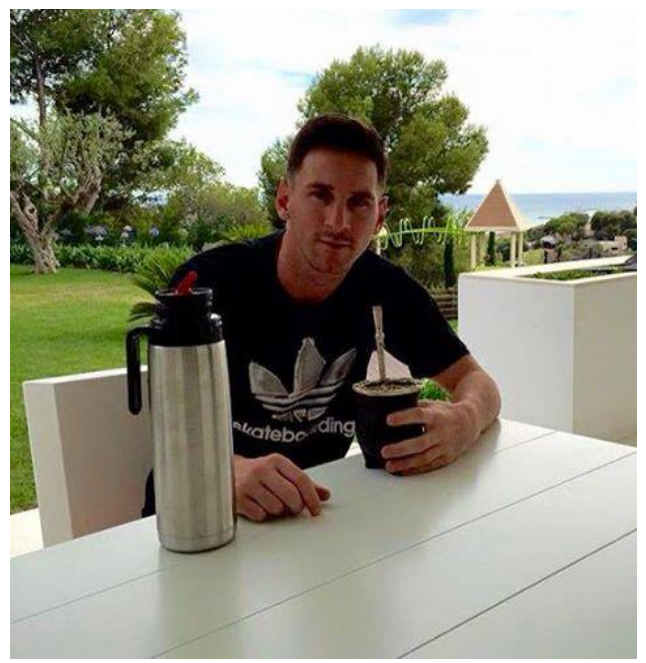


Se exporta yerba mate a más de treinta países en el mundo. El gráfico muestra algunos de los principales destinos, siendo los tres primeros: Siria, Chile y el Líbano, que juntos constituyen más del $80 \%$ de la cantidad total de yerba exportada.

Tabla 1.2: Primeros veinte países importadores de yerba maye y porcentaje correspondiente respecto del total exportado para el año 2013. (Fuente: Base de datos Exportaciones del INDEC).

\begin{tabular}{|l|l|}
\hline Países & $\begin{array}{l}\text { \% respecto del } \\
\text { peso total }\end{array}$ \\
\hline Siria & 0,7170 \\
\hline Chile & 0,1036 \\
\hline Líbano & 0,0325 \\
\hline EE.UU & 0,0078 \\
\hline Japón & 0,0081 \\
\hline Brasil & 0,0165 \\
\hline España & 0,0052 \\
\hline Corea Republicana & 0,0046 \\
\hline $\begin{array}{l}\text { Emiratos Árabes } \\
\text { Unidos }\end{array}$ & 0,0043 \\
\hline Alemania & 0,0027 \\
\hline Venezuela & 0,0036 \\
\hline Francia & 0,0032 \\
\hline Israel & 0,0029 \\
\hline Paises Bajos & 0,0016 \\
\hline Polonia & 0,0016 \\
\hline Arabia Saudita & 0,0019 \\
\hline Rusia & 0,0023 \\
\hline Turquia & 0,0016 \\
\hline
\end{tabular}

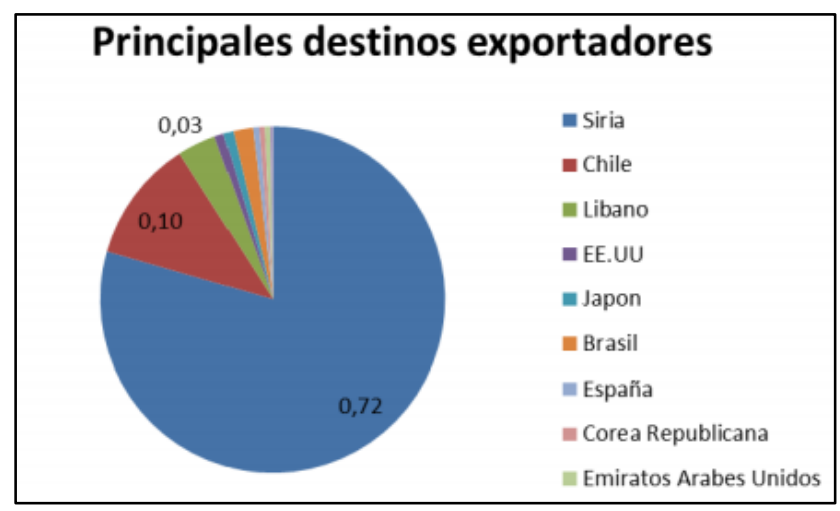

Figura 1.7: Primeros veinte países importadores de yerba maye y porcentaje correspondiente respecto del total exportado para el año 2013. (Fuente: Base de datos Exportaciones del INDEC).

\subsection{ACTIVIDADES BIOLÓGICAS Y EFECTOS EN LA SALUD}

La yerba mate se consume fundamentalmente como bebida estimulante, eliminadora de la fatiga y estimuladora de la actividad mental y física; tiene un efecto beneficioso en nervios y músculos y también aumenta el trabajo intelectual. 
Las investigaciones científicas señalan que la yerba mate es un muy buen antioxidante, diurético y laxante natural, y también puede resultar preventiva de las caries dentales. Otra de las acciones orgánicas de sus principios activos resulta muy apropiada para combatir patologías como el sobrepeso y la obesidad.

La acción estimulante de la yerba mate es más larga que la del café y no tiene los efectos perjudiciales de este como el

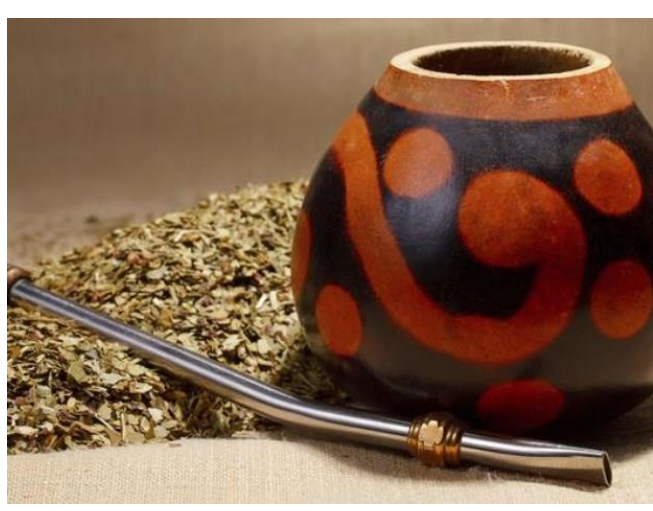
insomnio o la irritabilidad.

\subsubsection{La actividad antimicrobiana}

Se han realizado investigaciones al respecto, aunque los resultados no han sido tan interesantes como se esperaba. Un extracto acuoso de hojas de I. paraguariensis (no hay detalles en el documento sobre el tratamiento de las hojas antes de la extracción, ni la concentración, ni la temperatura del extracto acuoso, ni el momento de la extracción) mostró in vitro una fuerte actividad contra cepas VHS-1 KOS (IS = 15,8) y 29 R-(ES = 12.6). Se observó que no hay actividad contra el virus de la rabia (Müller y col., 2007). Los autores responsabilizan a los CQAs por dicha actividad. Sin embargo, es importante señalar que ácidos cafeoilquínicos son ubicuos y están presentes en la mayoría de las otras especies, por ejemplo, en los que se detectó menos o casi ninguna actividad que un extracto acuoso de I. paraguariensis. Anteriormente, la actividad antimicrobiana del aceite esencial de la hoja de yerba mate fue probada contra los microorganismos seleccionados (Kubo y col., 1993) pero principalmente contra Streptococcus mutans debido a la importancia que presenta en la formación de caries dentales (Hamada y Slade, 1980). Todos los componentes de esta fracción volátil mostraron actividad, aunque el efecto individual de los componentes ha demostrado ser de moderada a baja.

Sari y col. (2007) probaron la actividad inhibitoria de diversos tipos de extractos de yerba mate contra diversas bacterias. Todos los extractos de yerba mate demostrado ser activos contra todas las cepas probadas, Staphylococcus aureus, Listeria monocytogenes, E. coli $\mathrm{O}+/ 1: \mathrm{H} 1$, Hafnia alvei, Yersinia enterocolitica y Bacillus cereus, con la excepción de E. coli. 


\subsubsection{Actividad antiparasitaria}

Hay varias infecciones endémicas graves causadas por parásitos en el centro y el norte de Argentina. Uno de las más peligrosas es Chagas-Mazza, causada por el protozoo Trypanozoma cruzi. Taketa y col. (2004) ha probado la actividad antitripanosomial de algunas saponinas de diversas especies de Ilex, entre ellos I. paraguariensis donde encontraron que matesaponina 1, matesaponina 3 y 4 , mostraron IC50 > 32/M en contra de ambos T. brucei y T. cruzi.

\subsubsection{Capacidad antioxidante}

Se ha encontrado que el consumo de mate contribuye significativamente a la ingesta de antioxidantes en general y proporciona altas cantidades de derivados del ácido cafeilquínico, con efectos biológicos potencialmente beneficiosos para la salud humana (Bravo y col., 2006). De todas las especies de Ilex, se ha demostrado que Ilex paraguariensis tiene la mayor actividad antioxidante y se ha correlacionado positivamente con la concentración de los derivados del ácido cafeico (Filip y col., 2000; Bixby y col., 2005).

\subsubsection{Control del peso y la obesidad}

La obesidad es una preocupación creciente en muchos países y las investigaciones actuales en muchas áreas están dirigidas a encontrar una manera de frenar esta epidemia. El mate ha demostrado posibles efectos sobre la pérdida de peso como lo demuestran algunas investigaciones en curso. Los hombres y mujeres obesos que consumen mate han mostrado una disminución del cociente respiratorio (CR), lo que indica un aumento de la oxidación de grasas (Martinet y col., 1999).

El mate es actualmente considerado como suplemento dietético. La adición de ingredientes tales como mate junto con guaraná en los suplementos ha demostrado ser eficaz en la reducción de peso corporal (Pittler y Ernest, 2004).

Si bien se ha citado el efecto del mate en la pérdida de peso, no se conoce directamente el mecanismo de tal efecto. Podría ser debido a su concentración de cafeína, lo que contribuye a la actividad lipolítica, termogénica o la concentración de saponina, interfiriendo con el metabolismo del colesterol y retrasando la absorción intestinal de grasas en la dieta (Dickel y col., 2007). El mate también puede afectar otros aspectos del 
metabolismo de los lípidos, tiene la capacidad de inhibir la aterosclerosis en conejos cuando son alimentados con una dieta alta en colesterol conjuntamente con un extracto acuoso de yerba mate (Mosimann y col, 2006). El mate ha demostrado también, tener potencial como digestivo debido a un efecto colerético por el aumento de la tasa de flujo de la bilis (Gorzalczany y col., 2001).

\subsubsection{Actividades contra el cáncer}

Se ha reportado una importante cantidad de investigaciones sobre las actividades contra el cáncer de hojas de I. paraguariensis como así también de la yerba mate. La mayoría de ellas han sido experimentos in vitro y algunos experimentos in vivo o ex-vivo. Lamentablemente no se han realizado estudios epidemiológicos reales. Estas actividades han sido ampliamente revisadas por Bastos (2007), Heck y González de Mejía (2007) y más recientemente por Bracesco (2011).

Un estudio reciente mostró que las fracciones ricas de saponinas de I. paraguariensis inhibían la proliferación de células de cáncer de colon (HT-29) a través de la activación de un vía específica de apoptosis intracelular. Esta fracción de saponina también aumentó la expresión de la proteína Bax pro-apoptóticos, disminuyendo la expresión de proteínas anti-apoptóticas Bcl-2 y activando posteriormente la caspasa-3. Estos hallazgos sugieren que la inducción de la apoptosis en células HT-29 tratadas con matesaponinas podría estar asociada con una cascada caspasa-dependiente que implica la activación de la vía mitocondrial, iniciada por la inhibición de Bcl-2 y la activación de Bax (Puangpraphant y González de Mejía, 2009).

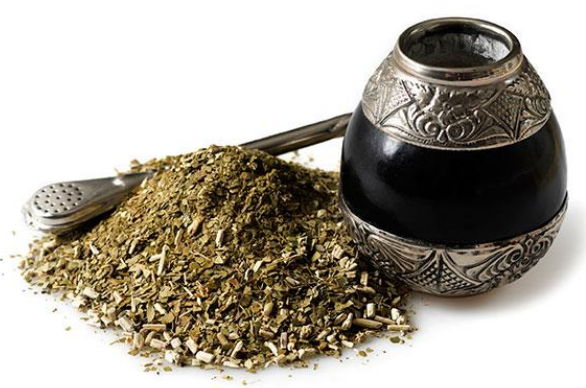
Una de las actividades relacionadas con la biología del cáncer es la angiogénesis, un estudio clave en la inflamación y reparación. Tratamientos realizados con el extracto acuoso de yerba mate y la cafeína en las membranas vasculares del saco vitelino de embriones de pollo revelaron propiedades pro-vasculo-angiogénicas así como la mejora del crecimiento embrionario (Strassmann y col., 2008). 


\subsection{PRODUCTOS ELABORADOS CON YERBA MATE}

- Yerba molida presentación tradicional: Yerba mate común, presentaciones suaves, orgánicas.

- Yerba molida presentaciones nuevas: yerba mate en saquitos para mate cocido, molienda especial para tereré, molienda con mezclas saborizadas con frutas $\mathrm{y} / \mathrm{o}$ hierbas.

- Productos elaborados para preparar infusiones: yerba mate soluble (en polvo o granulado).

- Otros productos elaborados con yerba mate: licores, bebidas no alcohólicas, gasificadas o no, cremas heladas, postres, salsas, masas, etc.

- Línea no gastronómica: jabones, cremas,

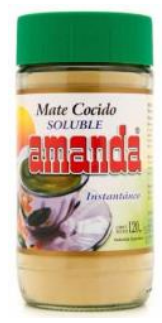
etc.
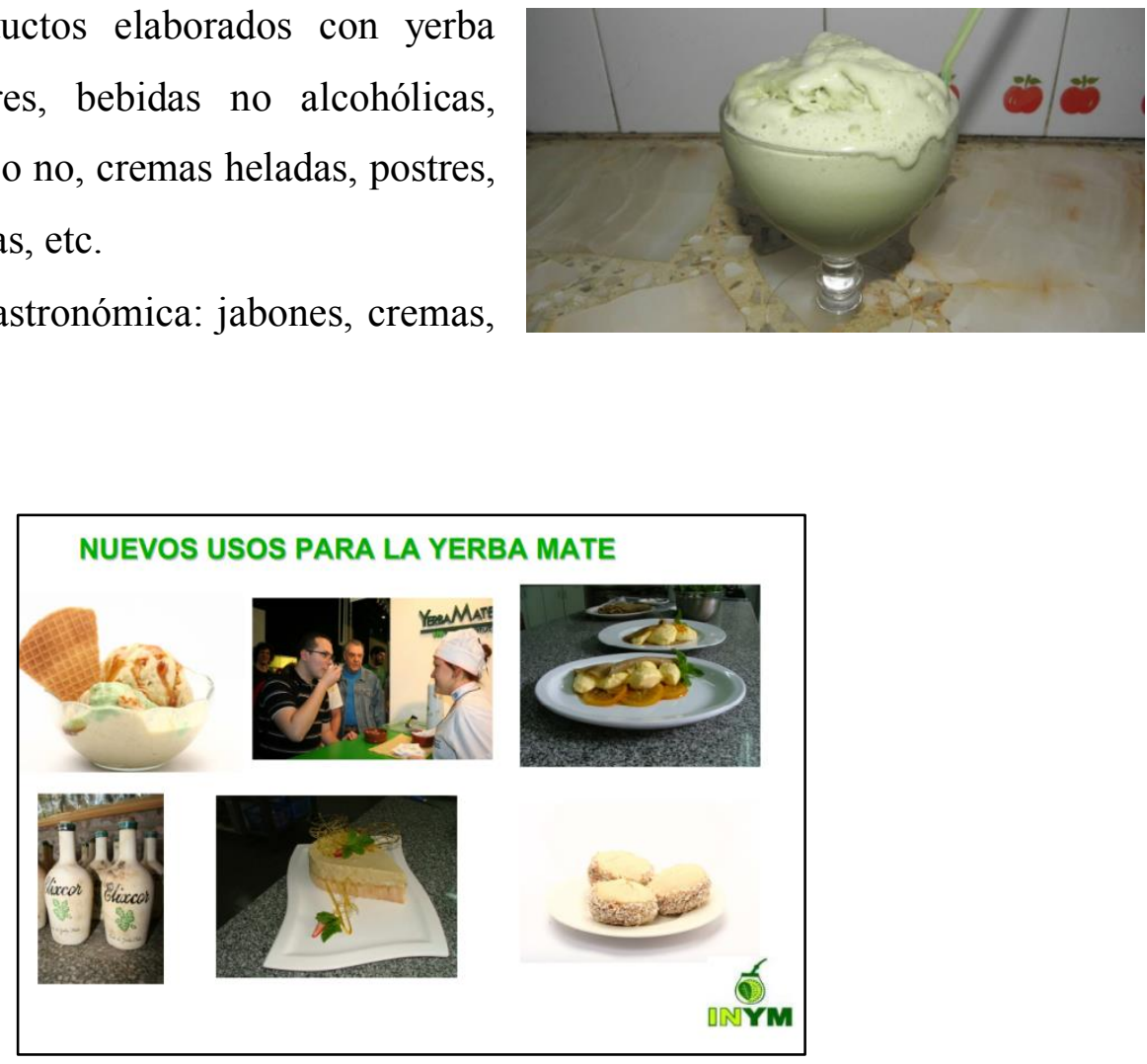

Algunas aplicaciones posibles se resumen en la Tabla 1.3. 
Tabla 1.3: Aplicaciones y productos alternativos de la yerba mate.

\begin{tabular}{|c|c|c|c|c|}
\hline Aplicacion Industrial & & Sub-producto & & Forma de Consumo \\
\hline \multirow{2}{*}{ Bebidas } & i & Mate, tereré, soluble, cocido & i & Infusión caliente o fría \\
\hline & I & Carbonatado, concentrado & 1 & Extracto de hojas diluido \\
\hline \multirow{2}{*}{ Alimentos } & 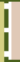 & Culur anle, cunser vante & I & \multirow{2}{*}{ Clorofila y esencias } \\
\hline & 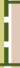 & Helados, caramelos, gomas de mascar & 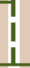 & \\
\hline \multirow{2}{*}{ Medicamentos } & 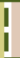 & Estimulante del sistema nervioso & I & Extracto de xantinas \\
\hline & 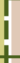 & $\begin{array}{l}\text { Compuestos para tratamiento de hipertensión, } \\
\text { bronquitis y neumonía }\end{array}$ & I & Extracto de flavenoles \\
\hline Higiene general & i & $\begin{array}{l}\text { Bactericida y antioxidante hospitalario y } \\
\text { doméstico. Emulsificante }\end{array}$ & i & $\begin{array}{l}\text { Extracto de saponinas y } \\
\text { esencias }\end{array}$ \\
\hline Productos de Uso Personal & 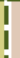 & Perfumes, desodorantes, cosméticos, jabones & I & Extracto de hojas y clorofila \\
\hline
\end{tabular}

Sin embargo, es dable destacar que a la fecha no hay datos sobre la utilización de la yerba mate como materia prima potencial, tanto para la industria química (elaboración de fine chemicals) como para la farmacéutica (elaboración de drogas), mediante la extracción y biotransformación de determinados compuestos presentes en altas concentraciones en Ilex paraguariensis. 


\section{$1^{0}$ ETAPA}

Obtención de un extracto acuoso de yerba mate con elevado contenido de ácido clorogénico (ACG)

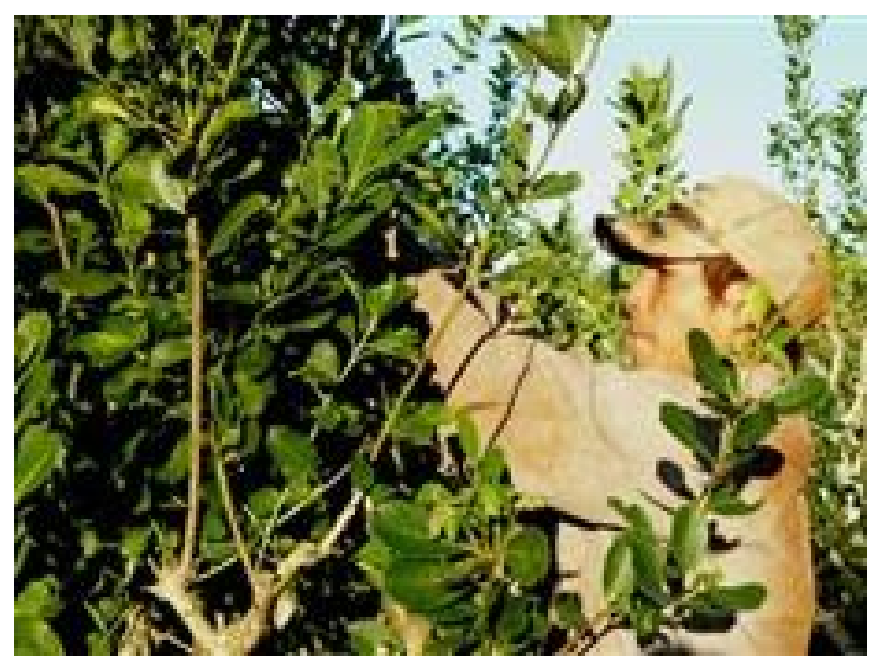




\section{Capítulo 2}

Extracción de ácido clorogénico de la yerba mate ( $/$ ex paraguariensis): efecto de la fracción vegetal, etapa de industrialización y época del año. 


\title{
CAPÍTULO 2 \\ EXTRACCIÓN DE ÁCIDO CLOROGÉNICO A PARTIR DE YERBA MATE (ILEX PARAGUARIENSIS): EFECTO DE LA FRACCIÓN VEGETAL, ETAPA DE INDUSTRIALIZACIÓN Y ÉPOCA DEL AÑO
}

\begin{abstract}
Resumen
Se analizó el contenido de ácido clorogénico (ACG) y sus diferentes isómeros en muestras de yerba mate obtenidas en dos plantas industriales ubicadas al Sur de la provincia de MisionesArgentina, a lo largo de su procesamiento y en dos épocas del año (inicio y final de la zafra). Las diferentes muestras proporcionadas por la Planta A y la Planta B fueron clasificadas en las fracciones de diferente granulometría con las cuales se formula el producto final: hojas, palos y polvo. Cada fracción fue molida por separado con un molino de cuchillas hasta la obtención de un polvo fino. Se utilizó la fracción de hoja molida y palo molido que atraviesa una malla de $500 \mu \mathrm{m}$ de apertura nominal (Ø tamaño de partícula $<500 \mu \mathrm{m}$ ). A continuación se determinó el contenido de humedad de las mismas utilizando una estufa convectiva $\left(103 \pm 2{ }^{\circ} \mathrm{C}\right.$ durante $\left.6 \mathrm{~h}\right)$. Los extractos acuosos fueron preparados agregando la muestra $(500 \mathrm{mg})$ sobre agua a ebullición $(50 \mathrm{ml})$ manteniendo la mezcla en baño termostatizado $\left(98-100{ }^{\circ} \mathrm{C}, 5 \mathrm{~min}\right)$ con agitación. Concluido el tiempo de extracción, la mezcla se filtró inmediatamente, se registró el volumen de filtrado recolectado, el cual se ajustó con agua destilada para recuperar el agua perdida durante la extracción. El paso de extracción se repitió una vez más sobre el material retenido en el filtro. La identificación y cuantificación del ACG y sus isómeros se llevó a cabo utilizando un método de cromatografía líquida de alta resolución (HPLC) en gradiente.

El contenido de ACG decreció a lo largo de las diferentes etapas de industrialización. El contenido total de ACG (expresado en base seca) varió desde 4,58 $\pm 0,04$ a $8,08 \pm 0,10 \mathrm{~g}$ ACG/100 g hojas, y de 3,16 $\pm 0,06$ a 7,89 $\pm 0,53 \mathrm{~g} \mathrm{ACG/100} \mathrm{g} \mathrm{palos,} \mathrm{durante} \mathrm{el} \mathrm{proceso} \mathrm{en} \mathrm{su}$ conjunto. El análisis cuantitativo-comparativo indicó que el mayor contenido de ACG fue encontrado en las muestras de yerba mate recién cosechada: hoja y palo verde. No hubo diferencias significativas $(p<0,05)$ en el contenido de ACG entre estas muestras. El contenido de ACG al inicio de la época de zafra fue sustancialmente mayor al obtenido al final de la época de zafra, tanto para las hojas como para los palos verdes.

Los presentes resultados indican que el "palo verde" obtenido al inicio de la época de zafra, residuo actualmente poco valorado en la industria yerbatera, podría constituir una materia prima valiosa para la obtención de extractos ricos en ACG.
\end{abstract}

\subsection{INTRODUCCIÓN}

Estructuralmente, el ácido clorogénico (ACG, CAS Number: 327-97-9) es un éster formado entre el ácido cafeico y el L-quínico (ácido 5-O-cafeoilquínico). Los isómeros del ACG incluyen el ácido 3-O-cafeoilquínico (ácido neoclorogénico, neo-ACG) y el ácido 4-O-cafeoilquínico (ácido criptoclorogénico, cripto-ACG) (Fig. 2.1). 


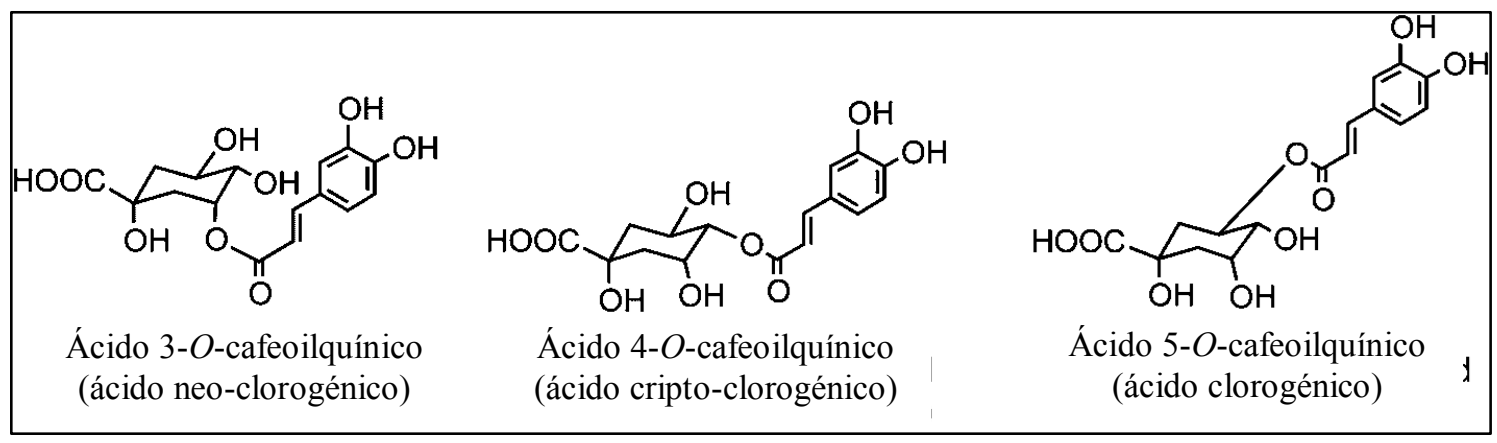

Figura 2.1: Estructura química del ácido clorogénico y sus compuestos isómeros.

El ACG, uno de los polifenoles ampliamente presente en plantas superiores (Delage y col., 1991), ha cobrado gran importancia debido a su utilización tanto en medicina como en industrias de productos químicos de consumo y de alimentos (Kweon y col., 2001). Se emplea como aditivo en bebidas, cosméticos, productos derivados del té y alimentos, así también como en sustancias medicinales (Jiang y col., 2000; Jin y col., 2005). Se han reportado actividades farmacológicas asociadas al ACG potencialmente beneficiosas para el ser humano, tales como agente contra el cáncer, hepatoprotectivo, antioxidante, antiviral, antibacterial, antifúngico con relativa baja toxicidad y efectos secundarios además de bajo potencial de desarrollo de resistencia antimicrobiana. Estas actividades han sido atribuidas al ACG como resultado de estudios in vitro, in vivo $\mathrm{y}$ epidemiológicos (Jiang y col., 2000; Farah y Donangelo, 2006). Otras actividades farmacológicas mencionadas incluyen la disminución de la gluconeogénesis hepática y la reducción de la absorción de glucosa, con disminución concomitante de picos de glucemia (Shearer y col., 2003).

El ACG está actualmente disponible en el mercado internacional tanto en forma de producto grado analítico, como así también de grado alimenticio y a granel, siendo en todos los casos considerado dentro de la categoría de Fine Chemicals. Su precio FOB China es del orden de US\$3.500/kg para un producto sólido a granel con $95 \%$ (p/p) de pureza (información obtenida de un trader, 2014). Actualmente, en nuestro país no hay producción de ACG por lo que las necesidades locales deben ser satisfechas por importación. El ACG se puede extraer de diferentes fuentes naturales, siendo los géneros Lonicera japonica Thunb y Eucommia ulmoides Oliver las principales fuentes comerciales, particularmente en el caso de empresas productoras chinas (Chun y Kim, 2004; Clifford y col., 2006; Li y col., 2005; Rønsted y col., 2002). Sin embargo, estas 
fuentes son generalmente limitadas y, por lo tanto, caras. El ACG está presente también en altas concentraciones en otras fuentes vegetales tales como manzanas, peras, berenjenas, tomates, arándanos, fresas y tubérculos como la batata y la papa, y principalmente en los frutos del café, particularmente en los granos de café verde, material que es considerado a la fecha como la fuente natural más importante de ACG (Clifford, 1999, 2000). Los granos de café verde son simplemente los granos no tostados de café (no quiere decir que se trate de granos no totalmente maduros aunque pueden presentar diferentes grado de madurez). El contenido de ACG total en los granos de café verde varía de acuerdo con la especie y cultivar del café, el grado de madurez y, en menor medida, con las prácticas agronómicas, el clima y el suelo (Farah y Donangelo, 2006). La diversidad en la metodología analítica para la determinación de ACG también es otro problema importante al comparar diferentes niveles. Se ha reportado que dependiendo de las especies, los granos de café verde pueden contener alrededor del 6-10\% de ACG en base seca. El ACG no es termoestable por lo que se degrada y forma compuestos fenólicos de bajo peso molecular durante el tostado del café. Este proceso origina su progresiva destrucción y transformación en una relación estimada en una pérdida del 8 al $10 \%$ del contenido inicial por cada $1 \%$ de pérdida de peso seco (Clifford, 1999, 2000).

La yerba mate (Ilex paraguariensis St. Hil., Aquifoliaceae) es una especie arbórea que crece de forma natural y es cultivada en las regiones climáticas templadas $\mathrm{y}$ subtropicales de Argentina, Brasil y Paraguay. Argentina es el principal productor de yerba mate $(\approx 60 \%$ de la producción mundial alcanzando un volumen promedio de 750.000 ton/año). La yerba mate es tradicionalmente utilizada como una decocción o una infusión debido a sus propiedades nutricionales y medicinales (tónicas, colerético, diurético, antirreumático, etc.). Sin embargo, resulta notable mencionar que la yerba mate, con contenidos del orden del 8-10 \% (p/p) en base seca (Marques y Farah, 2009; Isolabella y col., 2010; Pagliosa y col., 2010), puede constituir una fuente totalmente novedosa, autóctona, aún no explotada y altamente competitiva para la extracción de este compuesto.

A lo largo de las diferentes etapas del procesamiento industrial de la yerba mate (detalladas en el Capítulo 1 de la presente tesis), especialmente en la cosecha, el zapecado, el secado y el estacionamiento, pueden producirse algunos cambios en el 
perfil y en la concentración de los compuestos bioactivos de la yerba mate, con la consiguiente modificación de sus actividades farmacológicas (López y col., 2006). Hasta la fecha, sólo unos pocos estudios se han llevado a cabo para evaluar los cambios que se producen en el contenido de ACG de la yerba mate durante su procesamiento. Bastos y col. (2006) e Isolabella y col. (2010) han estudiado la variación del contenido de ACG, entre otros compuestos, únicamente en la fracción correspondiente a las hojas de la yerba mate en sus diferentes etapas del procesamiento industrial. Sin embargo, no existe información actualizada a cerca de la variación de este compuesto en las diferentes fracciones de la yerba mate (especialmente las hojas y palos) durante su procesamiento industrial y en diferentes épocas de cosecha.

La información científica disponible sobre la yerba mate incluye estudios sobre su composición, efectos físiológicos y posibles implicaciones para la salud, así como consideraciones tecnológicas para su procesamiento (Heck y González de Mejía, 2007). Sin embargo, a la fecha, no se han descrito estudios acerca de su utilización como materia prima para llevar a cabo biotransformaciones. Una nueva estrategia para la producción industrial de diversos materiales de importancia farmacéutica a partir de nuestra yerba mate se encuentra bajo investigación. Esta estrategia se basa en su alto contenido de ACG, comparable al hallado en los productos derivados del café, pero con un menor nivel de sustancias interferentes, particularmente de sustancias lipídicas. Por lo tanto, la yerba mate parece ser una fuente especial y única de ACG, que puede convertirse biotecnológicamente en compuestos de valor agregado de importancia farmacéutica, idénticos a los liberados por la vía del ácido siquímico. Se ha reportado que el ACG es fácilmente convertido a ácido siquímico vía quinato, 3-dehidroquinato y 3-dehidrosiquimato (Adachi y col., 2006a,b,c; Adachi y col., 2008b). El ASK es un precursor directo de la síntesis química de la droga antiviral Oseltamivir, el principio activo del Tamiflú ${ }^{\mathrm{MR}}$ (el inhibidor potente, selectivo y competitivo de la neuraminidasa del virus de la influenza A y B usado para tratar a las personas afectadas por esta gripe pandémica) (Enserink, 2006). También, el ASK se emplea para la síntesis de antibióticos, aminoácidos y agroquímicos.

De acuerdo con lo descrito anteriormente, el objetivo de la presente etapa fue investigar el contenido de ACG, tanto en las hojas como en los palos de yerba mate, a lo largo de las diferentes etapas de industrialización en dos plantas de procesamiento, al principio y 
al final de época de zafra. Esta información es necesaria para la selección de la fracción yerba mate más adecuada como materia prima para la preparación de extractos acuosos enriquecidos de ACG para su posterior biotransformación.

\subsection{MATERIALES Y MÉTODOS}

\subsubsection{Materiales y reactivos químicos}

Para las extracciones se utilizó agua destilada mientras que para la determinación del contenido de ácido clorogénico (ACG) se utilizaron los siguientes reactivos de grado analítico o cromatográfico: ácido clorogénico (ACG) $(98 \%$ p/p de pureza, SigmaAldrich, St. Louis, EE.UU.), agua (Panreac, Barcelona, España), ácido fórmico (96 \% de pureza, Tedia, Fairfield, EE.UU.) y acetonitrilo (J.T. Baker, Phillipsburg, EE.UU.).

\subsubsection{Selección de la materia prima}

En el presente estudio se utilizaron diferentes materiales vegetales derivados del procesamiento de la yerba mate. Entre ellos se incluyeron muestras de yerba mate verde recién recolectadas además de muestras tomadas durante diferentes etapas de procesamiento. Las diferentes muestras analizadas y clasificadas en hojas, palos y polvo fueron suministradas por dos plantas procesadoras de yerba mate localizadas al Sur de la Provincia de Misiones, Argentina (Planta A y Planta B).

La recolección y el almacenamiento del material vegetal se llevaron a cabo bajo estrictas condiciones de control. El material vegetal fue mecánicamente cosechado al inicio de la época de zafra (meses de abril-mayo de 2014) y al final de la época de zafra (septiembre de 2014). El análisis se llevó a cabo sobre muestras tomadas del mismo lote

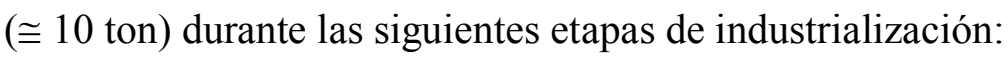

(a) Yerba mate verde (recién cosechada, muestras identificadas con "C"). Se utilizaron ramas de yerba mate $(\cong 20 \mathrm{~kg})$ las cuales fueron trozadas convenientemente y tratadas en nuestro laboratorio en un horno de microondas (Eslabon de Lujo, $700 \mathrm{~W}$ ) a potencia máxima durante 5 min para inhibir la actividad enzimática propia del material vegetal fresco.

(b) Zapecado (Z): yerba mate verde que ha sido expuesta a fuego directo a temperaturas entre 250 y $550{ }^{\circ} \mathrm{C}$ durante $2-4$ min dependiendo de la planta de 
procesamiento. Se analizaron ramas de yerba mate $(\cong 20 \mathrm{~kg})$, aleatoriamente elegidas)

(c) Secado (S): en ambos plantas de procesamiento el secado se desarrolló empleando un sistema de secado continuo.

- Para el caso de la "Planta A" el secado consistió de las siguientes subetapas:

(1) Pre-secado (PS): esta etapa tiene como objetivo reducir el contenido de humedad en las hojas, de tal forma que cuando las mismas se dispongan en el lecho de secado, éste tenga una porosidad alta para facilitar el flujo del gas de secado. El presecado se llevó a cabo en un secadero tubular de $7 \mathrm{~m}$ de largo en donde la temperatura de los gases de combustión osciló alrededor de los $250{ }^{\circ} \mathrm{C}$ y el tiempo de residencia fue de $7 \mathrm{~min}$.

(2) Secado a través de 2 cintas consecutivas (secado en $1^{\circ}$ cinta, S. $1^{\circ}$; secado en $2^{\circ}$ cinta, $\mathrm{S} .2^{\circ}$ ): consistió en un túnel de secado de $18 \mathrm{~m}$ de longitud en el cual las ramas se transportan a través de 2 cintas consecutivas donde son expuestas a una temperatura de 105-120 ${ }^{\circ} \mathrm{C}$ durante $1,5 \mathrm{~h}$, aproximadamente.

- Para el caso de la "Planta B" el sistema de secado continuo consistió en un túnel de secado a través del cual las ramas son transportadas horizontalmente en una cinta de secado de $30 \mathrm{~m}$ de longitud y 4-4,5 m de ancho y expuestas a un flujo de aire caliente proveniente de un intercambiador de calor con una temperatura media de entrada de $90{ }^{\circ} \mathrm{C}$. Este proceso duró aproximadamente 5-5,5 h.

Se analizaron muestras de ramas de yerba mate $(\cong 20 \mathrm{~kg}$ aleatoriamente elegidas) de cada proceso de secado. Además, en el caso de la Planta B, también se analizaron muestras tomadas después del proceso de molienda gruesa (MG).

(d) Yerba mate elaborada (PF): yerba mate que ha pasado por las etapas previas de estacionamiento, molienda y tamizado. Ambos establecimientos utilizan un proceso de estacionamiento mixto; esto es, el producto final constituye una mezcla de yerba mate con diferentes procesos y tiempos de estacionamiento, ya 
sea natural como acelerado.

Para el caso de esta última etapa, se tomaron muestras de cada una de las fracciones de diferente granulometría (hojas, palos y polvo, $\cong 5 \mathrm{~kg}$ de cada una) las cuales se mezclan en proporciones variables (blends) dependiendo de las características deseadas para el producto final antes de su envasado y comercialización.

Para cada una de las muestras descriptas anteriormente (excepto para la fracción polvo de la yerba mate elaborada, PF), se realizó un cuarteo sucesivo y posterior remoción manual de las fracciones de hoja y palo. Cada fracción (hojas y palos) de cada muestra fue molida por separado hasta la obtención de un polvo fino utilizando un molino de cuchillas. Se utilizó la fracción de hoja molida y palo molido que atraviesa una malla de $500 \mu \mathrm{m}$ de apertura nominal ( $\varnothing$ tamaño de partícula $<500 \mu \mathrm{m}$ ). Las muestras de polvo así obtenidas además de la fracción polvo de la yerba mate elaborada se empaquetaron en bolsas de plástico herméticas y se mantuvieron a $4{ }^{\circ} \mathrm{C}$ hasta su utilización.

\subsubsection{Determinación del contenido de humedad de las muestras}

El contenido de humedad se determinó secando las muestras en una estufa convectiva, a $103 \pm 2{ }^{\circ} \mathrm{C}$ durante $6 \mathrm{~h}$, tiempo en el cual se alcanza peso constante (Norma IRAM 20503). Las determinaciones se realizaron por duplicado y para los cálculos se tomaron los valores promedios de los mismos.

\subsubsection{Preparación de los extractos de yerba mate}

Para la determinación del tiempo de extracción, una muestra de yerba mate aleatoriamente elegida (aproximadamente $500 \mathrm{mg}$ pesados a la décima de miligramo) se extrajo con agua destilada $\left(50 \mathrm{ml}, 95-100{ }^{\circ} \mathrm{C}\right)$ (Heck y col., 2008; Isolabella y col., 2010) en un Erlenmeyer $(125 \mathrm{ml})$ colocado en un baño termostatizado $\left(95 \pm 5{ }^{\circ} \mathrm{C}\right)$ donde se lo mantuvo durante diferentes tiempos (5, 10, 20 y $30 \mathrm{~min})$ con agitación. Concluido el tiempo de extracción, el sobrenadante se filtró inmediatamente, se registró el volumen recolectado y el mismo fue ajustado a $50 \mathrm{ml}$ con agua destilada para recuperar el agua perdida durante la ebullición. El paso de extracción se repitió una vez más sobre el sólido remanente en las mismas condiciones antes descritas. Finalmente, se 
determinó el contenido de ACG como así también de sus diferentes isómeros y se calculó el contenido total de ACG para cada uno de los extractos obtenidos anteriormente. En base a la información obtenida se seleccionó un tiempo de extracción para las demás muestras a analizar.

La preparación de los extractos para la cuantificación del ACG y sus isómeros en las diferentes muestras de yerba mate se realizó de manera análoga a la descripta anteriormente empleando el tiempo de extracción seleccionado previamente.

Todos los extractos fueron preparados por duplicado y se mantuvieron a $4{ }^{\circ} \mathrm{C}$ luego de la extracción. El análisis de los mismos se llevó a cabo dentro de los 4 días posteriores a su preparación.

\subsubsection{Identificación y cuantificación de ácido clorogénico en los extractos de yerba mate}

La identificación y cuantificación del ACG y sus compuestos isómeros se llevó a cabo utilizando un método de cromatografía líquida de alta resolución (HPLC) adaptado de Bravo y col. (2006). El análisis se llevó a cabo mediante cromatografía líquida en gradiente utilizando un equipo Shimadzu Prominence, equipado con un autosampler Shimadzu SIL-20 A HT y un detector de arreglo de diodos UV/VIS Shimadzu SPDM20A. Las muestras $(20 \mu 1)$ se inyectaron en el sistema de HPLC y la separación se realizó en una columna de fase reversa $C_{18}$ Phenomenex Prodigy ODS3 $(250 \mathrm{~mm} \times 4,6$ $\mathrm{mm}, 5 \mu \mathrm{m}$ de tamaño de partícula) protegida con un guarda columna de fase reversa $\mathrm{C}_{18}$ de la misma marca. La columna se mantuvo a una temperatura de $30^{\circ} \mathrm{C}$ y la velocidad del flujo varió entre 1-1,2 $\mathrm{ml} / \mathrm{min}$. El gradiente binario estuvo compuesto por ácido fórmico al $1 \%$ en agua deionizada (solvente A) y acetonitrilo (solvente B). El gradiente de HPLC comenzó con un $10 \%$ de solvente B, que incrementó linealmente hasta un 17,5 \% en 15 min, luego se llevó a un $30 \%$ de solvente B en 2 min y se mantuvo isocráticamente por $8 \mathrm{~min}, \mathrm{y}$, finalmente, se incrementó linealmente a un $10 \%$ de solvente $\mathrm{B}$ en el último minuto. El detector de arreglo de diodos fue ajustado a $326 \mathrm{~nm}$. La identificación del ACG y sus compuestos isómeros se llevó a cabo por comparación de los picos con el tiempo de retención del compuesto estándar cuando corresponda, la absorbancia a $326 \mathrm{~nm}$ (máxima para el ACG), la comparación del espectro obtenido a 
250-400 nm y los patrones de elución con los datos disponibles en la literatura (Carini y col., 1998; Fang y col., 2002; Bravo y col., 2006).

La concentración del ACG y sus isómeros en las muestras de yerba mate fue calculada utilizando una curva de calibración del compuesto estándar disponible comercialmente $\left(y=6 \times 10^{8} x-18511, \mathrm{R}^{2}=1\right)$ debido a la igualdad en la estructura química. En todos los casos, los valores fueron expresados sobre una base de peso seco (g/100 g de muestra seca, $\% \mathrm{~ms})$.

\subsubsection{Análisis estadístico}

Los datos fueron expresados como media \pm error estándar de la media de dos experimentos independientes analizados por duplicado. Para el análisis de los datos experimentales se realizó un análisis de varianza (ANOVA) seguido por un análisis post-hoc mediante la prueba de Tukey. Todas las comparaciones fueron realizadas con un nivel de confianza del 95 \%. La comparación de muestras múltiples se realizó utilizando el paquete estadístico Statgraphics Centurion versión XVII.

\subsection{RESULTADOS Y DISCUSIÓN}

\subsubsection{Determinación del contenido de humedad de las muestras}

El contenido de humedad de las muestras, tanto de las hojas como del palo, varió de acuerdo a las diferentes etapas de procesamiento del material vegetal como era de esperarse (Tabla 2.1). Los valores promedio de humedad encontrados para las diferentes muestras resultaron similares a los reportados por otros autores (Bastos y col., 2006) indicando una clara disminución de la humedad de las muestras a lo largo de las diferentes operaciones. 
Tabla 2.1: Contenido de humedad en muestras de yerba mate obtenidas de las diferentes etapas del procesamiento en dos plantas industriales.

\begin{tabular}{clccc}
\hline \multirow{2}{*}{$\begin{array}{c}\text { Planta de } \\
\text { procesamiento }\end{array}$} & Etapa del procesamiento & \multicolumn{3}{c}{ Contenido de humedad (\% mh) } \\
\cline { 3 - 5 } & & Hoja & Palo & Polvo \\
\hline \multirow{2}{*}{ Cosecha (yerba mate } & $60,78 \pm 0,13^{a}$ & $61,81 \pm 0,00^{a}$ & - \\
& verde) & & & \\
& Zapecado & $20,69 \pm 0,13^{b}$ & $47,38 \pm 0,01^{b}$ & - \\
A & Pre-secado & $13,22 \pm 0,09^{c}$ & $34,71 \pm 0,10^{c}$ & - \\
& Secado en 1 $1^{\text {er }}$ cinta & $5,27 \pm 0,17^{d}$ & $7,19 \pm 0,02^{d}$ & - \\
& Secado en 2 $2^{\text {da }}$ cinta & $2,00 \pm 0,04^{e}$ & $2,26 \pm 0,05^{e}$ & - \\
& Yerba mate elaborada & $2,49 \pm 0,08^{e}$ & $2,80 \pm 0,01^{e}$ & $2,63 \pm 0,11$ \\
\hline & Cosecha (yerba mate & $62,30 \pm 0,05^{a}$ & $65,22 \pm 0,08^{a}$ & - \\
& verde) & & & \\
& Zapecado & $24,21 \pm 0,14^{b}$ & $47,96 \pm 0,10^{b}$ & - \\
& Secado en cinta & $5,95 \pm 0,16^{c}$ & $5,61 \pm 0,12^{c}$ & - \\
& Molienda gruesa & $5,63 \pm 0,00^{c}$ & $5,95 \pm 0,03^{c}$ & - \\
& Yerba mate elaborada & $6,42 \pm 0,13^{d}$ & $7,37 \pm 0,13^{d}$ & $7,31 \pm 0,18$ \\
\hline
\end{tabular}

${ }^{\mathrm{A}}$ Resultados expresados como media \pm error estándar.

${ }^{\mathrm{B}}$ Resultados expresados como g agua/100 g de muestra húmeda (\% $\left.\mathrm{mh}\right)$.

En cada columna, diferentes superíndices indican diferencias significativas $(p<0,05)$.

\subsubsection{Identificación y cuantificación de ácido clorogénico en los extractos de yerba} mate

2.3.2.1. Identificación de ácido clorogénico y sus compuestos isómeros en los extractos de yerba mate:

La identificación y cuantificación del ACG (ácido 5-O-cafeoilquínico) y sus isómeros, el ácido 3-O-cafeoilquínico (ácido neo-clorogénico) y el ácido 4-O-cafeoilquínico (ácido cripto-clorogénico), fue monitoreada mediante un arreglo de diodos. Todos los extractos preparados, a partir de la fracción de hojas, de palos y de polvo correspondientes a las distintas etapas presentaron un perfil cromatográfico de elución muy similar. En la Figura 2.2 se presenta un cromatograma típico de un extracto representativo en el cual se ven identificados los tres compuestos de interés. 


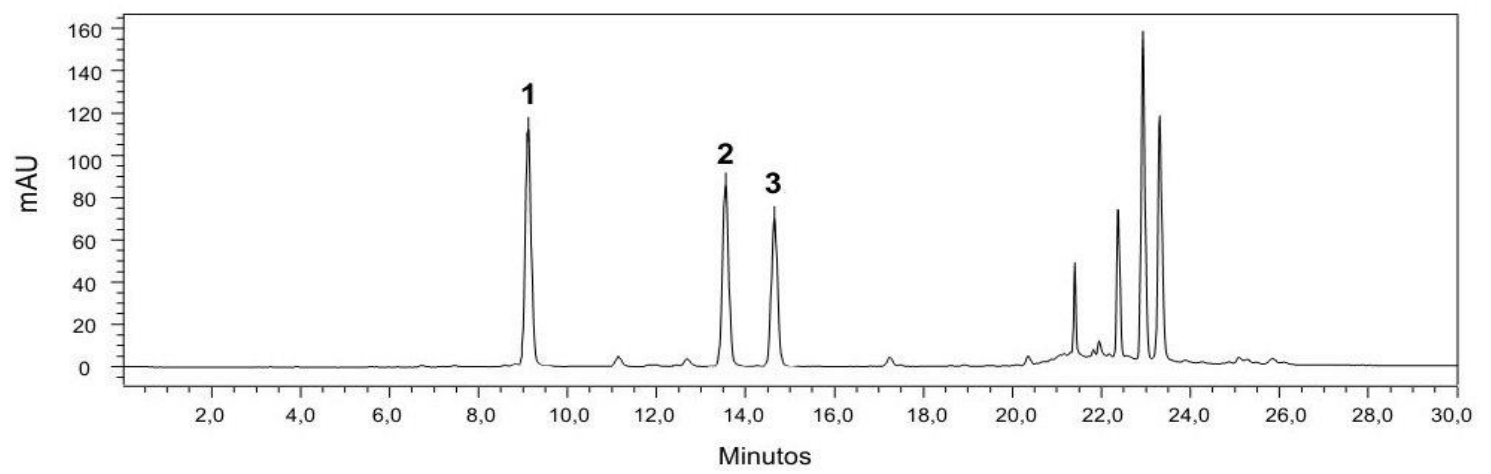

Figura 2.2: Perfil cromatográfico representativo de un extracto de yerba mate empleando un sistema de HPLC con columna de fase reversa. Señal obtenida a $326 \mathrm{~nm}$.

(1): ácido neo-clorogénico; (2): ácido clorogénico y (3): ácido cripto-clorogénico.

En la Tabla 2.2 se detallan las características UV de los picos cromatográficos.

Tabla 2.2: Características UV de los picos cromatográficos.

\begin{tabular}{ccccl}
\hline Pico & TR $(\min )$ & $\lambda_{\max }(\mathrm{nm})$ & Compuesto & Abreviación \\
\hline 1 & 9,0 & $326,296 \mathrm{~h}$ & ácido neo-clorogénico & neo-ACG \\
2 & 13,5 & $326,296 \mathrm{~h}$ & ácido clorogénico & ACG \\
3 & 14,6 & $326,296 \mathrm{~h}$ & ácido cripto-clorogénico & cripto-ACG \\
\hline
\end{tabular}

TR: tiempo de retención. h: hombro.

Los tres compuestos (picos 1, 2 y 3) presentaron el mismo espectro UV con un máximo a $326 \mathrm{~nm}$ y un hombro a $296 \mathrm{~nm}$, típico de compuestos derivados de los ácidos cafeoilquínicos. El tiempo de retención y el espectro UV del compuesto 2 fueron idénticos al del ACG estándar. Los otros compuestos se corresponden con los isómeros del ACG. Teniendo en cuenta el perfil de elución de los isómeros del ACG a partir de materiales vegetales reportados en la literatura sobre columnas de HPLC C18 (Fang y col., 2002; Bravo y col., 2006) y el espectro UV de los mismos, los compuestos 1 y 3 se identificaron como ácido 3-O-cafeoilquínico (ácido neo-clorogénico) y ácido 4-Ocafeoilquínico (ácido cripto-clorogénico), respectivamente.

\subsubsection{Experiencias preliminares y determinación del tiempo de extracción:}

En la Figura 2.3 se presentan los valores medios para el contenido total de ACG (neo$\mathrm{ACG}+\mathrm{ACG}+$ cripto-ACG) de una muestra de yerba mate aleatoriamente elegida obtenidos a partir de diferentes tiempos de extracción luego de dos extracciones 
sucesivas. En este caso, la muestra seleccionada consistió en la fracción de hojas correspondiente a la yerba mate elaborada proveniente de la Planta A.

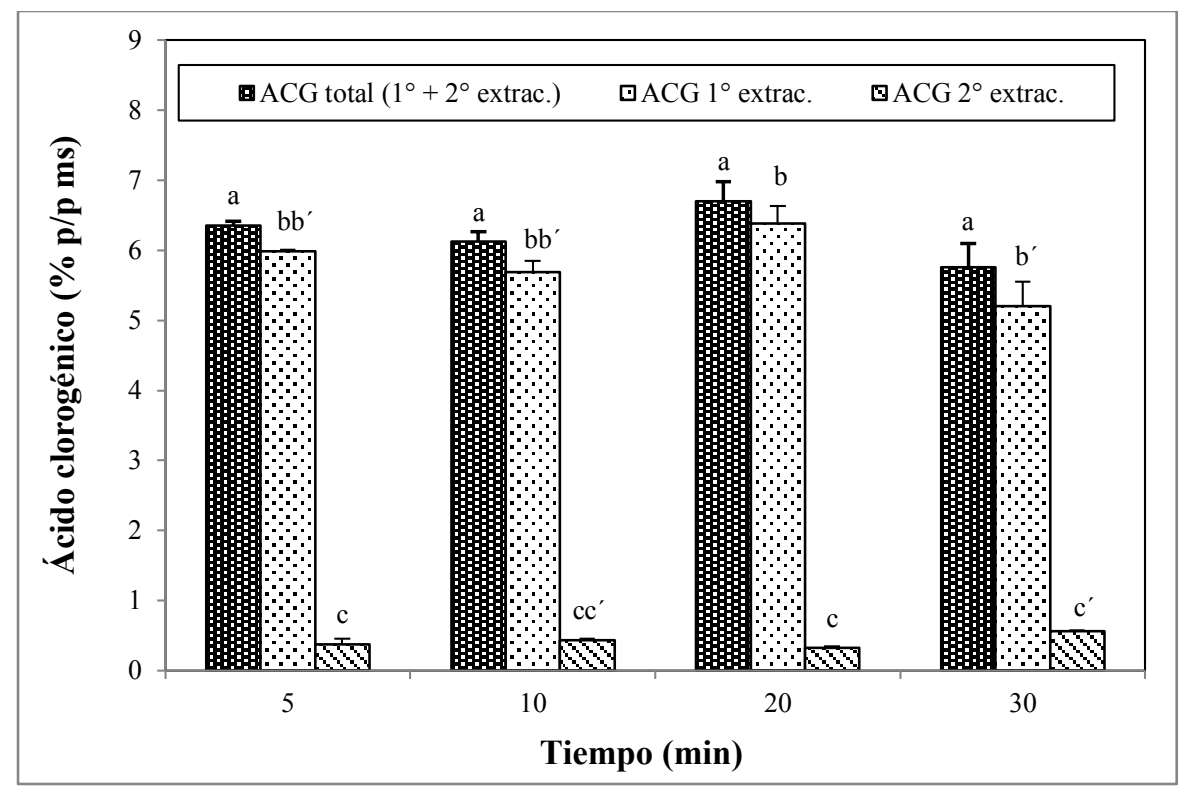

Figura 2.3: Contenido de ácido clorogénico total (neo-ACG + ACG + cripto-ACG) en la fracción de hojas correspondiente a la yerba mate elaborada (Establecimiento A) obtenido con diferentes tiempos de extracción mediante dos extracciones sucesivas. Resultados expresados como media \pm error estándar de dos experimentos independientes analizados por duplicado y expresados como porcentaje sobre la muestra seca $(\% \mathrm{~ms})$. Diferentes superíndices indican diferencias significativas $(\mathrm{p}<0,05)$.

Los resultados de la Figura 2.3 indican que, en las condiciones empleadas, el equilibrio en la extracción acuosa del ACG se alcanzó ya a los 5 min, con un valor experimental de equilibrio promedio del orden de 6,2 $\pm 0,40 \mathrm{~g} \mathrm{ACG} / 100 \mathrm{~g}$ de muestra seca. Por otra parte se puede observar que el procedimiento de extracción se repitió dos veces dando como resultado que la cantidad total de ACG más sus isómeros en el segundo extracto fue de alrededor del 5 al $10 \%$ de los valores obtenidos en la primera extracción. Una tercera extracción no dio lugar a valores de ACG significativos, siendo inferiores al $1 \%$ en comparación con los de la primera extracción (datos no mostrados). De este modo, se seleccionó un tiempo de extracción de 5 min y dos extracciones sucesivas para los estudios posteriores a los efectos de asegurar niveles de extracción similares para el caso de las demás muestras de yerba mate. Resultados similares han sido obtenidos por Negrão Murakami y col. (2011) y Aguiar Prudêncio y col. (2012), quienes han optimizado la extracción acuosa de polifenoles a partir de muestras de yerba mate 
obteniendo valores para el tiempo óptimo de extracción de 3 y 1,5 min, respectivamente.

\subsubsection{Cuantificación de ácido clorogénico y sus compuestos isómeros en los extractos} de yerba mate:

\subsection{Efecto de la fracción vegetal y la etapa de industrialización:}

Los extractos acuosos se prepararon a partir de muestras de las diferentes fracciones de yerba mate (hoja y palo) derivadas del procesamiento de la yerba mate. Se seleccionó una relación volumen del solvente/peso de la muestra (500 mg de muestra en $50 \mathrm{ml}$ de agua destilada) grande a fin de asegurar una completa y exhaustiva extracción de los compuestos solubles en agua.

Algunos autores informaron sobre la utilización de diferentes disolventes, tales como alcoholes (metanol, etanol, isopropanol) u otros compuestos orgánicos (acetona, dimetilformamida) para la extracción del ACG a partir de diferentes materiales vegetales (Li y col., 2005; Naczk y Shahidi, 2004). Sin embargo, se debe mencionar que el uso de estos disolventes podría conducir a la distorsión de los picos cromatográficos resultantes del HPLC. Mientras que estos disolventes orgánicos se han utilizado con el fin de obtener la máxima extracción de los constituyentes activos, el uso de los mismos provoca limitaciones en las subsecuentes aplicaciones de los extractos, impidiendo su utilización en las industrias alimentarias y farmacéuticas. Por otra parte, el manejo de disolventes orgánicos genera también residuos tóxicos, siendo por lo tanto un problema de contaminación grave (Sonaglio y col., 2007). Además, la hidrólisis enzimática del ACG para obtener ácido quínico (la primera etapa en la ruta metabólica del ácido siquímico, el objetivo último de la investigación) se lleva a cabo bajo condiciones acuosas, lo que confirma la conveniencia de preparar extractos acuosos de ACG.

En las Tablas 2.3 y 2.4 se detallan la concentración de cada isómero del ACG cuantificado individualmente y del total de ACG (cuantificado como la suma de los tres isómeros), respectivamente, para las fracciones de diferente granulometría (hoja, palo y polvo cuando corresponda) que componen la yerba mate. Las muestras se obtuvieron durante las diferentes etapas de industrialización de la yerba mate al inicio de la época de zafra (meses de abril-mayo de 2014) de las plantas de procesamiento A y B. 
Para el caso de la Planta A, los tres isómeros del ACG cuantificados en los extractos mostraron una variación significativa a lo largo de las diferentes etapas del procesamiento para las diferentes fracciones de yerba mate. Los niveles más altos de cada isómero del ACG fueron hallados en los extractos preparados a partir de hojas y palos verdes (muestras identificadas como “C”). Durante el zapecado se registró una pérdida considerable en el contenido de neo-ACG y de ACG pero no en el de crypoACG. No se encontraron diferencias significativas en el contenido de los tres isómeros en los extractos correspondientes a muestras de hojas obtenidas luego de las etapas de zapecado, pre-secado y secado. En el caso de los tallos se observó una disminución significativa en el contenido de los isómeros de ACG luego de la etapa de secado.

En caso de la Planta B, el contenido de cada isómero del ACG en las muestras correspondientes a las hojas fue prácticamente constante a lo largo de todas las etapas del procesamiento de la yerba mate, desde la yerba mate verde hasta el producto final. Se observó una pequeña disminución en el contenido de neo-ACG en tallos desde el zapecado hasta el final del procesamiento mientras que las variaciones observadas en los contenidos de ACG y cripto-ACG no son significativas. (Tabla 2.3).

Se observaron diferencias significativas en la concentración de los diferentes isómeros del ACG así también como en el contenido total de ACG cuando se compararon los valores obtenidos para la Planta A con los obtenidos para la Planta B en etapas de industrialización equivalentes (Tablas 2.3 y 2.4). Por otra parte, no se hallaron diferencias significativas en el contenido total de ACG entre las hojas y palos verdes (p $<0,05)$ para las muestras pertenecientes a una misma planta de procesamiento (Fig. 2.4). Por el contrario, se hallaron diferencias sustanciales cuando se compararon los resultados obtenidos en ambas plantas de procesamiento, evidenciando que la materia prima procesada en la Planta A contenía mayor cantidad de ACG que la procesada en la Planta B. Este hecho fue tentativamente atribuido a las posibles variaciones en las condiciones climáticas de las áreas de producción de los respectivos lotes de yerba mate y la variabilidad genética del material vegetal procesado. Se sabe que la edad de los tejidos vegetales y la exposición a la luz o la sombra influyen significativamente en la cantidad de sustancias bioactivas presentes en los tejidos de la yerba mate (Ashihara y Crozier, 2001; Gulati y Ravindranath, 1996; Mazzafera, 1994). 
Tabla 2.3: Contenido de ACG y sus isómeros (neo-ACG y cripto-ACG) en diferentes fracciones de yerba mate (hoja, palo y polvo) en las diferentes etapas del procesamiento de muestras obtenidas de dos establecimientos yerbateros ubicados al sur de la Provincia de Misiones-Argentina, durante los meses de abril-mayo de 2014. ${ }^{1,2}$

\begin{tabular}{|c|c|c|c|c|c|c|c|c|c|c|}
\hline \multirow{2}{*}{$P$} & \multirow{2}{*}{ E.P. } & \multicolumn{3}{|c|}{ neo-ACG (\% ms) } & \multicolumn{3}{|c|}{ ACG $(\% \mathrm{~ms})$} & \multicolumn{3}{|c|}{ cripto-ACG $(\% \mathrm{~ms})$} \\
\hline & & Hoja & Palo & Polvo & Hoja & Palo & Polvo & Hoja & Palo & Polvo \\
\hline \multirow{7}{*}{ A } & $\mathrm{C}$ & $3,59 \pm 0,07^{a}$ & $2,65 \pm 0,19^{a}$ & - & $2,39 \pm 0,02^{a}$ & $3,18 \pm 0,21^{a}$ & - & $2,11 \pm 0,00^{a}$ & $2,06 \pm 0,13^{a}$ & - \\
\hline & Z & $3,14 \pm 0,02^{b}$ & $\mathrm{sd}$ & - & $2,04 \pm 0,01^{b}$ & $\mathrm{sd}$ & - & $1,90 \pm 0,03^{a}$ & $\mathrm{sd}$ & \\
\hline & PS & $2,84 \pm 0,06^{b}$ & sd & - & $2,11 \pm 0,06^{b}$ & $\mathrm{sd}$ & - & $1,86 \pm 0,03^{a b}$ & $\mathrm{sd}$ & \\
\hline & S. $1^{\circ}$ & $2,89 \pm 0,05^{b}$ & $1,92 \pm 0,02^{b}$ & - & $2,00 \pm 0,07^{b}$ & $2,16 \pm 0,02^{b}$ & - & $1,76 \pm 0,09^{b}$ & $1,76 \pm 0,01^{b}$ & - \\
\hline & $\mathrm{S} .2^{\circ}$ & $3,02 \pm 0,02^{b}$ & $1,71 \pm 0,17^{b}$ & - & $2,07 \pm 0,00^{b}$ & $1,78 \pm 0,17^{c}$ & - & $1,74 \pm 0,02^{b}$ & $1,54 \pm 0,14^{b}$ & - \\
\hline & MG & $\mathrm{sd}$ & $\mathrm{sd}$ & - & $\mathrm{sd}$ & $\mathrm{sd}$ & - & $\mathrm{sd}$ & $\mathrm{sd}$ & - \\
\hline & $\mathrm{PF}$ & $2,73 \pm 0,04^{b}$ & $1,00 \pm 0,04^{c}$ & $2,19 \pm 0,09$ & $2,08 \pm 0,03^{b}$ & $1,62 \pm 0,02^{c}$ & $2,46 \pm 0,09$ & $1,54 \pm 0,03^{b}$ & $0,93 \pm 0,02^{c}$ & $1,65 \pm 0,04$ \\
\hline \multirow{5}{*}{$\mathrm{B}$} & $\mathrm{C}$ & $2,00 \pm 0,11^{a}$ & $1,75 \pm 0,04^{a}$ & - & $1,70 \pm 0,12^{a}$ & $1,96 \pm 0,02^{a}$ & - & $1,31 \pm 0,10^{a}$ & $1,34 \pm 0,03^{a}$ & - \\
\hline & Z & $1,84 \pm 0,01^{a}$ & $1,48 \pm 0,01^{a b}$ & - & $1,48 \pm 0,03^{a}$ & $1,93 \pm 0,03^{a}$ & - & $1,25 \pm 0,03^{a}$ & $1,32 \pm 0,02^{a}$ & - \\
\hline & S & $2,14 \pm 0,09^{a}$ & $1,52 \pm 0,01^{a b}$ & - & $1,50 \pm 0,06^{a}$ & $1,55 \pm 0,01^{b}$ & - & $1,24 \pm 0,05^{a}$ & $1,18 \pm 0,00^{a b}$ & - \\
\hline & MG & $1,95 \pm 0,04^{a}$ & $1,20 \pm 0,01^{b c}$ & - & $1,54 \pm 0,01^{a}$ & $1,34 \pm 0,00^{b d}$ & - & $1,23 \pm 0,01^{a}$ & $0,97 \pm 0,00^{b}$ & - \\
\hline & $\mathrm{PF}$ & $2,18 \pm 0,21^{a}$ & $0,89 \pm 0,01^{c}$ & $1,75 \pm 0,03$ & $1,69 \pm 0,17^{a}$ & $1,28 \pm 0,01^{c d}$ & $1,56 \pm 0,02$ & $1,26 \pm 0,14^{a}$ & $0,74 \pm 0,01^{c}$ & $1,15 \pm 0,01$ \\
\hline
\end{tabular}

${ }^{1}$ Resultados expresados como media \pm error estándar. ${ }^{2}$ Resultados expresados como g/100 g de muestra seca (\% ms).

En cada columna, diferentes superíndices indican diferencias significativas $(\mathrm{p}<0,05)$.

P: planta de procesamiento.

E.P.: etapas del procesamiento. C: Cosecha (yerba mate verde); Z: Zapecado; PS: pre-secado; MG: molienda gruesa; S. $1^{\circ}$ : secado en $1^{\text {er }}$ cinta; S. 2: secado en $2^{\text {da }}$ cinta; PF: Producto final (yerba mate elaborada); S: secado.

sd: sin datos. 
Tabla 2.4: Contenido de ácido clorogénico total (neo-ACG + ACG + cripto-ACG) en las diferentes fracciones de la yerba mate (hoja, palo y polvo) en las diferentes etapas del procesamiento de muestras obtenidas de dos establecimientos yerbateros ubicados al sur de la Provincia de Misiones-Argentina, durante los meses de abril-mayo de 2014. ${ }^{1,2}$

\begin{tabular}{ccrcc}
\hline \multirow{2}{*}{ Planta de procesamiento } & Etapa del procesamiento & \multicolumn{3}{c}{ ACG total (\% ms) } \\
\cline { 3 - 5 } & Cosecha (yerba mate verde) & $8,08 \pm 0,10^{a}$ & $7,89 \pm 0,53^{a}$ & Polvo \\
\hline Zapecado & $7,08 \pm 0,02^{b}$ & - & - \\
Pre-secado & $6,81 \pm 0,14^{b}$ & - & - \\
A & Secado en 1 $1^{\text {er }}$ cinta & $6,65 \pm 0,21^{b}$ & $5,84 \pm 0,05^{b}$ & - \\
& Secado en 2da cinta & $6,83 \pm 0,04^{b}$ & $5,03 \pm 0,48^{b}$ & - \\
& Molienda gruesa & sd & Sd & - \\
& Producto final & $6,35 \pm 0,10^{b}$ & $3,56 \pm 0,08^{c}$ & $6,29 \pm 0,21$ \\
\hline Cosecha (yerba mate verde) & $5,00 \pm 0,23^{a}$ & $5,05 \pm 0,18^{a}$ & - \\
B Zapecado & $4,58 \pm 0,04^{a}$ & $4,73 \pm 0,05^{a b}$ & - \\
& Secado en cinta & $4,88 \pm 0,21^{a}$ & $4,26 \pm 0,03^{b c}$ & - \\
& Molienda gruesa & $4,72 \pm 0,06^{a}$ & $3,52 \pm 0,00^{c d}$ & - \\
& Producto final & $5,13 \pm 0,52^{a}$ & $3,16 \pm 0,06^{d}$ & $4,46 \pm 0,06$
\end{tabular}

Resultados expresados como media \pm error estándar. ${ }^{2}$ Resultados expresados como $\mathrm{g} / 100 \mathrm{~g}$ de muestra seca $(\% \mathrm{~ms})$.

En cada columna, diferentes superíndices indican diferencias significativas $(\mathrm{p}<0,05)$. sd: sin datos.

Aunque han habido varios estudios sobre la identificación del ACG y sus compuestos isómeros en la yerba mate, no existen estudios exhaustivos sobre la cuantificación total de estas sustancias y su variación cuantitativa en las diferentes fracciones de la yerba mate. En general, la concentración total de ACG (expresado como la suma de los tres isómeros combinados, expresado en base seca) varió de 4,58 $\pm 0,04$ a 8,08 $\pm 0,10 \mathrm{~g}$ ACG/100 g de hojas, y de 3,16 $\pm 0,06$ a 7,89 $\pm 0,53 \mathrm{~g}$ ACG/100 g de palos, independientemente de la planta de procesamiento (Tabla 2.4). Cualquiera que sea el caso, la mayor concentración de ACG (considerando los tres isómeros sumados) se encuentra en la muestra correspondiente a la yerba mate recién cosechada (hoja verde y palo verde), no habiendo diferencias significativas en el contenido de ACG total encontrado tanto en las hojas como en los palos. La pérdida principal en la concentración de todos los isómeros del ACG tuvo lugar durante zapecado, particularmente para el caso de la Planta A. 


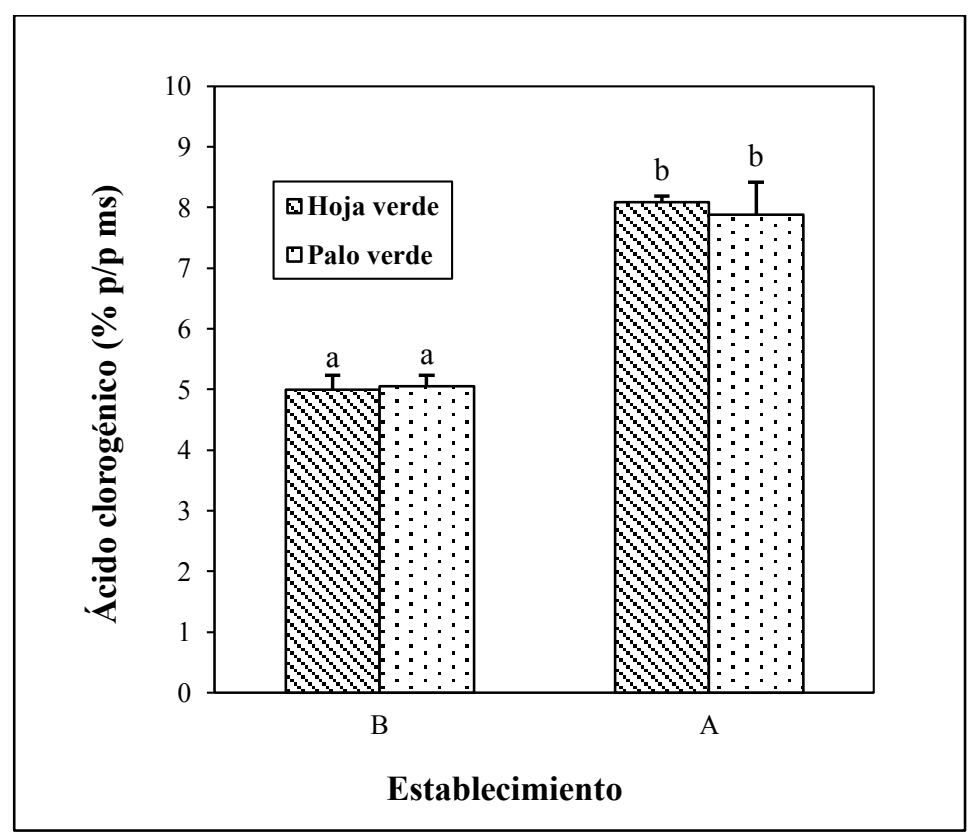

Figura 2.4: Contenido de ACG total en yerba mate recién cosechada (hoja verde y palo verde) obtenida de dos plantas de procesamiento ubicadas al sur de la Provincia de MisionesArgentina, durante los meses de abril-mayo de 2014. Resultados expresados como media \pm error estándar de dos experimentos independientes analizados por duplicado y expresados como porcentaje sobre la muestra seca $(\% \mathrm{~ms})$. Diferentes superíndices indican diferencias significativas $(\mathrm{p}<0,05)$.

La distribución cuantitativa de los isómeros del ACG fue diferente entre las hojas y palos verdes. En las hojas verdes, el isómero predominante fue el neo-ACG ( 40-44 \%) tanto en las muestras de la Planta A como en las muestras de la Planta B, mientras que el menos abundante fue el cripto-ACG $(\sim 26 \%)$. Aunque resulta difícil comparar debido a las diferencias entre las muestras de yerba mate analizadas, el predominio de neoACG está de acuerdo con los informes reportados por Marques y Farah (2009). Respecto a los palos verdes, el isómero predominante fue el ACG ( 39-40 \%), siendo el cripto-ACG el menos abundante nuevamente $(\sim 26 \%)$, tanto en las muestras de la Planta A como en las muestras de la Planta B.

Bastos y col. (2006) reportaron que el contenido de ACG (así como el de cafeína) en infusiones preparadas a partir de hojas de yerba mate aumentó a lo largo de las diferentes etapas del procesamiento de la yerba mate, lo que indicó que el uso de las hojas obtenidas luego de la etapa de secado sería más ventajoso que el uso de hojas verdes para la producción de extractos de yerba mate. Ellos postularon que la ruptura celular y el impacto mecánico durante las etapas del procesamiento podrían incrementar el rendimiento de la extracción a partir de hojas secas procesadas. Del mismo modo, 
Isolabella y col. (2010) han estudiado la variación de compuestos bioactivos durante el procesamiento de la yerba mate e informaron un aumento en el contenido total de ACG en las hojas de yerba mate luego de la etapa de zapecado en comparación con las hojas verdes, seguido por una disminución durante el proceso de secado. Estos autores postularon que el ACG es atrapado por la cafeína y que las condiciones de temperatura y humedad empleadas durante el zapecado liberarían estos compuestos, resultando en un incremento de sus concentraciones. Por el contrario, los resultados alcanzados en la presente investigación indican que las hojas y palos verdes contienen concentraciones de ACG más elevadas que los materiales industrializados. Resulta interesante mencionar que los materiales obtenidos a partir de la yerba mate verde (hojas y palos verdes) son bastante inestables a la oxidación (el proceso de "browning" tiene lugar poco después de la cosecha). En cambio, los materiales de yerba mate industrializados son estabilizados mediante el calentamiento (etapa de zapecado), y el análisis de ACG puede llevarse a cabo días después de realizado el muestreo sin que se produzca una variación significativa en los resultados. Cabe destacar que en el presente trabajo de investigación, los materiales derivados de la yerba mate verde que presentasen incluso pequeños cambios en su coloración (pardeamiento incipiente) fueron inmediatamente descartados a fin de garantizar la correcta estabilidad del material analizado. Por otra parte, las muestras fueron tratadas térmicamente dentro de las $12 \mathrm{~h}$ de la cosecha para inhibir la actividad enzimática (el tiempo de transporte se redujo sustancialmente teniendo en cuenta que nuestro laboratorio se encuentra en una región de productora de yerba mate). Por lo tanto, el contenido original de ACG en las muestras de yerba mate verde fue rápidamente estabilizado, lo que resultó en una materia prima conveniente y ventajosa para la extracción ACG.

\subsection{Efecto de la fracción vegetal y la época del año:}

Teniendo en cuenta los resultados previos, se estudió la influencia de la etapa de desarrollo de la planta de yerba mate sobre el contenido total de ACG, particularmente para las muestras de yerba mate verde. Para ello, un nuevo lote de muestras tomadas durante el mes de septiembre de 2014 (final de la época de zafra) fue analizado y comparado con las muestras provenientes del inicio de la época de zafra. En la Tabla 2.5 se presentan los valores obtenidos para el contenido total de ACG presente en 
muestras obtenidas al inicio y al final de la época de zafra para las fracciones de diferente granulometría (hoja y palo) que componen la yerba mate.

Tabla 2.5: Contenido de ácido clorogénico total (neo-ACG + ACG + cripto-ACG) en las muestras de hojas y palos verdes obtenidas de dos establecimientos yerbateros ubicados al sur de la Provincia de Misiones-Argentina, al inicio (abril-mayo de 2014) y al final (septiembre de 2014) de la época de zafra. ${ }^{1,2}$

\begin{tabular}{cccc}
\hline \multirow{2}{*}{ Planta de procesamiento } & \multirow{2}{*}{ Época de cosecha } & \multicolumn{2}{c}{ ACG total (\% ms) } \\
\cline { 3 - 4 } & & Hojas verdes & Palos verdes \\
\hline \multirow{2}{*}{ A } & IZ & $8,08 \pm 0,10^{a}$ & $7,89 \pm 0,53^{a}$ \\
& FZ & $2,27 \pm 0,17^{\mathrm{b}}$ & $2,04 \pm 0,12^{\mathrm{b}}$ \\
\hline \multirow{2}{*}{ B } & IZ & $5,00 \pm 0,23^{c}$ & $5,05 \pm 0,18^{c}$ \\
& FZ & $2,15 \pm 0,29^{\mathrm{b}}$ & $2,61 \pm 0,07^{\mathrm{b}}$
\end{tabular}

\footnotetext{
$1 \overline{\text { Resultados expresados como media } \pm \text { error estándar. }{ }^{2} \text { Resultados expresados }}$ como $\mathrm{g} / 100 \mathrm{~g}$ de muestra seca (\% ms).

Diferentes superíndices indican diferencias significativas $(\mathrm{p}<0,05)$.

IZ: inicio de la época de zafra; FZ: final de la época de zafra.
}

El contenido total de ACG tanto en hojas como en los palos fue fuertemente influenciado por la época de cosecha. Las muestras tomadas al final de la época de zafra presentaron una reducción sustancial en el contenido total de ACG, en comparación con las muestras tomadas al inicio de la época de zafra.

El crecimiento de la yerba mate es monopodial y rítmico (Hallé y col., 1978), con dos ciclos de brotación, que se dan en los meses de marzo a mayo y de septiembre a diciembre (Rakocevic y col., 2006). Entre otros factores, el grado de madurez de las hojas (o edad) podría influenciar en el contenido total de ACG, ya que en abril-mayo el crecimiento foliar sería entre intermedio y completo (es decir con hojas que completaron su crecimiento foliar y otras que no) mientras que en septiembre la cosecha tendría una mayor proporción de brotes nuevos (Escalada y col., 2011). Estos autores también informaron un mayor contenido de polifenoles totales en muestras de hojas de yerba mate obtenidas al inicio de la época de zafra, en concordancia con nuestros resultados. Del mismo modo, Da Croce (2002) informó una influencia significativa de la época de cosecha sobre el contenido total de cafeína en muestras de yerba mate cultivadas en Brasil. Por el contrario, Holovatty y col. (2007) evaluaron el contenido de polifenoles totales y la capacidad antioxidante de hojas y palos frescos, cosechados en 
dos épocas del año, noviembre de 2004 (mes dentro del período de brotación con floración) y en septiembre de 2004 (mes dentro del período de mayor madurez de las hojas), y reportaron que no se encontraron diferencias en ambas variables con la época de cosecha, tanto en las hojas como en los palos $(p<0,05)$. Asimismo, Bortoluzzi y col. (2006), reportaron un mayor contenido de compuestos fenólicos (ACG y ácido gálico) en muestras obtenidas en octubre (mes dentro del período de mayor tasa de brotación) respecto de las obtenidas en abril (mes intermedio entre los períodos de crecimiento foliar intermedio y completo) de 2004. Esta aparente contradicción puede justificarse mencionando que otros compuestos fenólicos presentes en la yerba mate, especialmente los ácidos dicafeoilquínicos, contribuyen positivamente en la determinación del contenido de polifenoles totales incrementando los valores obtenidos.

La composición química de las diferentes especies de Ilex, así como la de cualquier producto agrícola, puede variar de forma significativa con el tipo de suelo, el clima, la estación del año, la edad de la planta y las hojas, el dimorfismo sexual y las características genéticas (Oliva y col., 2006). En conclusión, los cambios en el contenido de ACG se podrían atribuir a la etapa de desarrollo de la planta (Silva y Rakocevic, 2010), así como las diferentes condiciones climáticas (temperatura, humedad, intensidad solar, etc.) y otros factores no identificados. Cualquiera sea el caso, se demostró que los materiales derivados de la yerba mate verde (hojas y palos) cosechados al inicio de la época de zafra son las fuentes más convenientes para la extracción de ACG, debido a su mayor contenido de ACG en comparación con los cosechados al final de la época de zafra.

\subsection{CONCLUSIONES}

Se analizó el contenido de ACG en muestras de yerba mate (hoja y palo) provenientes de dos plantas de procesamiento, a lo largo de las diferentes etapas de industrialización y en dos épocas del año. El análisis cuantitativo-comparativo de todas las muestras analizadas indicó que el contenido de ACG total es ligeramente superior en las muestras correspondientes a la yerba mate recién cosechada (hoja y palo verde). No se encontraron diferencias significativas $(p<0,05)$ en el contenido de ACG entre la hoja y el palo verde. Una pérdida sustancial de ACG fue hallada durante la etapa de zapecado. La época de cosecha tuvo una influencia significativa en el contenido de ACG para 
tanto para las hojas como para los palos de yerba mate. El contenido de ACG al inicio de la época de zafra fue sustancialmente mayor al obtenido al final de la época de zafra, tanto para las hojas verdes como para los palos verdes.

Los resultados alcanzados en el presente trabajo de investigación podrían constituir una guía para la obtención de extractos de yerba mate enriquecidos en ACG a partir de uno de los mayores residuos menos valorado derivado de la industria yerbatera: los palos verdes obtenidos al inicio de la época de zafra. 


\section{Capítulo 3}

Optimización y modelado de la extracción acuosa de ácido clorogénico a partic de palos verdes de yerba mate ( $/$ ex paraguariensis) 


\title{
CAPÍTULO 3 \\ OPTIMIZACIÓN Y MODELADO DE LA EXTRACCIÓN ACUOSA DE ÁCIDO CLOROGÉNICO A PARTIR DE PALOS VERDES DE YERBA MATE (ILEX PARAGUARIENSIS)
}

\begin{abstract}
Resumen
Se evaluó el método de extracción sólido-líquido (S/L) más adecuado para obtener un extracto acuoso rico en ácido clorogénico (ACG) a partir de muestras de palo verde de yerba mate $\left(\mathrm{PV}_{\mathrm{YM}}\right)$, material vegetal previamente seleccionado por a su elevado contenido en ACG (ver capítulo 2). Posteriormente, se evaluó la cinética de extracción acuosa de ACG a partir de los $\mathrm{PV}_{\mathrm{YM}}$, su ajuste a modelos empíricos y finalmente la optimización mediante la metodología de superficie de respuesta (MSR).

Las extracciones se realizaron en frascos Erlenmeyers de $50 \mathrm{ml}$ conteniendo la cantidad correspondiente de muestra y un volumen fijo de $25 \mathrm{ml}$ de agua destilada. El procedimiento de extracción se llevó a cabo en un baño termostatizado con agitación (100 golpes/min), a tiempos y temperaturas variables, y fue detenido mediante una filtración rápida. Luego, el volumen de cada extracto se ajustó a $25 \mathrm{ml}$ con agua destilada y el contenido en ACG se cuantificó por HPLC. Se evaluó el efecto de diferentes factores que normalmente influyen sobre los procesos de extracción $\mathrm{S} / \mathrm{L}$ : tamaño de partícula ( $\varnothing$ partícula $<500 \mu \mathrm{m}$ y $1 \times 5 \mathrm{~mm}<$ tamaño de partícula $<2,5 \times 5 \mathrm{~mm})$, relación $\mathrm{S} / \mathrm{L}(1: 10-1: 150, \mathrm{p} / \mathrm{v})$, número de etapas de extracción $(1,2$ y 3$)$ y temperatura de extracción $\left(30-100{ }^{\circ} \mathrm{C}\right)$. A continuación, se estudió la cinética de extracción a diferentes temperaturas para determinar el tiempo necesario hasta alcanzar la región asintótica en la extracción. Para ello se utilizó la relación óptima S/L previamente seleccionada y las partículas de mayor tamaño. También se estudió la aplicabilidad de diferentes modelos matemáticos empíricos para describir la cinética del proceso de extracción. Finalmente, con los datos proporcionados por la cinética se seleccionó el rango de tiempo a ser utilizado en la MSR mediante la cual se determinaron las condiciones óptimas de tiempo y temperatura para la extracción del ACG.

La relación S/L óptima fue de 1:20 (p/v), a mayor relación disminuyó la extracción de ACG. El ACG extraído en 2 etapas de extracción representó el 98,5\% del total de ACG alcanzado en 3 etapas por lo cual se descartó la tercera etapa. A partir de la relación $\mathrm{S} / \mathrm{L}$ óptima se evaluó la cinética de extracción a $80^{\circ} \mathrm{C}$ para los dos tamaños de partículas. El tiempo de extracción tuvo influencia significativa únicamente para las partículas de mayor tamaño, mientras que la mayor concentración de ACG (1,051 g ACG/l) fue extraída con partículas de menor tamaño, siendo en este caso el proceso de extracción prácticamente instantáneo. Por lo tanto, para las partículas de menor tamaño, se seleccionó un sistema de 2 extracciones consecutivas, a $65{ }^{\circ} \mathrm{C}$ durante $5 \mathrm{~min}$, con una relación $\mathrm{S} / \mathrm{L}$ de 1:20 (p/v), para extraer la mayor parte del ACG presente en los $\mathrm{PV}_{\mathrm{YM}}$ $(\sim 1,05 \mathrm{~g} \mathrm{ACG} / \mathrm{l})$. El estudio cinético realizado con las partículas de mayor tamaño indicó que la cantidad de ACG extraído aumentó con el tiempo de extracción hasta los 30 min para todas las temperaturas evaluadas. Asimismo, la extracción de ACG aumentó con la temperatura de extracción hasta los $80{ }^{\circ} \mathrm{C}$; sin embargo, un incremento adicional de la temperatura $\left(100{ }^{\circ} \mathrm{C}\right)$ condujo a una disminución de la extracción. Los modelos matemáticos aplicados mostraron una buena concordancia con los resultados experimentales $\left(R^{2}>0,90\right)$, lo que permite su aplicación en el modelado del proceso de extracción S/L de ACG a partir de $\mathrm{PV}_{\mathrm{YM}}$. La MSR para la extracción de ACG a partir de las partículas de mayor tamaño reveló que los valores óptimos para tiempo y temperatura de extracción son 25-30 $\min$ y $80-90{ }^{\circ} \mathrm{C}$, respectivamente, alcanzando en este caso una concentración de ACG de 0,43 g ACG/l.
\end{abstract}




\subsection{INTRODUCCIÓN}

La yerba mate es un cultivo tradicional de la Provincia de Misiones y de la región noreste de la Provincia de Corrientes, Argentina. Su proceso de producción implica las etapas de cosecha, zapecado, secado, molienda, estacionamiento y envasado. Como ocurre con cualquier material de origen natural, a lo largo de las diferentes etapas del procesamiento industrial pueden producirse cambios en el perfil y en la concentración de los compuestos bioactivos de la yerba mate (López y col., 2006). Estudios previos demostraron que, efectivamente, su contenido en ácido clorogénico (ACG) varía según la época de cosecha como así también en las distintas etapas de su procesamiento, y que la mayor concentración se encuentra en la yerba mate recién cosechada, tanto en hoja como en palo verde (ver capítulo 2).

La extracción es una etapa muy importante para el aislamiento y la identificación de sustancias naturales a partir de materiales biológicos. En el caso particular de los compuestos fenólicos, la eficiencia en su extracción de materiales vegetales depende de varios parámetros tales como temperatura, tiempo, tamaño de partícula, polaridad del solvente y $\mathrm{pH}$, entre otros, y sus efectos pueden ser independientes o interactivos (Mylonaki y col., 2008; Naczk y Shahidi, 2004). Algunos autores informaron sobre la utilización de diferentes disolventes, tales como alcoholes (metanol, etanol, isopropanol) $\mathrm{u}$ otros compuestos orgánicos (acetona, dimetilformamida) para la extracción de compuestos fenólicos a partir de diferentes materiales vegetales ( $\mathrm{Li}$ y col., 2005; Naczk y Shahidi, 2004). Estos disolventes orgánicos fueron seleccionados con el fin de obtener la máxima extracción de los constituyentes activos; sin embargo, su uso provoca limitaciones en las subsecuentes aplicaciones de los extractos, dificultando su utilización como tales en las industrias alimentarias y farmacéuticas. También, se debe mencionar que estos disolventes podrían conducir a la distorsión de los picos cromatográficos del HPLC, dando lugar a errores analíticos. Por otra parte, el manejo de disolventes orgánicos siempre está asociado de algún modo a riesgos laborales de diferente magnitud. Además, pueden generarse residuos tóxicos, constituyendo por lo tanto un potencial problema de contaminación (Sonaglio y col., 2007). Finalmente, la hidrólisis enzimática del ACG para obtener ácido quínico (la primera etapa en el bioproceso para obtener ácido siquímico, el objetivo último de la presente 
investigación) se lleva a cabo en medio acuoso. Todas estas razones confirman la conveniencia de preparar extractos acuosos de ACG para el fin propuesto.

Se han llevado a cabo numerosos estudios sobre la extracción de compuestos fenólicos a partir de yerba mate, bajo diferentes condiciones (Lunceford y Gugliucci, 2005; Ramírez-Mares y col., 2004). Negrão Murakami y col. (2011) han estudiado la optimización de la extracción acuosa de estos compuestos a partir de hojas de $I$. paraguariensis. Sin embargo, a la fecha, no existen estudios sobre la extracción acuosa de ACG a partir de la fracción denominada "palos" de I. paraguariensis. Tampoco existen estudios publicados sobre el modelado de la cinética de extracción sólidolíquido de polifenoles (menos aún para ACG a partir de la fracción denominada "palos") de yerba mate. Los modelos matemáticos son herramientas ingenieriles útiles que facilitan considerablemente la simulación, optimización, diseño y control de los procesos y, a la vez, contribuyen a la correcta utilización de la energía, el tiempo, la materia prima y los solventes (Jokić y col., 2010). Por lo tanto, resulta conveniente realizar el modelado matemático de este proceso.

De acuerdo a lo antes mencionado, y teniendo en cuenta que el "palo" es un residuo actualmente poco valorado en la industria yerbatera, el objetivo del presente trabajo fue desarrollar un método de extracción sólido-líquido adecuado, a escala de laboratorio, para obtener un extracto rico en ACG a partir de muestras de palo verde de yerba mate $\left(\mathrm{PV}_{\mathrm{YM}}\right)$. El trabajo se complementó con estudios sobre la cinética de extracción acuosa de ACG a partir de los $\mathrm{PV}_{\mathrm{YM}}$, su ajuste a modelos empíricos $\mathrm{y}$, finalmente, su optimización mediante la metodología de superficie de respuesta.

\subsection{MATERIALES Y MÉTODOS}

\subsubsection{Materiales y reactivos químicos}

Las extracciones se realizaron con agua destilada. En la cuantificación de ácido clorogénico (ACG) se utilizaron los siguientes reactivos (grado analítico o cromatográfico): ACG (98 \% p/p de pureza, Sigma, EE.UU.), agua (Panreac, España), ácido fórmico (96 \% de pureza, Tedia, EE.UU.) y acetonitrilo (J.T. Baker, EE.UU.). 


\subsubsection{Preparación de la muestra}

Se utilizaron ramas de yerba mate (Ilex paraguariensis St. Hil.) sin procesar (hojas y palos verdes), manualmente recolectadas al final de la época de zafra (meses de agostoseptiembre de 2014), provenientes de una planta de procesamiento de yerba mate (La Cachuera S.A.) ubicada al Sur de la Provincia de Misiones, Argentina. Este material vegetal fue sometido a un tratamiento térmico para inhibir la actividad enzimática dentro de las $36 \mathrm{~h}$ posteriores a la cosecha. Este tratamiento se realizó en nuestro laboratorio utilizando un horno de microondas marca "Eslabón de Lujo" de 700 W, a potencia máxima durante $5 \mathrm{~min}$. A continuación se realizó un cuarteo sucesivo y posterior remoción manual de las fracciones de hoja y palo verdes. Esta última fracción (palos verdes) fue molida utilizando un molino de cuchillas y posteriormente tamizada y clasificada en dos tamaños: a) partículas de mayor tamaño, que atravesaron una malla de $2,5 \times 5 \mathrm{~mm}$ y fueron retenidas en una de $1 \times 5 \mathrm{~mm}(1 \times 5 \mathrm{~mm}<\varnothing$ de partícula $<2,5$ $\times 5 \mathrm{~mm}$ ) y b) partículas de menor tamaño, que atravesaron una malla con diámetro de apertura de $500 \mu \mathrm{m}(\varnothing$ partícula $<500 \mu \mathrm{m})$. Las muestras fueron mantenidas a $4{ }^{\circ} \mathrm{C}$ hasta su utilización y por un tiempo no mayor a los 90 días.

\subsubsection{Preparación de los extractos}

En todos los experimentos, las extracciones se llevaron a cabo en frascos Erlenmeyers de $50 \mathrm{ml}$ conteniendo la cantidad correspondiente de muestra $(0,16$ a 2,5 g de acuerdo al propósito de la experiencia) y un volumen fijo de $25 \mathrm{ml}$ de agua destilada ( $\mathrm{pH}$ final del extracto: 5,8). El procedimiento de extracción se llevó a cabo en un baño termostatizado con agitación recíproca (100 golpes/min), a tiempos y temperaturas variables, y fue detenido mediante una filtración rápida a través de filtro de nitrato de celulosa (0,45 $\mu \mathrm{m}$ de tamaño de poro, E04WP04700, MSI, EE.UU.) mediante la ayuda de una bomba de vacío. Luego, el volumen de cada extracto fue ajustado a $25 \mathrm{ml}$ con agua destilada para recuperar el agua perdida durante el proceso de extracción, ya sea por evaporación o retención en el sólido. Todos los extractos (preparados por duplicado) se mantuvieron a $4{ }^{\circ} \mathrm{C}$ y fueron analizados dentro un período no mayor a 4 días. 


\subsubsection{Selección de variables relevantes y rangos experimentales}

Se realizó un primer conjunto de pruebas para seleccionar los factores más relevantes que influyen en los procesos de extracción a los efectos de determinar los rangos experimentales de las variables independientes. Esta información es importante para llevar a cabo el proceso de optimización de la extracción acuosa del ACG a partir de los palos verdes de yerba mate $\left(\mathrm{PV}_{\mathrm{YM}}\right)$ mediante la metodología de superficie de respuesta (MSR).

\subsubsection{Efecto de la relación sólido/líquido:}

Se evaluó la influencia de la relación sólido/líquido $(\mathrm{S} / \mathrm{L})$ sobre el proceso de extracción acuosa del ACG utilizando $\mathrm{PV}_{\mathrm{YM}}$ molidos con un $\varnothing$ partícula $<500 \mu \mathrm{m}$ (partículas de menor tamaño). Las cinco relaciones $\mathrm{S} / \mathrm{L}$ evaluadas fueron $(\mathrm{p} / \mathrm{v}): 1: 150(6,67 \mathrm{~g} / 1), 1: 100$ $(10 \mathrm{~g} / 1), 1: 50(20 \mathrm{~g} / 1), 1: 20(50 \mathrm{~g} / 1)$ y 1:10 (100 g/l). Los extractos fueron incubados en un baño termostatizado durante $30 \min$ a $95-100{ }^{\circ} \mathrm{C}$, con agitación reciprocante constante (100 golpes/min). Con los valores experimentales obtenidos se calculó la tendencia polinómica para la cantidad de ACG extraído en función de la relación $\mathrm{S} / \mathrm{L}$ específica.

\subsubsection{Efecto del número de extracciones:}

El efecto del número de extracciones sobre la extracción total del ACG fue estudiado utilizando la relación S/L seleccionada en la etapa anterior, bajo las mismas condiciones previamente descriptas. Luego de la primera extracción, el residuo fue re-suspendido en $25 \mathrm{ml}$ de agua destilada y el proceso se repitió dos veces más.

\subsubsection{Efecto del tamaño de partícula y la temperatura de extracción:}

Se estudió el efecto del tamaño de partícula $(1 \times 5 \mathrm{~mm}<\varnothing$ de partícula $<2,5 \times 5 \mathrm{~mm}$ y $\varnothing$ partícula $<500 \mu \mathrm{m})$ y la temperatura de extracción en el rango de 30 a $100{ }^{\circ} \mathrm{C}$, utilizando la relación óptima $\mathrm{S} / \mathrm{L}$ previamente seleccionada.

\subsubsection{Cinética de extracción sólido-líquido (S/L)}

Se realizó un estudio cinético a diferentes temperaturas de extracción (entre 30 y 100 $\left.{ }^{\circ} \mathrm{C}\right)$ con objeto de seleccionar el rango de tiempo necesario para alcanzar la región 
asintótica en la extracción. Las temperaturas axiales $\left(30\right.$ y $\left.100{ }^{\circ} \mathrm{C}\right)$ y la central $\left(65^{\circ} \mathrm{C}\right)$ seleccionadas para realizar el diseño experimental se utilizaron en el estudio cinético. Además, se utilizó la relación óptima $\mathrm{S} / \mathrm{L}$ previamente seleccionada y un tamaño de partícula de $1 \times 5 \mathrm{~mm}<\varnothing$ de partícula $<2,5 \times 5 \mathrm{~mm}$ (partículas de mayor tamaño). Los datos experimentales se ajustaron a dos modelos empíricos previamente aplicados a distintos procesos extractivos a partir de yerba mate (Linares y col., 2010; Scipioni y col., 2010). En primer lugar, se utilizó el modelo de Pilosof y col. (1985) (ec. 3.1). En este caso, la concentración de ACG en el extracto $(C, \mathrm{~g} / \mathrm{l})$ queda expresada como una función del tiempo de extracción $(t, \mathrm{~min})$. En la ec. 3.1, $Q(\mathrm{~g} / \mathrm{l})$ es la concentración de ACG obtenido a un tiempo infinito, y $b$ (min) es el tiempo necesario para extraer la mitad de $Q$. De esta manera la velocidad de extracción del ACG mediante el modelo de Pilosof y col. (1985) puede expresarse como:

$$
C=\frac{Q * t}{(b+t)} \quad(\text { ec. } 3.1)
$$

Los datos experimentales también fueron ajustados al modelo de Spiro y Jago (1982) (ec. 3.2). En este modelo, $k\left(\mathrm{~min}^{-1}\right)$ es el parámetro de la ecuación de pseudo primer orden y $a$ es la constante de integración. De esta manera la velocidad de extracción del ACG mediante el modelo de Spiro y Jago (1982) puede expresarse como:

$$
C=Q-\frac{Q}{\exp (k * t+a)} \quad(\text { ec. } 3.2)
$$

\subsubsection{Diseño experimental: Metodología de superficie de respuesta (MSR)}

La MSR fue utilizada para determinar las condiciones óptimas para la extracción del ACG a partir de $\mathrm{PV}_{\mathrm{YM}}$. En el presente estudio se utilizó el diseño experimental de Doehlert (Doehlert 1970) para dos variables independientes. Las variables analizadas fueron: temperatura de extracción $(T)$ y tiempo de extracción $(t)$. Los niveles seleccionados para cada variables se basaron en estudios previos (sección 3.2.4. y 3.2.5.). En la Tabla 3.1 se presenta la matriz utilizada en el diseño experimental de Doehlert (valores reales y codificados de las variables). Todas las experiencias fueron 
realizadas en orden aleatorio para evitar los errores sistemáticos. Se utilizó un análisis de regresión lineal para eliminar términos de $\mathrm{p}>0,05$.

Tabla 3.1: Valores codificados y reales utilizados en el diseño experimental de Doehlert.

\begin{tabular}{cccccc}
\hline \multirow{2}{*}{ Exp. $\mathrm{N}^{\circ}$} & \multicolumn{2}{c}{ Valores codificados } & & \multicolumn{2}{c}{ Valores reales } \\
\cline { 2 - 3 } \cline { 5 - 6 } \cline { 5 - 6 } & $\mathrm{t}(\min )$ & $\mathrm{T}\left({ }^{\circ} \mathrm{C}\right)$ & & $\mathrm{t}(\min )$ & $\mathrm{T}\left({ }^{\circ} \mathrm{C}\right)$ \\
\hline 1 & 1 & 0 & & 30 & 65 \\
2 & 0,5 & 0,866 & & 23,125 & 100 \\
3 & $-0,5$ & 0,866 & & 9,375 & 100 \\
4 & -1 & 0 & & 2,5 & 65 \\
5 & $-0,5$ & $-0,866$ & & 9,375 & 30 \\
6 & 0,5 & $-0,866$ & & 23,125 & 30 \\
7 & 0 & 0 & & 16,25 & 65 \\
8 & 0 & 0 & & 16,25 & 65 \\
9 & 0 & 0 & & 16,25 & 65 \\
\hline
\end{tabular}

t: tiempo; T: temperatura.

\subsubsection{Determinación del contenido de ácido clorogénico en los extractos de yerba mate}

La identificación y cuantificación del ACG se realizó mediante cromatografía líquida de alta resolución (HPLC) con gradiente, utilizando un equipo Shimadzu Prominence, equipado con un autosampler Shimadzu SIL-20 A HT y un detector de arreglo de diodos UV/VIS Shimadzu SPD-M20A. El volumen de inyección fue de $20 \mu \mathrm{y}$ la separación se realizó en una columna de fase reversa C18 Phenomenex Prodigy ODS3, con un gradiente binario compuesto por ácido fórmico al $1 \%$ en agua deionizada y acetonitrilo (el detalle completo de la técnica fue descripto en el capítulo 2). La identificación del ACG y sus compuestos isómeros se llevó a cabo por comparación de los picos con el tiempo de retención del compuesto estándar cuando corresponda, la absorbancia a $326 \mathrm{~nm}$ (máxima para el ACG), la comparación del espectro obtenido a 250-400 nm y los patrones de elución con la literatura (Carini y col., 1998; Fang y col., 2002; Bravo y col., 2006). 


\subsubsection{Análisis estadístico}

Los datos experimentales fueron ajustados a los modelos propuestos para la cinética de extracción S/L (Pilosof y col. y Spiro y Jago) mediante una técnica de regresión no lineal usando el programa estadístico Statgraphics Centurion XV (Freund y Wilson, 1997). La bondad del ajuste fue determinada utilizando cuatro parámetros estadísticos: el coeficiente de determinación $\left(R^{2}\right)$, el valor de Chi-cuadrado $\left(X^{2}\right.$, ec. 3.3), la raíz cuadrada del error cuadrático medio (RMSE, ec. 3.4) y el error medio porcentual (EMP, ec. 3.5).

$$
\begin{gathered}
X^{2}=\frac{\sum\left(C_{\text {exp }}-C_{p r e}\right)^{2}}{N-n p} \quad(\text { ec. } 3.3) \\
R M S E=\left[\frac{\sum\left(C_{\text {exp }}-C_{p r e}\right)^{2}}{N}\right]^{0,5} \quad(\text { ec. } 3.4) \\
E M P=\frac{100}{N} \sum \frac{A B S\left(C_{\text {exp }}-C_{p r e}\right)}{C_{\text {exp }}} \quad(\text { ec. 3.5) }
\end{gathered}
$$

Los valores de $R^{2}$ proporcionan el porcentaje de la variación explicada por el modelo. El valor de $X^{2}$ tiene en cuenta las diferencias entre los datos experimentales (exp) y los datos predichos (pre), el número de datos $(N)$ y el número de parámetros $(n p)$ utilizados en el modelo ( $N-n p$, o grados de libertad). Este parámetro estadístico resulta útil cuando los modelos a comparar utilizan diferentes parámetros. El RMSE se expresó como la diferencia absoluta media entre los datos experimentales y los datos predichos, mientras que el EMP está relacionado con la diferencia relativa.

Cuando fue necesario, los resultados se expresaron como media \pm desviación estándar (SD). Para el análisis de los datos experimentales se realizó un análisis de varianza (ANOVA) seguido por un análisis post-hoc mediante la prueba de Tukey para verificar diferencias significativas. Las diferencias se consideraron estadísticamente significativas cuando $\mathrm{p}<0,05$. Los resultados se analizaron aplicando un programa estadístico Statgraphics Centurion XV (Freund y Wilson, 1997). 


\subsection{RESULTADOS Y DISCUSIÓN}

\subsubsection{Selección de variables relevantes y rangos experimentales}

En una primera etapa se estudió el efecto de la relación $\mathrm{S} / \mathrm{L}$, el número de extracciones, el tamaño de partícula y la temperatura de extracción para determinar los factores relevantes que podrían influir en la extracción acuosa del ACG.

\subsubsection{Efecto de la relación sólido/líquido:}

El efecto de la relación $\mathrm{S} / \mathrm{L}$ en la extracción acuosa del $\mathrm{ACG}$ a partir de los $\mathrm{PV}_{\mathrm{YM}}$ molidos $(\varnothing$ partícula $<500 \mu \mathrm{m})$ para las cinco relaciones ensayadas se presenta en la Figura 3.1.

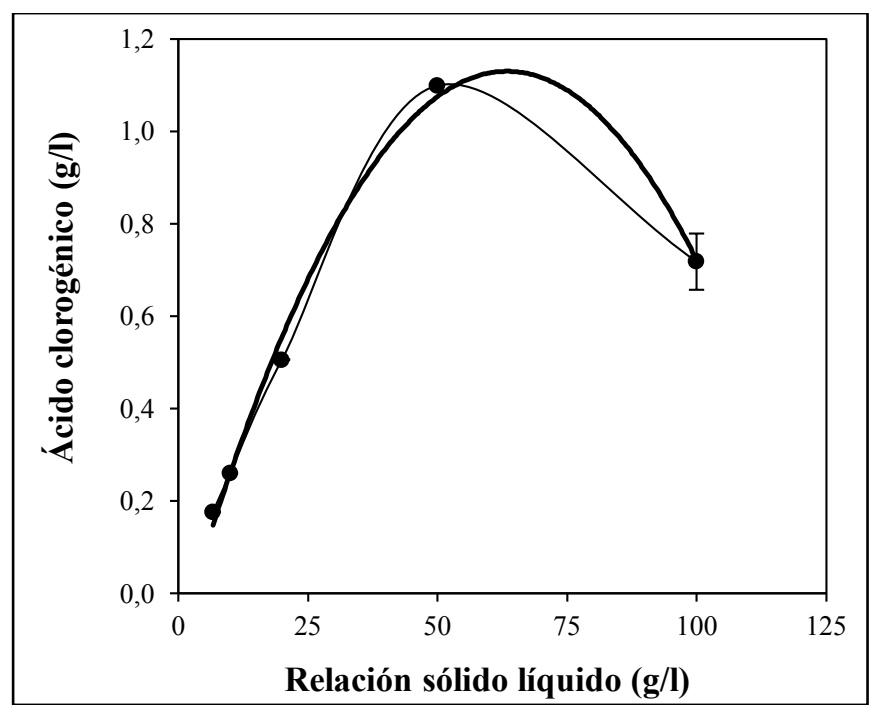

Figura 3.1: Efecto de la relación $\mathrm{S} / \mathrm{L}$ sobre la extracción acuosa de $\mathrm{ACG}$ a partir de $\mathrm{PV}_{\mathrm{YM}}$ molidos $(\varnothing$ partícula $<500 \mu \mathrm{m})$, durante un período de extracción de $30 \mathrm{~min}$ a $95-100{ }^{\circ} \mathrm{C}$ (la línea en negrita muestra la tendencia polinómica). Relaciones $\mathrm{S} / \mathrm{L}$ evaluadas $(\mathrm{p} / \mathrm{v}): 1: 150(6,67$ $\mathrm{g} / \mathrm{l}), 1: 100(10 \mathrm{~g} / \mathrm{l}), 1: 50(20 \mathrm{~g} / \mathrm{l}), 1: 20(50 \mathrm{~g} / 1)$ y $1: 10(100 \mathrm{~g} / \mathrm{l})$.

La concentración de ACG en los extractos se incrementó al aumentar la relación $\mathrm{S} / \mathrm{L}$, obteniéndose los máximos valores $(1,099 \pm 0,001$ g ACG/l) con una relación de 1:20 (50 g/l, p/v). Al utilizar una relación $\mathrm{S} / \mathrm{L}$ mayor $(1: 10, \mathrm{p} / \mathrm{v})$, la extracción fue menor. Esto se pudo deber a un exceso de sólido que no puede ser eficientemente penetrado por el solvente utilizado (Nawaz y col., 2006). Además, se observó que en este caso, el sólido retiene una considerable cantidad de solución con una alta concentración en ACG, el cual no se incorpora al filtrado resultando en un menor rendimiento en la extracción. 
El siguiente modelo de regresión relaciona al ACG extraído con la proporción $\mathrm{S} / \mathrm{L}$ empleada:

$$
y=-0,0968+0,0387 x-0,0003 x^{2}
$$

donde $y$ es la concentración de ACG (en g/l) y $x$ es la relación $\mathrm{S} / \mathrm{L}$ (en g/l) utilizada.

\subsubsection{Efecto del número de extracciones sobre la extracción total del ACG:}

En la Figura 3.2 se presenta el porcentaje respecto del total extraído de ACG obtenido en cada etapa de extracción, a partir de $\mathrm{PV}_{\mathrm{YM}}$ molidos $(\varnothing$ partícula $<500 \mu \mathrm{m})$ para las dos relaciones S/L estudiadas: 1:20 (p/v) y 1:10 (p/v).

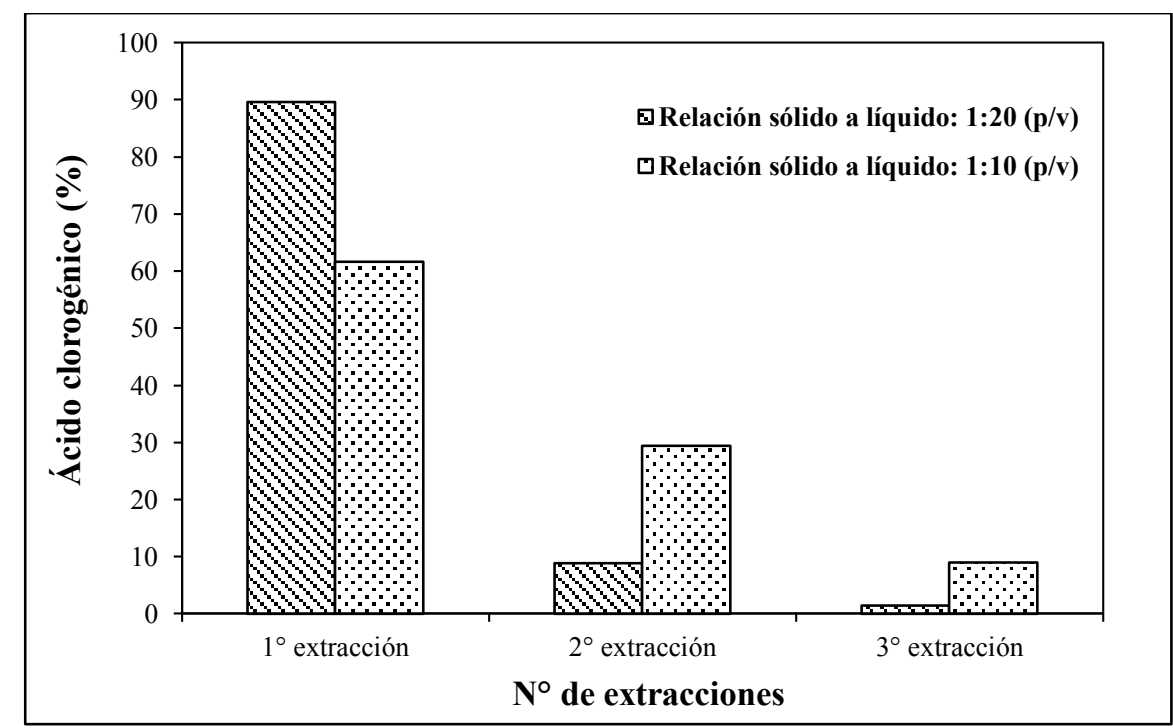

Figura 3.2: ACG extraído (expresado en \% respecto del total) en cada etapa de extracción a partir de $\mathrm{PV}_{\mathrm{YM}}$ molidos $(\varnothing$ partícula $<500 \mu \mathrm{m}$ ), durante un período de extracción de $30 \mathrm{~min}$ a $95-100{ }^{\circ} \mathrm{C}$.

El mayor porcentaje de ACG fue extraído en la primera etapa, con valores del $90 \%$ y del $62 \%$ respecto al total extraído para las relaciones 1:20 (p/v) y 1:10 (p/v), respectivamente. En la segunda extracción se obtuvo una mayor concentración de ACG en la relación 1:10 (p/v) que en la 1:20 (p/v). Esto confirma que el líquido retenido dentro del sólido en la mayor relación $(1: 10, \mathrm{p} / \mathrm{v})$ contiene una mayor cantidad de ACG que en el caso de la menor relación $(1: 20, \mathrm{p} / \mathrm{v})$ y que dicho ACG es incorporado al extracto de la segunda extracción. Algo similar ocurre al analizar los valores de ACG obtenidos en la tercera extracción.

Las cantidades de ACG extraídas disminuyeron en las subsecuentes etapas de extracción, siendo prácticamente despreciable en la tercera etapa $(<9,0 \%$ para la 
relación 1:10, p/v). El ACG extraído en las dos primeras etapas representó el 98,5\% $(1,244 \pm 0,043$ g ACG/l) y el 91,1\% (1,116 \pm 0,016 g ACG/l) del total extraíble en 3 etapas para las relaciones 1:20 (p/v) y 1:10 (p/v), respectivamente.

Por otra parte, es importante recordar que el uso de una relación 1:10 (p/v) resultaba en que una importante proporción de extracto quedaba retenida por el sólido, sobre todo en la primera extracción. Teniendo en cuenta esto, además de los anteriores resultados, se decidió utilizar una relación 1:20 (p/v) y una única etapa de extracción para el subsiguiente estudio del efecto del tamaño de partícula y la temperatura. Por otra parte, para el caso de un proceso productivo de extracción de ACG sería recomendable utilizar dos etapas de extracción ya que no resultaría económicamente aceptable agregar una tercera etapa de extracción teniendo en cuenta la relativamente baja cantidad de ACG obtenida $(\sim 1,5 \%)$ respecto del total extraído. La incorporación del extracto de una tercera etapa a los provenientes de las dos anteriores ocasionaría una dilución en el contenido de ACG de los mismos, más allá de los inconvenientes operativos inherentes a una etapa más de extracción. Esto está de acuerdo con lo informado por otros autores quienes estudiaron la extracción de polifenoles a partir de diferentes materiales vegetales (Shi y col., 2003; Nawaz y col., 2006).

\subsubsection{Efecto del tamaño de partícula sobre la extracción total del ACG:}

La influencia del tamaño de partícula sobre la cinética de extracción acuosa de ACG a $80{ }^{\circ} \mathrm{C}$ utilizando una relación $\mathrm{S} / \mathrm{L}$ de 1:20 (p/v) se muestra en la Figura 3.3. La mayor concentración de ACG fue obtenida con partículas de menor tamaño ( $\varnothing$ partícula $<500$ $\mu \mathrm{m})$ y estuvo en el orden de $1,051 \pm 0,015 \mathrm{~g}$ ACG/l, mientras que la concentración de ACG alcanzada a partir de partículas de mayor tamaño $(1 \times 5 \mathrm{~mm}<\varnothing$ partícula $<2,5 \times$ $5 \mathrm{~mm}$ ) fue de $0,416 \pm 0,010 \mathrm{~g}$ ACG/l. El análisis de varianza reveló que no hubo diferencias significativas entre las concentraciones de ACG obtenidas a diferentes tiempos de extracción (a partir de $1 \mathrm{~min}$ ) para las partículas de menor tamaño $(\mathrm{p} \leq 0,05)$, demostrando que la extracción de ACG fue prácticamente instantánea para la temperatura evaluada $\left(80^{\circ} \mathrm{C}\right)$. Para las partículas de mayor tamaño, la extracción de ACG fue relativamente rápida en el primer minuto, extrayéndose $\cong$ el $55 \%$ del total extraíble. Luego, la velocidad de extracción se redujo substancialmente para completarse entre los 10 y $20 \mathrm{~min}$, momento a partir del cual la concentración de ACG 
permaneció aproximadamente constante. Este comportamiento asintótico podría atribuirse a la disminución de la fuerza impulsora para la transferencia de ACG desde el interior del sólido hacia el seno de la solución.

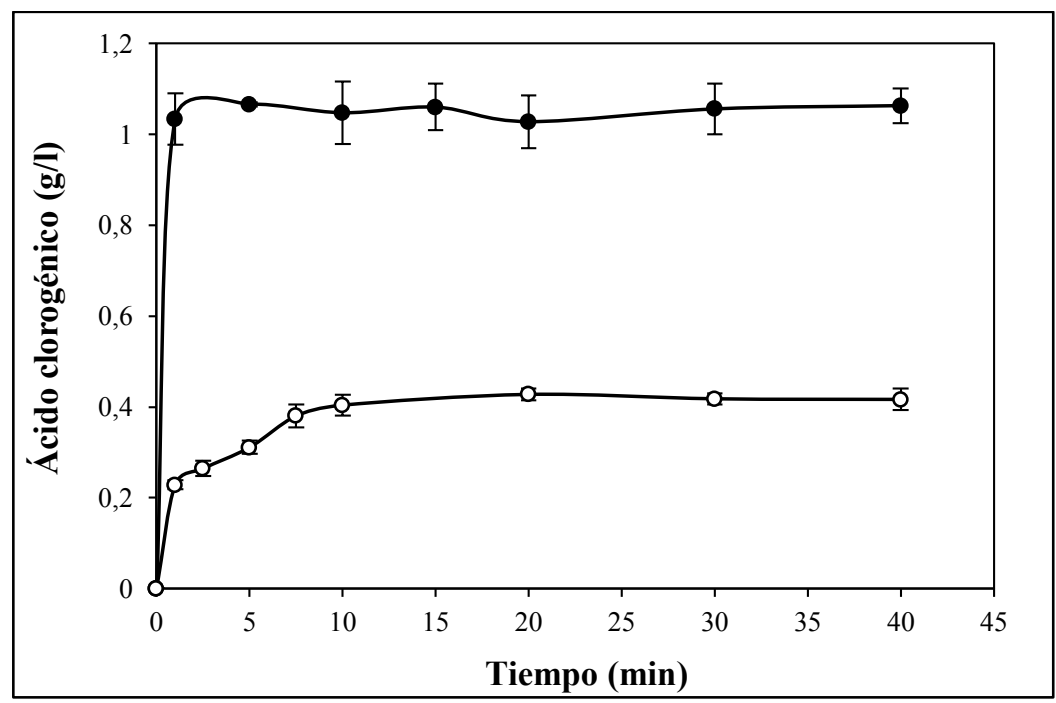

Figura 3.3: Influencia del tamaño de partícula sobre la extracción acuosa de ACG a partir de $\mathrm{PV}_{\mathrm{YM}}$, a $80^{\circ} \mathrm{C}$ y una relación sólido/líquido de 1:20 (p/v). Símbolos: Ø partícula $<500 \mu \mathrm{m}(\bullet)$ y $1 \times 5 \mathrm{~mm}<\varnothing$ partícula $<2,5 \times 5 \mathrm{~mm}(\circ)$.

Negrão Murakami y col. (2011) y Aguiar Prudêncio y col. (2012) estudiaron la extracción acuosa de polifenoles a partir de hojas molidas de yerba mate ( $\varnothing$ partícula $<$ $350 \mu \mathrm{m})$ y a partir de residuos molidos de corteza de yerba mate, respectivamente. Dichos autores reportaron que la variable tiempo no ejerció una influencia significativa durante el proceso de extracción $(\mathrm{p} \leq 0,05)$. Este resultado concuerda con el descrito previamente y confirma que la cinética de extracción acuosa de este tipo de sustancias en partículas pequeñas de yerba mate (con tamaños $<500 \mu \mathrm{m}$ ) es muy rápida.

Podría asumirse que la concentración de ACG en el material sólido de partida es la misma tanto en las partículas más chicas como en las más grandes, esto es que el $\mathrm{PV}_{\mathrm{YM}}$ presenta una distribución homogénea de ACG dentro de su matriz. Si esto fuera así, se podría postular que en el caso de las partículas más grandes existe una fracción de ACG extraíble y otra que queda sin extraer independientemente del tiempo de extracción. Esta fracción no extraíble está cuantitativamente relacionada con la diferencia entre los valores de la región asintótica de las dos curvas mostradas en la Figura 3.3. Siendo el ACG perfectamente soluble en agua en las condiciones y concentraciones del caso, la 
razón por la cual una parte significativa del ACG de las partículas más grandes no se solubiliza, aún a tiempos largos de extracción, no queda en claro. Este comportamiento es similar al observado por Bucic'-Kojic' y col. (2007) para la extracción de polifenoles totales a partir de partículas de semillas de uva de diferente granulometría y también al reportado por Pinelo y col. (2007) para el caso de polifenoles de granos de café con variados grados de molienda.

\subsubsection{Efecto de la temperatura sobre la extracción total del ACG:}

En la Figura 3.4 se muestra el efecto de la temperatura sobre la extracción de ACG para los dos tamaños de partícula estudiados, durante un período de extracción fijo de 5 min $(\varnothing$ partícula $<500 \mu \mathrm{m})$ y de $30 \mathrm{~min}(1 \times 5 \mathrm{~mm}<\varnothing$ partícula $<2,5 \times 5 \mathrm{~mm})$. Nuevamente se observó que la cantidad de ACG extraído de las partículas más grandes es substancialmente menor que las de las partículas más chicas independientemente de la temperatura de extracción. La extracción de ACG aumentó con la temperatura de extracción hasta $65^{\circ} \mathrm{C}$, para ambos tamaños de partícula. El análisis de varianza reveló que no hubo diferencias significativas en la cantidad de ACG extraído a 65 y $80{ }^{\circ} \mathrm{C}$, para cada uno de los dos tamaños de partícula evaluados. En ambos casos, la cantidad de ACG cuantificada en los extractos obtenidos a $100{ }^{\circ} \mathrm{C}$ disminuyó levemente.

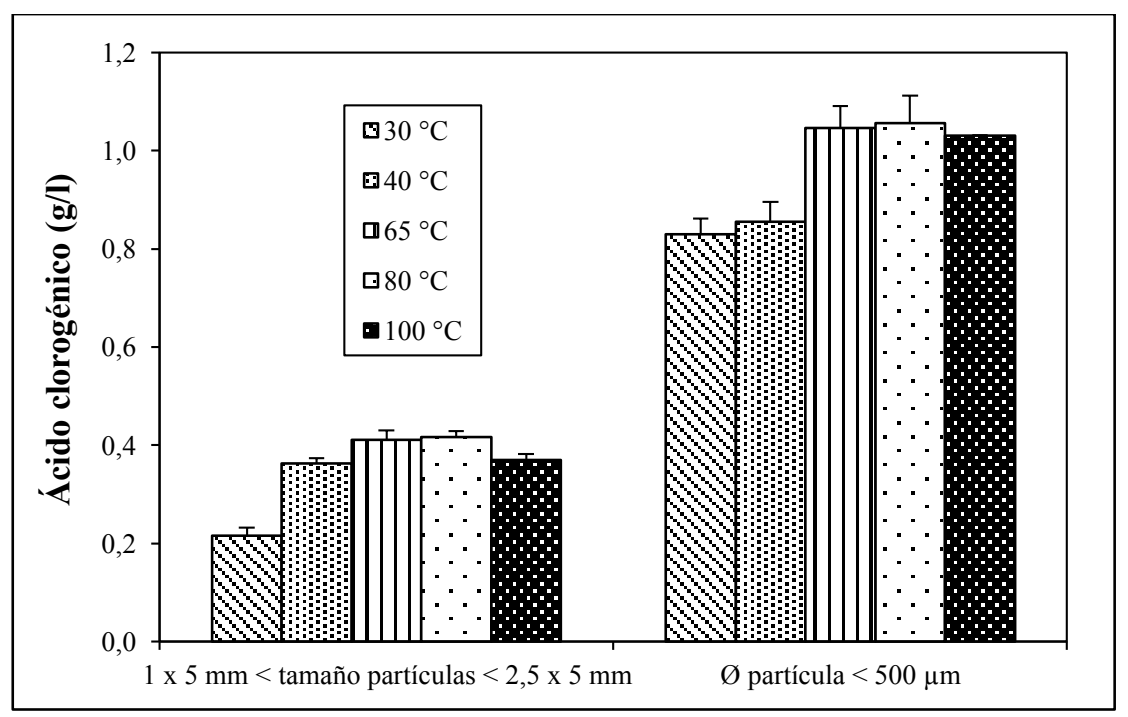

Figura 3.4: Influencia de la temperatura sobre la extracción acuosa de ACG a partir de $\mathrm{PV}_{\mathrm{YM}}$ de diferentes tamaños, utilizando una relación sólido/líquido de 1:20 (p/v), durante un período de extracción de $5 \min (\varnothing$ partícula $<500 \mu \mathrm{m})$ y de $30 \min (1 \times 5 \mathrm{~mm}<$ tamaño partícula $<2,5 \times 5$ $\mathrm{mm})$. 
Resultados similares fueron obtenidos por Aguiar Prudêncio y col. (2012) al estudiar la extracción acuosa de polifenoles a partir de residuos de yerba mate. Estos autores reportaron que una temperatura superior a $90{ }^{\circ} \mathrm{C}$ produjo un decrecimiento en la cantidad detectada de compuestos fenólicos en los extractos. Una posible inestabilidad térmica de los compuestos extraídos podría explicar estos resultados.

\subsubsection{Cinética de extracción sólido-líquido}

Los resultados alcanzados en la etapa anterior (sección 3.3.1.3.) indicaron que la extracción de ACG fue prácticamente instantánea para las partículas de menor tamaño (Ø partícula $<500 \mu \mathrm{m})$ y que además el uso de esta fracción granulométrica resulta en mayores concentraciones en ACG en los extractos cualquiera sea la temperatura de extracción (sección 3.3.1.4). Sin embargo, el uso de partículas de este tamaño puede conducir a problemas operativos, particularmente en mayores escalas de trabajo. Uno de ellos está asociado al proceso de molienda que debe ser más intenso si se pretende un rendimiento importante en esta fracción granulométrica. También debe considerarse el aumento en la viscosidad de las suspensiones con los inherentes incrementos en la potencia necesaria para su bombeo. La etapa de separación de los sólidos extraídos del solvente se torna más compleja al reducir el tamaño de partícula. Finalmente, y no menos importante, son los problemas respiratorios que pueden sufrir los operarios que manejan este tamaño de partículas. Por estas razones, además de la imposibilidad práctica para obtener datos experimentales con tiempos de extracción tan cortos, fue que se decidió considerar a las partículas de mayor tamaño $(1 \times 5 \mathrm{~mm}<$ tamaño partícula $<$ $2,5 \times 5 \mathrm{~mm}$ ) para realizar el estudió cinético de la extracción de ACG.

La cinética de extracción de ACG a partir de $\mathrm{PV}_{\mathrm{YM}}$ se realizó para conocer la velocidad de extracción y de este modo poder seleccionar apropiadamente el rango experimental a ser utilizado en la MSR para la variable tiempo. Esta información es importante a los efectos de evitar un rango de tiempo que conduzca a una baja variabilidad en el rendimiento del ACG para una temperatura dada.

En las Figuras 3.5 y 3.6 se observan los datos experimentales obtenidos como así también las correspondientes curvas de aproximación de acuerdo a los modelos de Pilosof y de Spiro y Jago, respectivamente. 


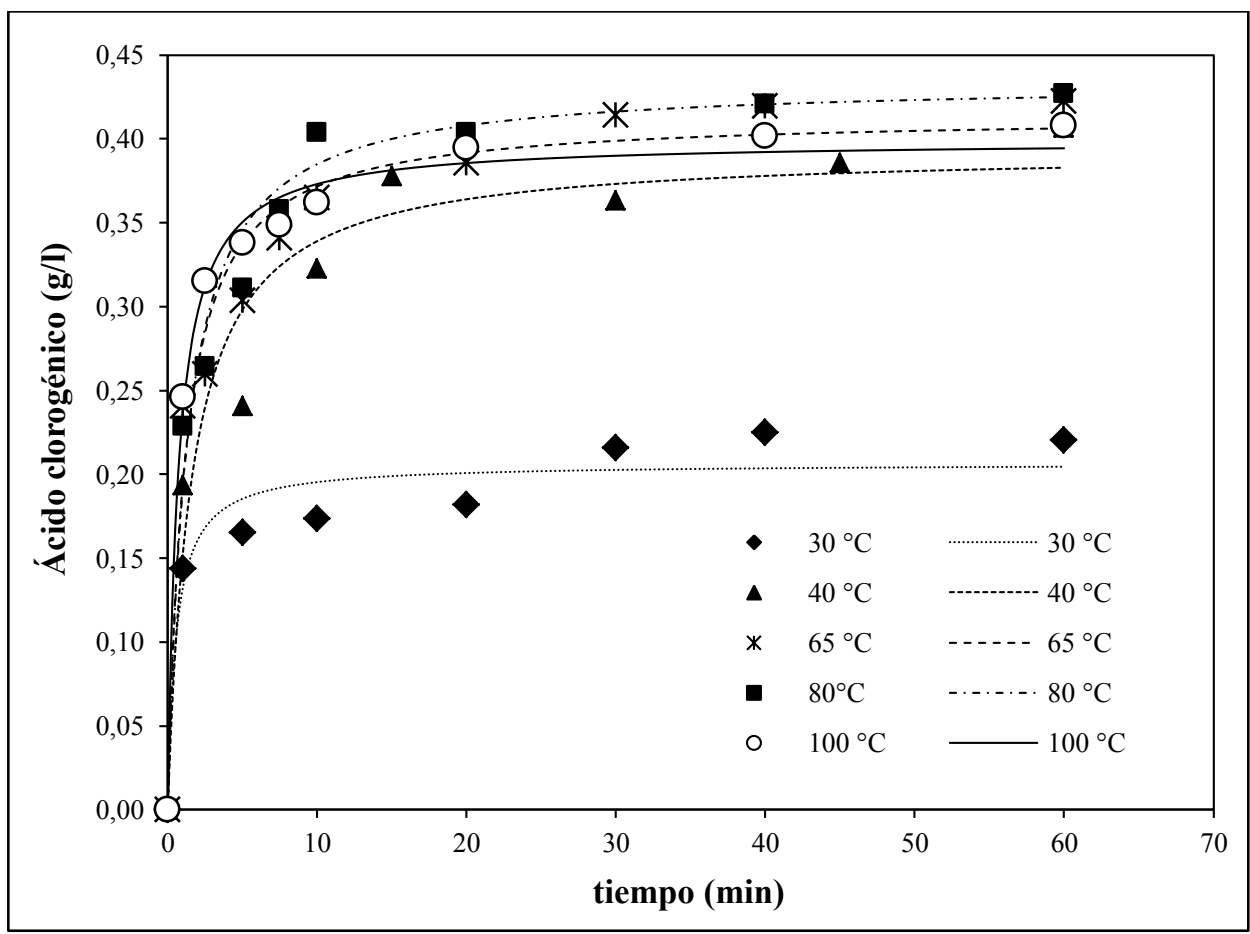

Figura 3.5: Influencia de la temperatura sobre la cinética de extracción de ACG a partir de $\mathrm{PV}_{\mathrm{YM}}$, utilizando una relación $\mathrm{S} / \mathrm{L}$ de 1:20 (p/v). Símbolos: datos experimentales; líneas: aproximación de acuerdo al modelo de Pilosof.

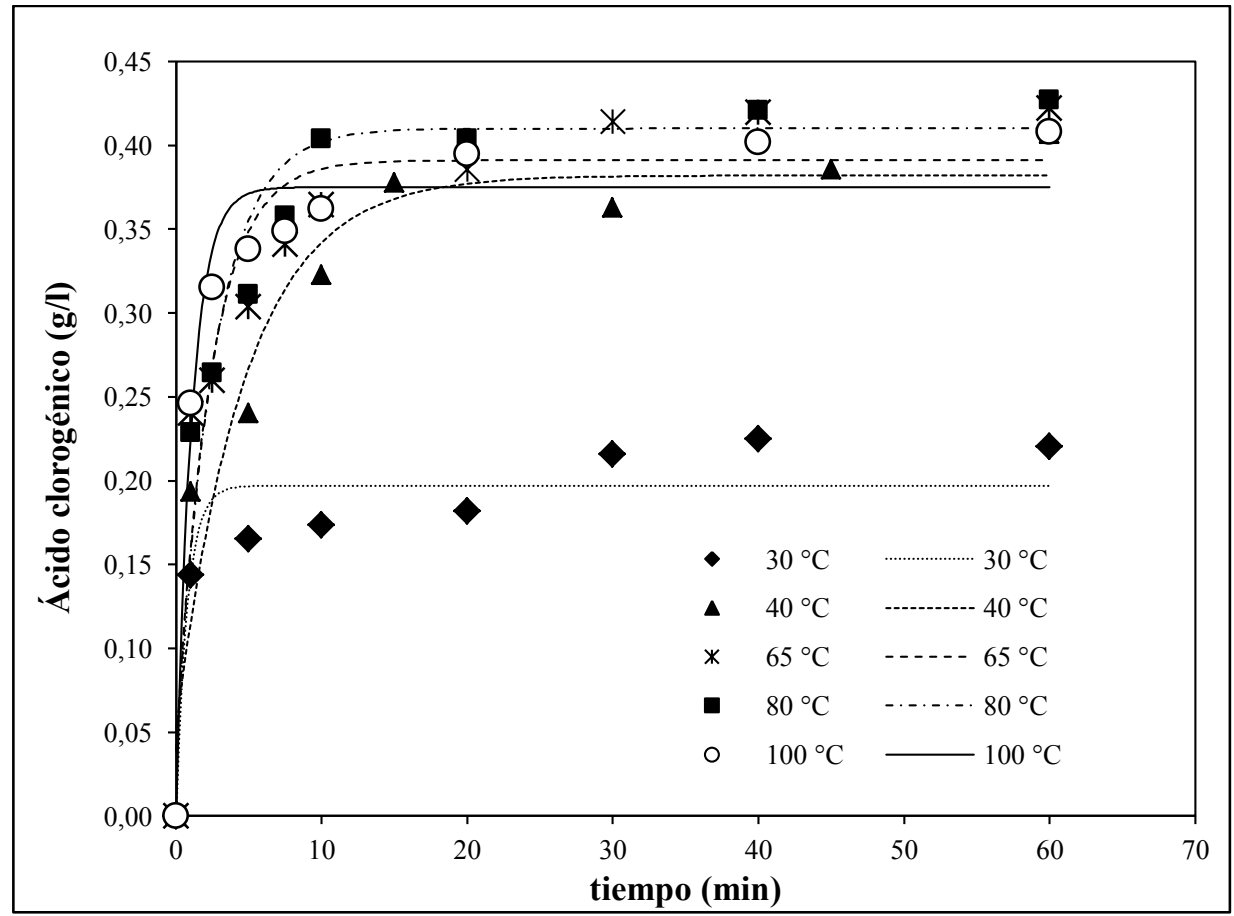

Figura 3.6: Influencia de la temperatura sobre la cinética de extracción de ACG a partir de $\mathrm{PV}_{\mathrm{YM}}$, utilizando una relación $\mathrm{S} / \mathrm{L}$ de 1:20 (p/v). Símbolos: datos experimentales; líneas: aproximación de acuerdo al modelo de Spiro y Jago. 
La cantidad de ACG extraída a partir de los $\mathrm{PV}_{\mathrm{YM}}$ aumentó con el tiempo de extracción hasta $\cong 20$ min para las temperaturas evaluadas, tendiendo luego de este tiempo a la región asintótica correspondiente para cada temperatura ensayada. Se observa una elevada velocidad de extracción en los primeros $10 \mathrm{~min}$, excepto para $30{ }^{\circ} \mathrm{C}$, seguido de una velocidad de extracción más lenta que se aproxima asintóticamente a la concentración de equilibrio a los $30 \mathrm{~min}$, aproximadamente. Más precisamente, en los primeros $10 \mathrm{~min}$, dependiendo de la temperatura de extracción, entre el $77 \%$ y el $95 \%$ de ACG se extrajo respecto a la cantidad total extraída a los $30 \mathrm{~min}$. Asimismo, la cantidad de ACG extraído aumentó con la temperatura de extracción hasta los $80{ }^{\circ} \mathrm{C}$. Un incremento adicional de la temperatura $\left(100^{\circ} \mathrm{C}\right)$ condujo a una disminución de la extracción. Los resultados muestran que el máximo grado de extracción se alcanzó a una temperatura de $80^{\circ} \mathrm{C}$ y un tiempo de $30 \min (\sim 0,42 \mathrm{~g} \mathrm{ACG} / 1)$, mientras que para el mismo tiempo de extracción la cantidad más baja de ACG fue extraída a $30{ }^{\circ} \mathrm{C}(\sim 0,20 \mathrm{~g}$ ACG/l). Estas concentraciones de ACG alcanzadas en los extractos se corresponden adecuadamente a los valores anteriormente reportados en 3.3.1.3 y 3.3.1.4.

Aguiar Prudêncio y col. (2012) estudiaron la extracción acuosa de compuestos fenólicos a partir de residuos de la corteza de la planta de yerba mate e informaron una disminución en la extracción de los compuestos fenólicos de la yerba mate a temperaturas superiores a $90{ }^{\circ} \mathrm{C}$.

El aumento de temperatura de extracción da como resultado, en la mayoría de los casos, un aumento de la tasa de difusión y la solubilidad de las sustancias extraídas; sin embargo, debe tenerse en cuenta que algunas sustancias importantes biológicamente activas se pueden degradar a elevadas temperaturas (Cacace y Mazza, 2003).

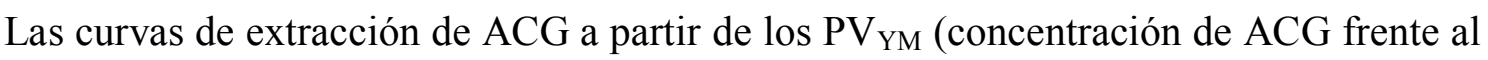
tiempo) presentan una forma muy similar a las curvas de sorción (contenido de humedad en función del tiempo); por lo tanto, es posible describirlas utilizando modelos matemáticos aplicados a la transferencia de masa. Consecuentemente, para describir la cinética de extracción de ACG a partir de los $\mathrm{PV}_{\mathrm{YM}}$, se utilizaron dos modelos matemáticos, los propuestos por Pilosof y por Spiro y Jago.

Los valores de las constantes, el coeficiente de determinación $\left(\mathrm{R}^{2}\right)$, la raíz cuadrada del error cuadrático medio (RMSE), el valor de Chi-cuadrado $\left(x^{2}\right)$ y el error medio 
porcentual $(E M P)$ se obtuvieron para cada modelo matemático utilizando el programa estadístico Statgraphics Centurion XV para métodos no lineales.

Los resultados obtenidos para los modelos de Pilosof y de Spiro y Jago, se presentan en la Tabla 3.2 y 3.3, respectivamente. Los coeficientes de determinación $\left(R^{2}\right)$ fueron altos en todos los experimentos $(90,74-98,34 \%)$, las raíces medias de la desviación al cuadrado (RMSD) estuvieron en el rango de 0,0161 a 0,0371 y los valores de Chicuadrado $\left(x^{2}\right)$ y el error medio porcentual $(E M P)$ fueron relativamente bajos, lo que implicó una buena concordancia entre los valores experimentales y los valores predichos por ambos modelos.

Tabla 3.2: Constantes del modelo matemático de Pilosof, coeficientes de determinación $\left(R^{2}\right)$, raíces cuadradas del error cuadrático medio $(R M S D)$, valores de Chi-cuadrado $\left(x^{2}\right)$ y valores del error medio porcentual $(E M P)$ correspondientes a la extracción acuosa de ACG a partir de $\mathrm{PV}_{\mathrm{YM}}$.

\begin{tabular}{ccccccc}
\hline $\mathrm{T}\left({ }^{\circ} \mathrm{C}\right)$ & $\mathrm{Q}(\mathrm{g} / \mathrm{l})$ & $\mathrm{b}(\mathrm{min})$ & $R^{2}$ & $R M S E$ & $x^{2}$ & $E M P$ \\
\hline 30 & 0,206 & 0,57 & 93,92 & 0,0168 & $3,78 \times 10^{-4}$ & 9,47 \\
40 & 0,393 & 1,59 & 95,05 & 0,0286 & $1,01 \times 10^{-3}$ & 9,54 \\
65 & 0,414 & 1,14 & 96,53 & 0,0227 & $6,44 \times 10^{-4}$ & 6,73 \\
80 & 0,434 & 1,27 & 97,35 & 0,0213 & $5,84 \times 10^{-4}$ & 6,24 \\
100 & 0,399 & 0,694 & 99,21 & 0,0106 & $1,46 \times 10^{-4}$ & 3,08 \\
\hline
\end{tabular}

Tabla 3.3: Constantes del modelo matemático de Spiro y Jago, coeficientes de determinación $\left(R^{2}\right)$, raíces cuadradas del error cuadrático medio $(R M S D)$, valores de Chi-cuadrado $\left(x^{2}\right)$ y valores del error medio porcentual $(E M P)$ correspondientes a la extracción acuosa de ACG a partir de $\mathrm{PV}_{\mathrm{YM}}$.

\begin{tabular}{cccccccc}
\hline $\mathrm{T}\left({ }^{\circ} \mathrm{C}\right)$ & $\mathrm{Q}(\mathrm{g} / \mathrm{l})$ & $\mathrm{k}\left(\mathrm{min}^{-1}\right)$ & $\mathrm{a}$ & $R^{2}$ & $R M S E$ & $x^{2}$ & $E M P$ \\
\hline 30 & 0,197 & 1,29 & 0,0010 & 90,74 & 0,0207 & $6,90 \times 10^{-4}$ & 10,48 \\
40 & 0,382 & 0,21 & 0,14581 & 91,63 & 0,0371 & $2,21 \times 10^{-3}$ & 10,31 \\
65 & 0,391 & 0,43 & 0,1059 & 90,50 & 0,0350 & $1,75 \times 10^{-3}$ & 10,03 \\
80 & 0,410 & 0,384 & 0,1001 & 93,34 & 0,0338 & $1,71 \times 10^{-3}$ & 8,34 \\
100 & 0,375 & 0,918 & 0,0132 & 96,16 & 0,0236 & $8,36 \times 10^{-4}$ & 6,92 \\
\hline
\end{tabular}

El modelo de Pilosof fue desarrollado para describir la absorción de agua a partir de una matriz sólida; sin embargo, se ajustó muy bien a los resultados experimentales cuando se lo aplicó para describir la velocidad de liberación de compuestos solubles a partir de yerba mate (Sabatella y col., 2009). Por otra parte, el modelo de Spiro y Jago es similar 
a una pseudo ecuación de primer orden y fue aplicado con éxito a la extracción de sólidos a partir de yerba mate (Linares y col., 2010). Las Figuras 3.5 y 3.6 muestran los valores experimentales y predichos obtenidos con el modelo Pilosof y el modelo de Spiro y Jago, respectivamente. Los parámetros de estos modelos resultan apropiados para describir las curvas de extracción (concentración de ACG en función del tiempo de extracción). Las figuras muestran un buen ajuste de los datos experimentales con los datos predichos utilizando tanto el modelo de Pilosof como el de Spiro y Jago para la extracción sólido-líquido de ACG a partir de $\mathrm{PV}_{\mathrm{YM}}$.

\subsubsection{Optimización de la extracción mediante metodología de superficie de respuesta}

La extracción de $\mathrm{ACG}$ a partir de $\mathrm{PV}_{\mathrm{YM}}$ fue optimizada aún más a través del enfoque de la metodología de superficie de respuesta. Se evaluó el efecto combinado del tiempo y la temperatura de extracción en un rango más acotado establecido de acuerdo a los resultados obtenidos en la sección anterior (sección 3.3.2.). Se utilizó una relación $\mathrm{S} / \mathrm{L}$ de 1:20 (p/v) y las partículas de mayor tamaño $(1 \times 5 \mathrm{~mm}<\varnothing$ partícula $<2,5 \times 5 \mathrm{~mm})$. Se realizaron 9 ensayos a partir del diseño experimental de Doehlert, cuyos resultados se representan en la Tabla 3.4.

Tabla 3.4: Valores reales (datos experimentales) y concentración de ACG obtenidos en el diseño experimental de Doehlert para el estudio del tiempo y temperatura de extracción sobre la extracción de ACG a partir de $\mathrm{PV}_{\mathrm{YM}}$.

\begin{tabular}{cccc}
\hline Exp. $\mathrm{N}^{\circ}$ & $\mathrm{t}(\min )$ & $\mathrm{T}\left({ }^{\circ} \mathrm{C}\right)$ & $\mathrm{ACG}(\mathrm{g} / \mathrm{l})$ \\
\hline 1 & 30 & 65 & 0,414 \\
2 & 23,125 & 100 & 0,399 \\
3 & 9,375 & 100 & 0,380 \\
4 & 2,5 & 65 & 0,260 \\
5 & 9,375 & 30 & 0,194 \\
6 & 23,125 & 30 & 0,202 \\
7 & 16,25 & 65 & 0,387 \\
8 & 16,25 & 65 & 0,385 \\
9 & 16,25 & 65 & 0,384 \\
\hline
\end{tabular}

t: tiempo; T: temperatura. 
Los valores de la Tabla 3.4 fueron convertidos en una ecuación polinomial de segundo orden. Los valores de los coeficientes lineal, cuadrático y de interacción entre variables junto con sus respectivos niveles de significancia (calculados mediante ANOVA) se muestran en la Tabla 3.5.

Tabla 3.5: Valores de los coeficientes y nivel de significancia, calculados por ANOVA, obtenidos para el modelo cuadrático mediante el diseño experimental de Doehlert.

\begin{tabular}{ccc}
\hline & Coeficientes & $\boldsymbol{p}$ \\
\hline Constante & 0,385333 & \\
Temperatura & 0,110566 & 0,0001 \\
Tiempo & 0,0558333 & 0,0002 \\
Temperatura $^{2}$ & $-0,106006$ & 0,0002 \\
Tiempo $^{2}$ & $-0,0483333$ & 0,0008 \\
Temperatura $^{*}$ tiempo $^{2}$ & 0,00635104 & 0,0692 \\
\hline $\mathrm{R}^{2}=0,95$ & &
\end{tabular}

En la Figura 3.7 se presenta la superficie de respuesta y el gráfico de contorno obtenido para la extracción de $\mathrm{ACG}$ a partir de $\mathrm{PV}_{\mathrm{YM}}$ como una función de las dos variables independientes estudiadas (tiempo y temperatura de extracción).

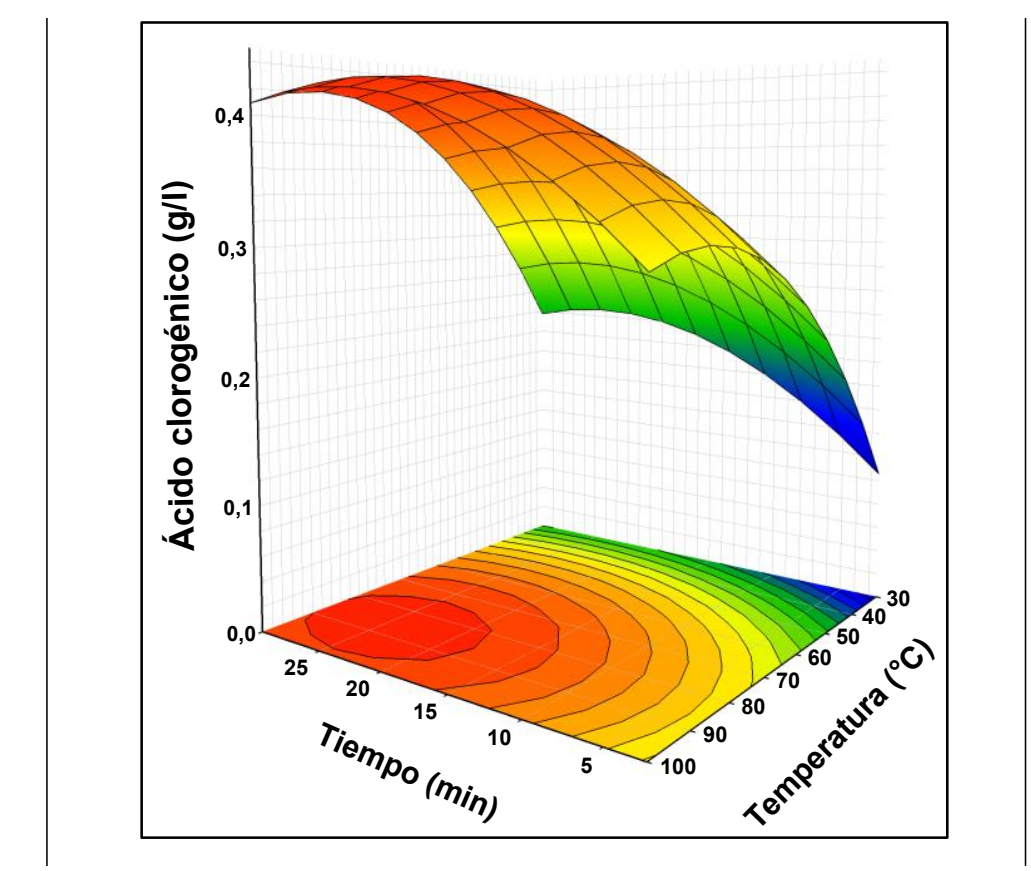

Figura 3.7: Superficie de respuesta y gráfico de contorno mostrando el efecto de la temperatura y el tiempo de extracción sobre la extracción de ACG a partir de $\mathrm{PV}_{\mathrm{YM}}$. 
El análisis estadístico de los resultados reveló que, en el rango estudiado, las dos variables analizadas mostraron un efecto cuadrático negativo (Tabla 3.5), indicando la existencia de un máximo como función de estas variables en el rango de 20-25 min y $80-90{ }^{\circ} \mathrm{C}$ (Fig. 3.7).

La ecuación polinomial estimada por el modelo presentó un muy buen ajuste a los datos experimentales $\left(\mathrm{R}^{2}=0,95\right)$. La superficie de respuesta y el gráfico de contorno construidos a partir del modelo de regresión (Fig. 3.7) muestran que hubo un aumento gradual en la extracción de ACG con el aumento simultáneo del tiempo y la temperatura de extracción. Sin embargo, se puede observar una tendencia a la disminución de la extracción de ACG cuando se utilizan largos tiempos de extracción y temperaturas por encima de $95^{\circ} \mathrm{C}$.

Basándose en los datos obtenidos en el presente estudio, las condiciones para maximizar la extracción de $\mathrm{ACG}$ a partir de los $\mathrm{PV}_{\mathrm{YM}}$ con un tamaño de partícula entre $1 \times 5 \mathrm{~mm}<$ $\varnothing$ partícula $<2,5 \times 5 \mathrm{~mm}$, podrían alcanzarse mediante el uso de una temperatura en el rango de 80-90 ${ }^{\circ} \mathrm{C}$ y un tiempo de extracción de 20-25 min, para obtener aproximadamente 0,43 g ACG/1 (dentro de los niveles estudiados).

Según Cacace y Mazza (2003), a mayor temperatura aumenta la solubilidad de los compuestos fenólicos, lo que permite una mayor tasa de extracción. Similarmente, Negrão Murakami y col. (2011) reportaron un aumentó en la extracción de polifenoles a partir de hojas de yerba mate al aumentar la temperatura de extracción. Bassani y col. (2014), quienes estudiaron la optimización de las condiciones de extracción de compuestos fenólicos a partir de hojas de yerba mate tostadas, reportaron que la mayor concentración de polifenoles se obtuvo a una temperatura de $90{ }^{\circ} \mathrm{C}$ y un tiempo de extracción de $10 \mathrm{~min}$.

\subsection{CONCLUSIONES}

En el presente estudio se estudió la influencia de varios factores que normalmente influyen en los procesos de extracción y se aplicaron técnicas de optimización y modelado a los efectos de estudiar el proceso de extracción acuosa de ACG a partir de $\mathrm{PV}_{\mathrm{YM}}$.

La extracción de ACG a partir de $\mathrm{PV}_{\mathrm{YM}}$ estuvo influenciada principalmente por la relación $\mathrm{S} / \mathrm{L}$, el tamaño de partícula y la temperatura de extracción. La relación $\mathrm{S} / \mathrm{L}$ 
óptima fue de 1:20 (p/v), a mayor relación disminuyó la extracción de ACG. El ACG extraído en las dos primeras etapas de extracción representó el 98,5\% del contenido total de ACG de las tres etapas. Teniendo en cuenta estos resultados, no resultó económicamente eficiente agregar una tercera etapa de extracción. A partir de la relación $\mathrm{S} / \mathrm{L}$ óptima se evaluó la cinética de extracción a $80{ }^{\circ} \mathrm{C}$ para los dos tamaños de partículas. El tiempo de extracción tuvo influencia significativa únicamente para las partículas de mayor tamaño, mientras que la mayor concentración de ACG (1,051 g ACG/l) fue extraída con partículas de menor tamaño, siendo en este caso el proceso de extracción prácticamente instantáneo.

Por lo tanto, para las partículas de menor tamaño (Ø partícula $<500 \mu \mathrm{m}$ ), se seleccionó un sistema de dos extracciones consecutivas, a $65{ }^{\circ} \mathrm{C}$ durante 5 min (extracción prácticamente instantánea), con una relación $\mathrm{S} / \mathrm{L}$ de 1:20 (p/v), para extraer la mayor parte del ACG presente en los $\mathrm{PV}_{\mathrm{YM}}$. Bajo estas condiciones se obtendría un extracto acuoso con un contenido de $\sim 1,25 \mathrm{~g} \mathrm{ACG} / 1$.

El estudió cinético de la extracción de ACG a partir de las partículas de mayor tamaño reveló que la concentración de ACG en el extracto aumentó con el tiempo de extracción hasta los 30 min para todas las temperaturas evaluadas, alcanzando luego de este tiempo la región asintótica. Asímismo la extracción de ACG aumentó con la temperatura de extracción hasta $\operatorname{los} 80^{\circ} \mathrm{C}$; sin embargo, un incremento adicional de la temperatura (100 ${ }^{\circ} \mathrm{C}$ ) condujo a una disminución de la extracción. Los modelos matemáticos aplicados mostraron una buena concordancia con los resultados experimentales $\left(\mathrm{R}^{2}>0,90\right)$, lo que permite su aplicación en el modelado del proceso de extracción sólido-líquido de ACG a partir de $\mathrm{PV}_{\mathrm{YM}}$.

El diseño de superficie de respuesta para la extracción de ACG a partir de las partículas de mayor tamaño, reveló que los valores óptimos para tiempo y temperatura de extracción fueron $25-30$ min y $80-90{ }^{\circ} \mathrm{C}$, respectivamente, alcanzando en este caso una concentración de ACG de 0,43 g ACG/l. 


\section{$2^{\circ}$ ETAPA}

Producción y caracterización de la enzima clorogenato hidrolasa (CHasa) a partir de hongos filamentosos
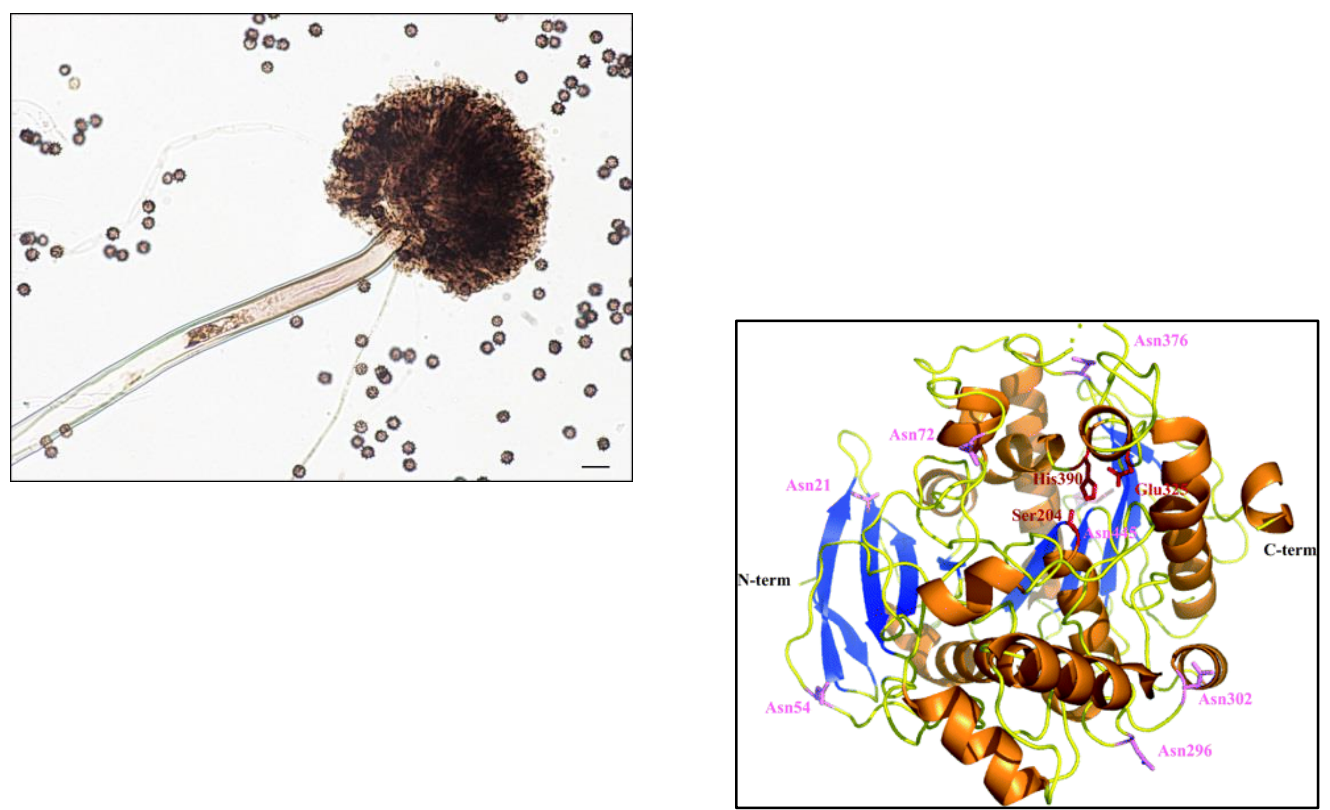


\section{Capítulo 4}

Produeción de elorogenato bidrolasa por hongos filamentosos 


\title{
CAPÍTULO 4 \\ PRODUCCIÓN DE CLOROGENATO HIDROLASA POR HONGOS FILAMENTOSOS
}

\begin{abstract}
Resumen
Se analizó la producción de la enzima clorogenato hidrolasa (EC 3.1.1.42, CHasa) por varias cepas fúngicas utilizando materiales derivados del procesamiento de la yerba mate (Ilex paraguariensis) como inductores de la actividad enzimática.

Se cultivaron diferentes cepas fúngicas (Aspergillus niger AKU 3302, A. sojae AKU 3312, A. kawachii IFO 4308, A. sydowii IFO 31296 y una cepa silvestre aislada de yerba mate) en frascos agitados con medio Czapek líquido modificado al cual se le adicionó extracto acuoso concentrado de yerba mate (EYM) como inductor al final de la etapa exponencial de crecimiento. Luego se examinó el efecto de diferentes materiales derivados del procesamiento de la yerba mate como inductores de actividad CHasa: mate cocido instantáneo sin malto dextrina (-MD) y con malto dextrina ( $+\mathrm{MD})$, polvo de yerba mate (PD, residuo de la elaboración de yerba mate) y EYM (todos provistos por La Cachuera S.A., Argentina). Posteriormente, se estudió el efecto del agregado de diferentes concentraciones del inductor preseleccionado $(0,0625$ a $2 \%, \mathrm{p} / \mathrm{v}$ en base seca), adicionado a un tiempo de inducción fijo (24 h), sobre la producción de CHasa. Se optimizó la producción enzimática mediante la metodología de superficie de respuesta. Los factores estudiados fueron: concentración del inductor $(0,1$ a $2 \%, \mathrm{p} / \mathrm{v}$ en base seca) y tiempo de inducción (11 a $33 \mathrm{~h})$. El micelio obtenido en cada experiencia fue separado, lavado y desintegrado en buffer fosfato de sodio (BFS, pH: 6,5). La suspensión resultante fue centrifugada y el sobrenadante obtenido fue utilizado como fuente de CHasa. La actividad CHasa se evaluó semi-cuantitativamente por TLC y espectrofotométricamente a $350 \mathrm{~nm}$, utilizando ácido clorogénico (ACG) como sustrato. La desaparición del ACG y la aparición de ácido cafeico (AC) en el TLC fueron examinadas bajo luz UV.

Todas las cepas fúngicas ensayadas presentaron actividad CHasa. Sin embargo, la enzima fue altamente inducida en los micelios de A. niger AKU 3302, observándose las manchas más intensas de AC en el TLC con las concomitantes reducciones en ACG, y el valor de actividad más elevado $(6,49 \mathrm{UE} / \mathrm{ml})$. Todas las muestras de yerba mate produjeron actividad CHasa, pero el EYM fue seleccionado como el inductor más conveniente. El diseño experimental reveló que la producción óptima de CHasa $(\approx 12 \mathrm{UE} / \mathrm{ml})$ se alcanza a largos tiempos de inducción $(\geq 25 \mathrm{~h})$ y bajas concentraciones de inductor $(0,1-0,2 \% \mathrm{p} / \mathrm{v}$, en base seca).

Los presentes resultados confirmaron que la yerba mate es un potente inductor de la actividad de CHasa fúngica. A. niger AKU 3302 exhibió la mayor actividad CHasa y el EYM a bajas concentraciones y largos tiempos de inducción resultó ser el inductor más conveniente entre los diferentes materiales derivados de la yerba mate evaluados.
\end{abstract}

\subsection{INTRODUCCIÓN}

Los ácidos hidroxicinámicos se encuentran ampliamente distribuidos en la naturaleza, particularmente en los tejidos vegetales. Algunos de ellos, tales como los ácidos ferúlico y $p$-cumárico, existen como compuestos insolubles, generalmente en forma de ésteres ligados a restos de glucosa, y se cree que juegan un papel importante en la estructura de la pared celular de los vegetales. Los ácidos hidroxicinámicos también existen como 
ésteres solubles conjugados de ácido quínico (AQ); el conjugado más conocido se denomina ácido clorogénico (ACG, ácido 5-O-cafeoilquínico, 5-CQA). Los isómeros del ACG incluyen el ácido 4-O-cafeoilquínico (ácido criptoclorogénico, 4-CQA) y el ácido 3-O-cafeoilquínico (ácido neoclorogénico, 3-CQA). Otros compuestos estrechamente relacionados contienen dos residuos de ácido cafeico (ácidos dicafeoilquínicos, di-CQA) y se denominan ácidos isoclorogénicos (3,4-diCQA, 3,5diCQA y 4,5-diCQA). Actualmente, el término ACG es el nombre trivial utilizado para describir la mezcla de al menos 5 de estos isómeros. El ACG está presente en altas concentraciones en manzanas, peras, berenjenas, tomates, arándanos, fresas y tubérculos como la batata y la papa, y principalmente en la pulpa de café, en particular en los granos de café verde, material que es considerado a la fecha como la fuente natural más importante de ACG (Clifford, 1999, 2000).

La hidrólisis del ACG produce cantidades estequiométricas de AQ y ácido cafeico (AC). El AC, ampliamente utilizado debido a su reconocida capacidad antioxidante, es obtenido a partir de vegetales ricos en compuestos polifenólicos. El AC tiene una elevada capacidad antioxidante, con múltiples mecanismos que involucran la captación de radicales libres, la quelación de iones metálicos, y un efecto inhibitorio sobre algunas enzimas específicas implicadas en la formación de radicales libres (Chen y Ho, 1997; Stanely Mainzen Prince y Senthil Kumaran, 2012).

Por otro lado, el AQ comercial se obtiene en cantidades limitadas a partir de corteza de quina, granos de café y otros productos vegetales. La producción de AQ ha recibido menor atención respecto a la de AC debido a su limitada utilización. Sin embargo, el AQ es considerado un intermediario clave en la síntesis de nuevos fármacos. Se ha reportado que el $\mathrm{AQ}$ es fácilmente convertido a ácido siquímico (ASK) vía 3dehidroquinato y 3-dehidrosiquimato, mediante la acción de enzimas de bacterias acéticas (Adachi y col., 2006a,b,c; Adachi y col., 2008b). El ASK es un precursor directo de la síntesis química de la droga antiviral Oseltamivir, el principio activo del Tamiflú $^{\mathrm{MR}}$ (Enserink, 2006). Por lo tanto, resulta importante desarrollar un proceso alternativo para la producción competitiva de AQ para su posterior conversión en químicos finos valiosos, como el ASK.

Una alternativa a la producción de AQ lo constituye el tratamiento ácido de vegetales ricos en ACG. Este método produce, además del $\mathrm{AC}$ y $\mathrm{AQ}$, una proporción 
relativamente alta de sub-productos, siendo necesario un proceso adicional de aislamiento y purificación muy laborioso y costoso, además de generar residuos altamente contaminantes difíciles de ser tratados adecuadamente antes de su disposición final (Adachi y col., 2008). Por lo tanto, resulta conveniente desarrollar un método alternativo para la obtención de AQ y AC a partir del ACG contenido en materiales vegetales ricos en este compuesto, que resulte en una producción más limpia y competitiva respecto a la hidrólisis ácida. En este sentido, las enzimas que permiten la liberación de estos compuestos son de especial interés debido a sus potenciales aplicaciones industriales.

Clorogenato hidrolasa (CHasa, EC 3.1.1.42) es el nombre sistemático de una enzima que cataliza la hidrólisis del ACG, formando AQ y AC. Esta enzima pertenece a la familia de las hidrolasas, específicamente a aquellas que actúan sobre los enlaces éster carboxílicos. Otros nombres de uso común incluyen clorogenasa y esterasa de ácido clorogénico. También actúa, más lentamente, sobre los ácidos isoclorogénicos. No se conocen otros sustratos.

Hay pocos datos en la literatura respecto a la hidrólisis enzimática del ACG. Schöbel y Pollmann (1980a,b) aislaron y caracterizaron una CHasa tetramérica a partir de una preparación de enzima pectinolítica de Aspergillus niger. Una hidroxicinamato éster hidrolasa fue purificada a partir A. japonicus por Okamura y Watanabe (1982b). Barbe y Dubourdieu (1998) aislaron una cinamato esterasa a partir de una preparación de pectinasa industrial de A. niger capaz de hidrolizar ACG. Luego, Couteau y col. (2001) demostraron la capacidad de las bacterias del colon humano para producir actividad esterasa capaz de actuar sobre el ACG. La purificación y caracterización de una nueva CHasa de A. niger BRFM 131 fue reportada por Asther y col. (2005). Estos autores demostraron la eficacia de la enzima para liberar AC a partir de subproductos agroindustriales naturales. La identificación, aislamiento y caracterización del primer gen que codifica para la CHasa fue reportado por Benoit y col. (2007). Adachi y col. (2008) han desarrollado un proceso práctico para la producción de AC y AQ a partir de fuentes vegetales ricas en ACG. Ellos prepararon y caracterizaron un catalizador microbiano inmovilizado con elevada actividad CHasa, basado en la inducción de la enzima mediante el agregado de pulpa de café y/o café instantáneo. 
Varios sustratos han sido utilizados como componentes del medio de cultivo para la producción de CHasa. La mayoría de ellos son polisacáridos complejos tales como salvado de trigo, subproductos derivados de procesos agroindustriales, pulpa de remolacha azucarera, xilano de avena y materiales derivados del café. Se considera que estos polisacáridos contienen compuestos esterificados en concentraciones suficientemente elevadas capaces de inducir la producción de CHasa por el microorganismo. En este sentido, los materiales derivados del café parecen contener la mayor concentración de ACG lo que resultaría en una alta inducción de la enzima. Además, diferentes sistemas de cultivo, tales como fermentaciones en sustrato sólido, así también como en cultivos líquidos conteniendo sólidos insolubles en suspensión, han sido utilizados empleando los sustratos mencionados anteriormente.

La yerba mate (Ilex paraguariensis St. Hil., Aquifoliaceae) es una de las especies de América del Sur más empleadas en forma de decocción o infusión debido a sus propiedades nutricionales y medicinales (tónica, colerética, diurética, antirreumática, etc.). Los principales países productores de yerba mate son: Argentina ( $\approx 60 \%$ de la producción mundial lo que representa unas 750.000 ton/año en promedio), Brasil y Paraguay. Actualmente, esta especie se exporta a Europa, EE.UU., Siria y a los países de Asia del Este, donde es comercializada tanto en forma de droga vegetal como de extracto. El proceso de producción de la yerba mate implica las etapas de cosecha, zapecado, secado, molienda, estacionamiento y envasado. El proceso de industrialización puede variar entre las industrias, aunque el procedimiento es básicamente el mismo (Isolabella y col., 2010).

La composición química de la yerba mate, particularmente en relación a sus compuestos bioactivos, ha sido reportada por diferentes autores. Se han identificado y cuantificado diferentes derivados del ácido cafeico en cantidades significativas en los extractos obtenidos por decocción de muestras de yerba mate; entre otros, el ACG incluyendo los diferentes isómeros del ácido isoclorogénico (3,4-diCQA, 3,5-diCQA y 4,5-diCQA) (Heck y Gonzalez De Mejia, 2007). Debido a sus estructuras químicas estrechamente relacionadas, todas estas sustancias podrían ser consideradas como posibles inductores de la actividad CHasa. Además, el contenido en sustancias lipídicas y compuestos polifenólicos coloreados de la yerba mate es más bajo que en los productos derivados del café. Por lo tanto, este factor hizo presumir que la yerba mate podría ser una 
novedosa y competitiva alternativa a los productos del café para una efectiva inducción de la actividad CHasa.

El objetivo del presente Capítulo fue evaluar el uso de diferentes muestras derivadas del procesamiento de la yerba mate como inductores de la actividad CHasa en algunas cepas de hongos previamente reportados como productores de CHasa.

\subsection{MATERIALES Y MÉTODOS}

\subsubsection{Selección de hongos filamentosos como fuentes potenciales de CHasa}

Diferentes hongos filamentos fueron preseleccionados y crecidos en medio Czapek líquido modificado a los efectos de determinar cuál de ellos producía la mayor actividad CHasa.

\subsubsection{Materiales y reactivos químicos:}

Los ácidos clorogénico (ACG) y cafeico (AC) fueron productos de Sigma-Aldrich (St. Louis, EE.UU.). Las placas de sílica gel para cromatografía en capa fina (TLC) fueron un producto de Merck (TLC Silicagel 60, Lote: 60 F254, Darmstadt, Alemania). Todos los demás reactivos empleados fueron comercialmente disponibles y de grado analítico. El extracto concentrado de yerba mate (EYM) fue preparado en instalaciones de La Cachuera S.A. (Misiones, Argentina) como se detalla a continuación. La materia prima, hojas de yerba mate canchada y estacionada, fue molida y clasificada por tamizado con objeto de remover aquellas partículas de granulometría muy pequeña que pudieran provocar taponamiento en los filtros. La extracción de los compuestos solubles de la yerba mate se realizó en un recipiente extractor de acero inoxidable (con agitación) mediante el agregado de $10 \mathrm{~kg}$ de hojas de yerba mate a 451 de agua caliente $\left(80^{\circ} \mathrm{C}\right)$. La mezcla se mantuvo por un lapso de $10 \mathrm{~min}$ con agitación obteniéndose un extracto con una concentración de sólidos solubles de $\approx 5 \%(\mathrm{p} / \mathrm{v})$. Luego, el extracto obtenido fue bombeado a través de un filtro de cartuchos de celulosa equipado con un separador de partículas $(\varnothing>5 \mu \mathrm{m})$. El filtrado resultante se concentró en un evaporador a presión reducida $(600 \mathrm{mmHg})$ hasta alcanzar una concentración de sólidos solubles de $\approx 25 \%$ $(\mathrm{p} / \mathrm{v})$. 


\subsubsection{Microorganismos:}

Se utilizaron cepas de Aspergillus niger AKU 3302, A. sojae AKU 3312, A. kawachii IFO 4308 y A. sydowii IFO 31296 Las cepas AKU fueron generosamente provistas por el Profesor J. Ogawa, Universidad de Kyoto, Japón. Una cepa silvestre (CS), aislada en nuestro laboratorio a partir de un cultivo sólido de yerba mate, fue también examinada. Las cepas fueron conservadas en forma de esporas a $-70{ }^{\circ} \mathrm{C}$ en una solución crioprotectora compuesta por leche descremada (5\%) y glicerol $(10 \%)$.

\subsubsection{Medios de cultivos:}

Medio de crecimiento (agar Czapek modificado, ACM): sacarosa, 25 g/l; $\mathrm{NaNO}_{3}, 2 \mathrm{~g} / \mathrm{l}$; $\mathrm{K}_{2} \mathrm{HPO}_{4}, 1 \mathrm{~g} / \mathrm{l} ; \mathrm{MgSO}_{4}, 0,5 \mathrm{~g} / \mathrm{l}$; agar, $15 \mathrm{~g} / \mathrm{l}$; extracto de levadura (Britania, Argentina), $3 \mathrm{~g} / \mathrm{l}$. Se ajustó el $\mathrm{pH} \sim 7$.

Medio de producción (Czapek líquido modificado, CLM): cuya composición fue la misma que la del medio de crecimiento, pero con sacarosa, $5 \mathrm{~g} / \mathrm{l}$ y sin el agregado de agar.

\subsubsection{Inóculo:}

A partir del hongo desarrollado en $\mathrm{ACM}$ a $30^{\circ} \mathrm{C}$, durante 7-10 días, se preparó una suspensión de esporos en Tween 80 al 0,01 \% de manera de obtener la concentración final requerida $\left(10^{6}\right.$ esporas $/ \mathrm{ml}$ de medio). El recuento del número de esporos se realizó en cámara de Neubauer modificada.

\subsubsection{Producción de CHasa:}

Se inocularon frascos Erlenmeyers de $1000 \mathrm{ml}$ conteniendo $100 \mathrm{ml}$ de medio CLM con la suspensión de esporas de modo de obtener una concentración final de $10^{6}$ esporas $/ \mathrm{ml}$ de medio. Los mismos se incubaron a $30^{\circ} \mathrm{C}$ en baño termostatizado rotatorio (New Brunswick, modelo 676; 1,27 cm de excentricidad) a $180 \mathrm{rpm}$. El contenido de sacarosa fue evaluado periódicamente en los sobrenadante del cultivo. Luego del agotamiento de la sacarosa (fase estacionaria de crecimiento $\approx 24 \mathrm{~h}$ de cultivo), se adicionó $0,5 \%$ (p/v, en base seca) del EYM como inductor de la actividad CHasa y el cultivo se continuó por $24 \mathrm{~h}$. La biomasa obtenida fue separada por filtración, mediante filtro de fibra de vidrio $(0,45 \mu \mathrm{m}$ tamaño de poro, E04WP04700, MSI, USA) y lavada varias veces con exceso 
de agua destilada. El exceso de agua fue removido cuidadosamente y se midió inmediatamente el peso húmedo de la biomasa fúngica. Luego, una fracción de biomasa fúngica húmeda se separó, pesó y utilizó para la determinación del peso seco (hasta peso constante a $80{ }^{\circ} \mathrm{C}$ ). La biomasa húmeda restante fue desintegrada en un mortero con adición de $2 \mathrm{mM}$ de buffer fosfato de sodio (BFS), pH 7,0 (relación: $1 \mathrm{~g}$ de biomasa húmeda $+2 \mathrm{ml}$ de buffer). La suspensión resultante fue centrifugada a $10.000 \times g$ durante $25 \mathrm{~min}$, a $5{ }^{\circ} \mathrm{C}$. Luego, el sobrenadante obtenido, designado como extracto crudo (EE), fue mantenido a $-20^{\circ} \mathrm{C}$ hasta su utilización como fuente de enzima.

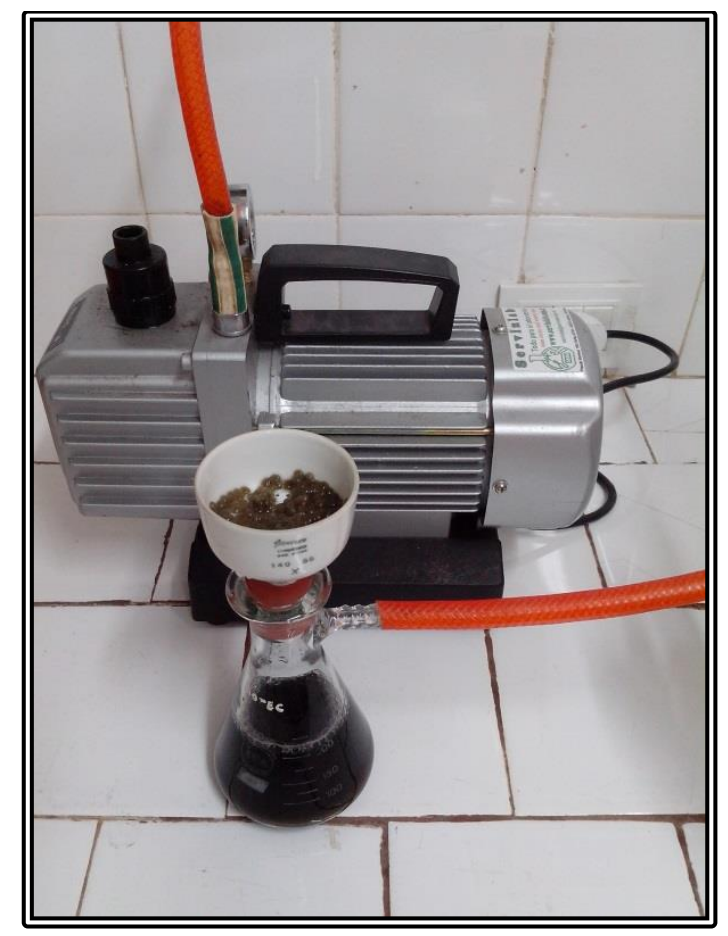

Figura 4.1: Biomasa fúngica obtenida al final de un cultivo que fue lavada y separada por filtración.

\subsubsection{Efecto de diferentes muestras de yerba mate (Ilex paraguariensis) como inductores de CHasa}

Se evaluaron diferentes materiales derivados del procesamiento de la yerba mate como inductores de la actividad CHasa, utilizando la cepa seleccionada en la etapa anterior. Posteriormente, se determinó el contenido de ACG en cada uno de los materiales utilizados como inductor de la actividad enzimática. 


\subsubsection{Materiales y reactivos químicos:}

Se utilizaron los materiales y reactivos químicos descriptos en 4.2.1.1. Para la determinación del contenido de ACG se utilizaron, además, los siguientes reactivos: agua (Panreac, grado HPLC), ácido fórmico (Tedia, $96 \%$ de pureza y grado HPLC) y acetonitrilo (J.T. Baker, grado HPLC).

Las diferentes muestras de yerba mate fueron provistas por La Cachuera S.A. (Misiones, Argentina) y tentativamente caracterizadas como se detalla a continuación: Mate cocido instantáneo con maltodextrina ( $+\mathrm{MD})$, Mate cocido instantáneo sin maltodextrina (-MD); Polvo de yerba mate (PD, residuo de la elaboración de yerba mate) y EYM (previamente descrito en 4.2.1.1.). Las muestras solubles (-MD y +MD) fueron preparadas como se detalla a continuación. El EYM obtenido fue bombeado mediante una bomba dosificadora a un secadero en spray (las temperaturas del aire de secado y del aire de escape fueron $190{ }^{\circ} \mathrm{C}$ y $90{ }^{\circ} \mathrm{C}$, respectivamente). Finalmente, se recogió un polvo seco (-MD) con un contenido de humedad del $3 \%$ en un separador ciclónico. Para preparar $+\mathrm{MD}$, se agregó una cantidad suficiente de maltodextrina (agente dispersante) al EYM con el fin de lograr una concentración de sólidos solubles de $\approx 40 \%(\mathrm{p} / \mathrm{v})$ y luego se secó por pulverización como se mencionó anteriormente. Esta preparación final $(+\mathrm{MD})$, denominada mate cocido instantáneo, está disponible comercialmente en nuestro país.

\subsubsection{Microorganismo:}

Se utilizó la cepa seleccionada en la sección 4.2.1.

\subsubsection{Producción de CHasa:}

Se cultivó la cepa previamente seleccionada bajo las mismas condiciones descriptas en 4.2.1.5. Luego del agotamiento de la sacarosa ( $\approx 24 \mathrm{~h}$ de cultivo), se adicionó $0,25 \%$ $(\mathrm{p} / \mathrm{v}$, base seca) de cada material derivado de la yerba mate al medio de cultivo como inductor de la actividad CHasa. El cultivó se continuó por 24 h y el EE fue preparado como se describió previamente para el posterior ensayo de la actividad enzimática. 


\subsubsection{Efecto de la concentración del inductor sobre la producción de CHasa}

A partir del inductor seleccionado en la etapa anterior, se evaluó el efecto de la concentración del inductor sobre la actividad CHasa.

\subsubsection{Microorganismo:}

Se utilizó la cepa seleccionada en la etapa 4.2.1.

\subsubsection{Producción de CHasa:}

Se cultivó la cepa previamente seleccionada en 4.2.1. bajo las mismas condiciones descriptas en 4.2.1.5. Luego del agotamiento de la sacarosa ( $\approx 24 \mathrm{~h}$ de cultivo), el inductor previamente seleccionado fue adicionado al cultivo en diferentes concentraciones: 0,$0625 ; 0,125 ; 0,25 ; 0,50 ; 1,0$ y $2,0 \%$ (p/v, base seca). Los cultivos fueron incubados bajo las mismas condiciones durante un tiempo de inducción fijo de 24 h. El EE del micelio fue obtenido como se describió previamente y mantenido a $20^{\circ} \mathrm{C}$ hasta su utilización como fuente de enzima.

\subsubsection{Condiciones óptimas para la producción de CHasa mediante un diseño experimental}

Se aplicó la metodología de superficie de respuesta para evaluar el efecto simultáneo de la concentración del inductor y el tiempo de inducción sobre la producción de CHasa por la cepa seleccionada en las etapas anteriores.

\subsubsection{Microorganismo:}

Se utilizó la cepa seleccionada en la sección 4.2.1.

\subsubsection{Producción de CHasa:}

Se cultivó la cepa previamente seleccionada bajo las mismas condiciones descriptas en 4.2.1.5. Luego del agotamiento de la sacarosa $(\approx 24 \mathrm{~h}$ de cultivo), el inductor previamente seleccionado fue adicionado en diferentes concentraciones $(0,1$ a $2 \% \mathrm{p} / \mathrm{v}$, base seca) según el diseño experimental planteado. Luego, los cultivos fueron incubados bajo las mismas condiciones durante diferentes tiempos de inducción (11 a 33 h) según 
el diseño experimental. El EE del micelio fue obtenido como se describió previamente y mantenido a $-20{ }^{\circ} \mathrm{C}$ hasta su utilización como fuente de enzima.

\subsubsection{Análisis estadístico:}

Se aplicó la metodología de superficie de respuesta mediante un diseño experimental de Doehlert (Doehlert, 1970; Légier and Comeau, 1992) para evaluar el efecto simultáneo de la concentración del inductor $(0,1$ a $2 \%$ p/v, base seca) y el tiempo de inducción (11 a 33 h) sobre la producción de CHasa. Las técnicas multivariadas son muy importantes porque son útiles para estudiar diferentes variables y el efecto de sus interacciones. A su vez, permiten la optimización simultánea de las variables estudiadas y, por lo tanto, son más económicas y efectivas. En el diseño experimental seleccionado, el número de experiencias requeridas está dado por $\mathrm{N}=\mathrm{n} * 2+\mathrm{n}+\mathrm{n}_{0}$, donde $\mathrm{n}$ es el número de variables y $\mathrm{n}_{0}$ es el número de puntos centrales. En nuestro caso, el valor de $\mathrm{n}_{0}$ se fijó a 3; por lo tanto, con dos variables (tiempo de inducción y concentración del inductor), el número total de puntos de la matriz de Doehlert fue de 9. Las repeticiones en el nivel central se realizan con objeto de validar el modelo a los datos experimentales y determinar el error experimental. Para optimizar la inducción de la actividad CHasa, los valores en el nivel central fueron fijados a $22 \mathrm{~h}$ y $1,05 \%(\mathrm{p} / \mathrm{v}$, base seca) del inductor previamente seleccionado. Los valores reales de las variables independientes fueron codificados utilizando la siguiente función lineal:

$$
X=Z \times \frac{\Delta X}{\Delta Z}+X_{0} \quad \text { ec. } 4.1
$$

donde $X_{0}$ y $Z$ son los valores real y codificado del punto central, respectivamente, y $\Delta X$ y $\Delta Z$ son la diferencia entre el valor más alto y el más bajo de los valores reales y codificados, respectivamente.

En la Tabla 4.1 se presenta la matriz utilizada en el diseño experimental de Doehlert. 
Tabla 4.1: Valores codificados y reales utilizados en el diseño experimental de Doehlert.

\begin{tabular}{cccccc}
\hline \multirow{2}{*}{ Exp. $\mathrm{N}^{\circ}$} & \multicolumn{2}{c}{ Valores codificados } & & \multicolumn{2}{c}{ Valores reales } \\
\cline { 2 - 3 } \cline { 5 - 6 } & EYM \% (p/v) & Tiempo (h) & & EYM \% (p/v) & Tiempo (h) \\
\hline 1 & 1 & 0 & & 2 & 22 \\
2 & 0,5 & $-0,866$ & & 1,525 & 11 \\
3 & $-0,5$ & $-0,866$ & & 0,575 & 11 \\
4 & -1 & 0 & & 0,1 & 22 \\
5 & $-0,5$ & 0,866 & & 0,575 & 33 \\
6 & 0,5 & 0,866 & & 1,525 & 33 \\
7 & 0 & 0 & & 1,05 & 22 \\
8 & 0 & 0 & & 1,05 & 22 \\
9 & 0 & 0 & & 1,05 & 22 \\
\hline
\end{tabular}

EYM: extracto acuoso concentrado de yerba mate.

El análisis de regresión múltiple basado en el método de los mínimos cuadrados fue desarrollado utilizando el software Mathcad 2001.

Por simplicidad se utilizó un modelo cuadrático completo que contiene seis coeficientes para describir la respuesta observada.

$$
Y=b_{0}+\sum b_{i} x_{i}+\sum b_{i} x_{i i}^{2}+\sum b_{i j} x_{i} x_{j} \quad \text { ec. } 4.2
$$

donde $\mathrm{Y}$ es la variable respuesta, $b_{0}$ una constante, $\mathrm{y}, b_{i}, b_{i i}$, y $b_{i j}$ son los coeficientes de los efectos lineal, cuadrático y de interacción, respectivamente.

El orden de los experimentos se seleccionó al azar, lo que proporcionó protección contra efectos de las variables indeseables. Los experimentos se desarrollaron por triplicado y los resultados fueron presentados como promedio \pm desvío estándar.

Los resultados se analizaron aplicando un programa estadístico Statgraphics Centurion XV (Freund y Wilson, 1997). 


\subsubsection{Determinaciones analíticas}

\subsubsection{Determinación de la actividad clorogenato hidrolasa:}

La actividad CHasa del EE se determinó espectrofotométricamente de acuerdo al método de Okamura y Watanabe (1982a) con algunas modificaciones.

Sustrato: ACG (Sigma), 1,5 mM en buffer fosfato de sodio (BFS) $50 \mathrm{mM}, \mathrm{pH}$ 6,5.

Procedimiento: La solución de sustrato $(250 \mu \mathrm{l})$ y $15 \mu \mathrm{l}$ de la de enzima fueron incubadas en baño termostatizado a $30{ }^{\circ} \mathrm{C}$ durante $10-15$ min. Posteriormente, la reacción fue terminada con $5 \mathrm{ml}$ de metanol al $80 \%$. Se determinó espectrofotométricamente el cambio de absorbancia a $350 \mathrm{~nm}$, consecuentemente, la cantidad equivalente de ACG hidrolizado durante la reacción. El blanco de la reacción se realizó con la enzima inactivada térmicamente $\left(5 \mathrm{~min}, 100{ }^{\circ} \mathrm{C}\right)$. La actividad fue calculada como UE/ml.

Cálculo de actividad CHasa (UE/ml):

$$
\operatorname{CHasa}(U E / m l)=\frac{\Delta D O}{t(\min )} * * \frac{1000}{\varepsilon * b} * \frac{V_{F}}{V_{I}}
$$

donde:

$\triangle D O$ : cambio de absorbancia a $350 \mathrm{~nm}$.

$t$ : tiempo de reacción en min.

$\varepsilon$ : coeficiente de extinción molar del ACG $\left(\varepsilon_{\mathrm{ACG}}=7200 \mathrm{~mol}^{-1} \mathrm{1}^{-1} \mathrm{~cm}^{-1}\right)$.

$b$ : espesor de la cubeta en $\mathrm{cm}$.

$V_{F}$ : volumen total de reacción en $\mathrm{ml}$.

$V_{I}$ : volumen de muestra en el ensayo en $\mathrm{ml}$.

Una diferencia en absorbancia a $350 \mathrm{~nm}$ de 1 es equivalente al consumo de 0,14 mol de ACG basado en el coeficiente de extinción molecular $\left(\varepsilon_{\mathrm{CGA}}=7200 \mathrm{~mol}^{-1} \mathrm{l}^{-1} \mathrm{~cm}^{-1}\right)$. El AC no mostró una absorbancia a $350 \mathrm{~nm}$ apreciable.

La unidad de actividad CHasa se definió como la cantidad de enzima que hidroliza 1 $\mu \mathrm{mol}$ de ACG por min bajo las condiciones de ensayo.

Todas las determinaciones se realizaron por triplicado y los resultados fueron presentados como promedio \pm desvío estándar. 


\subsubsection{Determinación del contenido de ACG en los inductores de la actividad CHasa:}

Se determinó el contenido de humedad y, consecuentemente, el peso seco de todas las muestras de yerba mate (EYM, -MD, +MD y PD), secando las mismas en una estufa convectiva, a $103 \pm 2{ }^{\circ} \mathrm{C}$ durante $6 \mathrm{~h}$, tiempo en el cual se alcanza peso constante (Norma IRAM 20503). Las determinaciones se realizaron por duplicado. El contenido de ACG fue determinado mediante un sistema de cromatografía líquida de alta resolución (HPLC) utilizando un método adaptado de Bravo y col. (2006) y se expresó como g/100 g muestra seca (\% ms). Las muestras solubles (50 mg) fueron disueltas en 5 $\mathrm{ml}$ de agua. En el caso de PD, las muestras fueron extraídas con $5 \mathrm{ml}$ de agua caliente $\left(95{ }^{\circ} \mathrm{C}\right)$ durante $10 \mathrm{~min}$, con agitación constante. Concluido el tiempo de extracción y luego de alcanzar la temperatura ambiente, la mezcla fue centrifugada (15 min; 6.000 $\mathrm{rpm}$ ), el sobrenadante fue recolectado y el volumen del mismo fue ajustado (a $5 \mathrm{ml}$ con agua destilada). El paso de extracción se repitió una vez más sobre el sólido remanente en las mismas condiciones antes descritas. Finalmente, se determinó el contenido de ACG en los sobrenadantes. El análisis se llevó a utilizando un equipo Shimadzu Prominence, equipado con un autosampler Shimadzu SIL-20 A HT y un detector de arreglo de diodos UV/VIS Shimadzu SPD-M20A. Las muestras (20 $\mu 1)$ se inyectaron en el sistema de HPLC y la separación se realizó en una columna de fase reversa C18 Phenomenex Prodigy ODS3 (250 $\mathrm{mm} \times 4,6 \mathrm{~mm}, 5 \mu \mathrm{m}$ de tamaño de partícula) protegida con un guarda columna de fase reversa C18 de la misma marca. La columna se mantuvo a una temperatura de $30{ }^{\circ} \mathrm{C}$ y la velocidad del flujo varió entre 1-1,2 $\mathrm{ml} / \mathrm{min}$. El gradiente binario estuvo compuesto por ácido fórmico al $1 \%$ en agua deionizada (solvente A) y acetonitrilo (solvente B). El gradiente de HPLC comenzó con un $10 \%$ de solvente $\mathrm{B}$, que incrementó linealmente hasta un $17,5 \%$ en $15 \mathrm{~min}$, luego se llevó a un $30 \%$ de solvente $\mathrm{B}$ en 2 min y se mantuvo así por $8 \mathrm{~min}$, y, finalmente, se incrementó linealmente a un $10 \%$ de solvente $\mathrm{B}$ en el último minuto. El detector de arreglo de diodos fue ajustado a $326 \mathrm{~nm}$. La identificación del ACG se llevó a cabo por comparación de los picos con el tiempo de retención del compuesto estándar cuando corresponda, la absorbancia a $326 \mathrm{~nm}$ (máxima para el ACG), la comparación del espectro obtenido a 250-400 nm y los patrones de elución con la literatura (Carini y col., 1998; Fang y col., 2002; Bravo y col., 2006). 
La concentración del ACG en las muestras de yerba mate fue calculada utilizando una curva de calibración del compuesto estándar disponible comercialmente $\left(y=6 \times 10^{8} x-\right.$ $\left.18511, \mathrm{R}^{2}=1\right)$.

\subsubsection{Determinación de sacarosa:}

El contenido de sacarosa en los sobrenadantes de cultivos se evaluó después de la hidrólisis ácida con $\mathrm{HCl}$ concentrado $(0,125 \%$ v/v) durante 15 min en un baño de agua hirviendo, seguido de la neutralización del $\mathrm{pH}$ mediante el agregado de $\mathrm{NaHCO}_{3}$ (sólido). La glucosa liberada a partir de la sacarosa se determinó con un kit comercial de glucosa oxidasa/peroxidasa (Wiener, Argentina), contra un blanco sin hidrólisis (Bergmeyer y Bernt, 1974).

\subsubsection{Cromatografia en capa fina (TLC):}

La medida semi-cuantitativa de la actividad CHasa se realizó por cromatografía en capa fina (TLC) chequeando la aparición de AC y la desaparición de ACG.

Procedimiento: La reacción enzima-sustrato se realizó bajo las mismas condiciones descriptas en 4.2.5.2. Luego de inactivar la mezcla de reacción en un baño de aguahielo, una alícuota de la muestra $(12 \mu \mathrm{l})$ fue sembrada en placas comerciales de aluminio (sílica gel 60 GF 254, Merck) de $10 \mathrm{~cm} \times 10 \mathrm{~cm} \times 0,25 \mathrm{~mm}$. La cromatografía fue realizada mediante la técnica ascendente empleando un sistema formado por $\mathrm{n}$ butanol: ácido acético: agua (4:2:1 v/v/v). Como patrón se utilizó ACG comercial.

La hidrólisis del ACG por acción de la enzima CHasa produce cantidades equimolares de ácido cafeico (AC) y ácido quínico (AQ). La desaparición del ACG y la aparición de ácido cafeico (AC) fueron examinadas bajo luz UV. El ACG y el AC presentan valores de $\mathrm{Rf}$ de 0,88-0,89 y 0,72-0,74, respectivamente, bajo las condiciones de ensayo. La determinación de AQ no es posible por observación bajo luz UV ya que dicha sustancia no presenta ninguna estructura fenólica en su molécula. No obstante su localización aproximada se realizó considerando que posee un valor de $\mathrm{Rf}$ de 0,15 en las condiciones experimentales empleadas (Adachi y col., 2006a). 


\subsection{RESULTADOS Y DISCUSIÓN}

\subsubsection{Preselección de hongos filamentosos como fuentes potenciales de CHasa}

La elección de un sustrato apropiado es de gran importancia para la producción de cualquier enzima inducible. En la mayoría de los casos reportados, el sustrato utilizado para la producción de esterasas fúngicas es el principal componente del medio de cultivo estando presente desde el comienzo del cultivo. Por lo tanto, no sólo sirve como una fuente de carbono y energía sino que también proporciona los compuestos necesarios para realizar la inducción de la enzima en el microorganismo.

Diversos materiales vegetales conteniendo altas cantidades de sustratos esterificados, tales como salvado de trigo, salvado de trigo desalmidonado, salvado de maíz, bagazo de cerveza, pulpa de remolacha azucarera y otros, han sido utilizados con éxito como componentes del medio de cultivo (Topakas y col., 2007). Estos sustratos están compuestos principalmente de materiales insolubles en agua. Por lo tanto, se podría suponer que proporcionan un suministro continuo de nutrientes (así como inductores) mediante su disolución lenta en el medio de cultivo debido a la degradación de la matriz del polisacárido original, a lo largo del tiempo de cultivo. En el caso particular de CHasas, se ha reportado el uso de salvado de trigo y pulpa de remolacha como sustratos. Sin embargo, parece mucho más razonable utilizar materiales vegetales que contengan cantidades significativas de ACG como componentes de medios de cultivo. De este modo, podrían proporcionar los compuestos inductores necesarios para la producción de CHasa, como lo fue el caso reportado para la pulpa de café (Adachi y col., 2008). En este sentido, los materiales derivados de la yerba parecen cumplir esta condición. Pero en este caso, se debe tener en cuenta una estrategia de cultivo diferente porque los compuestos solubles contenidos en la yerba mate son fácil, completa y rápidamente disueltos en agua. Además, muestran una cierta actividad antimicrobiana (especialmente antifúngica) debido a su alto contenido de polifenoles (Filip y col., 2010). Por lo tanto, los materiales derivados de la yerba mate tienen que ser añadidos en la fase estacionaria de crecimiento con el fin de evitar cualquier efecto inhibidor sobre el desarrollo microbiano. Este tipo de cultivo comprende dos fases: la primera o fase de producción de la biomasa y la segunda llamada fase de inducción. Este esquema de inducción fue seguido en el curso de nuestra investigación como se describe a continuación. 
Se evaluaron diferentes cepas de hongos (A. niger AKU 3302, A. kawachii IFO 4308, A. sojae AKU 3312 y A. sydowii IFO 31296, así como una cepa silvestre aislada de la yerba mate), (Fig. 4.2) respecto a la producción de CHasa en cultivos líquidos.

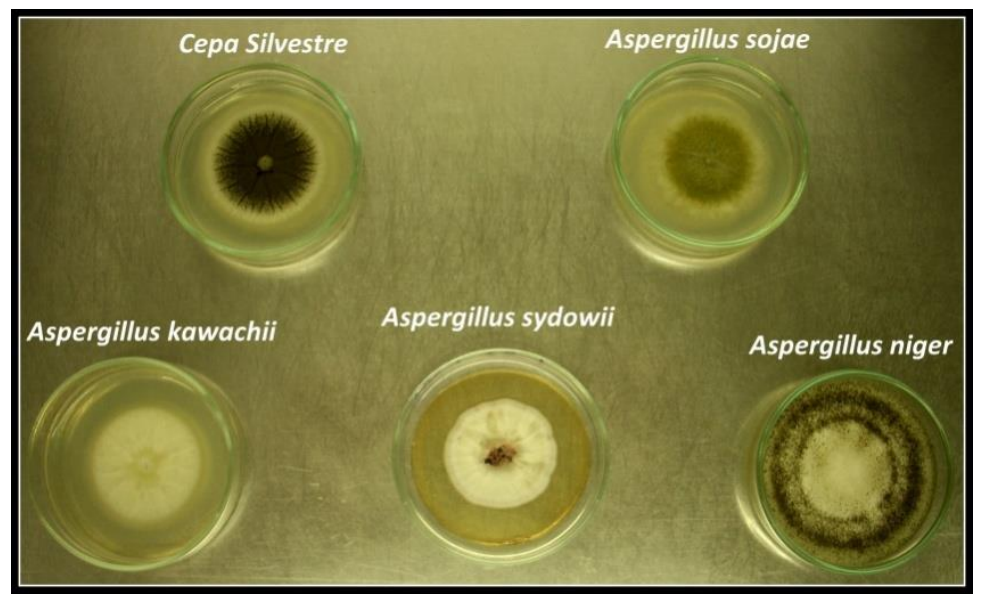

Figura 4.2: Colonias de Aspergillus y cepa silvestre en agar Czapek modificado a $30^{\circ} \mathrm{C}$.

Todos los hongos crecieron bien en medio CLM en forma de pellets ( $\varnothing \approx 2-5 \mathrm{~mm}$ ). En todos los cultivos, la sacarosa se consumió por completo luego de $24 \mathrm{~h}$ (inicio de la fase estacionaria de crecimiento). No se observaron diferencias sustanciales en los parámetros de cultivo para las cepas ensayadas (peso seco de biomasa en un rango de 2,0 a 2,2 g/l, $\mathrm{pH}$ en un rango de 7,8 a 8,2). En esta etapa, los cultivos fueron inducidos mediante la adición de EYM $(0,5 \%, \mathrm{p} / \mathrm{v}$ en base seca). Como el EYM es un líquido muy viscoso, se cuantificó en unidades de masa. No se detectó actividad CHasa antes de la inducción, tanto en el micelio como en los filtrados de cultivo (datos no mostrados). Por el contrario, la actividad CHasa en el EE fue evidente luego de $24 \mathrm{~h}$ posteriores a la inducción. Cabe mencionar que la medición de la actividad CHasa en el EE mediante la lectura directa de absorbancia de ACG a $350 \mathrm{~nm}$ resultó, en algunos casos, difícil de llevar a cabo debido a la presencia de materiales altamente fluorescentes a la luz UV. Por lo tanto, la actividad CHasa también fue examinada mediante TLC, comprobando tanto la aparición de AC como el consumo de ACG, con el fin de confirmar los datos. En la Figura 4.3 A se presentan los resultados de la hidrólisis enzimática de ACG por acción de la CHasa producida por las diferentes cepas del género Aspergillus en medio líquido, mediante el método cromatográfico (TLC) y en la Figura 4.3 B los respectivos valores de actividad CHasa mediante el método espectrofotométrico. 
El análisis de la hidrólisis del ACG por TLC demostró que todas las cepas de Aspergillus, con excepción de A. sydowii IFO 31296, produjeron actividad CHasa en mayor o menor proporción, bajo las mismas condiciones estudiadas. Se observaron claramente manchas de ACG (Rf: 0,72-0,74) con intensidad decreciente y manchas de AC (Rf: 0,88-0,89) con intensidad creciente (Fig. 4.3 A). La actividad CHasa producida por las diferentes cepas estuvo en el rango de $0,17 \mathrm{UE} / \mathrm{ml}$ (A. sydowii IFO 31296) a 6,49 $\mathrm{UE} / \mathrm{ml}$ (A. niger AKU 3302) (Fig. 4.3 B) y estuvo de acuerdo con los resultados observados en el TLC.

La actividad CHasa sólo fue detectada en los micelios luego de la inducción con el EYM, mientras que en los filtrados de cultivo la actividad fue prácticamente despreciable. Estos resultados fueron análogos a los reportados por Adachi y col. (2008) quienes utilizaron derivados del café (café instantáneo y la pulpa de café) como inductores de la actividad CHasa fúngica. Por el contrario, Asther y col. (2005) informaron la presencia de actividad CHasa extracelular en filtrados de cultivo de $A$. niger BRFM 131 recién luego de 3-12 días de crecimiento, utilizando pulpa de remolacha azucarera como fuente de carbono y energía e inductor. Okamura y Watanabe (1982b) purificaron una CHasa a partir de un cultivo de A. japonicus desarrollado durante 8 días en un medio conteniendo salvado de trigo. La existencia de actividad CHasa fúngica intra o extracelular parece ser controversial y depende de la cepa evaluada, incluso dentro del mismo género de hongos.

(A)

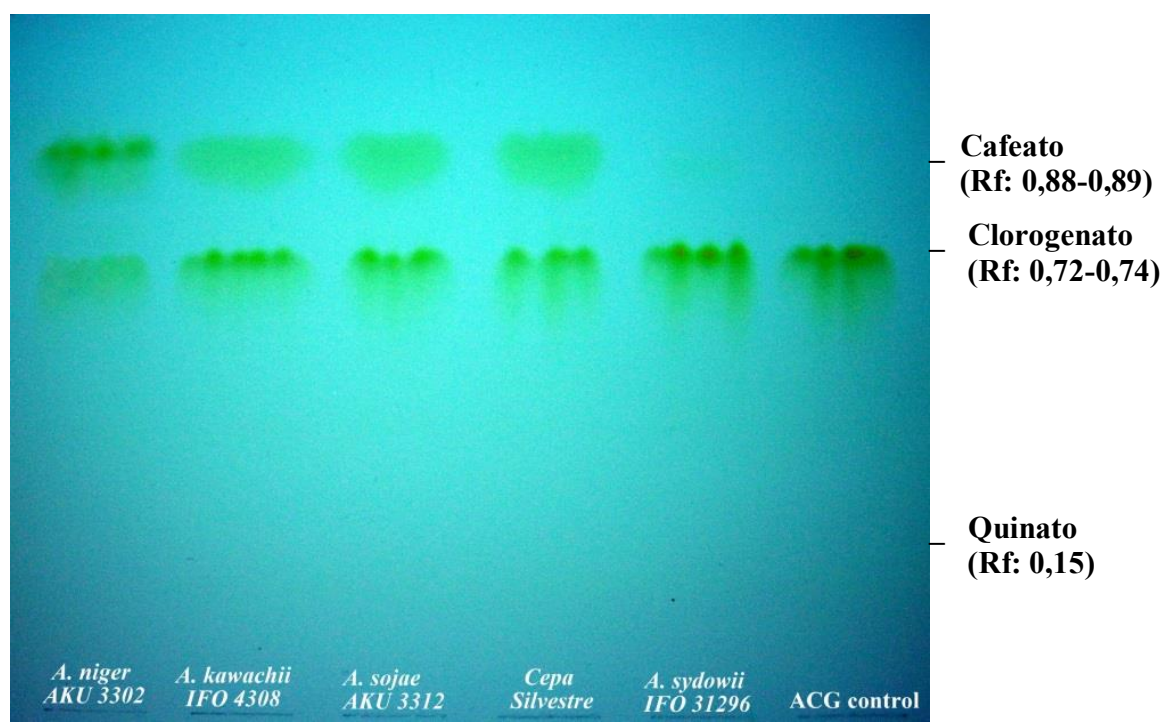


(B)

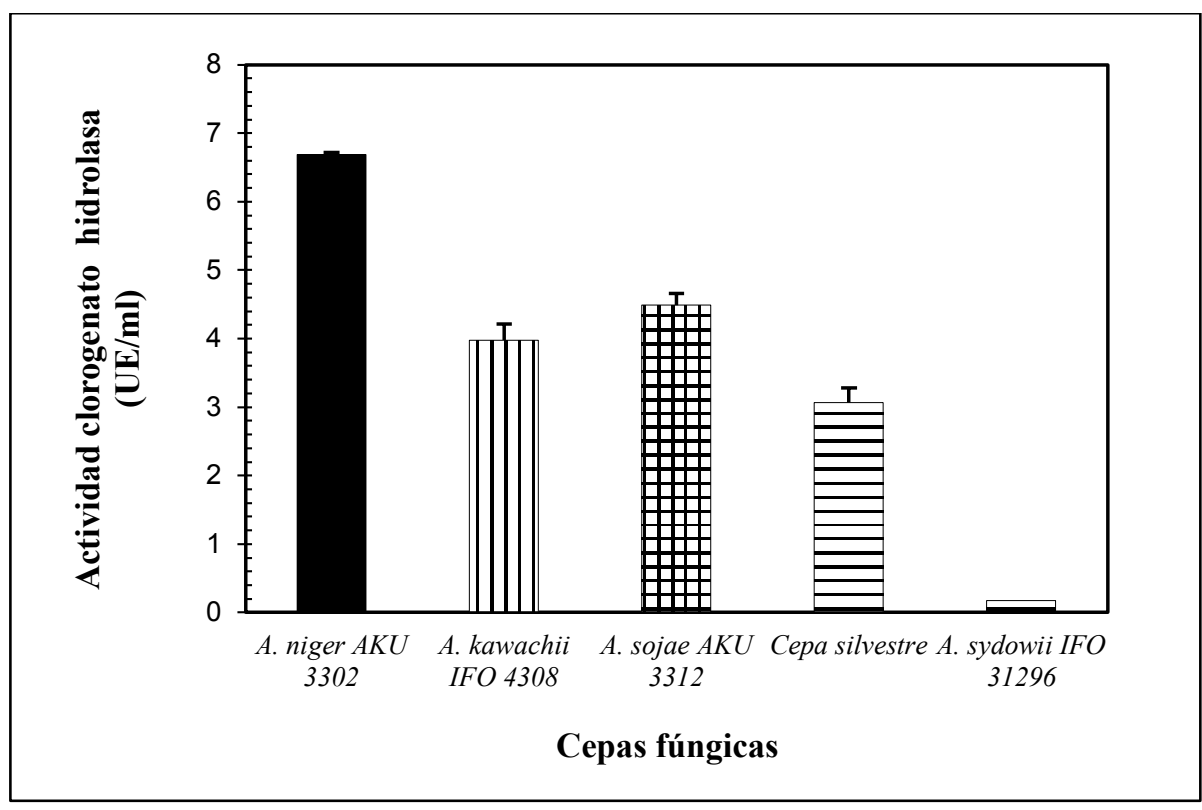

Figura 4.3: Preselección de cepas fúngicas productoras de CHasa: formación de AC por TLC (A) y análisis del cambio de absorbancia a $350 \mathrm{~nm}$ (B).

Adachi y col. (2008) realizaron una preselección de cepas, incluyendo A. niger AKU 3302 y A. sojae AKU 3312, para la producción de CHasa a partir de productos derivados del café. Curiosamente, encontraron mayor actividad CHasa en la cepa de $A$. sojae AKU 3312 que en la de A. niger AKU 3302 (determinado por análisis TLC), lo inverso a nuestros resultados. No hemos podido encontrar una explicación satisfactoria a la diferencia hallada en el comportamiento de estas cepas de hongos, pero podría estar asociado con el tipo de inductor utilizado. Sin embargo, se puede concluir que los mecanismos de inducción que implican la utilización de diferentes materiales vegetales complejos como inductores no son simples y los resultados obtenidos difíciles de extrapolar.

A. niger AKU 3302 presentó las manchas más intensas de AC en el TLC con las concomitantes reducciones en ACG y el valor de actividad CHasa más elevado $(6,69$ $\mathrm{U} / \mathrm{ml})$. Por lo tanto, esta cepa fue seleccionada para los estudios posteriores.

\subsubsection{Efecto de diferentes muestras de yerba mate (Ilex paraguariensis) como inductores de CHasa por A. niger AKU 3302}

Diferentes materiales derivados del procesamiento de la yerba mate fueron evaluados y comparados como potenciales inductores de la actividad CHasa por A. niger AKU 3302. 
EYM, -MD y +MD son materiales rápida y completamente solubles, mientras que PD corresponde a un polvo generalmente descartado a partir de la etapa de molienda del procesamiento de la yerba mate. Este material contiene un alto nivel de polifenoles solubles en agua, incluyendo el ACG, entre otros (Vieira y col., 2010). La completa solubilización del ACG contenido en el PD es comparativamente rápida, incluso a 30 ${ }^{\circ} \mathrm{C}$ (datos no mostrados). Por lo tanto, el PD se perfila como un candidato interesante para la inducción de la actividad CHasa debido a su interesante composición química y precio nulo.

Los cultivos se llevaron a cabo bajo las mismas condiciones descriptas anteriormente. Luego del agotamiento de la sacarosa (inicio de la fase estacionaria de crecimiento $\approx 24$ h), se añadieron diferentes muestras de yerba mate en una concentración de $0,25 \%(\mathrm{p} / \mathrm{v}$, en base seca) al cultivo de $A$. niger AKU 3302 como inductores de la actividad CHasa y el mismo fue incubado durante un tiempo fijo ( $24 \mathrm{~h}$ de inducción). La cantidad de inductor utilizado fue arbitrariamente elegida. Cabe mencionar que la adición de cada inductor se llevó a cabo bajo condiciones no asépticas; sin embargo, no se observó evidencia alguna de contaminación microbiana en los cultivos. La actividad antimicrobiana atribuida a la yerba mate podría estar parcialmente asociada a este fenómeno. La actividad CHasa en los EE se examinó mediante TLC, comprobando aparición de AC y la desaparición de ACG, como se ha descripto anteriormente.

Como se muestra en la Figura 4.4, todos los materiales derivados de la yerba mate indujeron la actividad CHasa en mayor o menor proporción. 


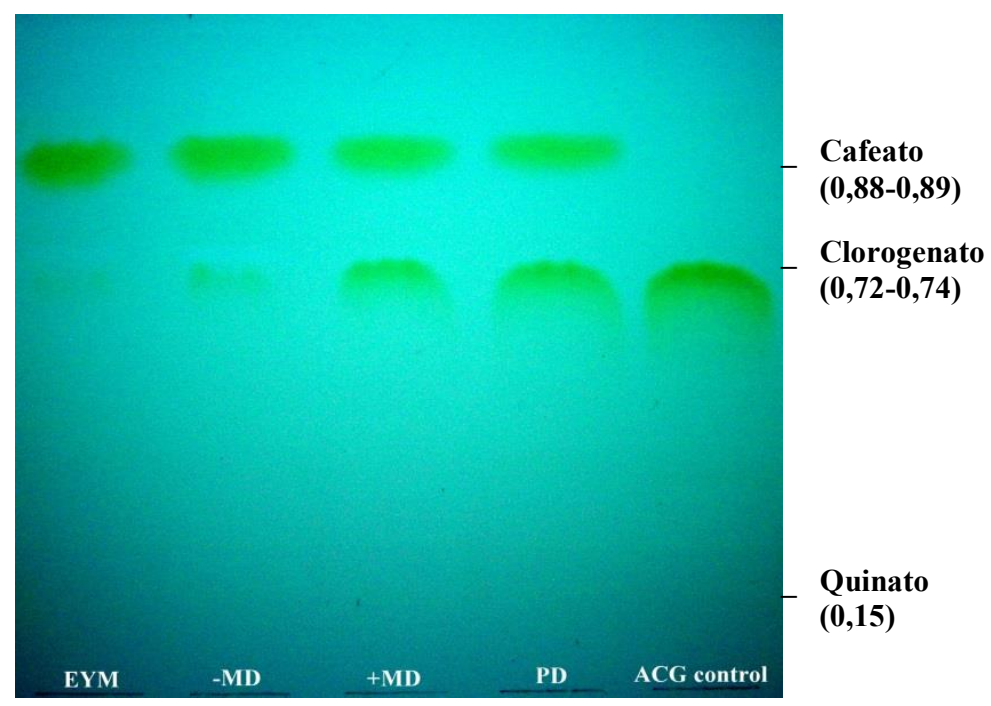

Figura 4.4: Diferentes materiales derivados del procesamiento de la yerba mate fueron examinados como inductores la actividad CHasa analizando la formación de AC por TLC. (EYM: extracto acuoso concentrado de yerba mate; -MD: Mate cocido instantáneo sin maltodextrina; +MD: Mate cocido instantáneo con maltodextrina; PD: polvo de yerba mate, descarte obtenido del procesamiento de la yerba mate).

Como puede observarse (Fig. 4.4), EYM y -MD dieron resultados muy similares, con una actividad CHasa aparente ligeramente superior en el primer caso. Una mayor inducción de CHasa se observó con -MD en comparación con + MD. La actividad CHasa más baja se detectó en los cultivos inducidos con PD. Es interesante mencionar que las partículas insolubles de PD no pudieron ser visualizadas después de la separación de la biomasa fúngica mediante filtración. Por lo tanto, se asumió que $A$. niger AKU 3302 es capaz de producir enzimas celulolíticas (y/o hemicelulolíticas) capaces de degradar las partículas sólidas insolubles contenidas en PD.

Con el fin de aclarar los resultados descritos anteriormente, se consideró importante evaluar el contenido total de ACG en los diferentes materiales utilizados como inductores de la actividad CHasa. Los valores mostrados en la Tabla 4.2 representan el contenido total de en cada material (en base seca) ACG determinado por HPLC, así como la correspondiente concentración de ACG en el medio de cultivo después de la adición de $0,25 \%(\mathrm{p} / \mathrm{v}$, en base seca) de cada inductor. 
Tabla 4.2: Contenido total de ACG en los diferentes inductores de CHasa y concentración resultante de ACG en los medios de cultivo después de la adición de $0,25 \%(\mathrm{p} / \mathrm{v}$, en base seca) de cada inductor.

\begin{tabular}{ccc}
\hline Inductor & ACG (g/100 g ms) & ACG (mg/l de medio de cultivo) \\
\hline EYM & $5,68^{\mathrm{a}} \pm 0,025$ & $141,86^{\mathrm{a}} \pm 0,005$ \\
-MD & $5,72^{\mathrm{a}} \pm 0,260$ & $143,12^{\mathrm{a}} \pm 6,489$ \\
+MD & $3,70^{\mathrm{b}} \pm 0,183$ & $92,43^{\mathrm{b}} \pm 4,575$ \\
PD & $2,22^{\mathrm{c}} \pm 0,145$ & $55,53^{\mathrm{c}} \pm 3,614$
\end{tabular}

EYM: extracto acuoso concentrado de yerba mate; -MD: Mate cocido instantáneo sin maltodextrina; +MD: Mate cocido instantáneo con maltodextrina; PD: Polvo de yerba mate en polvo, descarte obtenido del procesamiento de la yerba mate; ms: muestra seca.

En cada columna, diferentes superíndices indican diferencias significativas $(\mathrm{p}<0,05)$.

Como era de esperarse, no se encontraron diferencias significativas en el contenido total de $\mathrm{ACG}$ entre $\mathrm{EYM}$ y $-\mathrm{MD}(\approx 5,7 \mathrm{~g}$ ACG/100 g). Las diferencias halladas en el contenido total de ACG entre -MD y +MD fueron proporcionales a la cantidad adicionada de maltodextrina. El contenido más bajo de ACG fue hallado en PD.

El contenido total de ACG en cada inductor estuvo relacionado con la magnitud de la actividad CHasa inducida, indicando que este sustrato actuó como inductor de la expresión de la enzima.

Por lo tanto, se demostró que la concentración total ACG en el medio de cultivo juega un papel clave en la inducción de la actividad CHasa en A. niger AKU 3302. Debido a razones prácticas (por ejemplo: facilidad de preparación, elevada estabilidad a lo largo del tiempo), el EYM fue seleccionado para los estudios posteriores.

\subsubsection{Efecto de la concentración del extracto concentrado de yerba mate sobre la producción de CHasa por $A$. niger AKU 3302}

Se evaluó el efecto de la concentración de EYM sobre la producción de CHasa por $A$. niger AKU 3302. Para este propósito, se añadieron diferentes concentraciones de EYM a cultivos en etapa estacionaria de crecimiento y el mismo se incubó durante un tiempo fijo (24 h de inducción) bajo las mismas condiciones previamente descriptas. En la Figura 4.5 (A y B) se muestra la actividad CHasa obtenida a partir del EE del micelio al evaluar el efecto de distintas concentraciones del inductor. 
(A)

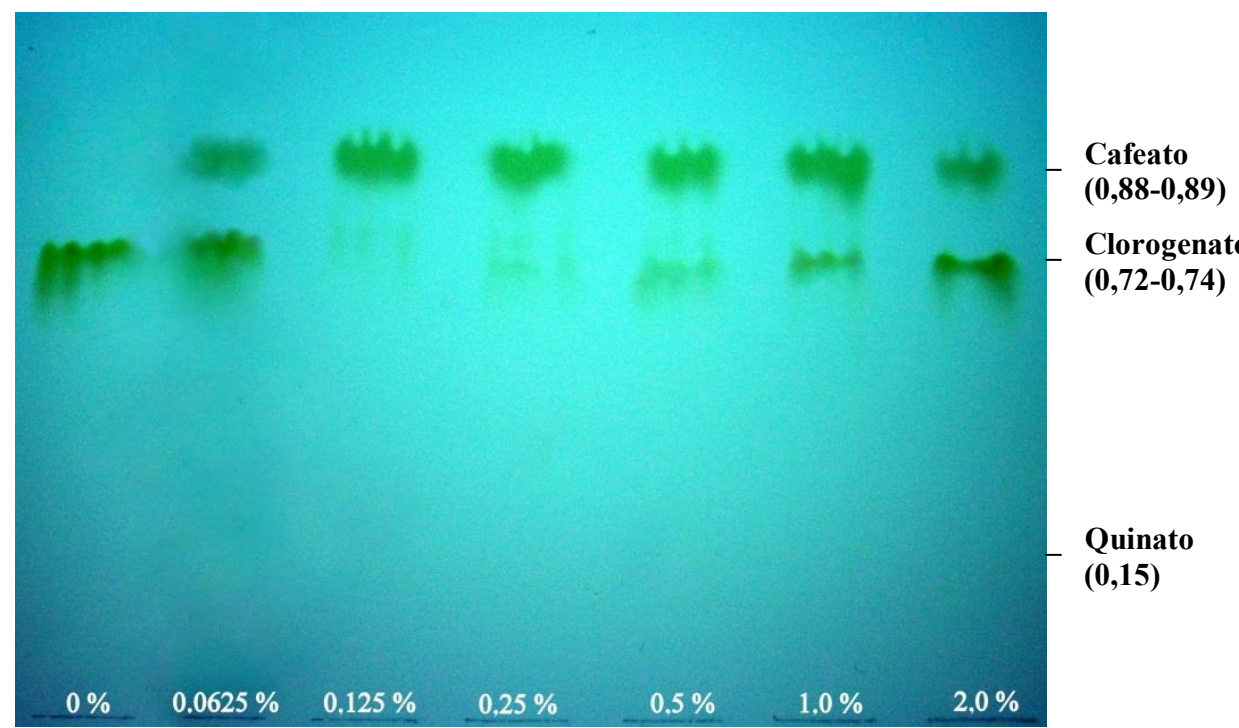

(B)

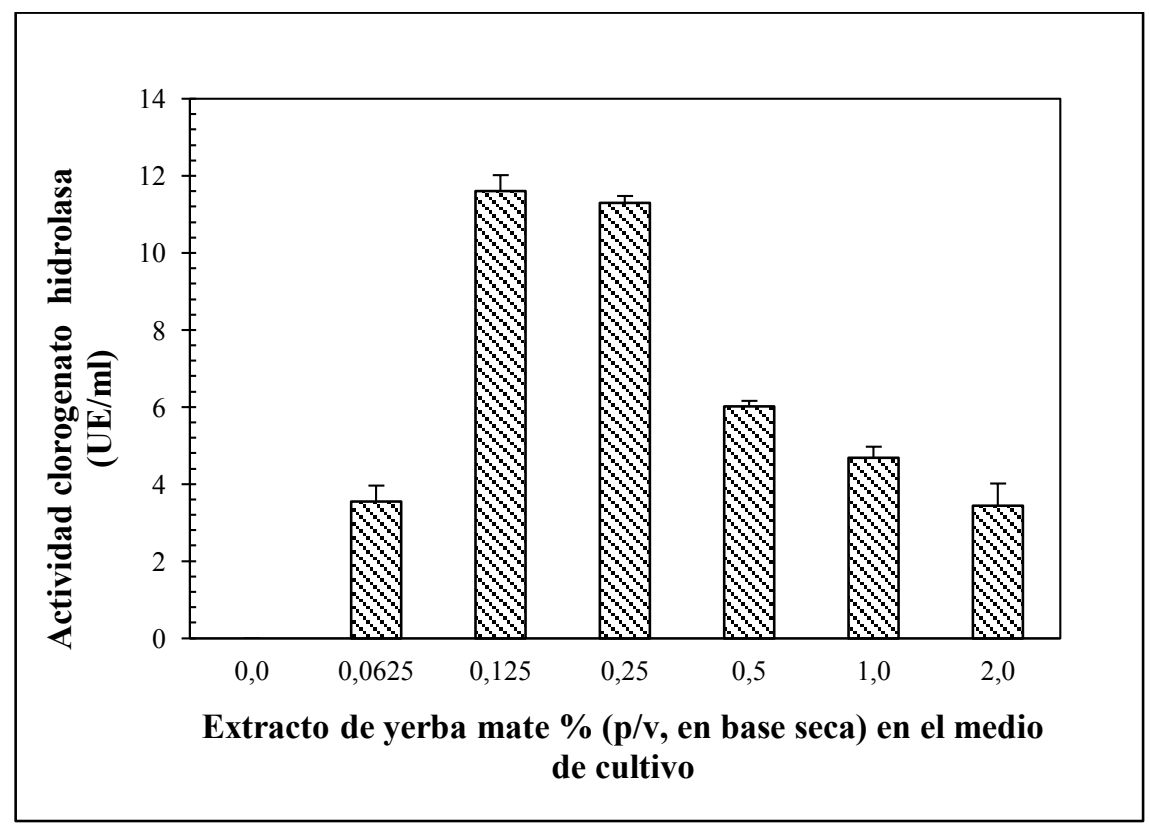

Figura 4.5: Efecto de diferentes concentraciones de Extracto de yerba mate como inductor de la actividad CHasa: formación de AC por TLC (A) y análisis del cambio de absorbancia a 350nm (B).

Como se puede observar en la Figura 4.5, no se detectó actividad CHasa en el extracto crudo de A. niger AKU 3302 preparado en ausencia del inductor (no se observaron manchas de $\mathrm{AC}$ en el análisis por TLC, resultado que estuvo de acuerdo con las determinaciones espectrofotométricas). Aparentemente, el sistema de expresión de 
CHasa por esta cepa fúngica permanece inactivo bajo condiciones de cultivo no inducidas, incluso luego de un período de cultivo prolongado (48 h en total). Resultados similares fueron obtenidos por Adachi y col. (2008) quienes informaron que la actividad CHasa no fue detectada en el EE preparado a partir de micelios de A. sojae AKU 3312 cultivados en ausencia del inductor (en ese caso, café instantáneo o pulpa de café). Este hecho constituye una nueva evidencia de la naturaleza inducible de la CHasa fúngica. La adición del EYM resultó en la producción de la actividad CHasa, en todas las concentraciones examinadas. El análisis por TLC del ACG y sus productos de hidrólisis, indicaron que cuando la concentración del inductor aumentó de 0,25 a $2 \%$ (p/v, en base seca), la actividad CHasa disminuyó, ya que se observó un incremento en el ACG residual con la concomitante reducción en la concentración de AC obtenido. (Fig. 4.5 A). Como se observa en la Figura 4.5 B, los valores más altos de actividad CHasa, alcanzados luego de 24 h de inducción, fueron de 11,6 UE/ml y 11,3 UE/ml, utilizando 0,125 y $0,25 \%$ (p/v, en base seca) de EYM, respectivamente. El análisis de varianza $(\mathrm{p} \leq 0,05)$ reveló que no hubo diferencia significativa entre estos valores.

Curiosamente, la actividad CHasa obtenida al utilizar una concentración de EYM de $0,125 \%(\mathrm{p} / \mathrm{v}$, en base seca) fue sustancialmente mayor a la obtenida al utilizar +MD (véase más arriba). En ambos casos, la concentración de CGA en los medios de cultivo fue similar ( $\approx 70 \mathrm{mg} / 1$ y $92 \mathrm{mg} / \mathrm{l}$, respectivamente). Este resultado, aparentemente contradictorio, se atribuyó tentativamente a la presencia de maltodextrina en $+\mathrm{MD}$, la cual podría inducir a la producción de amilasas fúngicas con un efecto negativo concomitante en la inducción de la enzima de interés.

A partir de una concentración de 0,5\% (p/v, en base seca) de EYM se observó una disminución en la producción de la enzima, alcanzando valores de 5,8 U/ml con $2 \%$ (p/v, en base seca) de EYM (resultados similares fueron obtenidos en el TLC). Este resultado podría estar asociado a un efecto inhibitorio del inductor sobre la producción enzimática a concentraciones elevadas del mismo. Similarmente, Adachi y col. (2008) informaron que la adición de polvo de café en concentraciones superiores al $2 \%(\mathrm{p} / \mathrm{v})$ a un cultivo de $A$. sojae AKU 3312 pareciera ser un inhibidor del crecimiento.

El peso seco de la biomasa fúngica se determinó al final de la fase de producción de biomasa (después del agotamiento de la sacarosa) y durante la fase de inducción con $0,25 \%(\mathrm{p} / \mathrm{v}$, en base seca) de EYM. Después de $24 \mathrm{~h}$ de inducción, la biomasa 
producida fue de $3,1 \mathrm{~g} / 1$ lo que representa una producción neta de biomasa de $\approx 1 \mathrm{~g} / 1$ durante la fase de inducción. Por lo tanto, se pudo concluir que los compuestos orgánicos contenidos en el EYM no sólo inducen la actividad CHasa, sino que también pueden ser asimilados como fuente de carbono y energía por la cepa $A$. niger AKU 3302 .

\subsubsection{Efecto combinado de la concentración de extracto de yerba mate y del tiempo de inducción sobre la producción de CHasa por A. niger AKU 3302}

Se evaluó el efecto combinado de la concentración del EYM y la duración del tiempo de inducción sobre la producción de CHasa mediante un diseño experimental de Doehlert. Para este propósito, los cultivos fueron inducidos con diferentes cantidades de EYM $(0,10,0,575,1,05,1,525,1,575$, y $2,0 \% \mathrm{p} / \mathrm{v}$, en base seca) como se describió anteriormente y luego fueron incubados durante tiempos de inducción variables $(11,22$ y 33 h). La Tabla 4.3 representa la combinación de tratamientos y la variable respuesta obtenida, expresada en actividad CHasa.

Tabla 4.3: Valores reales (datos experimentales) y actividad enzimática obtenidos en el diseño experimental de Doehlert para el estudio de la concentración del inductor y el tiempo de inducción sobre la producción de CHasa.

\begin{tabular}{cccc}
\hline Exp. $\mathrm{N}^{\circ}$ & EYM \% (p/v) & Tiempo (h) & CHasa (UE/ml) \\
\hline 1 & 2,0 & 22 & 3,95 \\
2 & 1,525 & 11 & 1,32 \\
3 & 0,575 & 11 & 3,77 \\
4 & 0,10 & 22 & 10,75 \\
5 & 0,575 & 33 & 8,33 \\
6 & 1,525 & 33 & 4,13 \\
7 & 1,05 & 22 & 4,99 \\
8 & 1,05 & 22 & 5,00 \\
9 & 1,05 & 22 & 4,82 \\
\hline \multicolumn{5}{c}{ EYM: extracto acuoso concentrado de yerba mate. }
\end{tabular}

Los valores de la Tabla 4.3 fueron convertidos en una ecuación polinomial de segundo orden. Los valores de los coeficientes lineal, cuadrático y de interacción entre variables junto con sus respectivos niveles de significancia (calculados mediante ANOVA) se muestran en la Tabla 4.4. 
Tabla 4.4: Valores de los coeficientes y nivel de significancia, calculados por ANOVA, obtenidos para el modelo cuadrático mediante el diseño experimental de Doehlert.

\begin{tabular}{lcc}
\hline & Coeficientes & $\boldsymbol{P}$ \\
\hline Constante & 4,94 & \\
Concentración & $-3,37$ & 0,0008 \\
Tiempo & 2,13 & 0,0003 \\
Concentración $^{2}$ & 2,41 & 0,0036 \\
Tiempo $^{2}$ & $-1,54$ & 0,0015 \\
Concentración• tiempo $^{2}$ & $-1,01$ & 0,0008 \\
\hline $\mathrm{R}^{2}=0,99$ & &
\end{tabular}

El análisis estadístico de los resultados reveló que, en el rango estudiado, las dos variables, así como sus interacciones, tuvieron un efecto significativo sobre la producción enzimática. La ecuación polinomial estimada por el modelo presentó un muy buen ajuste a los datos experimentales $\left(\mathrm{R}^{2}=0,99\right)$.

En la Figura 4.6 se presenta el gráfico de contorno obtenido para la producción de CHasa como una función de las dos variables independientes estudiadas (tiempo de inducción y concentración del inductor).

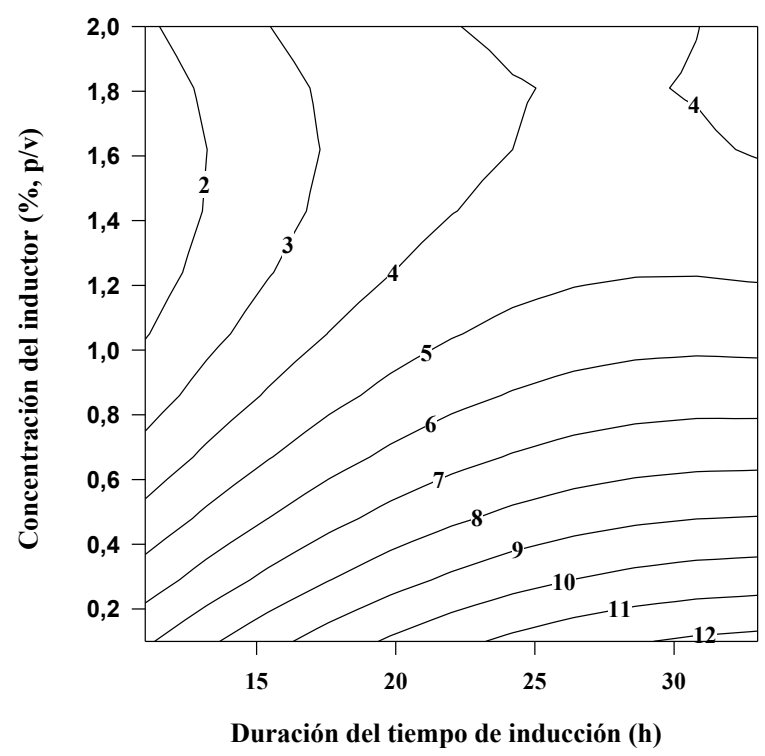

Figura 4.6: Gráfico de contorno mostrando el efecto del tiempo de inducción y la concentración del inductor sobre la producción de CHasa, utilizando extracto de yerba mate como inductor. 
Como puede observarse en el gráfico de contorno (Fig. 4.6), la trayectoria que marca el ascenso de la actividad CHasa está dirigida hacia bajas concentraciones del inductor y altos tiempos de inducción. El diseño experimental reveló que la producción de actividad CHasa óptima se alcanzó luego de un tiempo de inducción $\geq 25 \mathrm{~h}$ y una concentración de inductor entre 0,1-0,2 \% (p/v, en base seca) de EYM. Bajo estas condiciones se obtiene una actividad máxima de $\sim 12 \mathrm{UE} / \mathrm{ml}$. El modelo fue validado con datos obtenidos a partir de dos cultivos independientes para la producción de CHasa. Las condiciones de inducción evaluadas fueron $0,15 \%$ y 28 h y $0,2 \%$ y $32 \mathrm{~h}$ para la concentración del EYM (p/v, en base seca) y el tiempo de inducción, respectivamente. Los valores de actividad CHasa obtenidos en estos casos fueron 11,5 $\mathrm{UE} / \mathrm{ml}$ y $12,6 \mathrm{UE} / \mathrm{ml}$ (valores promedios de tres determinaciones independientes) 1o cual indicó una diferencia menor al $10 \%$ entre los valores obtenidos experimentalmente y los predichos por el modelo.

Es interesante observar que, de acuerdo con este modelo, la actividad CHasa tiende a aumentar con la duración del tiempo de inducción, particularmente para concentraciones bajas inductor. Por ejemplo, la adición de $0,2 \%(\mathrm{p} / \mathrm{v}$, en base seca) de inductor resultó en una actividad CHasa de 6,0 UE/ml luego de un tiempo de inducción $\mathrm{de} \approx 10 \mathrm{~h}$, y un valor igual al doble de actividad después de $30 \mathrm{~h}$ de inducción. Por el contrario, las concentraciones elevadas de inductor tal como $1,8 \%$ (p/v, en base seca) resultaron en bajas actividades enzimáticas, que tienden a disminuir después de $30 \mathrm{~h}$ de inducción. Por lo tanto, se podría suponer que la síntesis neta de la enzima se produce durante todo el tiempo de incubación y que la actividad CHasa es muy estable en los micelios fúngicos. Estos resultados sugieren que es necesario realizar estudios detallados sobre el mecanismo de inducción de la CHasa de hongos y su estabilidad intracelular con el fin de aclarar las presentes observaciones.

\subsection{CONCLUSIONES}

Se confirmó la naturaleza inducible de la CHasa fúngica. La actividad CHasa se detectó en los micelios de diferentes cepas de hongos cuando fue inducida con diferentes materiales derivados del procesamiento de la yerba mate, que contienen ACG en su composición. No se detectó actividad CHasa en ausencia del inductor. Los filtrados de cultivos arrojaron actividades CHasa nulas, tanto en los cultivos inducidos como en los 
no inducidos lo que evidencia la naturaleza intracelular de esta enzima en las cepas fúngicas empleadas. A. niger AKU 3302 exhibió la mayor actividad CHasa y el EYM resultó ser el inductor más conveniente entre los diferentes materiales derivados de la yerba mate evaluados. La eficacia de EYM como un potente inductor de la actividad CHasa se evaluó utilizando un diseño experimental de Doehlert. La producción óptima de CHasa se obtuvo a bajas concentraciones del inductor y largos tiempos de inducción. 


\section{Capítulo 5}

Clorogenato hidrolasa de $\mathcal{A}$. miger AX21 3302: caractecización y aplicación en la bidkólisis del ácido elorogénico contenido en un sustrato natural 


\title{
CAPÍTULO 5 \\ CLOROGENATO HIDROLASA DE $A$. NIGER AKU 3302: CARACTERIZACIÓN Y APLICACIÓN EN LA HIDRÓLISIS DEL ÁCIDO CLOROGÉNICO CONTENIDO EN UN SUSTRATO NATURAL
}

\begin{abstract}
Resumen
Se caracterizó a la clorogenato hidrolasa (CHasa, EC 3.1.1.42) de Aspergillus niger AKU 3302, enzima intracelular producida en cultivos líquidos e inducida con un extracto concentrado de yerba mate (EYM). Se estudió el efecto del $\mathrm{pH}$ y la temperatura sobre la actividad y estabilidad de la enzima y se determinaron los parámetros cinéticos y termodinámicos de la misma, a fin de establecer las condiciones apropiadas para su utilización en la hidrólisis del ácido clorogénico (ACG) presente en sustratos naturales.

La producción de la enzima se realizó a partir de cultivos de A. niger AKU 3302 en medio Czapek líquido modificado, en frascos agitados (180 rpm), al cual se le adicionó un EYM al final de la etapa exponencial de crecimiento. La biomasa obtenida fue separada, lavada y desintegrada en el buffer correspondiente (de acuerdo a la experiencia planteada). La suspensión resultante fue centrifugada y el sobrenadante obtenido fue utilizado como extracto enzimático (EE). La posible presencia de actividad polifenoloxidasa (PPO) fue evaluada por determinación de las actividades lacasa y tirosinasa, utilizando como sustratos ABTS y L-DOPA y midiendo el cambio de absorbancia a 436 y $476 \mathrm{~nm}$, respectivamente. El efecto del $\mathrm{pH}$ sobre la actividad CHasa se evaluó entre pHs 5,0 y 8,0 con buffer fosfato de sodio (BFS) y entre 2,0 y 10,0 con buffer Tris-MES-Glicina (BTMG). EL rango de estabilidad de la enzima respecto al $\mathrm{pH}$ y la temperatura se determinó por preincubación del $\mathrm{EE}$ a diferentes valores de $\mathrm{pHs}$ (entre 2,0 a 10,0 con BTMG y entre 5,0 a 8,0 con BFS) durante 24 y 48 h a $5{ }^{\circ} \mathrm{C}$ y a diferentes temperaturas (entre 30 a $60{ }^{\circ} \mathrm{C}$ ), al pH óptimo durante 15 min y posterior determinación de la actividad enzimática residual. Se evaluó el efecto simultáneo del $\mathrm{pH}$ y la temperatura de incubación utilizando la metodología de superficie de respuesta. Los parámetros cinéticos $V_{\text {máx }}$ y $K_{m}$ fueron determinados a partir de medidas de velocidad inicial, empleando ACG como sustrato, al pH óptimo y $30^{\circ} \mathrm{C}$. La energía de activación $\left(\mathrm{E}_{\mathrm{a}}\right)$ fue determinada utilizando una expresión del tipo Arrhenius. Finalmente, se evaluó la capacidad del EE para hidrolizar el ACG contenido en un sustrato natural (EYM).

El EE mostró actividad CHasa y no se detectó actividad PPO. CHasa presentó mayor actividad a $\mathrm{pH}$ entre 7,0-7,5 en BTMG y entre 6,5-7,0 en BFS, y fue estable en un rango de $\mathrm{pH}$ entre 2,0 a 9,0 y hasta $50{ }^{\circ} \mathrm{C}$ con los dos tipos de buffer usados. El diseño experimental reveló que la actividad CHasa óptima se alcanza a una temperatura de $45^{\circ} \mathrm{C}$, independientemente del tipo de buffer. Los valores de $\mathrm{K}_{\mathrm{m}}$ para CHasa, estimados a partir de la gráfica de Lineweaver-Burk y la gráfica de Eadie-Hofstee, fueron de 0,257 y 0,229 g/l, respectivamente, en tanto que los valores de $\mathrm{V}_{\text {máx }}$ obtenidos con cada gráfica fueron de 1,996 y $1,901 \mu \mathrm{mol} / \mathrm{l} . \mathrm{min}$, respectivamente. El coeficiente de temperatura fue de 1,5 y la $\mathrm{E}_{\mathrm{a}}$ de $6,38 \mathrm{kcal} / \mathrm{mol}$. Se demostró la capacidad de la CHasa para hidrolizar el ACG contenido en sustratos naturales como el EYM.

La utilización del extracto enzimático crudo con elevada actividad CHasa representa una nueva herramienta clave con potencial para la producción de compuestos fenólicos (AC y AQ) de interés y aplicación industrial (como antioxidantes, intermediarios clave en la síntesis de nuevos fármacos, etc.) a partir de extractos de yerba mate.
\end{abstract}




\subsection{INTRODUCCIÓN}

Los compuestos fenólicos de origen vegetal son los antioxidantes más reconocidos dentro de la dieta alimenticia, pudiendo jugar un papel importante en la prevención de enfermedades cardiovasculares y de diferentes tipos de cáncer (Rice-Evans y col., 1996). Dentro de ellos, y debido a su elevada biodisponibilidad, el ácido clorogénico (ACG) constituye un importante componente bioactivo dietario pero, sin embargo, muchas veces es pasado por alto. A su vez, sus productos de hidrólisis, los ácidos quínico (AQ) y cafeico (AC), son químicos finos de alto interés y valor comercial que, al igual que el ACG, no se producen en nuestro país. El AC, ampliamente utilizado por su reconocida capacidad antioxidante, se obtiene de materiales vegetales ricos en compuestos fenólicos. El AQ, un intermediario clave en la síntesis de diferentes drogas dada su particular estructura quiral, se produce en cantidades limitadas a partir de la corteza de la quina, granos de café y otros productos vegetales (Chen y Ho, 1997; Adachi y col., 2006a,b,c; Enserink, 2006; Adachi y col., 2008b; Stanely Mainzen Prince y Senthil Kumaran, 2012). Las fuentes naturales ricas en ACG son diferentes materiales vegetales: pulpas de remolacha, papa y batata, salvado de trigo, manzana y particularmente los granos verdes de café (Schobel y Pollmann, 1980; Okamura y Watanabe, 1982b; Asther y col., 2005). Sin embargo, recientemente se ha reportado que la yerba mate (Ilex paraguarienses A. St. Hil) sería uno de los materiales vegetales con mayor contenido de ACG, con valores del orden de $10 \%$ en base seca (Marques y Farah, 2009; Isolabella y col., 2010; Pagliosa y col., 2010). Por lo tanto, y debido a sus posibles usos industriales, resulta de sumo interés la producción de una enzima que permita la obtención de AC y AQ a partir de una fuente con alto contenido de ACG.

La clorogenato hidrolasa (CHasa, EC 3.1.1.42) cataliza la hidrólisis de ACG con la consecuente formación de AQ y AC. Es una enzima inducible intracelular producida por diferentes especies de Aspergillus cultivados en medios suplementados con materiales vegetales ricos en ACG (Okamura and Watanabe, 1982b; Asther y col., 2005; Adachi y col., 2008).

Anteriormente (capítulo 4) se describió que la cepa A. niger AKU 3302 produce un extracto enzimático (EE) con elevada actividad CHasa al crecer en medio Czapek líquido modificado (CLM), con sacarosa como fuente de carbono y energía (FCE) y extracto concentrado de yerba mate como inductor de la actividad enzimática. 
Resulta importante caracterizar las actividades enzimáticas presentes en un EE en vistas a su posible aplicación industrial. En este sentido, se debe determinar si la actividad detectada respecto a un determinado sustrato se debe a la acción de una única enzima o a varias que actúan de manera sinérgica (o no) sobre el sustrato. El ACG también es sustrato de otras enzimas tales como las polifenoloxidasas (PPO) que lo transforman en diversos productos de oxidación. La presencia de alguna de estas actividades enzimáticas en la mezcla de reacción para la obtención de $\mathrm{AQ}$ y AC a partir de ACG resultaría sumamente perjudicial ya que, entre otros inconvenientes, limitaría la cantidad de sustrato disponible para la acción de la CHasa con la concomitante reducción en el rendimiento. Asimismo cada enzima tiene un $\mathrm{pH}$ y una temperatura óptima donde presenta el máximo de actividad. La velocidad de una reacción aumenta con la temperatura, pero también tiene lugar la desnaturalización progresiva de la enzima. La temperatura óptima para una determinada enzima será entonces la resultante de estos dos efectos contrapuestos. Toda esta información resulta esencial para el diseño de un proceso de biotransformación enzimática como el propuesto, esto es la bioconversión del ACG en AQ y AC.

En el presente capítulo se caracterizó el EE producido por A. niger AKU 3302 a fin de detectar posibles actividades enzimáticas perjudiciales presentes (PPO), se estudió el efecto del $\mathrm{pH}$ y la temperatura sobre la actividad y estabilidad de la CHasa y se determinaron los valores de los parámetros cinéticos y termodinámicos. Finalmente, se evaluó la capacidad del EE para hidrolizar el ACG contenido en un sustrato natural: extracto de yerba mate, determinándose las cantidades de $\mathrm{ACG}, \mathrm{AC}$ y $\mathrm{AQ}$ antes $\mathrm{y}$ después de la hidrólisis enzimática.

\subsection{MATERIALES Y MÉTODOS}

\subsubsection{Materiales y reactivos químicos}

Para la determinación del contenido de ACG, AC y AQ por HPLC se utilizaron los siguientes reactivos de grado analítico o cromatográfico: ACG (Sigma-Aldrich, St. Louis, EE.UU.), AC (Sigma-Aldrich), AQ (Merck, Hohenbrunn, Alemania), agua grado HPLC (Panreac, Barcelona, España), acetonitrilo (J.T. Baker, Phillipsburg, EE.UU.) y ácido acético (Merck). Los demás productos usados fueron mencionados anteriormente. 


\subsubsection{Obtención del extracto enzimático}

El extracto enzimático (EE) se obtuvo a partir de cultivos de A. niger AKU 3302 en medio CLM, con sacarosa ( $5 \mathrm{~g} / \mathrm{l})$ y extracto de yerba mate (EYM, 0,125 \% p/v, en base seca) como FCE e inductor, respectivamente, en frascos Erlenmeyers agitados (180 rpm), durante $48 \mathrm{~h}$ a $30{ }^{\circ} \mathrm{C}$, según se describió en el capítulo 4 de la presente tesis. La biomasa obtenida al final del cultivo fue separada por filtración y desintegrada en mortero con adición del buffer correspondiente de acuerdo a la experiencia planteada: a) buffer fosfato de sodio (BFS, $2 \mathrm{mM}$, pH 6,5) y b) buffer Tris-MES-Glicina (BTMG, 2 $\mathrm{mM}, \mathrm{pH} 7,0)$. La suspensión resultante fue centrifugada $\left(10.000 \times g, 25 \mathrm{~min}, 5^{\circ} \mathrm{C}\right)$ y el EE obtenido se mantuvo a $-18{ }^{\circ} \mathrm{C}$ hasta su utilización como fuente de enzima.

\subsubsection{Determinación de las actividades enzimáticas}

\subsubsection{Actividad clorogenato hidrolasa:}

La actividad CHasa de los EE se determinó por incubación de la mezcla de reacción durante $15 \mathrm{~min}$, usando como sustrato una solución 1,5 mM de ACG (Sigma) en el buffer correspondiente. Posteriormente, se determinó el cambio de absorbancia a 350 nm (Okamura y Watanabe, 1982a). La temperatura de incubación y el pH y tipo de buffer fueron seleccionados de acuerdo al propósito del experimento. El detalle de la técnica experimental se describió en el capítulo 4 de la presente tesis (4.2.5.1).

Una unidad de actividad CHasa se define como la cantidad de enzima que hidroliza 1 $\mu \mathrm{mol}$ de ACG por min bajo las condiciones estándar de ensayo $\left(30^{\circ} \mathrm{C}\right.$ en $\mathrm{BFS}, 50 \mathrm{mM}$, $\mathrm{pH}: 6,5)$.

\subsubsection{Actividad polifenoloxidasa:}

Las polifenoloxidasas (PPO) reaccionan ampliamente con diversos compuestos fenólicos para formar $o$-quinonas, compuestos muy reactivos que tienden a producir pigmentos oscuros: los polifenoles (Matheis, 1983). Resulta muy difícil evitar la formación de estos pigmentos bajo circunstancias biológicas cuando la PPO está activa. La presencia de PPO activas en los EE de A. niger AKU 3302 podría resultar en la rápida transformación del sustrato de la CHasa, el ACG, provocando una disminución en la producción de AQ y AC. Por lo tanto resulta necesario determinar la potencial presencia de actividad PPO en los EE. 
Las PPO se clasifican de acuerdo con sus especificidades de sustrato y el mecanismo de acción de las mismas en: lacasa, peroxidasa y tirosinasa. Teniendo en cuenta el mecanismo de acción sobre los sustratos, en el presente trabajo se ha determinado las siguientes actividades PPO en los EE de A. niger AKU 3302:

\subsection{Actividad lacasa:}

Se determinó espectrofotométricamente a $436 \mathrm{~nm}$ (Muñoz y col. 1997) en buffer fosfato potásico/ácido cítrico (50 mM, pH: 3,0) utilizando como sustrato ABTS (2,2'-azinobis3-etilbenzotiazoline-6-ácido sulfónico) (Sigma) en una concentración final de $3 \mathrm{mM}$. Para las determinaciones se incubaron $100 \mu \mathrm{l}$ de la solución de sustrato, $500 \mu \mathrm{l}$ de la solución buffer y $20 \mu \mathrm{l}$ del EE, llevando a un volumen final de $1 \mathrm{ml}$ con agua destilada. Se registró continuamente la variación de absorbancia a $436 \mathrm{~nm}$, a $30{ }^{\circ} \mathrm{C}$, hasta $\operatorname{los} 60$ $\min$.

La actividad se calculó convirtiendo el valor de la pendiente inicial (suministrada por el equipo en unidades de absorbancia) a concentración de ABTS oxidado $\left(\varepsilon_{\mathrm{ABTS}}=29.300\right.$ $\left.\mathrm{mol}^{-1} 1^{-1} \mathrm{~cm}^{-1}\right)$.

\subsection{Actividad peroxidasa:}

Se determinó espectrofotométricamente a $436 \mathrm{~nm}$ (Muñoz y col. 1997) en buffer fosfato potásico/ácido cítrico (50 mM, pH: 4,0) utilizando como sustratos ABTS (2,2'-azinobis3-etilbenzotiazoline-6-ácido sulfónico) (Sigma) y $\mathrm{H}_{2} \mathrm{O}_{2}$ en una concentración final de 3 $\mathrm{mM}$ y $0,4 \mathrm{mM}$, respectivamente.

Para las determinaciones se incubaron $100 \mu \mathrm{l}$ de la solución de ABTS, $500 \mu \mathrm{l}$ de la solución buffer y $20 \mu \mathrm{l}$ del EE, llevando a un volumen final de $1 \mathrm{ml}$ con agua destilada. Luego se agregaron $50 \mu \mathrm{H}_{2} \mathrm{O}_{2}$ e inmediatamente se registró el cambio de absorbancia a $436 \mathrm{~nm}$, a $30^{\circ} \mathrm{C}$, hasta los $60 \mathrm{~min}$.

La actividad se calculó sustrayendo el valor obtenido en la reacción peroxidasa al valor obtenido por la reacción lacasa. 


\subsection{Actividad tirosinasa:}

Se determinó espectrofotométricamente a 475 nm (Dalfard y col., 2006; Halaouli y col., $2005)$ en buffer fosfato potásico $(100 \mathrm{mM}, \mathrm{pH}$ : 6,5) utilizando como sustrato L-DOPA (L-3,4-dihidroxifenilalanina) (Sigma) en una concentración final de $2 \mathrm{mM}$.

Para las determinaciones se incubaron $100 \mu \mathrm{l}$ de la solución de sustrato, $500 \mu \mathrm{l}$ de la solución buffer y $20 \mu \mathrm{l}$ del EE, llevando a un volumen final de $1 \mathrm{ml}$ con agua destilada. Luego se registró el cambio de absorbancia a $475 \mathrm{~nm}$, a $30^{\circ} \mathrm{C}$, hasta los $60 \mathrm{~min}$.

La actividad se calculó convirtiendo el valor de la pendiente inicial (suministrada por el equipo en unidades de absorbancia) a concentración de L-DOPA oxidado $\left(\varepsilon_{\mathrm{L}-\mathrm{DOPA}}=\right.$ $3.700 \mathrm{~mol}^{-1} \mathrm{1}^{-1} \mathrm{~cm}^{-1}$ ).

Todas las determinaciones enzimáticas antes mencionadas se realizaron por triplicado y los resultados fueron presentados como promedio \pm desvío estándar.

\subsubsection{Caracterización de la actividad CHasa}

Numerosas investigaciones tendientes a encontrar las condiciones óptimas de reacción de una dada enzima se han realizado con el extracto enzimático crudo, sin purificación previa de la enzima. Esto se debe a que en muchas aplicaciones industriales, por cuestiones de costo se tiende a utilizar el extracto crudo y no la enzima purificada, razón por la cual dichos estudios de caracterización resultan de interés práctico. Llegado el caso, y si se justifica, se puede encarar la purificación de la enzima en el grado requerido para su utilización. Los ensayos de actividad y estabilidad que a continuación se describen se realizaron con el EE, sin tratamiento previo alguno.

\subsubsection{Efecto del pH sobre la actividad CHasa:}

Se evaluó el efecto del pH sobre la actividad de CHasa empleando 2 tipos de buffer con objeto de determinar si el pH óptimo de la enzima cambia con el tipo de buffer de incubación. El pH óptimo para CHasa fue determinado midiendo la actividad enzimática en los rangos de $\mathrm{pH}$ de 5,0 a 8,0 y de 4,0 a 10,0 empleando BFS (50 mM) y BTMG (20 mM), respectivamente, bajo condiciones de ensayo estándar.

Las soluciones de ACG se prepararon en BFS $50 \mathrm{mM}$ o BTMG $20 \mathrm{mM}$, y fueron ajustadas a los diferentes valores de $\mathrm{pHs}$, de la siguiente manera:

a) Se preparó una solución de ACG 7,5 mM, en agua destilada. 
b) Se prepararon las soluciones buffers: BFS $2 \times$ y BTMG $2 \times$.

c) Se tomaron $2 \mathrm{ml}$ de la solución de ACG 7,5 mM y $5 \mathrm{ml}$ de la solución de buffer.

d) Se ajustó el $\mathrm{pH}$ al valor deseado utilizando $\mathrm{NaOH}(0,1 \mathrm{~N})$ o $\mathrm{HCl}(0,1 \mathrm{~N})$.

e) La solución resultante se llevó a $10 \mathrm{ml}$ de volumen final.

\subsubsection{Efecto del $\mathrm{pH}$ sobre la estabilidad CHasa:}

Se evaluó el efecto del $\mathrm{pH}$ sobre la estabilidad CHasa empleando 2 tipos de buffer con objeto de determinar si el rango de estabilidad cambia con el tipo de buffer de incubación. El efecto del pH sobre la estabilidad de la enzima se determinó por preincubación a $5{ }^{\circ} \mathrm{C}$, durante $24 \mathrm{~h}$ y $48 \mathrm{~h}$, de la enzima en BTMG y en BFS a diferentes valores de $\mathrm{pH}$ (entre 2,0 a 10,0 para BTMG y entre 5,0 a 8,0 para BFS), en ausencia de sustrato. Luego de la incubación, se midió la actividad residual a pH óptimo, bajo condiciones de ensayo estándar. Cada buffer se preparó con una concentración $2 \times y$ cuando fue requerido, se diluyó y su pH se modificó al valor deseado mediante el agregado de solución de $\mathrm{HCl}(0,1 \mathrm{~N})$ o de $\mathrm{NaOH}(0,1 \mathrm{~N})$.

\subsubsection{Efecto de la temperatura sobre la estabilidad de CHasa:}

La termoestabilidad de una enzima se define como la capacidad que tiene de resistir tratamientos térmicos en ausencia de sustrato (Tari y col., 2007). La termoestabilidad de CHasa se determinó midiendo la actividad residual luego de incubar la enzima extraída del micelio con BFS $(50 \mathrm{mM})$ al pH óptimo, en ausencia de sustrato, a temperaturas comprendidas entre 30 a $60{ }^{\circ} \mathrm{C}$. Se tomaron muestras periódicamente, durante $8 \mathrm{~h}$. Las mismas fueron rápidamente enfriadas en baño agua-hielo e inmediatamente se midió la actividad enzimática residual bajo condiciones de ensayo estándar.

\subsubsection{Efecto combinado del pH y la temperatura sobre la actividad CHasa:}

Se estudió el efecto combinado del pH y la temperatura sobre la actividad CHasa utilizando la metodología de superficie de respuesta basada en el uso de una matriz de experimentos mediante la cual puede ser estudiada la variación simultánea de los factores. El diseño experimental de Doehlert fue seleccionado para diseñar las superficies de respuesta, en las cuales las variables estudiadas fueron: $\mathrm{pH}$ (6,5 a 8,5 para BTMG y 6,0 a 8,0 para BFS) y temperatura de incubación $\left(30\right.$ a $60{ }^{\circ} \mathrm{C}$ para ambos 
ensayos). Para las determinaciones, los valores centrales del diseño experimental de Doehlert fueron: $\mathrm{pH}$ 7,5 para BTMG y $\mathrm{pH} 7,0$ para BFS y $45{ }^{\circ} \mathrm{C}$ (temperatura de incubación) para ambos ensayos.

Los valores reales de las variables independientes fueron codificados sobre la base de una función lineal entre los valores codificados $(Z)$ y reales $(X)$ de acuerdo a:

$$
X=Z \times \frac{\Delta X}{\Delta Z}+X_{0} \quad(\text { ec. } 5.1)
$$

donde $X_{0}$ y $Z$ son los valores real y codificado del punto central, respectivamente, y $\Delta X \mathrm{y}$ $\Delta Z$ son la diferencia entre el valor más alto y el más bajo de los valores reales y codificados, respectivamente.

En la Tabla 5.1 se presenta la matriz utilizada en el diseño experimental de Doehlert.

Tabla 5.1: Valores codificados y reales utilizados en el diseño experimental de Doehlert.

\begin{tabular}{ccccccc}
\hline \multirow{2}{*}{ Exp. $\mathrm{N}^{\circ}$} & \multicolumn{2}{c}{ Valores codificados } & & \multicolumn{3}{c}{ Valores reales } \\
\cline { 2 - 3 } \cline { 5 - 7 } \cline { 5 - 7 } & $\mathrm{pH}$ & Temperatura $\left({ }^{\circ} \mathrm{C}\right)$ & & Temperatura $\left({ }^{\circ} \mathrm{C}\right)$ & $\mathrm{pH}_{\mathrm{BFS}}$ & $\mathrm{pH}_{\mathrm{BTMG}}$ \\
\hline 1 & 1 & 0 & & 45 & 8,0 & 8,5 \\
2 & 0,5 & $-0,866$ & & 30 & 7,5 & 8,0 \\
3 & $-0,5$ & $-0,866$ & & 30 & 6,5 & 7,0 \\
4 & -1 & 0 & & 45 & 6,0 & 6,5 \\
5 & $-0,5$ & 0,866 & & 60 & 6,5 & 7,0 \\
6 & 0,5 & 0,866 & & 60 & 7,5 & 8,0 \\
7 & 0 & 0 & & 45 & 7,0 & 7,5 \\
8 & 0 & 0 & & 45 & 7,0 & 7,5 \\
9 & 0 & 0 & & 45 & 7,0 & 7,5 \\
\hline
\end{tabular}

BFS: buffer fosfato de sodio (50 mM). BTMG: buffer Tris-MES-Glicina (20 mM).

El análisis de regresión múltiple basado sobre el método de los mínimos cuadrados fue desarrollado utilizando el software Mathcad 2001.

Por simplicidad se utilizó un modelo cuadrático completo que contiene seis coeficientes para describir la respuesta observada (ec. 5.2).

$$
y=b_{0}+\sum b_{i} x_{i}+\sum b_{i} x_{i i}^{2}+\sum b_{i j} x_{i} x_{j} \quad(\text { ec. 5.2) }
$$


donde $y$ es la variable respuesta, $b_{0}$ una constante, $\mathrm{y}, b_{i}, b_{i i}$, y $b_{i j}$ son los coeficientes de los efectos lineal, cuadrático y de interacción, respectivamente.

El orden de los experimentos se seleccionó al azar, lo que proporcionó protección contra efectos de las variables indeseables. Los experimentos se desarrollaron por triplicado y los resultados corresponden a los valores medios de las actividades. Los resultados se analizaron aplicando un programa estadístico Statgraphics Centurion XV (Freund y Wilson, 1997).

\subsubsection{Determinación de los parámetros cinéticos:}

Los parámetros cinéticos $\mathrm{V}_{\text {máx }}$ y $\mathrm{K}_{\mathrm{m}}$ fueron determinados a partir de medidas de velocidad inicial empleando ACG como sustrato en un rango de concentraciones de 0,025 a 1,12 g/l, en BFS (50 mM) al pH óptimo y a $30{ }^{\circ} \mathrm{C}$. Las constantes de Michaelis Menten fueron determinadas por regresiones lineales (Lineweaver-Burk y EadieHofstee).

\subsubsection{Energía de activación y parámetros termodinámicos:}

La energía de activación $\left(\mathrm{E}_{\mathrm{a}}\right)$ requerida por la CHasa para iniciar la reacción de hidrólisis fue determinada utilizando una expresión del tipo Arrhenius (ec. 5.3):

$$
A=A_{0} * e^{\frac{-E_{a}}{R T}} \quad(\text { ec. } 5.3)
$$

donde: $A$ es la actividad enzimática, $A_{0}$ es el factor de Arrhenius, $E_{a}$ es la energía de activación, $R$ es la constante de los gases $\left(8,314 \mathrm{~kJ} \mathrm{~mol}^{-1} \mathrm{~K}^{-1}\right)$ y $T$ es la temperatura absoluta. La gráfica de $\operatorname{Ln}(A)$ en función de $1 / T$ genera una línea recta de pendiente $-E_{a} / R$

Los valores para la entalpía de activación $\left(\Delta H^{*}\right)$, la energía libre de activación $\left(\Delta G^{*}\right)$ y la entropía de activación $\left(\Delta S^{*}\right)$ fueron determinados utilizando la ec. 5.3 y la ecuación de Eyring (ec. 5.4):

$$
A=\frac{k_{B} \cdot T}{h} * e^{\frac{-\Delta H^{*}}{R T}} * e^{\frac{\Delta S^{*}}{R}} \quad \text { (ec. 5.4) }
$$


donde: $k_{B}$ y $h$ son las constantes de Boltzmann y Planck, respectivamente. Tomando logaritmos de ambas ecuaciones y derivando respecto a la temperatura llegamos a la siguiente ecuación que nos permite calcular $\Delta H^{*}$ :

$$
\Delta H^{*}=E_{a}-R T \quad(\text { ec. } 5.5)
$$

Sustituyendo el valor de $\Delta H^{*}$ en la ecuación de Eyring (ec. 5.4) tenemos:

$$
A=\frac{k_{B} \cdot T}{h} * e^{\frac{-E_{a}}{R T}} * e^{\frac{\Delta S^{*}}{R}} \quad \text { (ec. 5.6) }
$$

Comparando esta última ecuación con la ecuación de Arrhenius (ec. 5.3), se obtiene el siguiente valor para la constante $A_{0}$ :

$$
A_{0}=\frac{k_{B} \cdot T}{h} * e * e^{\frac{\Delta S^{*}}{R}} \quad(e c .5 .7)
$$

La ecuación anterior (ec. 5.7) nos permite calcular el valor de $\Delta S^{*}$ :

$$
\Delta S^{*}=R\left[\ln \frac{A_{0} \cdot h}{k_{B} \cdot T}-1\right] \quad(\text { ec. } 5.8)
$$

donde el valor experimental de $A_{0}$ se puede obtener a partir del valor de la ordenada al origen de la gráfica de Arrhenius. Finalmente, el valor de $\Delta G^{*}$ se determina a partir de la siguiente ecuación:

$$
\Delta G^{*}=\Delta H^{*}-T * \Delta S \quad(\text { ec. 5.9) }
$$




\subsubsection{Determinación del coeficiente $Q_{10}$ :}

El incremento en la velocidad de reacción, $\mathrm{Q}_{10}$, por cada $10{ }^{\circ} \mathrm{K}$ de incremento en la temperatura, de $T_{1}$ a $T_{2}$, fue determinado utilizando el valor de energía de activación previamente calculado de acuerdo a la siguiente ecuación:

$$
\operatorname{Ln}\left(Q_{10}\right)=\frac{E_{a} \cdot\left(T_{1}-T_{2}\right)}{R \cdot T_{1} \cdot T_{2}} \quad(\text { ec. 5.10) }
$$

Todas las determinaciones se realizaron por triplicado y los resultados fueron presentados como promedio \pm desvío estándar.

\subsubsection{Ensayos de hidrólisis enzimática de ácido clorogénico en el extracto concentrado de yerba mate}

Se evaluó la capacidad de la CHasa producida por A. niger AKU 3302 para hidrolizar el ACG contenido en el EYM. En el capítulo 4 de la presente tesis se mostró que el contenido de ACG en el EYM es de 12,19 g ACG/1 de EYM (5,68 g ACG/100 g ms).

\subsubsection{Hidrólisis enzimática del ACG en función del tiempo de tratamiento:}

La hidrólisis enzimática del ACG en el EYM en función del tiempo de tratamiento se llevó a cabo bajo condiciones de ensayo estándar utilizando como sustrato una solución de 4,40 ml de EYM (pH: 5,8) diluida en BFS $(50 \mathrm{mM}$, $\mathrm{pH}: 6,5)$ en un volumen final de $100 \mathrm{ml}$. La concentración de ACG en la solución de sustrato preparada fue de $\approx 1,5$ $\mathrm{mM}$. Para los ensayos se colocaron $25 \mathrm{ml}$ de la solución de sustrato $\left(\mathrm{pH}_{\text {final }}\right.$ : 6,0) en frascos erlenmeyers de $100 \mathrm{ml}$, a los que se les adicionó 1,5 ml del EE y la mezcla se incubó a $30{ }^{\circ} \mathrm{C}$ en baño termostatizado con agitación. Al erlenmeyer control se le adicionó $1,5 \mathrm{ml}$ de agua destilada. Se tomaron muestras en función del tiempo (hasta 45 min). Se midió el cambio de absorbancia a $350 \mathrm{~nm}$ (Okamura y Watanabe, 1982a) y mediante una curva de calibración de ACG (Sigma) en el rango de 0 a $0,12 \mathrm{mM}$ se determinó la cantidad equivalente de ACG hidrolizado durante la reacción.

Todas las determinaciones se realizaron por triplicado y los resultados fueron presentados como promedio \pm desvío estándar. 
5.2.5.2. Análisis cuantitativo del sustrato (ACG) y los productos de hidrólisis (AQ y $A C)$ :

Para el análisis cuantitativo del contenido de ACG y los productos de su hidrólisis enzimática en el EYM, se incubaron $990 \mu 1$ del EYM diluido 1/50 en BFS (50 mM, pH: $6,5)$ con $10 \mu \mathrm{lEE}$, durante una noche $(8 \mathrm{~h})$ a $30^{\circ} \mathrm{C}$. El contenido inicial y final de cada compuesto fue determinado mediante un sistema de cromatografía líquida de alta resolución (HPLC) utilizando un método adaptado de Adachi y col. (2008) y se expresaron como $\mu \mathrm{mol} / \mathrm{g}_{\text {materia seca }}$ en el EYM $\left(\mu \mathrm{mol} / \mathrm{g}_{\mathrm{ms}}\right)$. El análisis se llevó cabo utilizando un sistema modular (Waters HPLC) equipado con una bomba (Modelo 1525) y un detector de índice de refracción (Modelo 2414) lo que permitió detectar cualquier compuesto, incluyendo aquellos que no presentaban ninguna intensidad UV. Las muestras $(20 \mu \mathrm{l})$ se inyectaron manualmente en el sistema de HPLC con jeringa Hamilton de $25 \mu 1$ y la separación se realizó en una columna de fase reversa C18 (Phenomenex Prodigy ODS3, $250 \mathrm{~mm} \times 4,6 \mathrm{~mm}, 5 \mu \mathrm{m}$ de tamaño de partícula) protegida con un guarda columna de fase reversa C18 de la misma marca. La columna se mantuvo a una temperatura de $30^{\circ} \mathrm{C}$, la velocidad del flujo fue de $0,8 \mathrm{ml} / \mathrm{min}$ y la fase móvil estuvo compuesta por una solución $50 \mathrm{mM}$ ácido acético/ $\mathrm{CH}_{3} \mathrm{CN}=8: 2$. Los compuestos fueron identificados por comparación de los tiempos de retención con sus respectivos patrones $\mathrm{y}$, posteriormente, cuantificados utilizando una curva de calibración de cada compuesto estándar disponible comercialmente. Todas las determinaciones se realizaron por triplicado y los resultados fueron presentados como promedio \pm desvío estándar.

\subsection{RESULTADOS Y DISCUSIÓN}

\subsubsection{Caracterización parcial de actividades enzimáticas}

A. niger AKU 3302 produce actividad CHasa $(\sim 12,51 \mathrm{UE} / \mathrm{ml})$ en medio líquido, con sacarosa y EYM, como FCE e inductor, respectivamente, como fue mencionado en el capítulo anterior. No se detectaron actividades lacasa ni peroxidasa en los EE, considerando que no se evidenció incremento de absorbancia a $436 \mathrm{~nm}$ al utilizar ABTS y $\mathrm{H}_{2} \mathrm{O}_{2}$, como sustratos, respectivamente. Tampoco se detectó actividad tirosinasa en los EE ya que no se evidenció un cambio de absorbancia a $475 \mathrm{~nm}$ al utilizar L-DOPA como sustrato (Tabla 5.2). La ausencia de dichas actividades enzimáticas resulta de 
suma importancia para el uso directo de los EE de A. niger AKU 3302 en la hidrólisis de ACG.

Tabla 5.2: Actividades enzimáticas en el extracto enzimático.

\begin{tabular}{cc}
\hline Actividad enzimática & $\mathrm{UE} / \mathrm{ml}$ \\
\hline CHasa & $12,51 \pm 0,08$ \\
Lacasa & $\mathrm{ND}$ \\
Peroxidasa & $\mathrm{ND}$ \\
Tirosinasa & $\mathrm{ND}$ \\
\hline
\end{tabular}

ND: no detectado.

\subsubsection{Caracterización parcial de la actividad CHasa}

\subsubsection{Efecto del pH sobre la actividad y estabilidad CHasa:}

En la Figura 5.1 se presenta la influencia del pH sobre la actividad CHasa, tanto en BFS como en BTMG.

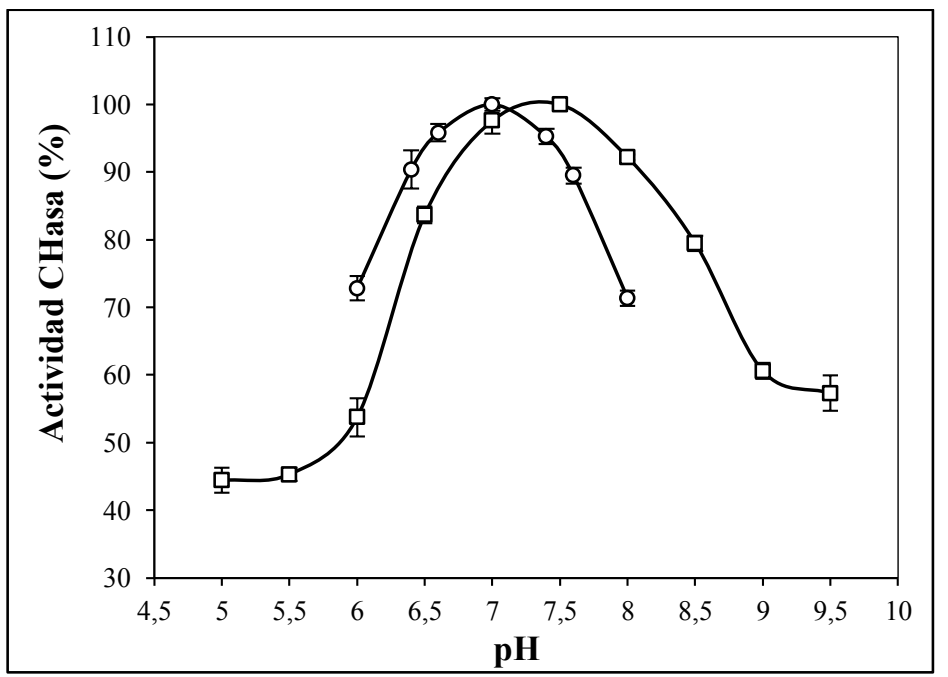

Figura 5.1: Efecto del pH sobre la actividad CHasa en BFS (०) y en BTMG ( $\square)$.

La mayor actividad se encontró alrededor de pHs cercanos a la neutralidad (7,0-7,5). El tipo de buffer de reacción ejerció una influencia significativa sobre la actividad de CHasa como así también sobre los valores de pH óptimos. Las curvas obtenidas empleando BFS y BTMG están separadas alrededor de 0,5 unidades de $\mathrm{pH}$. A valores de $\mathrm{pH} \leq 7$ se observan mayores actividades con BFS en tanto que a lo inverso ocurre a 
valores de $\mathrm{pH}>7$. Alrededor del $70 \%$ de la máxima actividad de CHasa se observa a pH 6,0 empleando BFS. Por otra parte, el costo de BFS es substancialmente inferior al de BTMG haciendo más conveniente su uso a escala industrial. Cabe recordar que los extractos de yerba mate presentan un $\mathrm{pH} \cong 5,8$. Estas circunstancias son todas positivas respecto de la potencial producción enzimática de AQ y AC a partir del ACG contenido en extractos de yerba mate mediante el uso de la CHasa de A. niger AKU 3302.

En las Figuras 5.2 y 5.3 se representan los valores de actividad enzimática residual luego de incubar la enzima a diferentes valores de $\mathrm{pH}$ por 24 y 48 horas a $5{ }^{\circ} \mathrm{C}$ en BTMG y en BFS, respectivamente.

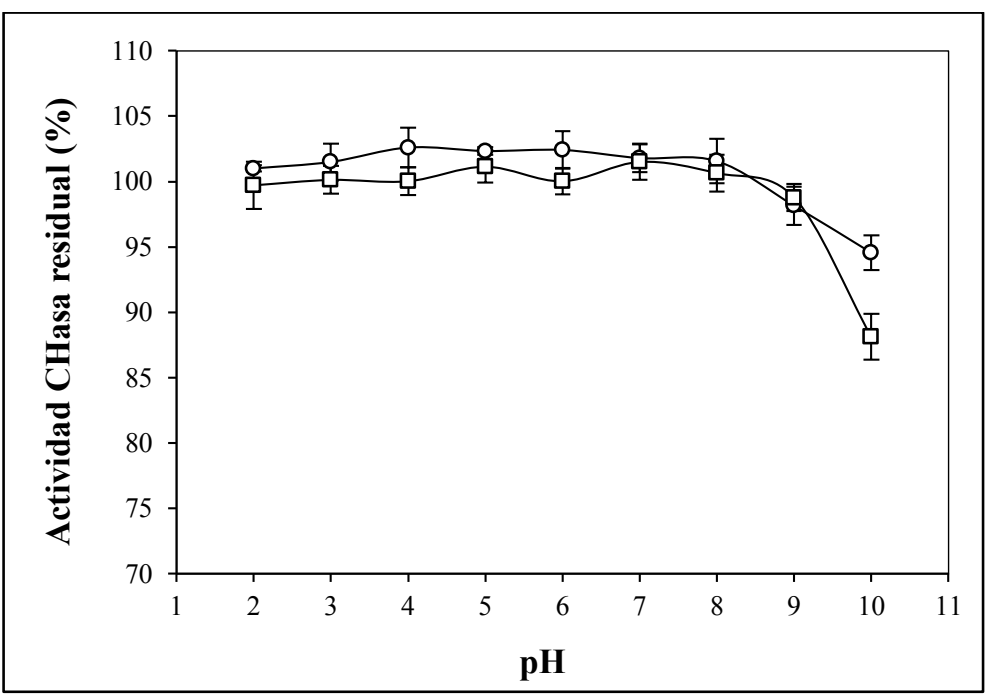

Figura 5.2: Efecto del $\mathrm{pH}$ sobre la estabilidad de CHasa en BTMG. Temperatura de incubación: $5{ }^{\circ} \mathrm{C}$. Tiempo de incubación: $24 \mathrm{~h}(\mathrm{O})$ y $48 \mathrm{~h}(\square)$.

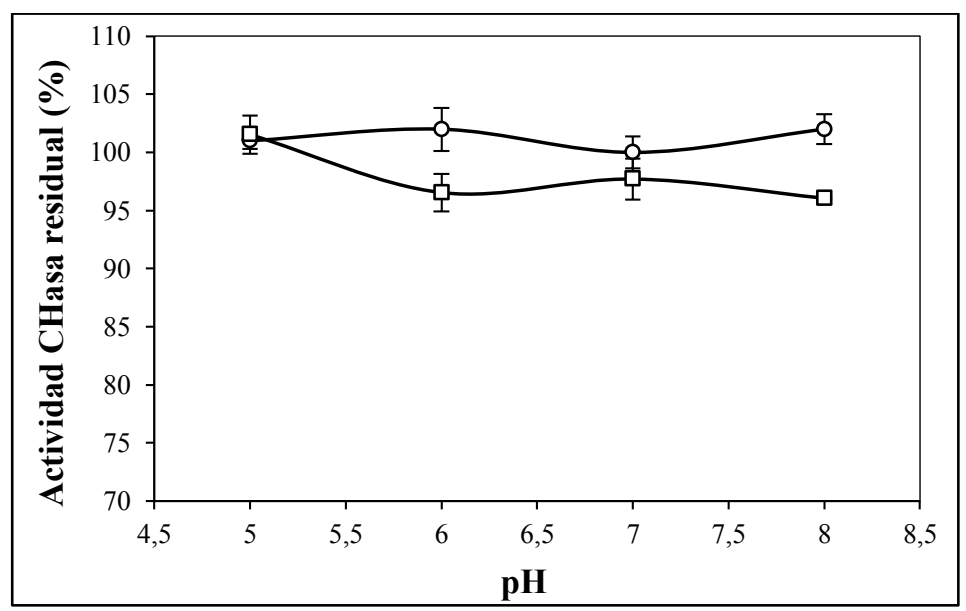

Figura 5.3: Efecto del pH sobre la estabilidad de CHasa en BFS. Temperatura de incubación: 5 ${ }^{\circ} \mathrm{C}$. Tiempo de incubación: 24 h (०) y 48 h (口). 
La enzima permaneció estable en el rango de pH entre 2,0 y 8,0, luego de ser incubada en buffer TMG durante $48 \mathrm{~h}$, a $5{ }^{\circ} \mathrm{C}$, observándose una leve disminución a pHs superiores. A pH 9,0 retuvo el $98 \%$ de su actividad máxima (Figura 5.2).

El tipo de buffer no influyó en la estabilidad de la enzima CHasa. El análisis de varianza no reveló diferencias significativas entre estos valores $(\mathrm{p} \leq 0,05)$ (Figura 5.3). La CHasa permaneció estable dentro del rango de $\mathrm{pH}$ evaluado $(5,0$ a 8,0) observándose una leve disminución de la estabilidad a las 48 h de incubación (96\% de su máxima actividad). Valores similares se observaron para CHasas producidas por otras cepas de Aspergillus. Una CHasa tetramérica de $A$. niger presentó actividad máxima a $\mathrm{pH}$ 6,5 y fue estable en un rango de $\mathrm{pH}$ entre 3,0 y 8,0 (Schöbel y Pollmann, 1980b). La máxima actividad enzimática de una hidroxicinamato éster hidrolasa de A. japonicus ATCC 20236, producida en un medio de cultivo con salvado de trigo como fuente de carbono y energía (FCE) e inductor, se observó a pH 6,5 y dicha enzima fue estable en un rango de pH entre 3,0 y 7,5 (Okamura y Watanabe, 1982b). Mientras que una CHasa de A. niger BRFM 131 presentó actividad máxima a $\mathrm{pH}$ 6,0 y fue estable en el rango de $\mathrm{pH}$ entre 5,5 y 7,0 (Asther y col., 2005). La CHasa de A. niger BRFM 131 fue clonada y caracterizada dando un pH óptimo de 6,0 y una estabilidad de $\mathrm{pH}$ entre 3,8 y 7,8 (Benoit y col., 2007). Adachi y col (2008) informaron que una CHasa producida por A. sojae AKU 3312 exhibió máxima actividad a $\mathrm{pH}$ 7,0-7,5 y fue estable en el rango de pH entre 4,0 y 9,0 .

\subsubsection{Efecto de la temperatura sobre la estabilidad CHasa:}

En la Figura 5.4 se presentan los valores de actividad enzimática residual, luego de incubar el EE a diferentes temperaturas durante $8 \mathrm{~h}$, a los efectos de evaluar la estabilidad térmica de CHasa. La enzima, luego de haber sido incubada durante $6 \mathrm{~h}$ a 30,40 y $50{ }^{\circ} \mathrm{C}$, permaneció prácticamente estable, al $\mathrm{pH}$ óptimo, conservando más del $90 \%$ de su actividad inicial. A partir de las 6 h se observa una leve disminución de la actividad CHasa cuando la enzima fue incubada a 40 y $50{ }^{\circ} \mathrm{C}(75 \%$ actividad inicial a las $8 \mathrm{~h}$ de incubación). En cambio, a $60{ }^{\circ} \mathrm{C}$ la velocidad de inactivación térmica fue mayor y luego de $1 \mathrm{~h}$ de incubación la actividad residual fue del $30 \%$. 


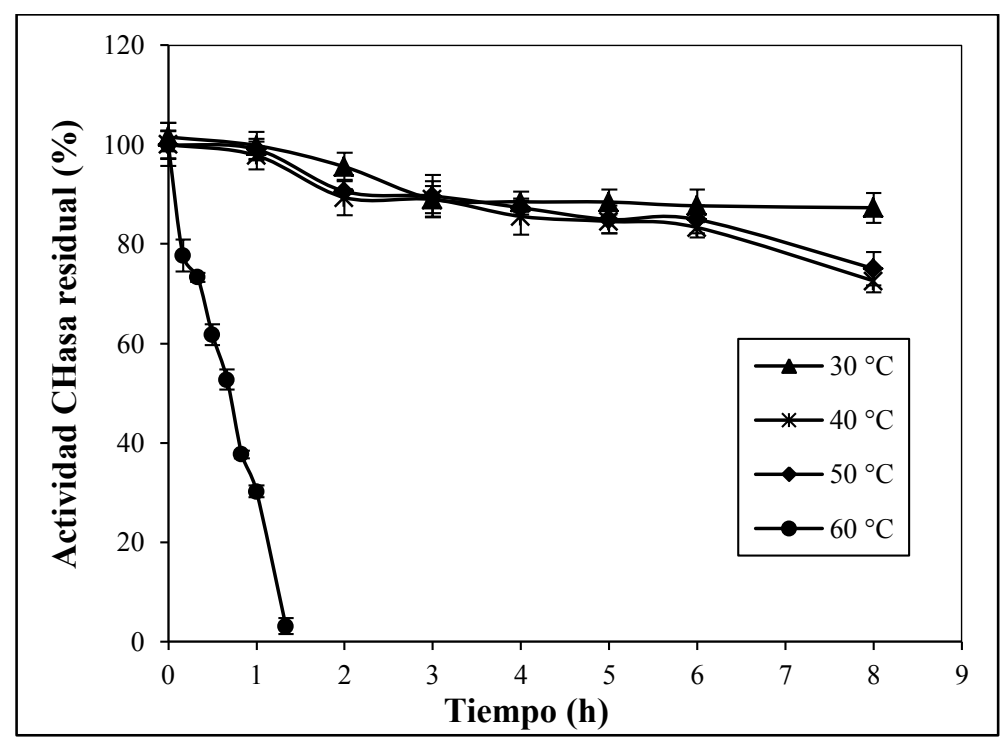

Figura 5.4: Efecto de la temperatura sobre la estabilidad de la enzima CHasa.

En general, la estabilidad térmica de la enzima CHasa producida por $A$. niger AKU 3302 fue superior a aquellas reportadas para otras CHasas producidas por diferentes cepas fúngicas.

Schobel and Pollmann (1980b) al estudiar el efecto de la temperatura de incubación sobre la actividad de una CHasa tetramérica producida por A. niger, observaron que dicha enzima fue estable hasta $\operatorname{los} 55{ }^{\circ} \mathrm{C}$ cuando fue incubada por $10 \mathrm{~min}$, momento a partir de la cual fue desnaturalizada rápidamente. Mientras que una hidroxicinamato éster hidrolasa de A. japonicus ATCC 20236 fue estable hasta los $60{ }^{\circ} \mathrm{C}$ cuando fue incubada por 10 min (Okamura y Watanabe, 1982b). La CHasa nativa de A. niger BRFM 131, fue estable por debajo de $\operatorname{los} 30^{\circ} \mathrm{C}$, menos estable a $55^{\circ} \mathrm{C}$ y a partir de 60 ${ }^{\circ} \mathrm{C}$ comenzó su inactivación térmica, inactivándose completamente dentro de los 10 min, a $70^{\circ} \mathrm{C}$ (Asther y col., 2005). La proteína recombinante clonada de A. niger BRFM 131 fue más estable frente a la temperatura reteniendo su actividad a $37{ }^{\circ} \mathrm{C}$ durante 90 min. La incubación durante el mismo período de tiempo a $45{ }^{\circ} \mathrm{C}$ y $50{ }^{\circ} \mathrm{C}$ llevó a pérdidas de actividad del $23 \%$ y el $40 \%$, respectivamente. A $60{ }^{\circ} \mathrm{C}$, hubo una disminución del $50 \%$ en la actividad y a $65{ }^{\circ} \mathrm{C}$, la CHasa se inactivó rápidamente (Benoit y col., 2007). Adachi y col. (2008) informaron que una CHasa de A. niger AKU 3312 fue estable hasta $\operatorname{los} 50^{\circ} \mathrm{C}$ durante $30 \mathrm{~min}$. 


\subsubsection{Efecto combinado del pH y la temperatura sobre la actividad CHasa:}

En general las condiciones de reacción enzimática han sido tradicionalmente optimizadas por la estrategia de modificar una variable por vez, mientras se mantienen las otras a un nivel constante. Aunque esta estrategia es sencilla, requiere un gran número de experimentos y la interacción entre factores es ignorada. En contraste, los diseños experimentales basados en la estadística son aproximaciones más eficientes que pueden llevarse a cabo con un gran número de variables simultáneamente, además se pueden estimar las interacciones entre las variables.

Se estudiaron las condiciones óptimas de reacción, en términos de $\mathrm{pH}$ y temperatura, empleando ACG como sustrato y analizando el efecto de ambos factores combinados mediante superficie de respuesta a fin de reducir el número de experimentos sin desechar las interacciones entre dichos parámetros (diseño de Doehlert). La Tabla 5.3 representa la combinación de tratamientos y la variable respuesta obtenida, expresada en actividad CHasa, para cada tipo de buffer de reacción utilizado.

Tabla 5.3: Valores reales (datos experimentales) y actividad enzimática obtenidos en el diseño experimental de Doehlert para el estudio del efecto del $\mathrm{pH}$ y la temperatura sobre la actividad CHasa.

\begin{tabular}{cccccc}
\hline Exp. $\mathrm{N}^{\circ}$ & Temperatura $\left({ }^{\circ} \mathrm{C}\right)$ & $\mathrm{pH}_{\mathrm{TMG}}$ & $\mathrm{CHasa}(\mathrm{UE} / \mathrm{ml})$ & $\mathrm{pH}_{\mathrm{BFS}}$ & $\mathrm{CHasa}(\mathrm{UE} / \mathrm{ml})$ \\
\hline 1 & 45 & 8,5 & 0,533 & 8,0 & 1,105 \\
2 & 30 & 8,0 & 0,761 & 7,5 & 1,016 \\
3 & 30 & 7,0 & 1,021 & 6,5 & 1,123 \\
4 & 45 & 6,5 & 0,970 & 6,0 & 1,340 \\
5 & 60 & 7,0 & 0,962 & 6,5 & 1,094 \\
6 & 60 & 8,0 & 0,956 & 7,5 & 0,893 \\
7 & 45 & 7,5 & 1,292 & 7,0 & 1,484 \\
8 & 45 & 7,5 & 1,311 & 7,0 & 1,443 \\
9 & 45 & 7,5 & 1,322 & 7,0 & 1,424 \\
\hline
\end{tabular}

BTMG: buffer Tris-MES-Glicina (20 mM). BFS: buffer fosfato de sodio (50 mM).

Los datos de la Tabla 5.3 fueron convertidos en una ecuación polinomial de segundo orden. A continuación se presentan las ecuaciones de regresión utilizadas para calcular la actividad CHasa: 
CHasa $(U E / m l)_{B T M G}=1,308-0,19 * p H-0,039 * T-0,557 * p H^{2}-0,325 * T^{2}-$ $-0,147 * p H * T$

$C H a s a(U E / m l)_{B N P}=1,45-0,142 * p H-0,228 * p H^{2}-0,508 * T^{2} \quad$ (ec. 5.12)

donde $p H$ y $T$ representan los datos codificados. Los valores de $\mathrm{r}^{2}$ para las ecuaciones (5.11) y (5.12) fueron iguales a 0,99 y 0,98 , respectivamente, de modo que ambas ecuaciones presentaron un muy buen ajuste a los datos experimentales. Las superficies de respuesta y gráficos de contorno de la actividad CHasa observada como respuesta a la interacción del pH frente a la temperatura se muestran en las Figuras 5.4 y 5.5 para cada tipo de buffer de reacción.

En la Figura 5.5 se observa que cuando se utilizó BTMG como buffer de reacción la temperatura óptima fue de $45^{\circ} \mathrm{C}$ y el $\mathrm{pH}$ óptimo estuvo en el rango de 7,0-7,5. Un resultado similar se observa en la Figura 5.6 al utilizar BFS como buffer de reacción, manteniéndose la temperatura óptima en $45^{\circ} \mathrm{C}$ pero con un leve corrimiento del $\mathrm{pH}$ óptimo al rango entre 6,5-7,0. Aunque la temperatura óptima para la hidrólisis del ACG es de $45{ }^{\circ} \mathrm{C}$, se propone una temperatura de $30{ }^{\circ} \mathrm{C}$ (temperatura ambiente) para aplicaciones prácticas a los efectos de reducir los costos inherentes al calentamiento. En estas condiciones la CHasa retiene más del $80 \%$ de su actividad óptima.

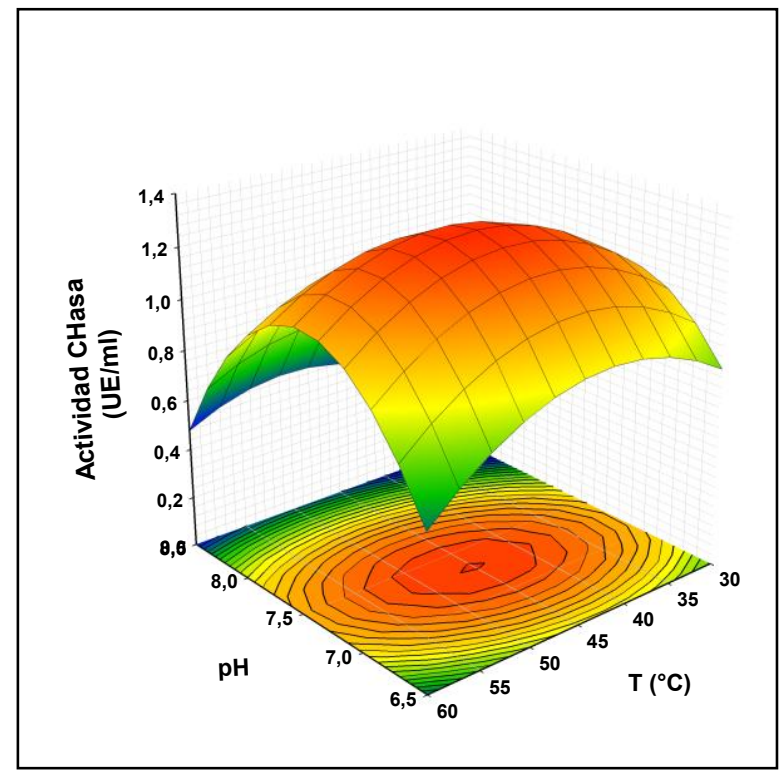

Figura 5.5: Superficie de respuesta y grafico de contorno mostrando el efecto del pH y la temperatura en la actividad CHasa utilizando BTMG como buffer de reacción. 


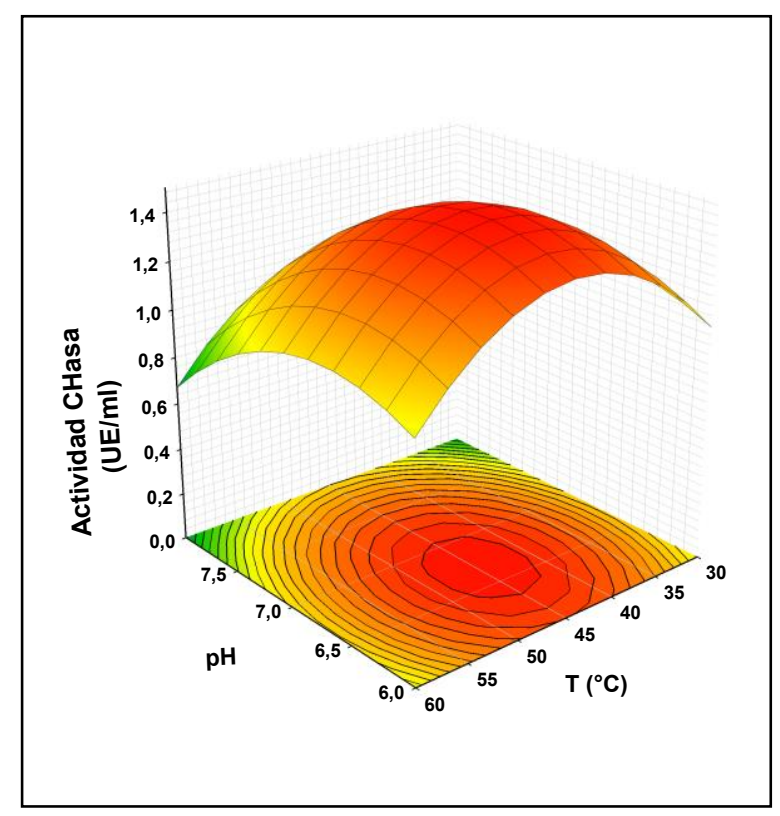

Figura 5.6: Superficie de respuesta y grafico de contorno mostrando el efecto del $\mathrm{pH}$ y la temperatura en la actividad CHasa utilizando BFS como buffer de reacción.

Resultados similares de $\mathrm{pH}$ y temperatura óptimos fueron informados por otros autores. Schöbel y Pollmann (1980b) informaron valores de $\mathrm{pH}$ y temperatura óptimos de 6,5 y $45{ }^{\circ} \mathrm{C}$, respectivamente, para una CHasa tetramérica producida por una cepa A. niger. Similarmente, el $\mathrm{pH}$ y la temperatura óptimos para una hidroxicinamato éster hidrolasa de A. japonicus ATCC 20236 (Okamura y Watanabe, 1982b) fueron de 6,5 y $55{ }^{\circ} \mathrm{C}$. Asther y col. (2005) obtuvieron valores de $\mathrm{pH}$ y temperatura óptimos para una CHasa de $A$. niger BRFM 131 de 6,0 y $55{ }^{\circ} \mathrm{C}$, respectivamente. La CHasa de A. niger BRFM 131 fue clonada y caracterizada dando el mismo valor de $\mathrm{pH}$ para el óptimo y una temperatura óptima más elevada e igual a $60{ }^{\circ} \mathrm{C}$ (Benoit y col., 2007). Adachi y col. (2008) reportaron un valor de $\mathrm{pH}$ óptimo en el rango de 7,0-7,5 para una CHasa de $A$. sojae AKU 3312.

\subsubsection{Determinación de los parámetros cinéticos:}

A los efectos de determinar las constantes cinéticas de la enzima $\left(V_{\text {máx }}\right.$ y $\left.K_{m}\right)$, se determinaron las velocidades iniciales con diferentes concentraciones de sustrato (ACG) (Fig. 5.7). 


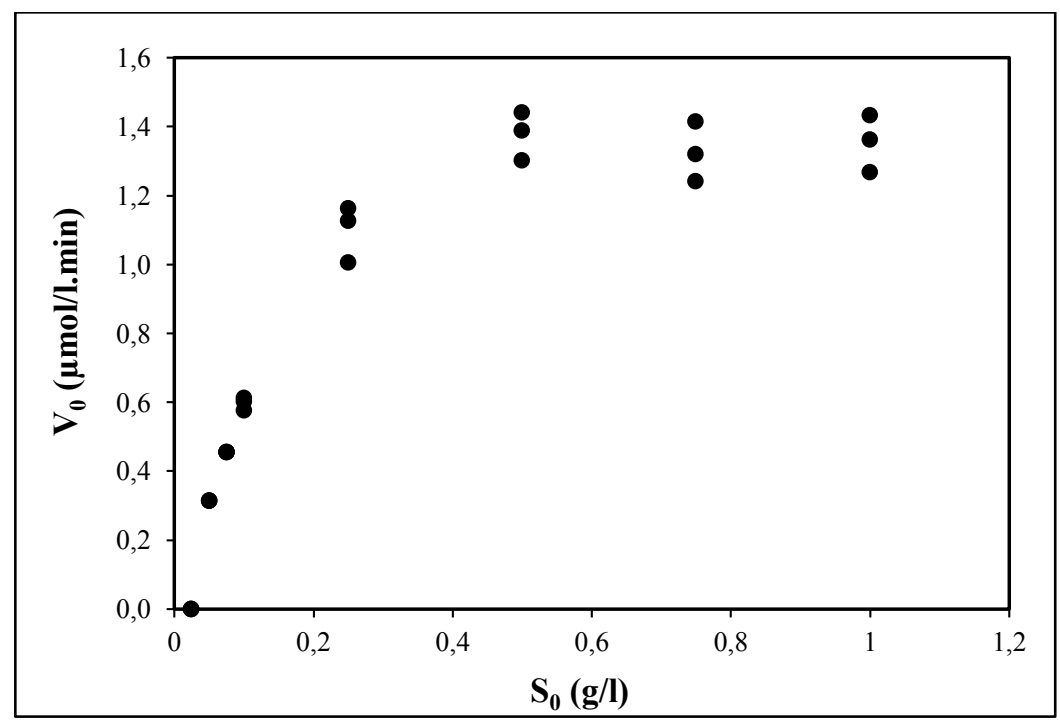

Figura 5.7: Gráfica de Michaelis-Menten. $V_{0}$ : Velocidad inicial. $S_{0}$ : concentración de sustrato.

Se encontró que la cinética de hidrólisis de ACG puede ser descripta por una cinética del tipo de Michaelis-Menten la cual responde a una ecuación del tipo:

$$
V=V_{\max } \frac{S}{K_{m}+S} \quad(\text { ec. 5.13) }
$$

Los valores de $\mathrm{K}_{\mathrm{m}}$ para CHasa, estimados a partir de la gráfica de Lineweaver-Burk (Fig. 5.8) y la gráfica de Eadie-Hofstee (Fig. 5.9) fueron de 0,257 y 0,229 g/l, respectivamente, con ACG como sustrato. Los valores de $\mathrm{V}_{\text {máx }}$ obtenidos a partir de las 2 gráficas fueron 1,996 y $1,901 \mu \mathrm{mol} / 1 . \mathrm{min}$, respectivamente.

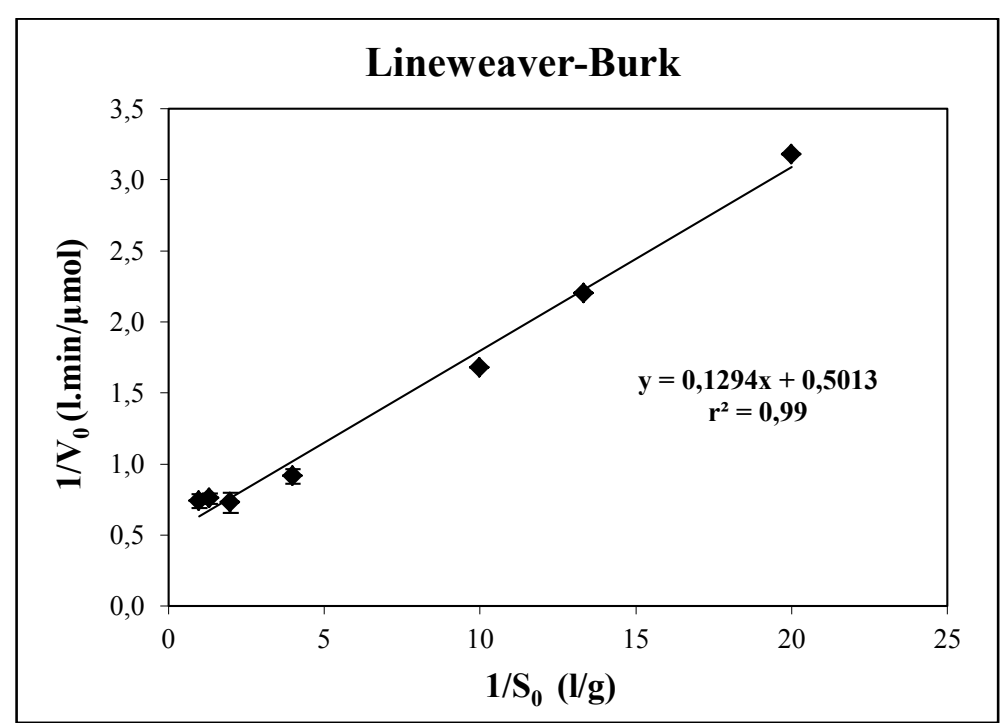

Figura 5.8: Gráfico de Lineweaver-Burk para la CHasa de A. niger AKU 3302. 


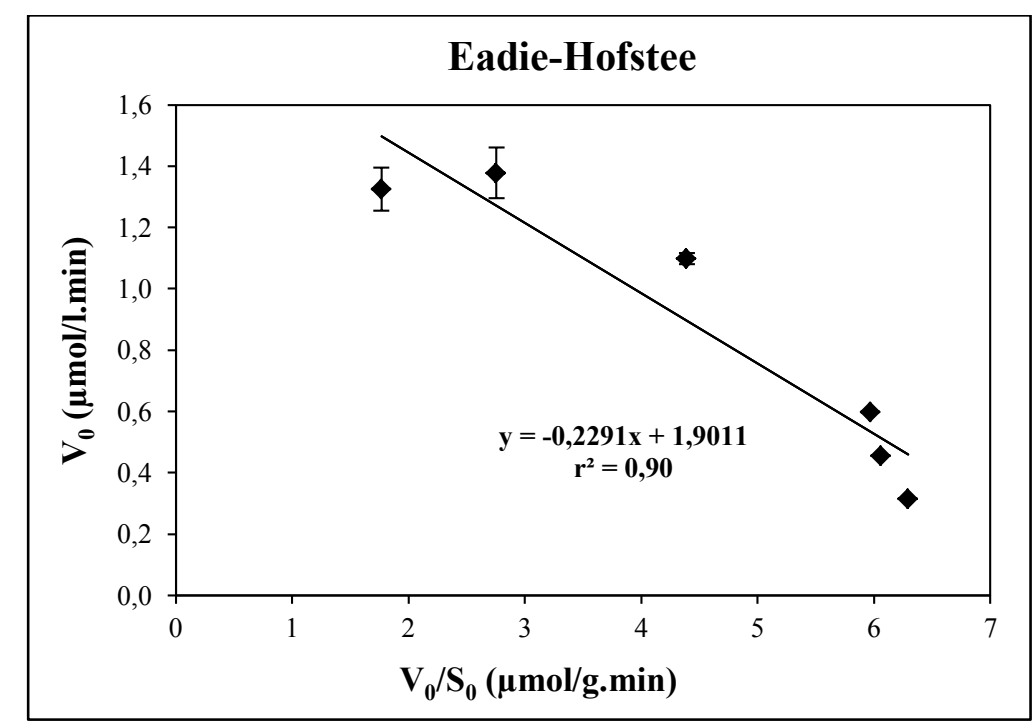

Figura 5.9: Gráfico de Eadie-Hofstee para la CHasa de A. niger AKU 3302.

Schobel y Pollmann (1980a) informaron un valor de $\mathrm{K}_{\mathrm{m}}$ muy similar e igual a 0,248 g/l para una CHasa de A. niger utilizando ACG como sustrato. Por el contrario, Asther y col. (2005) informaron valores de $\mathrm{K}_{\mathrm{m}}$ de $0,0035 \mathrm{~g} / 1$ para una CHasa de A. niger BRFM 131 utilizando ACG como sustrato. La CHasa de A. niger BRFM 131 fue clonada y caracterizada dando un valor de $\mathrm{K}_{\mathrm{m}}$ aún menor e igual a 0,0023 g/l (Benoit y col., 2007). Una CHasa de A. sojae AKU 3312 (Adachi y col., 2008) presentó un valor de $\mathrm{K}_{\mathrm{m}}$ similar a la CHasa de $A$. niger AKU 3302 e igual a 0,262 g/l utilizando diferentes concentraciones de ACG como sustrato a $\mathrm{pH}$ 7,5.

\subsubsection{Energía de activación y parámetros termodinámicos:}

La energía de activación ( $\left.\mathrm{E}_{\mathrm{a}}\right)$ para CHasa de A. niger AKU 3302, calculada mediante la gráfica de Arrhenius, fue de $6,38 \mathrm{kcal} / \mathrm{mol}$ con un coeficiente de determinación de $\mathrm{r}^{2}=0,98$ (Fig. 5.10).

A $45^{\circ} \mathrm{C}$ la CHasa exhibió su máxima actividad catalítica en la conversión del sustrato (ACG), utilizando la energía de activación antes mencionada. A partir de esta temperatura, la enzima comenzó el proceso de desnaturalización, disminuyendo su actividad hacia la conversión del sustrato en productos. Un valor bajo para la energía de activación indica una buena relación entre la enzima y el sustrato.

Schobel y Pollmann (1980b) informaron un valor de $E_{a}$ muy similar e igual a $6 \mathrm{kcal} / \mathrm{mol}$ para una CHasa tetramérica de $A$. niger. 


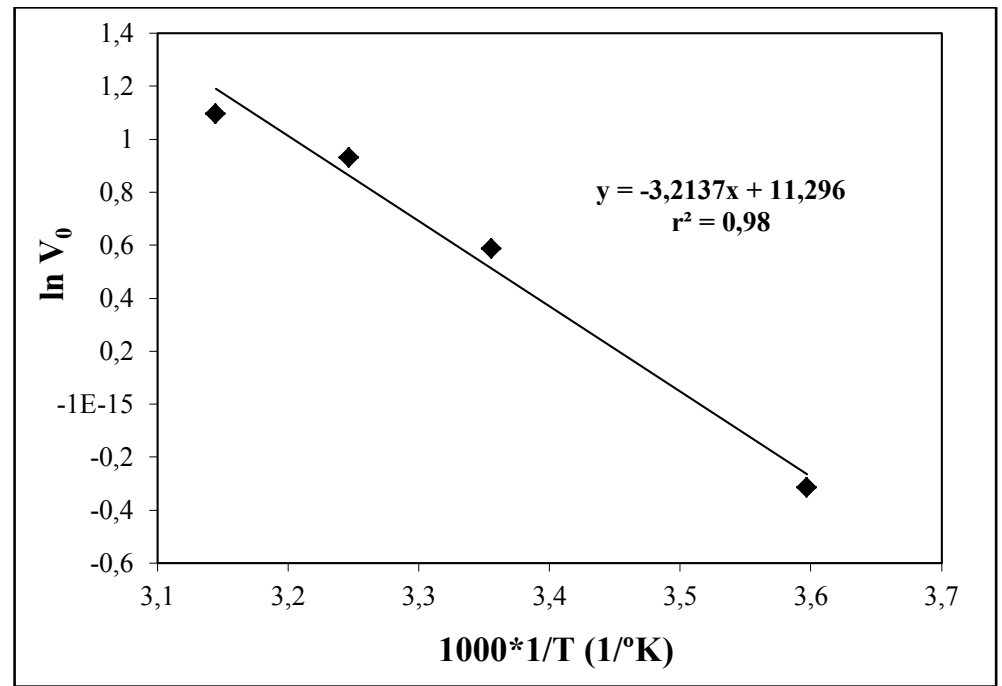

Figura 5.10: Grafico de Arrhenius para la determinación de la energía de activación de la CHasa de A. niger AKU 3302.

La entalpía de activación $\left(\Delta H^{*}\right)$ fue positiva y decreció con el aumento de la temperatura de incubación. Un valor de entalpía positivo indica que para formar el estado de transición deben tensionarse o distorsionarse algunos enlaces, consumiendo calor (energía). Los valores positivos para $\Delta G^{*}$ indicaron que se trató de una reacción endergónica. La entropía de la enzima $\left(\Delta S^{*}\right)$ fue negativa y disminuyó con el incremento de la temperatura de incubación (Tabla 5.4).

Tabla 5.4: Parámetros termodinámicos de CHasa de A. niger AKU 3302.

\begin{tabular}{cccc}
\hline Temperatura $\left({ }^{\circ} \mathrm{K}\right)$ & $\Delta \mathrm{G}^{*}(\mathrm{kcal} / \mathrm{mol})$ & $\Delta \mathrm{H}^{*}(\mathrm{kcal} / \mathrm{mol})$ & $\Delta \mathrm{S}^{*}\left(\mathrm{cal} / \mathrm{mol} .{ }^{\circ} \mathrm{K}\right)$ \\
\hline 278 & 16,38 & 5,832 & $-37,950$ \\
298 & 17,14 & 5,793 & $-38,088$ \\
308 & 17,52 & 5,773 & $-38,153$ \\
318 & 17,91 & 5,753 & $-38,217$ \\
\hline
\end{tabular}

\subsubsection{Determinación del coeficiente $Q_{10}$ :}

Una característica distintiva de la catálisis enzimática es que el valor de $\mathrm{Q}_{10}$ (incremento en la velocidad de la reacción enzimática por cada $10^{\circ} \mathrm{K}$ de incremento en la temperatura) de una reacción catalizada es menor en comparación con la misma reacción no catalizada. 
El valor del coeficiente $\mathrm{Q}_{10}$ obtenido para la CHasa de $A$. niger AKU 3302 fue de 1,405. Similarmente, una CHasa de A. niger (Schobel y Pollmann, 1980b) presentó un valor de $\mathrm{Q}_{10}$ de 1,5 .

\subsubsection{Ensayos de hidrólisis de ácido clorogénico en el extracto concentrado de yerba mate}

5.3.3.1. Hidrólisis enzimática del ACG en función del tiempo de tratamiento:

Se ensayó la capacidad del EE de A. niger AKU 3302 de hidrolizar el ACG contenido en el EYM. El estudio de hidrólisis del ACG en el EYM se realizó a $30{ }^{\circ} \mathrm{C}$. El EYM convenientemente diluido en BFS (50 $\mathrm{mM})$ presentó un valor final de $\mathrm{pH}$ de 6,0, bajo estas condiciones la actividad de la CHasa fue del $72 \%$ de su actividad máxima (pH: 7 7,5). En la Figura 5.11, se presenta la evolución de la hidrólisis del ACG en el EYM (valores porcentuales) en función del tiempo del tratamiento enzimático, utilizando un EE con actividad CHasa de $\sim 12,08 \mathrm{UE} / \mathrm{ml}$ y una relación sustrato/enzima: 25/1,5 (v/v). Puede observarse que la hidrólisis del ACG fue rápida y continuó con el tiempo de reacción hasta los 30 min, tiempo a partir del cual el ACG contenido en la solución de EYM fue completamente hidrolizado.

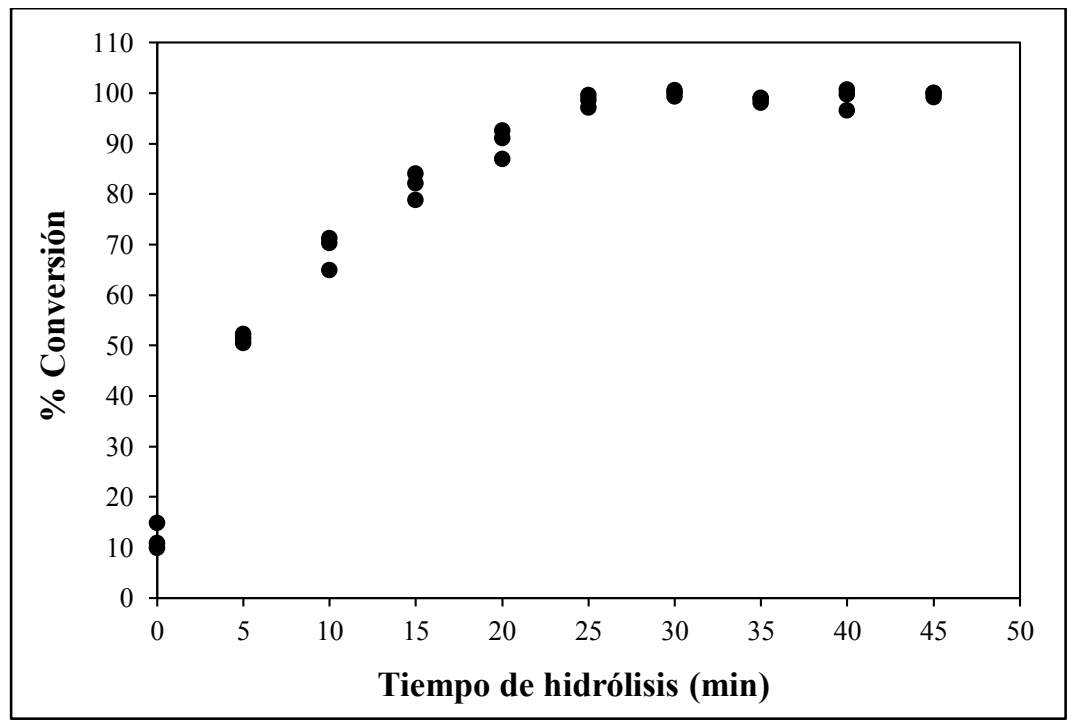

Figura 5.11: Hidrólisis enzimática de ACG en un extracto acuoso concentrado de yerba mate a $30{ }^{\circ} \mathrm{C}$ empleando un extracto enzimático de $A$. niger AKU 3302. 
5.3.3.2. Análisis cuantitativo del sustrato (ACG) y los productos de hidrólisis (AQ y $A C)$ :

La identificación y cuantificación del ACG, AC y AQ en el EYM antes y después de la hidrólisis enzimática con el EE, fue monitoreada por HPLC, utilizando un detector de índice de refracción. En la Figura 5.12 se presentan los cromatogramas de los respectivos patrones utilizados para la identificación y cuantificación de los distintos compuestos.

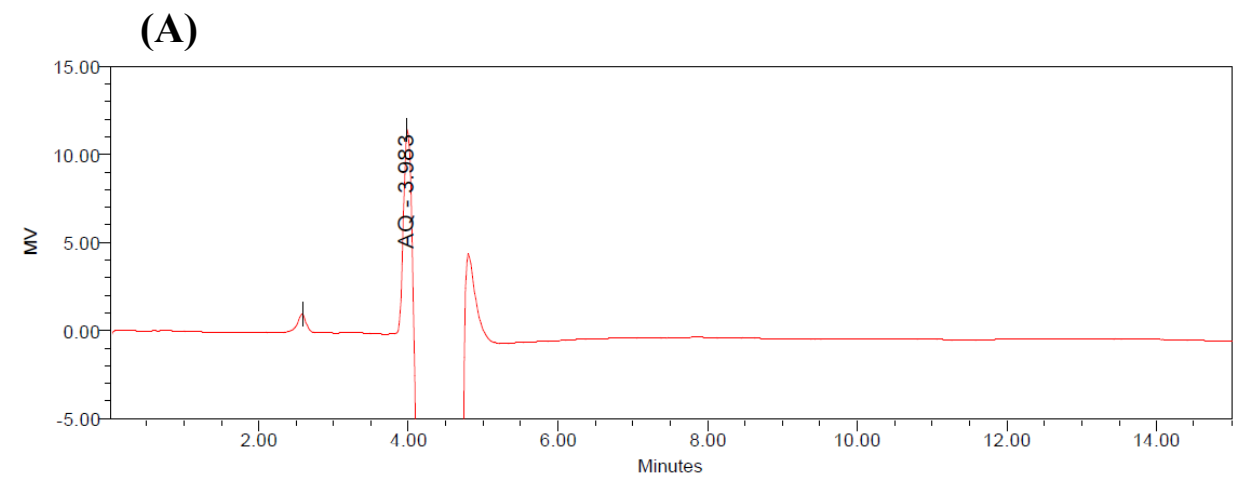

(B)

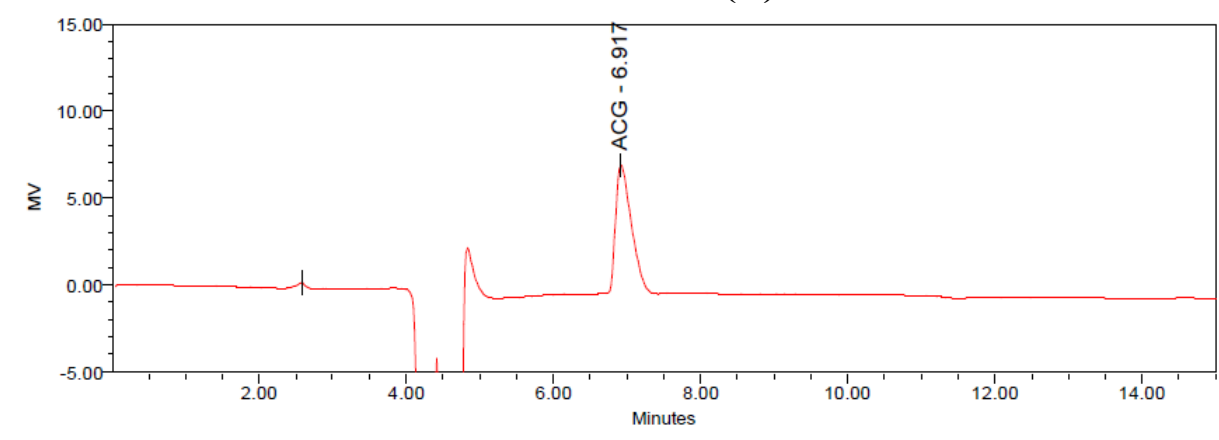

(C)

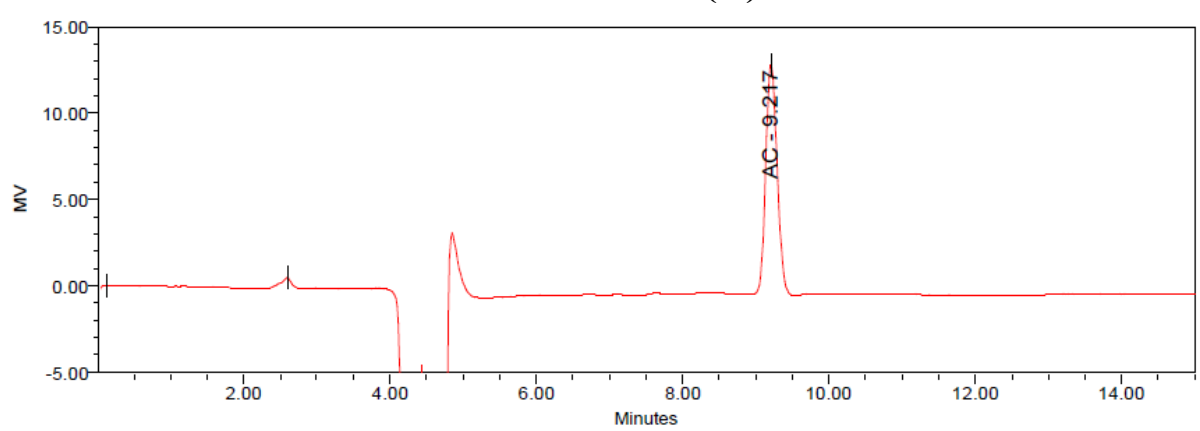

Figura 5.12: Perfil cromatográfico representativo de los respectivos patrones empleando un sistema de HPLC con detector de índice de refracción. (A): ácido quínico, AQ; (B): ácido clorogénico, ACG; (C): ácido cafeico, AC. 
Los tiempos de retención estándar para cada uno de los compuestos fueron 3,98 min para $A Q, 6,92$ min para $A C G$ y 9,22 min para $A C$, bajo las condiciones de ensayo.

En las Figuras 5.13 y 5.14, se presentan los cromatogramas del EYM antes y después de la hidrólisis con el EE, respectivamente, en los cuales se identifican los picos de ACG, $\mathrm{AC}$ y $\mathrm{AQ}$.

En la Tabla 5.5 se muestran las concentraciones de cada compuesto, expresadas en base seca.

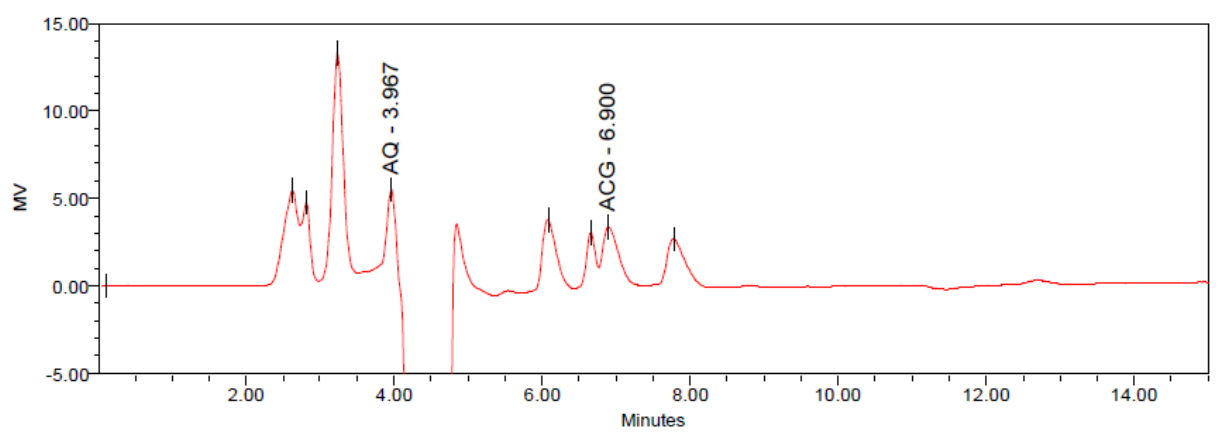

Figura 5.13: Perfil cromatográfico del EYM antes de la hidrólisis con el EE, empleando un sistema de HPLC con detector de índice de refracción.

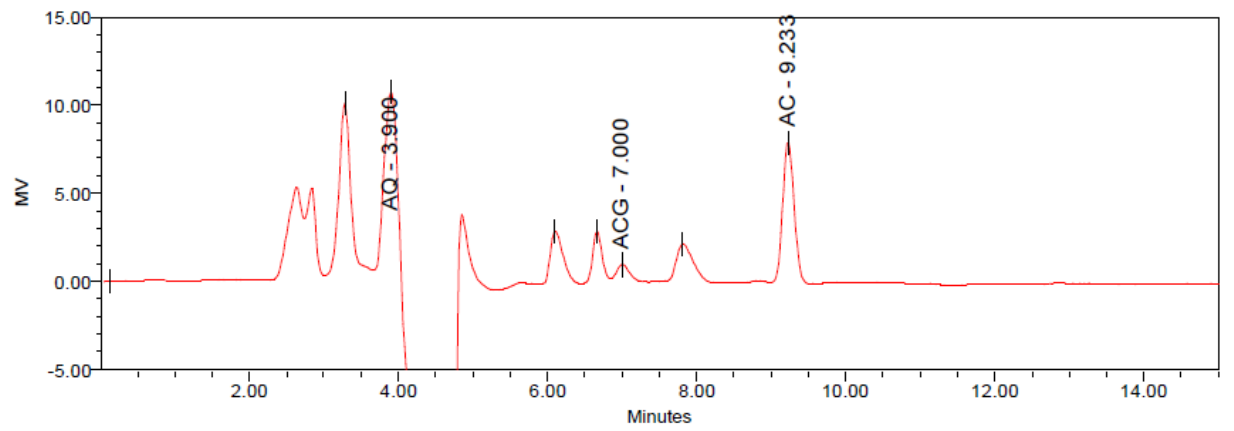

Figura 5.14: Perfil cromatográfico del EYM después de la hidrólisis con el EE durante $8 \mathrm{~h}$ a 30 ${ }^{\circ} \mathrm{C}$, empleando un sistema de HPLC con detector de índice de refracción. Se incubaron $990 \mu 1$ del EYM diluido 1/50 en BFS $(50 \mathrm{mM}, \mathrm{pH}: 6,5)$ con $10 \mu 1 \mathrm{EE}$.

Tabla 5.5: Contenido de ACG, AC y AQ antes y después de la hidrólisis enzimática del EYM con el EE de A. niger AKU 3302.

\begin{tabular}{cccc}
\hline $\begin{array}{c}\text { Compuesto } \\
\left(\mu \mathrm{mol} / \mathrm{g}_{\mathrm{ms}}\right)\end{array}$ & $\begin{array}{c}\text { Antes del tratamiento } \\
\text { (control) }\end{array}$ & $\begin{array}{c}\text { Después del tratamiento } \\
\text { (enzima) }\end{array}$ & Diferencia \\
\hline ACG & 2,98 & 0,74 & $-2,24$ \\
AC & nd & 3,86 & $+3,86$ \\
AQ & 1,54 & 6,85 & $+5,31$ \\
\hline
\end{tabular}

nd: no detectado. 
Se determinó el contenido inicial de ACG, AC y AQ en la solución de sustrato antes de la hidrólisis enzimática y se expresó como $\mu \mathrm{mol} / \mathrm{g}_{\mathrm{ms}}$. El EYM contenía inicialmente $2,98 \mu \mathrm{mol} / \mathrm{g}_{\mathrm{ms}}$ de ACG y $1,54 \mu \mathrm{mol} / \mathrm{g}_{\mathrm{ms}}$ de AQ y no se detectaron cantidades significativas de AC (Fig. 5.13 y Tabla 5.5). La incubación de la solución de sustrato con el EE con actividad CHasa durante $8 \mathrm{~h}$, condujo a la hidrólisis de $75 \%$ del ACG presente en el EYM. Por otra parte, después de la hidrólisis enzimática se evidenció un marcado incremento en las cantidades de AC y AQ. En el caso del AC, la cantidad producida resulta un $72 \%$ superior a la cantidad equivalente de ACG hidrolizado en tanto que en el del AQ este valor se incrementa al $137 \%$. Estos resultados indican que al menos el $42 \%$ del AC y el $58 \%$ del AQ producidos fueron obtenidos, probablemente, a partir de otros compuestos (i.e.: ésteres) diferentes al ACG (Fig. 5.14 y Tabla 5.5). En el capítulo 1 se describió una serie de compuestos de naturaleza polifenólica presentes en extractos de yerba mate. Entre ellos, los diferentes ácidos hidroxicinámicos que originan cantidades significativas de AQ por hidrólisis. También se mencionó la existencia de varios compuestos de estructura similar al ACG, pero con 2 restos de $\mathrm{AC}$ unidos al resto de $\mathrm{AQ}$ en diferentes posiciones (los ácidos dicafeoilquínicos, DCQ) tales como los isómeros 3,4-, 3,5- y 4,5-dicafeoilquínico. Todos estos compuestos pueden ser hidrolizados por la CHasa dada la similitud en sus estructuras químicas. Por ello, es muy razonable no encontrar una relación $1: 1$ entre la cantidad de ACG hidrolizado y las cantidades de AC y AQ producidas, como se verificó experimentalmente. Cualquiera sea el caso, la formación de cantidades de AC y fundamentalmente de AQ superiores a las esperadas a partir de la hidrólisis del ACG resulta ser sumamente positivo considerando el fin último de la presente investigación.

Asther y col. (2005) informaron que una CHasa purificada de A. niger BRFM 131 fue capaz de hidrolizar el $100 \%$ del ACG (12 $\mu \mathrm{mol}$ ACG/g ms) contenido en la de pulpa de café, produciendo simultáneamente una gran cantidad de AC (21 $\mu \mathrm{mol} \mathrm{AC/g} \mathrm{ms).} \mathrm{Estos}$ mismo autores, al estudiar la hidrólisis enzimática del ACG contenido en el orujo de manzana, alcanzaron rendimientos cercanos al $86 \%(1,9 \mu \mathrm{mol} \mathrm{ACG} / \mathrm{g} \mathrm{ms})$.

Adachi y col. (2008) obtuvieron rendimientos del $100 \%$ (75-280 mg ACG/2 g ms) luego de la hidrólisis del ACG contenido en diferentes extractos de café instantáneo mediante una CHasa inmovilizada en pulpa de café por fermentación tipo koji. 
Similarmente, se produjo un incremento notorio en el contenido de AC (98-110 $\mu$ mol $\mathrm{AC} / \mathrm{g} \mathrm{ms})$ luego de la hidrólisis enzimática.

De manera similar a las observaciones de Asther y col. (2005) y Adachi y col. (2008), en el presente estudio se produjo un aumento en la producción de AC y AQ luego de la hidrólisis enzimática, probablemente porque el EE crudo pudo haber producido varias clases de esterasas además de la CHasa.

\subsection{CONCLUSIONES}

Los resultados obtenidos demostraron que el extracto enzimático de A. niger AKU 3302 posee actividad CHasa. No se detectó actividad polifenoloxidasa.

La enzima CHasa, presentó estabilidad térmica a temperaturas relativamente altas (hasta $\left.50{ }^{\circ} \mathrm{C}\right)$ y fue estable en un amplio rango de $\mathrm{pH}(2,0$ a 9,0). El tipo de buffer no influyó en la estabilidad de la enzima. El pH óptimo de actividad CHasa estuvo entre 7,0 y 7,5 en BTMG y entre 6,5 y 7,0 en BFS, mientras que la temperatura óptima de actividad fue de $45{ }^{\circ} \mathrm{C}$. Sin embargo, se seleccionó una temperatura entre 28 y $30{ }^{\circ} \mathrm{C}$ para aplicaciones prácticas a los efectos de reducir los costos inherentes al calentamiento en las futuras etapas de escalado. En estas condiciones la CHasa muestra más del $80 \%$ de su actividad óptima. Los valores de $\mathrm{K}_{\mathrm{m}}$ para la enzima CHasa estimados a partir de la gráfica de Lineweaver-Burk y la gráfica de Eadie-Hofstee fueron de 0,257 y 0,229 g/l, respectivamente. Mientras que los valores de $\mathrm{V}_{\text {máx }}$ obtenidos con cada gráfica fueron de 1,996 y 1,901 $\mu \mathrm{mol} / 1$.min., respectivamente. El coeficiente de temperatura fue de 1,5 y la energía de activación $\left(\mathrm{E}_{\mathrm{a}}\right)$ de $6,38 \mathrm{kcal} / \mathrm{mol}$.

Se demostró la capacidad de la enzima CHasa para hidrolizar el ACG contenido en sustratos naturales. El EYM fue seleccionado debido a su elevado contenido en ACG. La enzima CHasa fue capaz de hidrolizar más del $75 \%$ del ACG contenido en distintas soluciones diluidas de EYM. Asimismo, las cantidades de AC y AQ liberadas del EYM fueron mayores que la cantidad de ACG hidrolizado. Estos resultados sugieren que la CHasa es capaz de actuar sobre otros ésteres del AQ presentes en la solución de sustrato, tales como, los ácidos dicafeoilquínicos, cafeoilquínicos y ferúlicos (Clifford, 1999, 2000).

La utilización del extracto enzimático crudo con elevada actividad CHasa representa una nueva herramienta clave potencial para la liberación de compuestos fenólicos (AC y 
AQ) de interés y aplicación industrial (como antioxidantes, intermediarios clave en la síntesis de nuevos fármacos, etc.). 


\section{Capítulo 6}

Jroducción y earacterización de un

\section{micelio inmovilizado de $\mathcal{A}$. miger \\ AX21 3302 eon actividad elorogenato hideolasa}




\title{
CAPÍTULO 6 \\ PRODUCCIÓN Y CARACTERIZACIÓN DE UN MICELIO INMOBILIZADO DE $A$. NIGER AKU 3302 CON ACTIVIDAD CLOROGENATO HIDROLASA
}

\begin{abstract}
Resumen
La cepa de A. niger AKU 3302 forma pellets con elevada actividad CHasa al crecer en medio líquido (capítulo 4). El uso de estos pellets directamente como biocatalizador no viable (enzima naturalmente inmovilizada) está condicionado por sus propiedades catalíticas, por lo que se hace necesaria su caracterización. A tal efecto, se plantearon los siguientes objetivos: preparar un micelio no viable de A. niger AKU 3302 con actividad CHasa naturalmente inmovilizada $\left(\mathrm{CHasa}_{\mathrm{NI}}\right)$ y determinar sus condiciones óptimas de operación así como sus parámetros cinéticos y termodinámicos a fin de establecer las condiciones apropiadas para su utilización en la hidrólisis del ácido clorogénico (ACG) presente en sustratos naturales.

Se cultivó la cepa de $A$. niger AKU 3302 en frascos agitados $\left(180 \mathrm{rpm}, 3\right.$ días, $\left.30^{\circ} \mathrm{C}\right)$ en medio Czapek líquido, utilizando un extracto acuoso concentrado de yerba mate como inductor. Los pellets fueron separados por filtración y lavados con agua destilada. Se estudiaron las condiciones óptimas para la inactivación térmica del micelio (pérdida de viabilidad) preservando la propiedad catalítica de interés (CHasa) utilizando la metodología de superficie de respuesta (diseño de Doehlert). Las variables estudiadas fueron: temperatura de incubación $\left(45\right.$ a $\left.60{ }^{\circ} \mathrm{C}\right)$ y tiempo de incubación $(20$ a $60 \mathrm{~min})$.

La posibilidad de limitaciones en la transferencia de masa externa fue evaluada midiendo el efecto de la velocidad de agitación ( 0 a 200 golpes $/ \mathrm{min}$ ) sobre la conversión del ACG. El pH y la temperatura óptimos de la $\mathrm{CHasa}_{\mathrm{NI}}$ se determinaron a diferentes $\mathrm{pHs}$ (entre 5,0 a 8,0 con buffer fosfato de sodio, BFS; y entre 2,0 a 10,0 con buffer Tris-MES-Glicina, BTMG) y temperaturas $\left(30\right.$ a $\left.80^{\circ} \mathrm{C}\right)$. El efecto del $\mathrm{pH}$ y la temperatura sobre la estabilidad de $\mathrm{CHasa}_{\mathrm{NI}}$ se determinaron por pre-incubación en ausencia de sustrato, a diferentes valores de pHs (2 a 10 para BTMG y 5 a 8 para BFS) durante 24 y $48 \mathrm{~h}$, a $5{ }^{\circ} \mathrm{C}$ y a diferentes temperaturas $\left(30\right.$ a $60{ }^{\circ} \mathrm{C}$ ) y posterior determinación de la actividad enzimática residual. Los parámetros cinéticos $V_{\text {máx }} \mathrm{y}$ $\mathrm{K}_{\mathrm{m}}$ fueron determinados a partir de medidas de velocidad inicial con ACG como sustrato, al $\mathrm{pH}$ óptimo y a $30{ }^{\circ} \mathrm{C}$. Se determinó el efecto de varios cationes $\left(\mathrm{Cu}^{+2}, \mathrm{Ca}^{+2}, \mathrm{Fe}^{+3}, \mathrm{~K}^{+}, \mathrm{Mg}^{+2}, \mathrm{Mn}^{+2}\right.$ y $\mathrm{Zn}^{+2}$ ) sobre la actividad enzimática. Finalmente, se evaluó la estabilidad de la CHasa ${ }_{\mathrm{NI}}$ durante su almacenamiento en BSF a 5 y $30{ }^{\circ} \mathrm{C}$ y la estabilidad operacional (luego de cada ciclo de hidrólisis, los pellets fueron separados, lavados con BFS y usados en una nueva reacción).

La relación óptima entre inactivación térmica del micelio y elevada actividad CHasa fue observada luego de un tratamiento térmico a $55{ }^{\circ} \mathrm{C}$ por $60 \mathrm{~min}$, reteniendo bajo estas condiciones cerca del $90 \%$ de la actividad inicial. Las condiciones óptimas de operación para la CHasa $_{\mathrm{NI}}$ naturalmente fueron: $50{ }^{\circ} \mathrm{C}, \mathrm{pH} 6,5$ (en BFS $50 \mathrm{mM}$ ) y una velocidad de agitación de 100 golpes/min. Los valores de $\mathrm{K}_{\mathrm{m}}$ para la $\mathrm{CHasa}_{\mathrm{NI}}$ estimados a partir de las gráficas de Lineweaver-Burk y de Eadie-Hofstee fueron de 0,48 y 0,50 g/l, respectivamente. Los valores de $\mathrm{V}_{\text {máx }}$ obtenidos con cada gráfica fueron de 4,149 y $4,414 \mu$ mol/l.min., respectivamente. CHasa $\mathrm{NI}_{\mathrm{N}}$ fue estable en un rango de $\mathrm{pH}$ entre $2,0-9,0$ y hasta $50{ }^{\circ} \mathrm{C}$ durante $8 \mathrm{~h}$. Se observó una disminución de la actividad enzimática en presencia de $\mathrm{Fe}^{+3}$ y $\mathrm{Zn}^{+2}$.

Los resultados obtenidos demuestran la aplicación potencial de los pellets del micelio de $A$. niger AKU 3302 como un biocatalizador naturalmente inmovilizado con actividad CHasa. La CHasa $_{N I}$ muestra propiedades interesantes y adecuadas para su aplicación futura en la bioconversión del ACG. Además, la alta estabilidad operacional de la $\mathrm{CHasa}_{\mathrm{NI}}$ propicia su aplicabilidad para la hidrólisis continua de este sustrato presente en extractos naturales.
\end{abstract}




\subsection{INTRODUCCIÓN}

El micelio, desarrollado durante el cultivo sumergido de hongos filamentosos, puede crecer en forma dispersa o bien en forma de agregados de diferentes características. Los agregados esféricos y estables, formados por una red ramificada y entrelazada de hifas, se denominan pellets y pueden ser utilizados como biocatalizadores naturalmente ligados a la biomasa (Romano y col., 2005). La frase "enzimas naturalmente inmovilizadas" suele aplicarse a aquella biomasa no viable que se utiliza directamente como fuente del catalizador. En este tipo de sistema, la estructura celular puede actuar como una matriz natural capaz de proteger a la actividad enzimática de agentes externos, suministrando un efecto análogo al ejercido por una matriz utilizada para inmovilizar enzimas. Además, el uso de células enteras como biocatalizador evita las etapas de purificación necesarias en el caso de las enzimas libres, con el consiguiente riesgo de inactivación y aumento de los costos. Por otra parte, esta forma de biocatalizador presenta varias posibilidades para las operaciones continuas de un proceso. Entre ellas, permite la reutilización de los pellets en ciclos de reacción consecutivos, mejora la reología de los cultivos y dirige el metabolismo hacia la producción de metabolitos específicos, condiciones que no podrían llevarse a cabo mediante el uso de un micelio crecido en forma dispersa (Braun y Vecht-Lifshitz, 1991).

En estudios previos encontramos que la cepa de A. niger AKU 3302 forma pellets con elevada actividad CHasa al crecer en medio líquido conteniendo un extracto acuoso concentrado de yerba mate como inductor (capítulo 4). El micelio fúngico desarrollado en medio líquido en forma de pellets se puede utilizar como biocatalizador naturalmente inmovilizado para la hidrólisis del ácido clorogénico (ACG) en ácidos quínico (AQ) y cafeico (AC). Mediante esta biotecnología innovadora se podrían reducir los problemas de contaminación ambiental generados por la hidrólisis química bajo condiciones ácidas (Adachi y col., 2008). Por lo tanto, para una potencial aplicación industrial, que implica las etapas de almacenamiento y transporte, se necesita de pellets no viables con una buena estabilidad operacional.

El primer objetivo de este estudio fue preparar un micelio no viable de $A$. niger AKU 3302 con actividad CHasa naturalmente inmovilizada $\left(\mathrm{CHasa}_{\mathrm{NI}}\right)$, mientras que el segundo objetivo fue determinar las condiciones óptimas de operación de la CHasa $\mathrm{NI}_{\text {, }}$ 
así como sus parámetros cinéticos y termodinámicos, a fin de establecer las condiciones apropiadas para su utilización en la hidrólisis del ACG presente en sustratos naturales.

\subsection{MATERIALES Y MÉTODOS}

\subsubsection{Producción de micelio de Aspergillus niger AKU 3302 con actividad CHasa}

La cepa A. niger AKU 3302, previamente reportada como la mayor productora de actividad CHasa entre las evaluadas, fue cultivada en frascos Erlenmeyers conteniendo medio Czapek líquido modificado (CLM), a $30{ }^{\circ} \mathrm{C}$ durante $48 \mathrm{~h}$, con agitación (180 rpm). El cultivo fue inducido con extracto de yerba mate (EYM, el cual proporciona una concentración final de $0,14 \mathrm{~g}$ ACG/ml de medio de cultivo) a las 24 h de cultivo, según se describió en el capítulo 4 de la presente tesis. El micelio, crecido en la forma de pellets, con actividad CHasa intracelular, fue separado por filtración, lavado varias veces bajo condiciones asépticas y, finalmente, suspendido en agua destilada estéril.

\subsubsection{Preparación de micelio no viable con actividad CHasa naturalmente inmovilizada (CHasa $\left.{ }_{\mathrm{NI}}\right)$}

La cepa de $A$. niger AKU 3302 crece en forma de pellets prácticamente esféricos $(\varnothing \approx$ 2-5 mm) cuando es cultivada a escala de frascos agitados en las condiciones experimentales previamente descritas. La inmovilización in situ de la actividad CHasa intracelular de dichos pellets se llevó a cabo mediante un proceso de inactivación térmica para luego ser utilizada como un biocatalizador fúngico no viable con elevada actividad CHasa. A tal efecto, se estudiaron las condiciones óptimas para el tratamiento de inactivación térmica de los pellets (con la consecuente pérdida de viabilidad) pero tratando de preservar la propiedad catalítica de interés (CHasa) utilizando la metodología de superficie de respuesta basada en el uso de una matriz de experimentos.

\subsubsection{Producción de CHasa ${ }_{N I}$}

Los pellets fúngicos, obtenidos de acuerdo a lo detallado en la sección 6.2.1., fueron suspendidos en agua destilada estéril, distribuidos asépticamente en una serie de tubos para hemólisis, de vidrio de pared fina $(0,5 \mathrm{~mm})$, estériles e incubados a diferentes combinaciones de tiempo (20 a $60 \mathrm{~min})$ y temperatura $\left(45\right.$ a $\left.60{ }^{\circ} \mathrm{C}\right)$ establecidas de acuerdo a un diseño experimental de Doehlert (Doehlert, 1970; Légier y Comeau, 
1992). A continuación, los tubos se enfriaron en un baño de agua-hielo. La viabilidad del micelio tratado térmicamente fue evaluada transfiriendo $1 \mathrm{ml}$ de la suspensión fúngica tratada térmicamente $\left(\cong 3,5 \mathrm{mg}_{\text {micelio seco }}\right)$ a un Erlenmeyer de $500 \mathrm{ml}$ conteniendo $50 \mathrm{ml}$ de medio de cultivo fresco (CLM). El cultivo fue incubado a $30{ }^{\circ} \mathrm{C}$ con agitación $(180 \mathrm{rpm})$ por $24 \mathrm{~h}$. El crecimiento del micelio vegetativo se evaluó mediante determinaciones de peso seco. El cultivo de cada Erlenmeyer se filtró por succión con filtro de fibra de vidrio previamente tarado (tamaño de poro: 0,45 $\mu \mathrm{m}$, E04WP04700, MSI, USA) y el filtro con la biomasa retenida se secó a $65^{\circ} \mathrm{C}$ hasta peso constante. La viabilidad del micelio (VM) fue evaluada por diferencia de peso seco entre la biomasa final crecida luego de la incubación y el inóculo inicial agregado.

La actividad CHasa residual asociada al micelio tratado térmicamente fue determinada bajo condiciones de ensayo estándar (como se detalla en 6.2.5.1) y expresada como \% de actividad residual relativa a un control (sin tratamiento térmico).

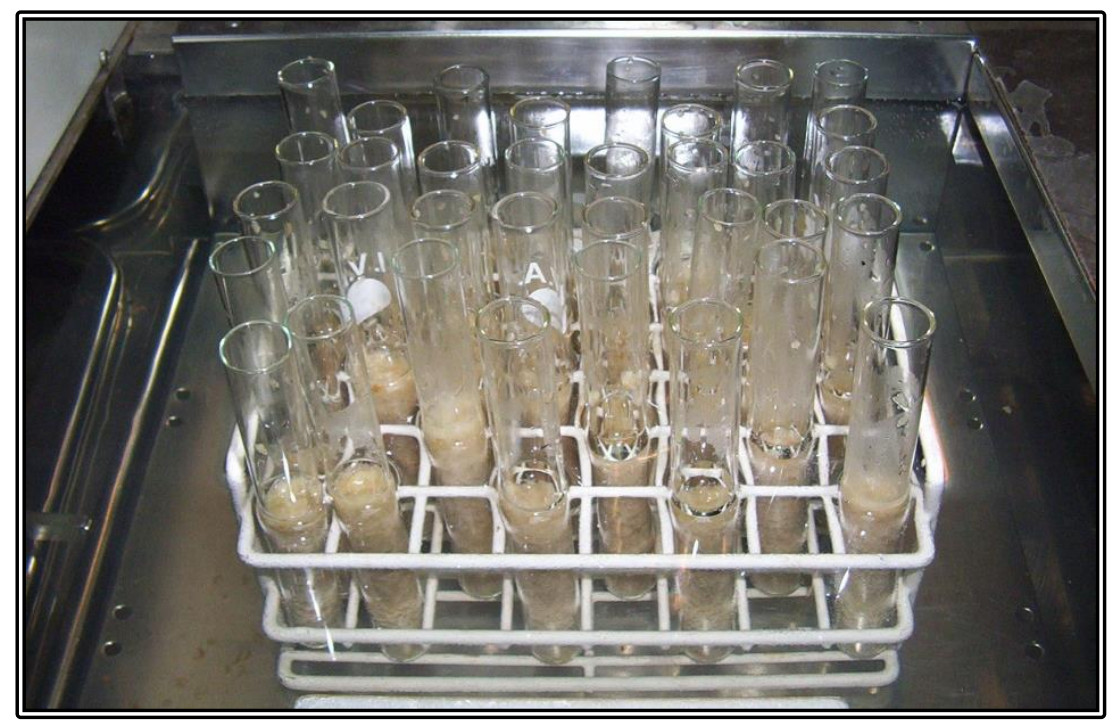

Figura 6.1: Tratamiento térmico de los pellets de A. niger AKU 3302.

\subsubsection{Análisis estadístico}

El diseño experimental de Doehlert fue seleccionado para determinar las condiciones óptimas para la inactivación térmica del micelio (pérdida de viabilidad) preservando la mayor proporción posible de la propiedad catalítica de interés (CHasa). En la Tabla 6.1 se presenta la matriz utilizada en el diseño experimental de Doehlert. 
Tabla 6.1: Valores codificados y reales utilizados en el diseño experimental de Doehlert.

\begin{tabular}{cccccc}
\hline \multirow{2}{*}{ Exp. $\mathrm{N}^{\circ}$} & \multicolumn{2}{c}{ Valores codificados } & & \multicolumn{2}{c}{ Valores reales } \\
\cline { 2 - 3 } \cline { 5 - 6 } & $\mathrm{t}(\mathrm{min})$ & $\mathrm{T}\left({ }^{\circ} \mathrm{C}\right)$ & & $\mathrm{t}(\mathrm{min})$ & $\mathrm{T}\left({ }^{\circ} \mathrm{C}\right)$ \\
\hline 1 & 1 & 0 & & 60 & 55 \\
2 & 0,5 & 0,866 & & 50 & 65 \\
3 & $-0,5$ & 0,866 & & 30 & 65 \\
4 & -1 & 0 & & 20 & 55 \\
5 & $-0,5$ & $-0,866$ & & 30 & 45 \\
6 & 0,5 & $-0,866$ & & 50 & 45 \\
7 & 0 & 0 & & 40 & 55 \\
8 & 0 & 0 & & 40 & 55 \\
9 & 0 & 0 & & 40 & 55 \\
\hline
\end{tabular}

Para las determinaciones, los valores centrales del diseño experimental de Doehlert fueron: $55^{\circ} \mathrm{C}$ (temperatura de incubación) y $40 \mathrm{~min}$ (tiempo de incubación). El orden de los experimentos se seleccionó al azar, lo que proporcionó protección contra efectos de las variables indeseables. Los experimentos se desarrollaron por triplicado y los resultados son presentados como promedio \pm desvío estándar. Finalmente, los resultados fueron analizados aplicando el programa estadístico Statgraphics Centurion XV (Freund y Wilson, 1997).

\subsubsection{Efecto de la velocidad de agitación y la carga del catalizador sobre la hidrólisis del ACG por CHasa $_{\mathrm{NI}}$}

El efecto de la velocidad de agitación sobre la conversión del sustrato (ACG) por la $\mathrm{CHasa}_{\mathrm{NI}}$ se llevó a cabo bajo condiciones de ensayo estándar pero variando la velocidad de agitación en un rango de 50 a 200 golpes/min. Seguidamente, la influencia de la carga del catalizador se estudió variando el número de pellets en la mezcla de reacción. Para ello, el número de pellets se varió de 3 a 15 manteniendo todas las demás condiciones constantes. 


\subsubsection{Caracterización parcial de la CHasa $\mathrm{NI}_{\mathrm{I}}$}

El uso directo de los pellets como biocatalizador (enzima naturalmente inmovilizada) está condicionado por sus propiedades catalíticas, por lo que se hace necesaria su caracterización para su posterior uso.

\subsubsection{Efecto del pH sobre la actividad y estabilidad CHasa $_{N I}$ :}

Se evaluó el efecto del pH sobre la actividad y estabilidad de la $\mathrm{CHasa}_{\mathrm{NI}}$ en 2 tipos de buffer (BFS y BTMG). De este modo, se determina si el pH óptimo y el rango de estabilidad de $\mathrm{pH}$ cambian con el buffer de incubación.

El pH óptimo de la $\mathrm{CHasa}_{\mathrm{NI}}$ fue determinado midiendo la actividad bajo condiciones de ensayo estándar, en los rangos de $\mathrm{pH}$ de 5,0 a 8,0 y de 4,0 a 10,0, para BFS (50 mM) y para BTMG $(20 \mathrm{mM})$, respectivamente.

El efecto del pH sobre la estabilidad de la $\mathrm{CHasa}_{\mathrm{NI}}$ se determinó por preincubación a 5 ${ }^{\circ} \mathrm{C}$, durante $24 \mathrm{~h}$ y $48 \mathrm{~h}$, tanto en BTMG como en BFS a diferentes valores de $\mathrm{pH}$ (entre 2 a 10 para BTMG y entre 5 a 8 para BFS), en ausencia de sustrato. Luego de la incubación, se midió la actividad residual al pH óptimo, bajo condiciones de ensayo estándar.

La preparación de cada buffer fue análoga a la descripta en la sección 5.2.3.1. del capítulo 5 de la presente tesis.

\subsubsection{Efecto de la temperatura sobre la actividad y estabilidad CHasa ${ }_{N I}$ :}

La temperatura óptima de actividad para la CHasa $_{\mathrm{NI}}$ fue determinada bajo condiciones de ensayo estándar, al pH óptimo y en un rango de temperaturas entre 30 y $80{ }^{\circ} \mathrm{C}$.

La termoestabilidad de la $\mathrm{CHasa}_{\mathrm{NI}}$ se determinó midiendo la actividad residual luego de incubar la enzima en BFS al pH óptimo, en ausencia de sustrato, a temperaturas comprendidas entre 30 y $60{ }^{\circ} \mathrm{C}$. Se tomaron muestras periódicamente durante $8 \mathrm{~h}$. La inactivación térmica se detuvo enfriando las muestras en baño de agua-hielo e inmediatamente se midió la actividad enzimática residual al $\mathrm{pH}$ óptimo, bajo condiciones de ensayo estándar. 
6.2.4.3. Determinación de los parámetros cinéticos y termodinámicos y del coeficiente $Q_{10}$ :

Los parámetros cinéticos $\mathrm{V}_{\text {máx }} \mathrm{y} \mathrm{K}_{\mathrm{m}}$ fueron determinados a partir de medidas de velocidad inicial empleando ACG (Sigma) como sustrato en un rango de concentraciones de 0,025 a 1,12 g/l, en BFS $(50 \mathrm{mM})$ al pH óptimo y a $30^{\circ} \mathrm{C}$. Las constantes de Michaelis-Menten fueron determinadas por regresiones lineales (Lineweaver-Burk y Eadie-Hofstee).

La energía de activación $\left(\mathrm{E}_{\mathrm{a}}\right)$ requerida por la $\mathrm{CHasa}_{\mathrm{NI}}$ para iniciar la reacción de hidrólisis fue determinada utilizando la expresión de Arrhenius (ec. 5.3). Los valores para la entalpía de activación $\left(\Delta H^{*}\right)$, la energía libre de activación $\left(\Delta G^{*}\right)$ y la entropía de activación $\left(\Delta S^{*}\right)$ fueron determinados utilizando las ecuaciones de Arrhenius (ec. 5.3) y de Eyring (ec. 5.4). El coeficiente $\mathrm{Q}_{10}$ para la $\mathrm{CHasa}_{\mathrm{NI}}$ fue determinado utilizando el valor de $\mathrm{E}_{\mathrm{a}}$ previamente calculado y la ec. 5.10. Todas estas ecuaciones fueron mostradas en el capítulo 5 de la presente tesis.

\subsubsection{Influencia de diferentes cationes sobre la actividad $\mathrm{CHasa}_{N I}$ :}

Se determinó la influencia de diferentes cationes $\left(\mathrm{Cu}^{+2}, \mathrm{Ca}^{+2}, \mathrm{Fe}^{+3}, \mathrm{~K}^{+}, \mathrm{Mg}^{+2}, \mathrm{Mn}^{+2} \mathrm{y}\right.$ $\left.\mathrm{Zn}^{+2}\right)$ sobre la actividad enzimática. Se prepararon soluciones de distintas sales $(0,2 \mathrm{~g} / \mathrm{l})$ en BFS al pH óptimo, a saber: $\mathrm{CuSO}_{4}, \mathrm{CaCl}_{2} \cdot 2 \mathrm{H}_{2} \mathrm{O}, \mathrm{FeCl}_{3} \cdot 6 \mathrm{H}_{2} \mathrm{O}, \mathrm{KCl}, \mathrm{MgSO}_{4}$. $7 \mathrm{H}_{2} \mathrm{O}, \mathrm{MnSO}_{4}$ y $\mathrm{ZnSO}_{4} \cdot 7 \mathrm{H}_{2} \mathrm{O}$. Con ellas se preparó la solución de sustrato (ACG 1,5 $\mathrm{mM}$ ) y se determinó la actividad enzimática de la $\mathrm{CHasa}_{\mathrm{NI}}$, bajo condiciones de ensayo estándar.

\subsubsection{Estabilidad durante el almacenamiento de CHasa ${ }_{N I}$ :}

Se determinó la estabilidad de la $\mathrm{CHasa}_{\mathrm{NI}}$ en función del tiempo de almacenamiento. Para ello, se almacenó un número adecuado de pellets conteniendo la CHasa inmovilizada en una solución de BFS $50 \mathrm{mM}$ (al pH óptimo) a 5 y $30^{\circ} \mathrm{C}$. La actividad enzimática residual se ensayó a intervalos regulares y al pH óptimo, bajo condiciones de ensayo estándar. 


\subsubsection{Estabilidad operacional de CHasa ${ }_{N I}$ :}

Para determinar la estabilidad operacional del sistema biocatalítico, la CHasa $\mathrm{NI}_{\text {fue }}$ utilizada en ciclos de reacción consecutivos a $30^{\circ} \mathrm{C}$. Luego de cada ciclo de hidrólisis, los pellets fueron separados de la mezcla de reacción, lavados varias veces con BFS 50 $\mathrm{mM}$ (al pH óptimo) para remover restos de la mezcla de reacción, secados a temperatura ambiente y reutilizados en una nueva mezcla de reacción. La actividad enzimática fue determinada al pH óptimo, bajo condiciones de ensayo estándar.

\subsubsection{Determinaciones analíticas}

6.2.5.1. Ensayo estándar para la determinación de la actividad $\mathrm{CHasa}_{N I}$ :

La actividad de CHasa $_{\mathrm{NI}}$ se determinó sobre la base del método de Okamura y Watanabe (1982a) para la determinación de la actividad CHasa libre con algunas modificaciones como se detalla a continuación.

Se utilizó como sustrato una solución 1,5 mM de ACG (Sigma) en BFS (50 mM, pH: 6,5). A menos que se indique lo contrario, la actividad CHasa asociada a los pellets $\left(\mathrm{CHasa}_{\mathrm{NI}}\right)$ fue ensayada agregando 4-6 pellets uniformes (diámetro promedio $\cong 2,5 \mathrm{~mm}$ ) a $750 \mu 1$ de la solución de sustrato. La mezcla de reacción, contenida en frascos ampollas de vidrio de $5 \mathrm{ml}$ de volumen con tapón de goma, fue incubada a $30{ }^{\circ} \mathrm{C}$ con una velocidad de agitación de 100 golpes/min. La reacción fue terminada después de 10-15 min tomando $250 \mu 1$ de la fase líquida de mezcla de reacción y mezclándola con 5 $\mathrm{ml}$ de metanol al $80 \%$. La actividad enzimática fue calculada por unidad de volumen de pellet y expresada como $\mathrm{UE} / \mathrm{cm}^{3}$.

Una diferencia en $\mathrm{A}_{350}$ de 1 es equivalente al consumo de 0,14 mol de ACG basado en el coeficiente de extinción molecular $\left(\varepsilon_{\mathrm{ACG}}=7.200 \mathrm{~mol}^{-1} \mathrm{l}^{-1} \mathrm{~cm}^{-1}\right)$. AC no mostró $\mathrm{A}_{350}$ apreciable.

La unidad de actividad CHasa para la CHasa $_{\mathrm{NI}}$ se definió como la cantidad de enzima que hidroliza $1 \mu \mathrm{mol}$ de ACG por min bajo las condiciones de ensayo previamente descritas.

Todas las determinaciones se realizaron por triplicado y los resultados fueron presentados como promedio \pm desvío estándar. 


\subsubsection{Cromatografia en capa fina (TLC):}

Los productos de la hidrólisis del ACG obtenidos mediante la $\mathrm{CHasa}_{\mathrm{NI}}$ fueron analizados por TLC. Para la corrida se sembraron $12 \mu \mathrm{l}$ de la mezcla de reacción en placas de Silica gel 60 F254 (Merck). La cromatografía fue realizada de modo ascendente utilizando como solvente una solución de n-butanol : ácido acético : agua (4 : $2: 1, \mathrm{v} / \mathrm{v} / \mathrm{v})$. Como patrones se utilizaron ACG y AC (Sigma). La desaparición del ACG y la aparición de AC fueron examinadas bajo luz UV. El AC y el ACG presentan valores de $\mathrm{Rf}$ de 0,88-0,89 y 0,72-0,74, respectivamente, bajo las condiciones de ensayo. El AQ no presenta ninguna estructura fenólica por lo que no produce fluorescencia bajo luz UV no siendo posible su observación por esta técnica. No obstante, su evaluación se realizó considerando que posee un valor de $\mathrm{Rf}$ de 0,15 (Adachi y col., 2006a).

\subsection{RESULTADOS Y DISCUSIÓN}

\subsubsection{Preparación de un micelio no viable con actividad CHasa $_{\mathrm{NI}}$}

Se estudiaron las condiciones óptimas para la inactivación térmica del micelio (pérdida de viabilidad) preservando la propiedad catalítica de interés (CHasa) utilizando la metodología de superficie de respuesta. La Tabla 6.2 representa la combinación de tratamientos y las variables respuestas obtenidas, expresadas en viabilidad del micelio (VM) y actividad CHasa residual, para la obtención del biocatalizador naturalmente inmovilizado. 
Tabla 6.2: Valores reales (datos experimentales) y variables respuestas obtenidos en el diseño experimental de Doehlert para la obtención de la enzima CHasa naturalmente inmovilizada.

\begin{tabular}{ccccc}
\hline Exp. $\mathrm{N}^{\circ}$ & $\mathrm{T}\left({ }^{\circ} \mathrm{C}\right)$ & $\mathrm{t}(\mathrm{min})$ & $\mathrm{VM}(\mathrm{g} / \mathrm{l})$ & CHasa (\%) \\
\hline 1 & 55 & 60 & 0,027 & 88,1 \\
2 & 65 & 50 & 0,019 & 50,7 \\
3 & 65 & 30 & 0,045 & 60,2 \\
4 & 55 & 20 & 0,763 & 89,9 \\
5 & 45 & 30 & 4,435 & 94,0 \\
6 & 45 & 50 & 4,091 & 93,0 \\
7 & 55 & 40 & 0,033 & 94,7 \\
8 & 55 & 40 & 0,025 & 93,0 \\
9 & 55 & 40 & 0,033 & 95,6
\end{tabular}

t: tiempo de incubación; T: temperatura de incubación; VM: viabilidad del micelio.

Las siguientes ecuaciones de regresión (ec. 6.1 y 6.2), que fueron obtenidas a partir de los datos de la Tabla 6.2, permiten calcular la viabilidad micelio (VM) tratado térmicamente y su actividad CHasa residual luego del tratamiento térmico, esta última expresada como un porcentaje relativo a un control (sin tratamiento térmico):

$$
\left.V M(\mathrm{~g} / \mathrm{l}): 0,030-0,307 * t-2,443 * T+0,365 * t^{2}+2,701 * T^{2}+0,184 * t * T \quad \text { (ec. } 6.1\right)
$$

$$
\text { CHasa }(\%): 94,43-21,97 * T-5,43 * t^{2}-24,80 * T^{2} \text { (ec. 6.2) }
$$

donde $t$ y $T$ son los valores codificados. Ambas ecuaciones presentaron un muy buen ajuste a los datos experimentales $\left(\mathrm{R}^{2}>0,90\right)$.

Las Figs. 6.2 y 6.3 muestran las superficies de respuesta y gráficos de contorno para cada una de las respuestas (VM y actividad CHasa residual) evaluadas como una función de las dos variables independientes estudiadas. 


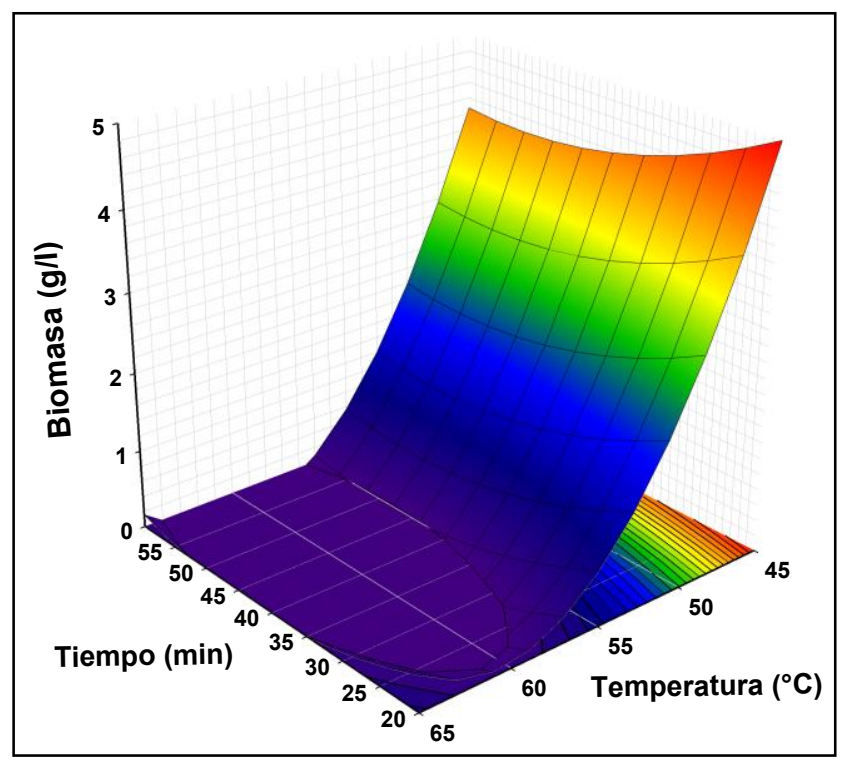

Figura 6.2: Superficie de respuesta y gráfico de contorno mostrando el efecto de la temperatura y el tiempo de incubación sobre la viabilidad de la biomasa.

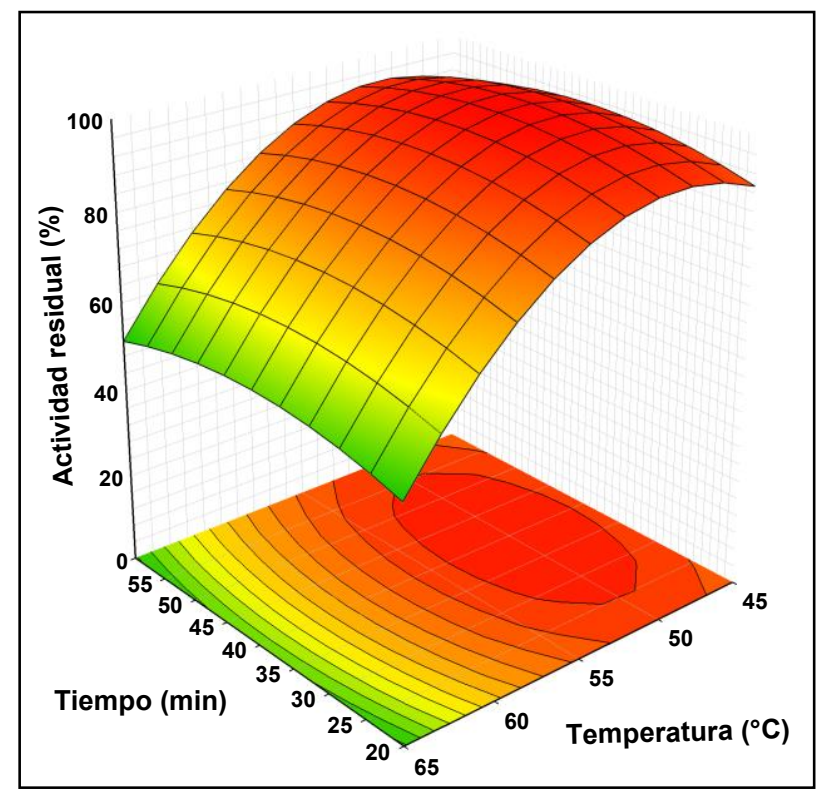

Figura 6.3: Superficie de respuesta y gráfico de contorno mostrando el efecto de la temperatura y el tiempo de incubación sobre la actividad CHasa residual asociada al micelio.

En este caso, la determinación de la actividad enzimática de la CHasa $\mathrm{NI}_{\mathrm{I}}$ se llevó a cabo, como una primera aproximación, mediante el ensayo estándar descrito previamente en la sección 6.2.5.1. cuyas condiciones de reacción (temperatura, $\mathrm{pH}$, velocidad de agitación y número de pellets en la mezcla de reacción) fueron seleccionadas arbitrariamente. Para esta etapa del estudio se consideró que era necesaria una técnica de medida aproximada de la actividad de la CHasa $_{\mathrm{NI}}$ a los efectos de optimizar las 
condiciones para el tratamiento de inactivación del micelio con preservación de la actividad enzimática. En secciones posteriores se muestran los detalles sobre la optimización de dichas condiciones de reacción para la medida de la actividad enzimática de la $\mathrm{CHasa}_{\mathrm{NI}}$.

El análisis estadístico para la VM reveló que, en el rango estudiado, las dos variables así como sus interacciones, tuvieron un efecto significativo sobre la misma. La interacción entre tiempo y temperatura fue significativa y positiva. La temperatura presentó el efecto negativo lineal más importante sobre la VM: se observó una reducción en el crecimiento de la biomasa a medida que se incrementó la temperatura. Los efectos cuadráticos para tiempo y temperatura fueron positivos indicando la existencia de un mínimo como una función de estas variables en el rango de 30-65 min y 55-65 ${ }^{\circ} \mathrm{C}$, respectivamente (ec. 6.1). El crecimiento de la biomasa fue despreciable cuando el tratamiento térmico se realizó a temperaturas por encima de los $55^{\circ} \mathrm{C}$ (Fig. 6.2).

En el caso de la actividad CHasa residual asociada al micelio, las dos variables analizadas mostraron un efecto cuadrático negativo, indicando la existencia de un máximo como función de estas variables en el rango de 25-50 min y 47,5-52,5 ${ }^{\circ} \mathrm{C}$ (Fig. 6.3). En estas condiciones, el micelio retuvo cerca del $98 \%$ de su actividad enzimática inicial. La actividad CHasa residual asociada al micelio permaneció estable hasta los 55 ${ }^{\circ} \mathrm{C}$ y 60 min. A los $60{ }^{\circ} \mathrm{C}$ y 60 min aún mantuvo el $75 \%$ de su actividad inicial (ec. 6.2). De acuerdo a los resultados previos, las condiciones óptimas para obtener un micelio no viable con elevada actividad CHasa $_{\mathrm{NI}}(\sim 90 \%$ de la actividad enzimática antes del tratamiento), fueron una temperatura y un tiempo de incubación de $55{ }^{\circ} \mathrm{C}$ y $30 \mathrm{~min}$, respectivamente. El modelo fue validado con los datos obtenidos de dos ensayos independientes a $45^{\circ} \mathrm{C}$ y $30 \mathrm{~min}$ y a $55^{\circ} \mathrm{C}$ y $60 \mathrm{~min}$. En ambos casos, se obtuvieron diferencias con el modelo menores al $10 \%$.

Adachi y col. (2008) prepararon un biocatalizador inmovilizado en pulpa de café por fermentación sobre sustrato sólido tipo koji de A. sojae AKU 3312 con elevada actividad CHasa y reportaron que no se registró una pérdida de actividad enzimática luego de un tratamiento térmico a $60{ }^{\circ} \mathrm{C}$ por 30 min pero si se produjo la inactivación del micelio vegetativo. Esta combinación de tiempo y temperatura para el tratamiento térmico es similar a la obtenida en nuestra investigación, con la diferencia que en nuestro caso, la temperatura óptima de inactivación es de $55^{\circ} \mathrm{C}$ en tanto que en el 
reportado por dichos autores es de $60{ }^{\circ} \mathrm{C}$. Debe destacarse que en nuestro caso, se trataron pellets fúngicos obtenidos en medio de cultivo líquido en tanto que en el otro se trata de micelio filamentoso obtenido por fermentación en medio sólido tipo koji sobre pulpa de café. Estas diferencias en el origen de la biomasa tratada térmicamente, más allá que se tratan de especies fúngicas diferentes aunque taxonómicamente muy cercanas, podrían estar relacionadas con esa pequeña diferencia en la temperatura necesaria para lograr su inactivación térmica.

Se evaluó la efectividad del micelio de $A$. niger AKU 3302 tratado térmicamente bajo las condiciones anteriormente optimizadas $\left(55^{\circ} \mathrm{C}\right.$ y $\left.30 \mathrm{~min}\right)$ como biocatalizador no viable con actividad $\mathrm{CHasa}_{\mathrm{NI}}$. Para ello, se incubaron concentraciones crecientes del micelio no viable ( 5 a $25 \mathrm{mg}$ ) con una concentración de ACG fija. Las condiciones de reacción fueron: $265 \mu \mathrm{L}$ ACG $(1,5 \mathrm{mM}), 30^{\circ} \mathrm{C}$ y $10 \mathrm{~min}$ de tiempo de reacción. Seguidamente, una alícuota de la mezcla de reacción fue analizada mediante TLC.

En la Figura 6.4 se muestra el análisis por TLC de los productos de la hidrólisis del ACG por medio del micelio no viable con actividad $\mathrm{CHasa}_{\mathrm{NI}}$.

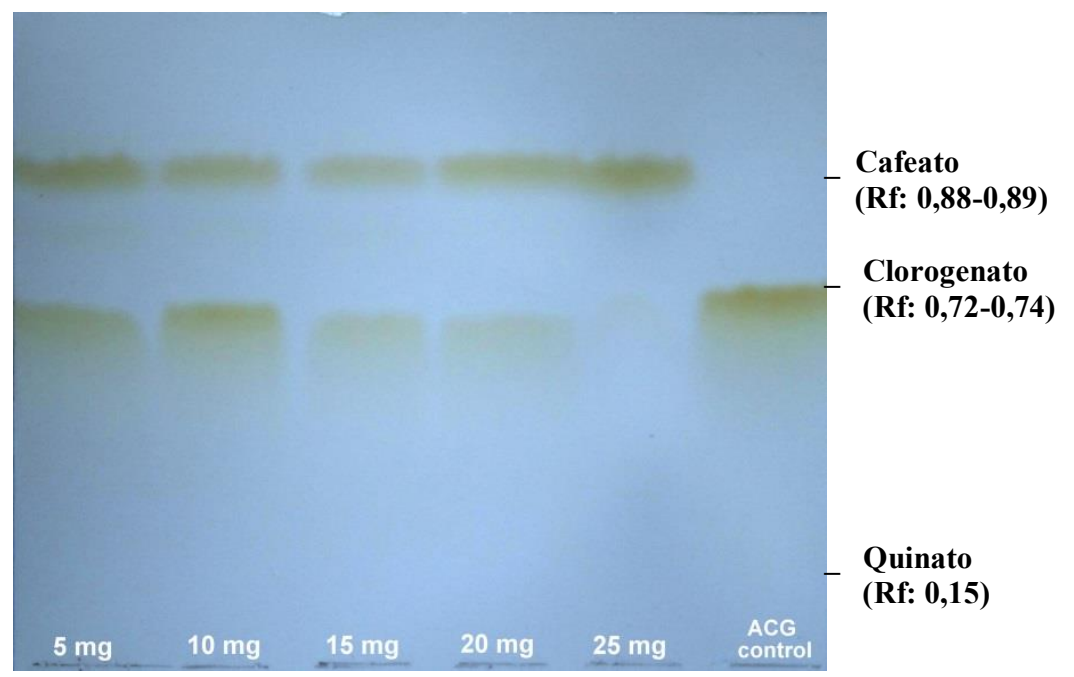

Figura 6.4: Evaluación de la efectividad del micelio de A. niger AKU 3302 tratado térmicamente como biocatalizador no viable con actividad $\mathrm{CHasa}_{\mathrm{NI}}$.

Se observa que, aún con la menor cantidad de micelio en la mezcla de reacción ensayada, hay disminución en la concentración de ACG y formación concomitante de AC. Además, la concentración final de ACG disminuyó al incrementar la cantidad de micelio en la mezcla de reacción, mientras que la concentración de AC aumentó. Los 
presentes resultados confirman la elevada actividad CHasa asociada al micelio no viable sometido al tratamiento térmico.

\subsubsection{Efecto de la velocidad de agitación y la carga del catalizador sobre la hidrólisis del ACG por CHasaNI}

Una vez optimizadas las condiciones para la preparación de la CHasa $_{\mathrm{NI}}$ se procedió a estudiar el efecto de diferentes variables sobre dicha actividad como se detalla a continuación.

\subsubsection{Efecto de la velocidad de agitación sobre la hidrólisis del ACG por CHasa $a_{N I}$ :}

En el caso de un catalizador inmovilizado, los reactivos o sustratos tienen que difundirse desde el seno del líquido hacia la superficie externa de la partícula y desde allí hacia el interior a través de los poros del biocatalizador. Las limitaciones en la transferencia de masa externa y las limitaciones difusionales internas pueden minimizarse llevando a cabo la reacción a una velocidad de agitación óptima y utilizando una baja carga de enzima con un tamaño de partícula óptimo, respectivamente.

Teniendo en cuenta que la velocidad de difusión del sustrato podría afectar la cinética enzimática, resultó necesario examinar las limitaciones difusionales internas y externas para la reacción catalizada por la $\mathrm{CHasa}_{\mathrm{NI}}$. La cinética de conversión del ACG (\%) para diferentes velocidades de agitación ( 0 a 200 golpes/min) se muestra en la Figura 6.5.

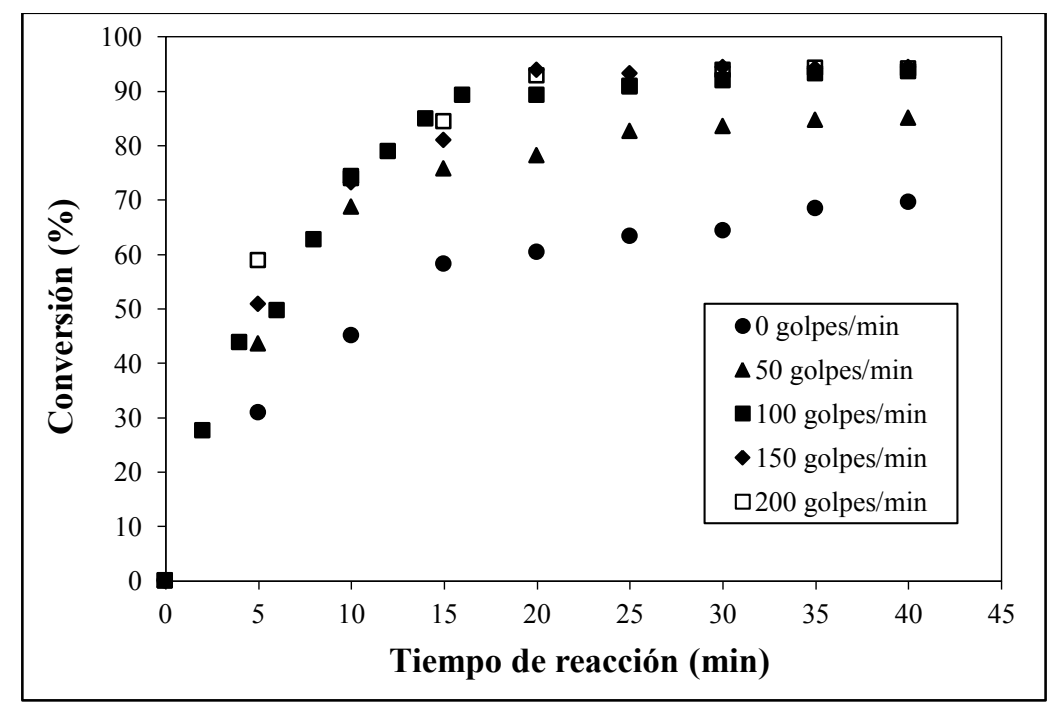

Figura 6.5: Efecto de la velocidad de agitación sobre la hidrólisis del ACG por la CHasa ${ }_{\mathrm{NI}}$. 
La conversión del ACG aumentó con el tiempo de reacción, rápidamente hasta los 20 min, para las velocidades de agitación examinadas hasta los 100 golpes/min, alcanzando en este caso una conversión de alrededor del 90 \%. Mayores velocidades de agitación no resultaron ni en mayores velocidades de reacción ni en mayores valores finales de conversión. Esto indica que no habría limitaciones en la transferencia de masa externa a partir de esa velocidad (Fig. 6.5) (Garlapati y Banerjee, 2013). Por otra parte, llama la atención que en estos ensayos no se alcancen conversiones aparentes mayores al 90 \%. En este sentido, debe recordarse que la determinación del ACG residual se hizo espectrofotométricamente, por medida de $\mathrm{A}_{350}$ de la mezcla de reacción. En este sentido, se consideró la posible liberación de sustancias que absorban a dicha longitud de onda a partir de los pellets fúngicos empleados. A tal fin, se incubaron pellets bajo condiciones de ensayo estándar pero sin el agregado de ACG, a diferentes velocidades de agitación que arrojaron incrementos en la $\mathrm{A}_{350}$ con el tiempo de reacción (datos no mostrados). Por lo tanto, se asumió que la no determinación de una conversión total en estos experimentos se debió a un artefacto de técnica.

Cualquiera sea el caso, y de acuerdo a estos resultados, se seleccionó una velocidad de agitación de 100 golpes/min para los estudios posteriores, valor este que se había elegido previamente para el ensayo estándar de medida de actividad.

Una evaluación más profunda de las limitaciones, tanto en la transferencia de masa en la fase líquida como en la difusión intra-partícula dentro del pellet, se realizó mediante un cálculo teórico para estimar el mecanismo controlante a la velocidad de reacción seleccionada (100 golpes/min).

Para determinar el papel de la transferencia de masa y la difusión intra-partícula, resulta útil comparar las contantes de tiempo de reacción $\left(t_{r}\right)$ y de difusión $\left(t_{d}\right)$ (ec. 6.3 y 6.4) (Blanch y Clark, 1997; Yadav y Trivedi, 2003). Estas constantes de tiempo se definen como se detalla a continuación:

$$
t_{r}=\frac{C_{0}}{r_{\left(C_{0}\right)}} \quad\left(\text { ec. 6.3) } \quad y \quad t_{d}=\frac{D_{S}}{\left(k_{S L}\right)^{2}} \quad(\text { ec. 6.4) }\right.
$$

donde $C_{0}$ es la concentración de sustrato en el seno de la fase líquida $\left(\mathrm{mol} / \mathrm{cm}^{3}\right), r_{(\mathrm{C} 0)}$ la velocidad de reacción $\left(\mathrm{mol} / \mathrm{cm}^{3} \mathrm{~s}\right), D_{S}$ la difusividad del sustrato en la fase líquida 
$\left(\mathrm{cm}^{2} / \mathrm{s}\right)$ y $k_{S L}$ es el coeficiente de transferencia de masa sólido-líquido en la fase líquida $(\mathrm{cm} / \mathrm{s})$.

Si $t_{r} \gg t_{d}$, implica que la reacción no se ve influenciada por la transferencia de masa.

$C_{0}$ y $r_{(C 0)}$ son determinados experimentalmente, $D_{S}$ podría ser estimado de la ecuación de Siebel (Perry y Green, 1984) y $k_{S L}$ fue calculado, para propósitos de comparación, asumiendo un valor límite del número de Sherwood, para sistemas no agitados (ec. 6.5).

$$
S h=k_{S L} \times \frac{d_{p}}{D_{S}}=2 \quad(\text { ec. } 6.5)
$$

donde $d_{p}$ es el diámetro de los pellets del micelio.

Los valores obtenidos en este estudio para $C_{0}$ y $r_{\left(C_{0}\right)}$ fueron $1,5 \times 10^{-6} \mathrm{~mol} / \mathrm{cm}^{3}$ y 1,165 $\times 10^{-10} \mathrm{~mol} / \mathrm{cm}^{3} \mathrm{~s}$, respectivamente, $D_{s}$ a $30^{\circ} \mathrm{C}$ fue calculado como $4,44 \times 10^{-6} \mathrm{~cm}^{2} / \mathrm{s}$ (ecuación de Siebel). El diámetro promedio de los pellets del micelio fue tomado como $0,25 \mathrm{~cm}$ (el tamaño de pellet osciló entre 0,20 y $0,50 \mathrm{~cm}$ ). El valor de $k_{S L}$ fue de 3,55 × $10^{-5} \mathrm{~cm} / \mathrm{s}\left(\right.$ ec. 6.5). Empleando estos valores resulta que los $t_{r} \mathrm{y} t_{d}$ obtenidos son $12876 \mathrm{~s}$ y $3517 \mathrm{~s}$, respectivamente. Estos resultados indican que no hay limitaciones en la transferencia de masa externa a 100 golpes/min en las condiciones experimentales empleadas, por lo que se confirma que la elección arbitraria de esta velocidad de agitación fue acertada.

Para evaluar la resistencia en la difusión intra-partícula, la velocidad de difusión del sustrato por unidad de área interfacial $\left(k_{S L} C_{0}\right)$ debe ser comparada con la velocidad de reacción por unidad de área $\left(\Phi r_{\left(C_{0}\right)} / a\right)$, donde $\Phi$ es la relación de volumen en la fase y $a$ es el área interfacial por unidad de volumen de la fase líquida. Para partículas esféricas $\Phi / a=\mathrm{R} / 3$, donde $\mathrm{R}$ es el radio del pellet que, en este caso, es igual a $0,125 \mathrm{~cm}$ (Perry y Green, 1984).

En el presente estudio se encontró que $k_{S L} C_{0}=5,33 \times 10^{-11} \mathrm{~mol} / \mathrm{cm}^{2}$ s y $\Phi r(C 0) / a=4,85$ $\times 10^{-12} \mathrm{~mol} / \mathrm{cm}^{2} \mathrm{~s}$, indicando que a velocidad de difusión del sustrato por unidad de área interfacial es mayor que la velocidad de reacción por unidad de área.

Por lo tanto, se concluyó que, en el caso de la $\mathrm{CHasa}_{\mathrm{NI}}$ la transferencia de masa no tiene influencia sobre la velocidad de reacción y que la misma es únicamente controlada por la cinética enzimática intrínseca. Por lo tanto, para lograr un aumento en la velocidad de 
reacción por unidad de masa de micelio, en primera instancia se debería incrementar la actividad enzimática específica del pellet, esto es, aumentar la cantidad de enzima activa dentro del biocatalizador.

\subsubsection{Efecto de la carga del catalizador $\left(\mathrm{CHasa}_{N I}\right)$ sobre la hidrólisis del ACG:}

Se estudió el efecto de la carga del catalizador (número de pellets en mezcla de reacción) sobre la conversión de $\mathrm{ACG}$ mediada por $\mathrm{CHasa}_{\mathrm{NI}}$, bajo condiciones de ensayo estándar y a una velocidad de agitación de 100 golpes/min (Fig. 6.6).

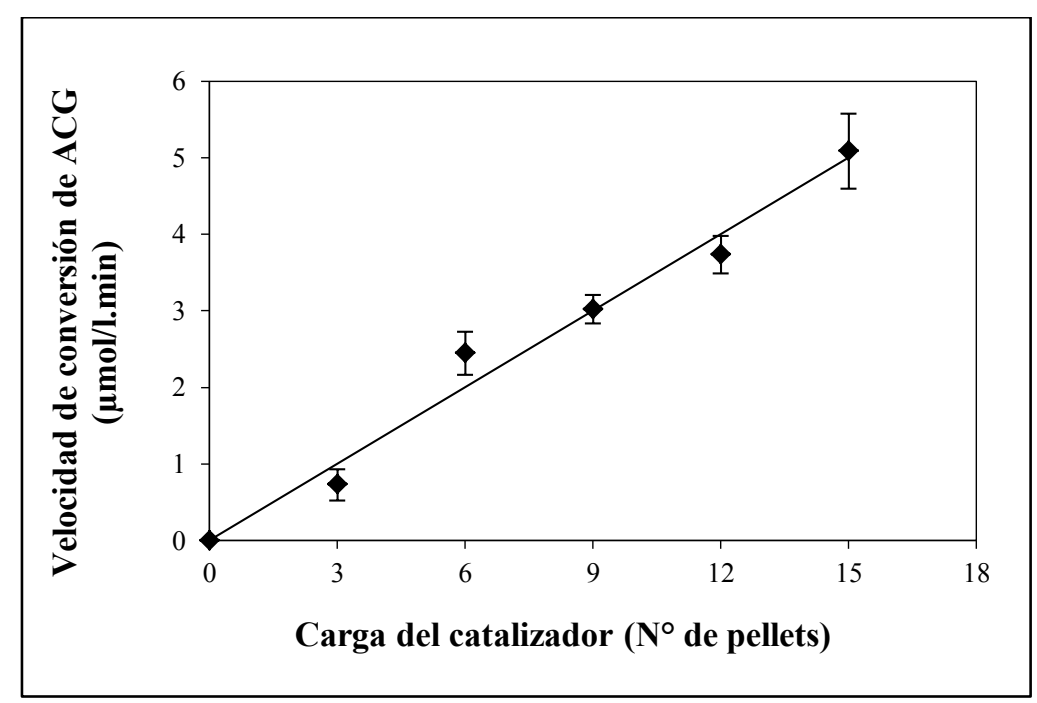

Figura 6.6: Efecto de la carga del catalizador $\left(\mathrm{CHasa}_{\mathrm{NI}}\right)$ sobre la velocidad de reacción de ACG.

La velocidad de reacción aumentó proporcionalmente con la carga del catalizador en el rango estudiado. Una mayor cantidad de pellets a la ensayada en la mezcla de reacción resultaba en evidentes inconvenientes en el mezclado debido a un aumento significativo en la relación volumen de fase sólida a volumen de fase líquida. Se obtuvo una relación lineal entre el número de pellets ensayado y la velocidad volumétrica de conversión de ACG, lo cual indica que la reacción estuvo cinéticamente controlada. Estos resultados están de acuerdo con otros similares reportados por diferentes autores para varias enzimas inmovilizadas en pellets de diferentes materiales (Pencreac'h y Baratti, 1997). 


\subsubsection{Caracterización parcial de la CHasa ${ }_{N I}$}

\subsubsection{Efecto del pH sobre la actividad y estabilidad CHasa $_{N I}$ :}

En las Figuras 6.7 y 6.8 se presenta la influencia del $\mathrm{pH}$ sobre la actividad $\mathrm{CHasa}_{\mathrm{NI}}$, tanto en BFS como en BTMG, respectivamente.

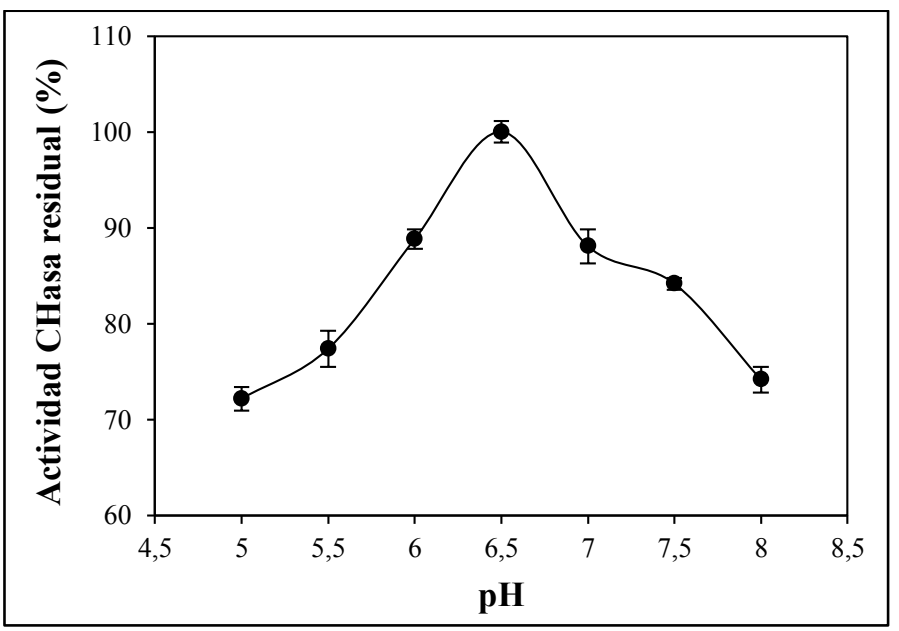

Figura 6.7: Efecto del pH sobre la actividad $\mathrm{CHasa}_{\mathrm{NI}}$ en $\mathrm{BFS}$.

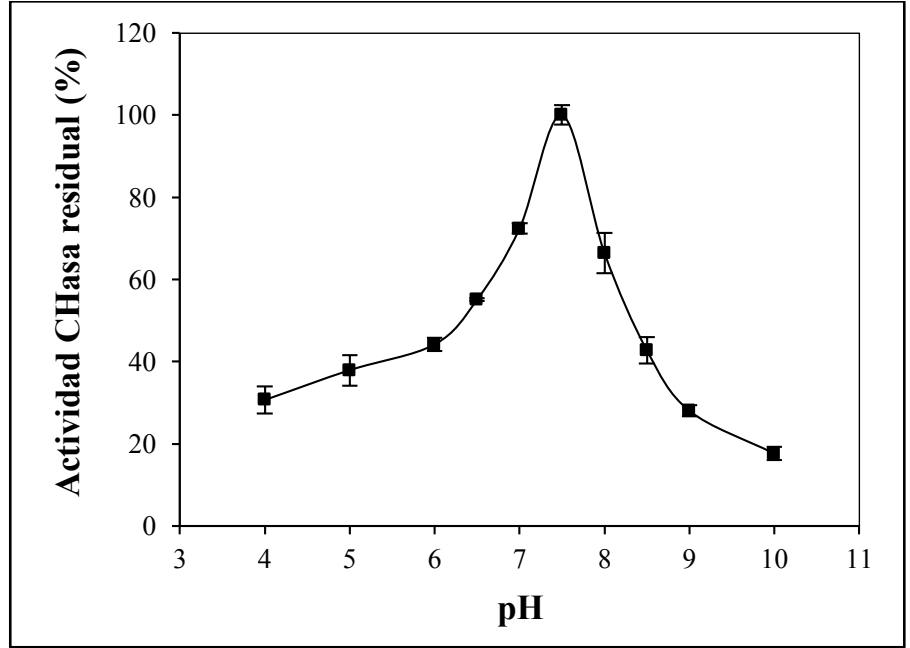

Figura 6.8: Efecto del pH sobre la actividad $\mathrm{CHasa}_{\mathrm{NI}}$ en BTMG.

Cuando se utilizó BFS como buffer de reacción, la CHasa ${ }_{\mathrm{NI}}$ exhibió máxima actividad a $\mathrm{pH}$ 6,5 (Fig. 6.7) en tanto que la CHasa libre presentaba un máximo a $\mathrm{pH}$ 7,0 (ver capítulo 5). En el caso de BTMG, el valor de pH óptimo para la actividad de la enzima fue de aproximadamente 7,5 (Fig. 6.8) coincidente con el máximo encontrado para la CHasa libre. Se desconoce la causa que explique estas pequeñas diferencias en los pH 
óptimos para una misma enzima entre sus formas libre e inmovilizada de acuerdo con el tipo de buffer empleado.

En las Figuras 6.9 y 6.10 se representan los valores de actividad enzimática residual luego de incubar la enzima a diferentes valores de $\mathrm{pH}$ por 24 y $48 \mathrm{~h}$ a $5{ }^{\circ} \mathrm{C}$, en $\mathrm{BFS}$ y en BTMG, respectivamente.

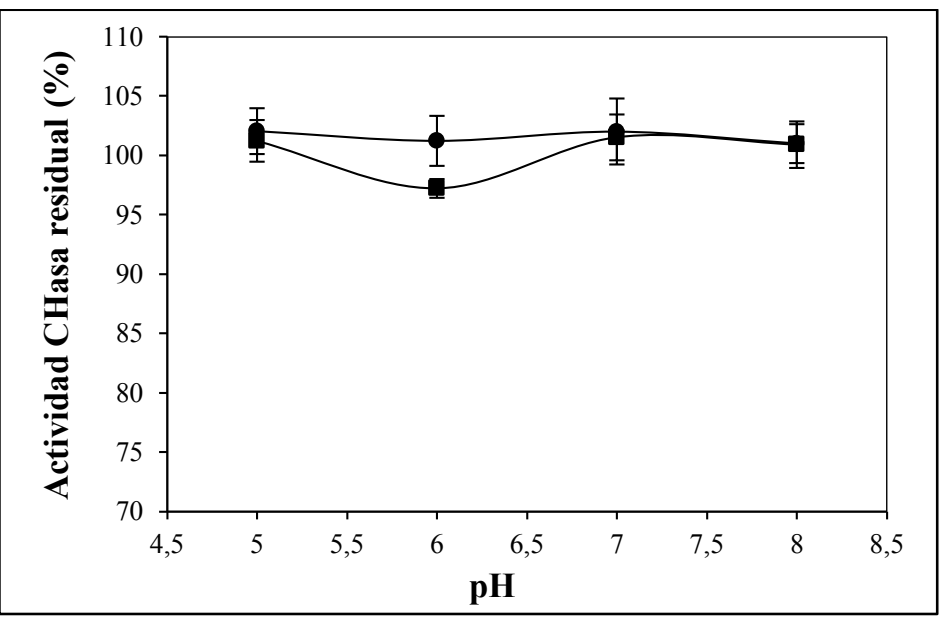

Figura 6.9: Efecto del $\mathrm{pH}$ sobre la estabilidad de la enzima $\mathrm{CHasa}_{\mathrm{NI}}$ en BFS. Temperatura de incubación: $5^{\circ} \mathrm{C}$. Tiempo de incubación: $24 \mathrm{~h}(\bullet)$ y $48 \mathrm{~h}(\boldsymbol{\bullet})$.

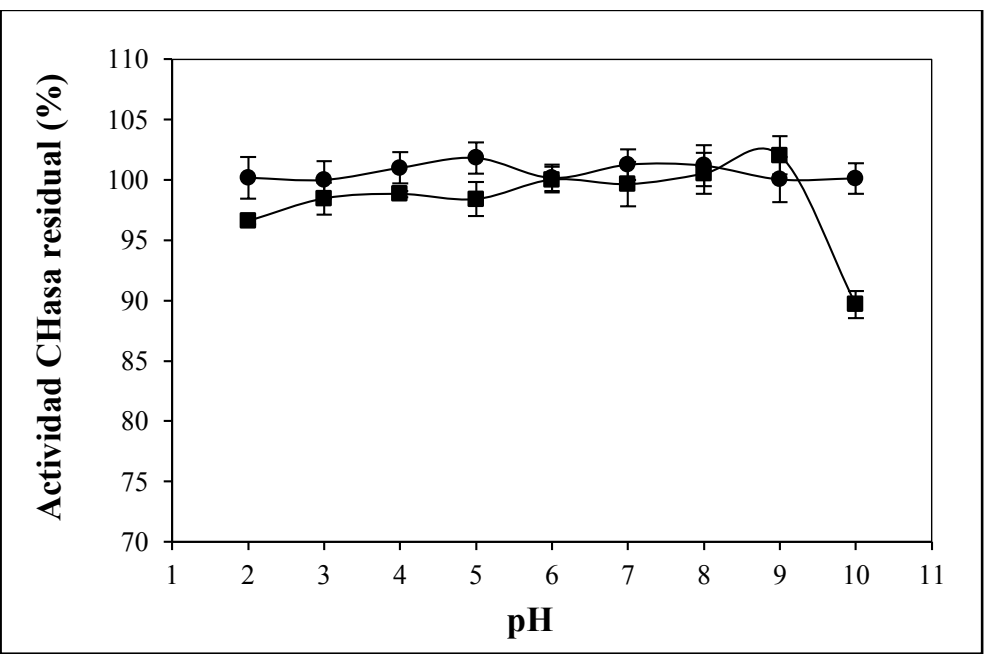

Figura 6.10: Efecto del $\mathrm{pH}$ sobre la estabilidad de la enzima $\mathrm{CH}_{\mathrm{N}} \mathrm{N}_{\mathrm{NI}}$ en BTMG. Temperatura de incubación: $5^{\circ} \mathrm{C}$. Tiempo de incubación: 24 h (•) y $48 \mathrm{~h}(\boldsymbol{\bullet})$.

Tanto el BFS como el BTMG no tuvieron influencia significativa sobre la estabilidad de la enzima. La $\mathrm{CHasa}_{\mathrm{NI}}$ se mantuvo estable en un intervalo de $\mathrm{pH}$ entre 2,0 y 9,0, después de haber sido incubada durante $48 \mathrm{~h}$ a $5{ }^{\circ} \mathrm{C}$ (Figs. 6.9 y 6.10). El análisis de varianza no reveló diferencias significativas entre estos valores $(\mathrm{p} \leq 0,05)$. La enzima retuvo aproximadamente el $90 \%$ de su actividad inicial después de 48 h de incubación a 
pH 10,0 (Fig. 6.10). Resultados similares fueron obtenidos para la CHasa libre (ver capítulo 5).

\subsubsection{Efecto de la temperatura sobre la actividad CHasa $_{N I}$ :}

El efecto de la temperatura sobre la actividad $\mathrm{CHasa}_{\mathrm{NI}}$ fue estudiado en BFS a pH 6,5.

El perfil de actividades a diferentes temperaturas se muestra en la Figura 6.11.

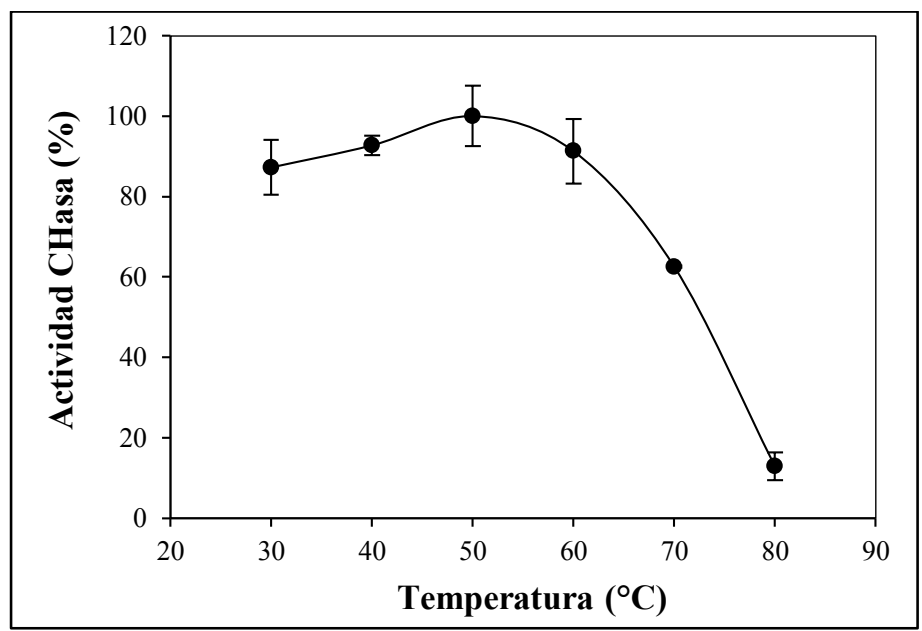

Figura 6.11: Efecto de la temperatura sobre la actividad de $\mathrm{CHasa}_{\mathrm{NI}}$. La actividad CHasa fue determinada como un porcentaje de la actividad enzimática bajo condiciones de ensayo estándar a pH óptimo.

En este caso, se encontró que la inmovilización cambió la temperatura óptima de actividad CHasa, de aproximadamente $45{ }^{\circ} \mathrm{C}$ para la enzima libre (Fig. 5.6) a $50{ }^{\circ} \mathrm{C}$ para la enzima inmovilizada (Fig. 6.11). A temperaturas superiores a $50^{\circ} \mathrm{C}$, la actividad de $\mathrm{CHasa}_{\mathrm{NI}}$ fue superior a la actividad de la enzima libre. A una temperatura de $60{ }^{\circ} \mathrm{C}$, la actividad $\mathrm{CHasa}_{\mathrm{NI}}$ fue $\sim 90 \%$ (Fig. 6.11), mientras que la actividad de la enzima libre fue $\sim 75 \%$ (Fig. 5.6).

Se observó que la $\mathrm{CHasa}_{\mathrm{NI}}$ fue más termoestable que la CHasa libre. El proceso de inmovilización ofrece, generalmente, un microambiente que tiende a minimizar el efecto de factores externos tales como la temperatura, el $\mathrm{pH}$, la presencia de especies iónicas, etc. A mayor temperatura, la enzima libre sufre un proceso de desnaturalización mientras que la enzima inmovilizada es protegida, probablemente, por su estructura conformacional y, por lo tanto, es capaz de retener una mayor actividad catalítica (Changa y Juangb, 2005). 
En general, las enzimas inmovilizadas presentan su actividad catalítica óptima a una temperatura de reacción más elevada que las respectivas enzimas libres (Wang y col., 2006).

\subsubsection{Efecto de la temperatura sobre la estabilidad CHasa $_{N I}$ :}

En la Figura 6.12 se presentan los valores de actividad enzimática residual luego de incubar la $\mathrm{CHasa}_{\mathrm{NI}}$ a diferentes temperaturas hasta $8 \mathrm{~h}$, a los efectos de evaluar la estabilidad térmica de la enzima naturalmente inmovilizada.

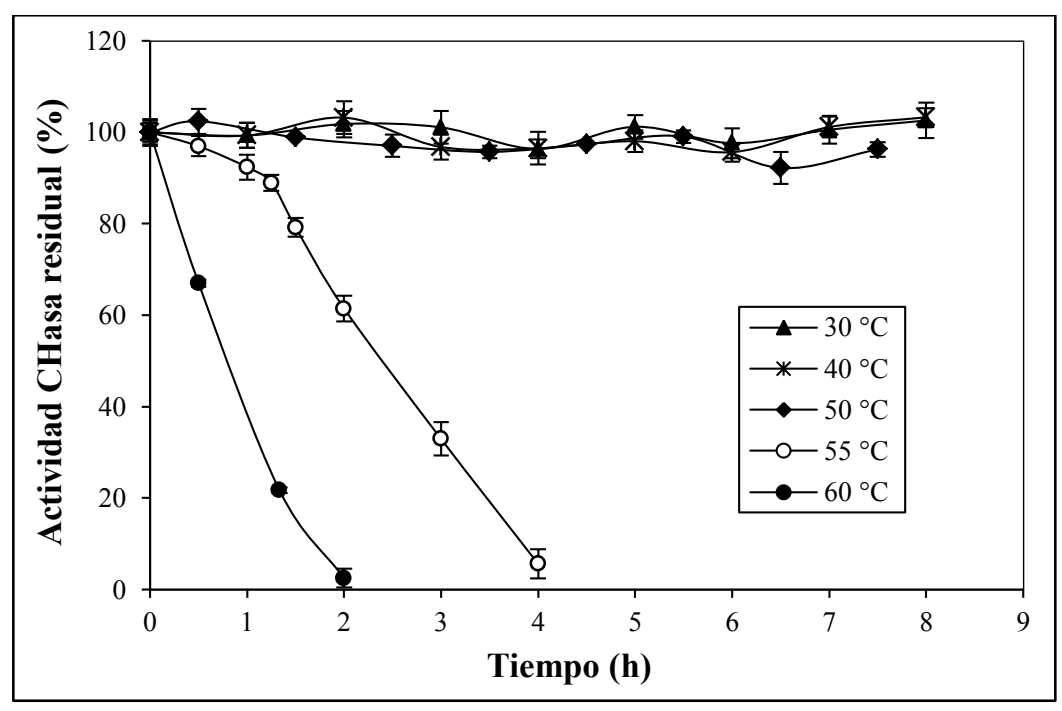

Figura 6.12: Estabilidad térmica de $\mathrm{CHasa}_{\mathrm{NI}}$ a diferentes temperaturas.

En la Fig. 6.12 se observa que la enzima, en ausencia de sustrato, retuvo más del $97 \%$ de su actividad inicial luego de haber sido incubada a 30,40 y $50{ }^{\circ} \mathrm{C}$ por $8 \mathrm{~h}$, al $\mathrm{pH}$ óptimo. El análisis de varianza no reveló diferencias significativas entre estos valores (p $\leq 0,05)$. A $55^{\circ} \mathrm{C}$ la estabilidad disminuyó con el tiempo de incubación, reteniendo la enzima el $79 \%$ y $33 \%$ de la actividad inicial luego de 1,5 h y 3 h de incubación, respectivamente. A $60{ }^{\circ} \mathrm{C}$ la velocidad de inactivación térmica fue mayor y luego de 80 min de incubación la actividad residual fue del $22 \%$.

Adachi y col. (2008) prepararon un biocatalizador inmovilizado en pulpa de café por fermentación tipo koji con elevada actividad CHasa y reportaron que no se registró una pérdida de actividad enzimática luego de un tratamiento térmico a $60{ }^{\circ} \mathrm{C}$ por $30 \mathrm{~min}$, siendo inactivada a $70^{\circ} \mathrm{C}$, durante el mismo tiempo de incubación. 
Al comparar la estabilidad de la enzima CHasa cruda presente en el EE (capítulo 5 de la presente tesis) con la CHasa $_{\mathrm{NI}}$ se observó que la misma aumentó luego del proceso de inmovilización natural. Si bien, en ambos casos la actividad CHasa fue inactivada rápidamente a partir de $\operatorname{los} 60^{\circ} \mathrm{C}$, en el caso de la enzima libre luego de $80 \mathrm{~min}$ de incubación a dicha temperatura, la actividad residual fue prácticamente despreciable, mientras que para la CHasa inmovilizada fue del $23 \%$ luego del mismo tiempo de incubación.

Resultados similares fueron informados por otros autores. Adachi y col. (2008) informaron un aumento en la estabilidad de la enzima CHasa de A. sojae AKU 3312 luego de la inmovilización de la misma en pulpa de café por fermentación tipo koji. La CHasa asociada al micelio de $A$. sojae AKU 3312 fue más termoestable que la CHasa libre en solución y no se registraron pérdidas de la actividad enzimática después la incubación a $60{ }^{\circ} \mathrm{C}$ durante $30 \mathrm{~min}$.

Se dice que la termoestabilidad de la enzima CHasa está altamente relacionada con el grado de glicosilación (Chu y col., 1978; Wyss y Wagner, 1996; Benoit y col., 2006). Benoit y col. (2007), quienes llevaron a cabo la sobreexpresión del gen que codifica para la CHasa de A. niger BRFM 131 en una cepa de A. niger recombinante, manifestaron que la CHasa recombinante presentó una mayor termoestabilidad por un mayor grado de glicosilación, y que el $50 \%$ de la actividad enzimática se conservó luego de un proceso de incubación a $60{ }^{\circ} \mathrm{C}$ durante $90 \mathrm{~min}$, mientras que la CHasa nativa fue completamente inactivada después de 10 min de incubación a $55^{\circ} \mathrm{C}$.

La inmovilización de la CHasa en los pellets del micelio de A. niger AKU 3302 implica una mayor preservación de la estructura terciaria de la enzima además de una mejor protección de la misma frente a los cambios conformacionales provocados por los efectos del medio ambiente (Abdel-naby, 1993; Jiang y Zhang, 1993; Changa y Juangb, 2005). Los resultados antes descritos confirman que dichos mecanismos tienen lugar en la CHasa ${ }_{\mathrm{NI}}$.

\subsubsection{Determinación de los parámetros cinéticos:}

A los efectos de determinar las constantes cinéticas de la enzima ( $\mathrm{V}_{\text {máx }} \mathrm{y} \mathrm{K}_{\mathrm{m}}$ aparente), se determinaron las velocidades iniciales con diferentes concentraciones de sustrato (ACG) (Fig. 6.13). 


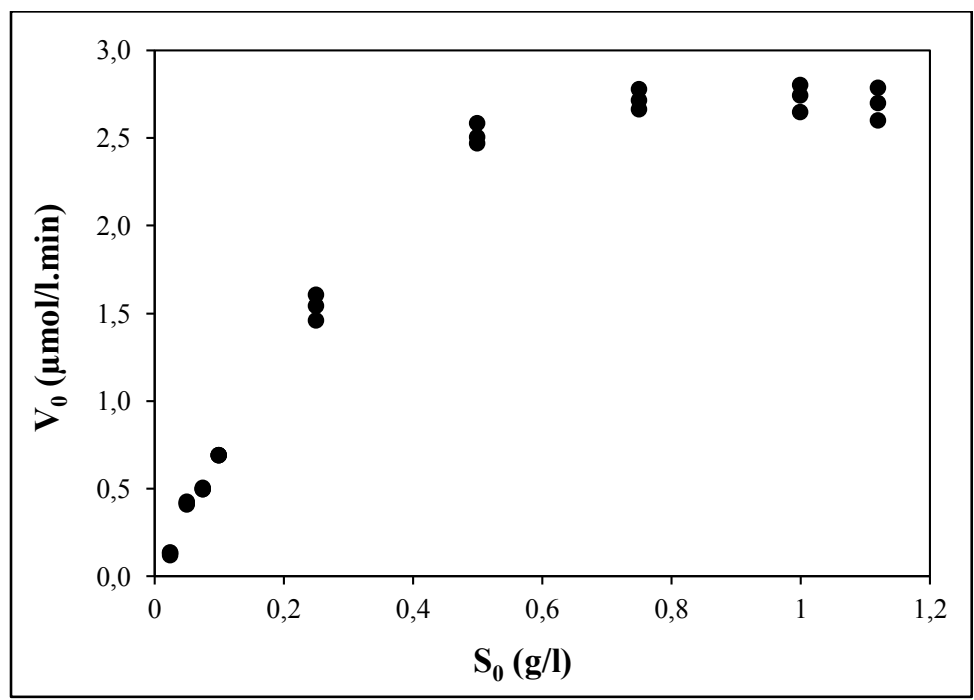

Figura 6.13: Gráfica de Michaelis-Menten. Velocidad inicial en función de la concentración de sustrato.

Como puede verse en la Fig. 6.13, la cinética de hidrólisis de ACG puede ser descripta por una cinética del tipo de Michaelis-Menten (ec. 5.13).

Los valores de $\mathrm{K}_{\mathrm{m}}$ aparente para la enzima $\mathrm{CHasa}_{\mathrm{NI}}$, estimados a partir de la gráfica de Lineweaver-Burk (Fig. 6.14) y la gráfica de Eadie-Hofstee (Fig. 6.15) fueron de 0,48 y 0,50 g/l, respectivamente con ACG como sustrato. Los valores de $\mathrm{V}_{\text {máx }}$ obtenidos a partir de las 2 gráficas fueron 4,149 y 4,414 $\mu \mathrm{mol} / 1$.min., respectivamente.

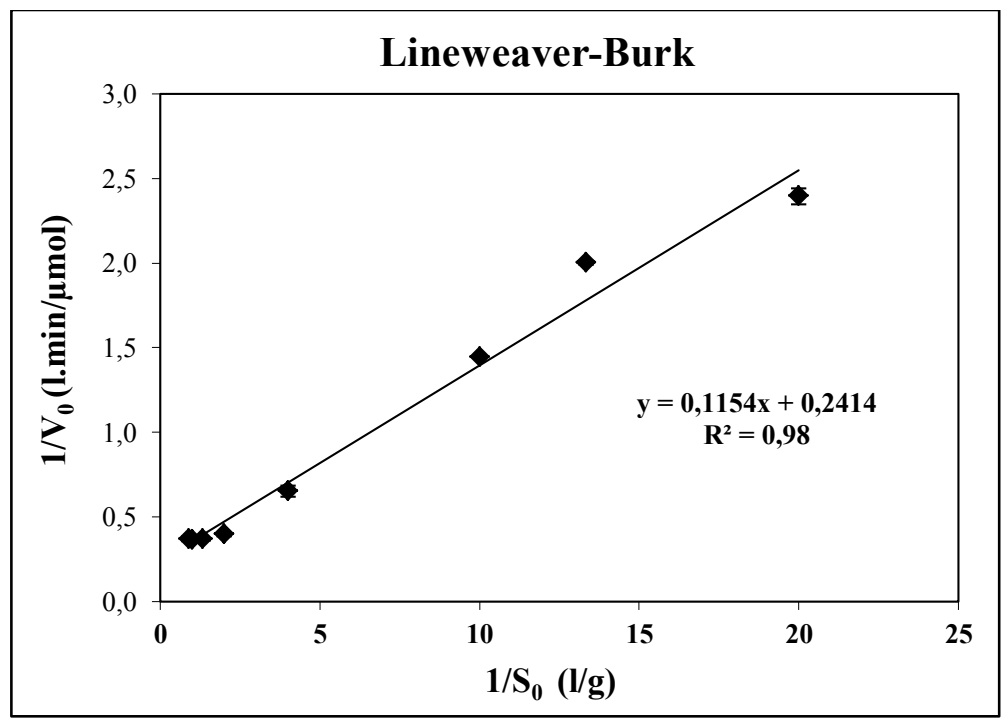

Figura 6.14: Gráfico de Lineweaver-Burk para la $\mathrm{CHasa}_{\mathrm{NI}}$ de A. niger AKU 3302. 


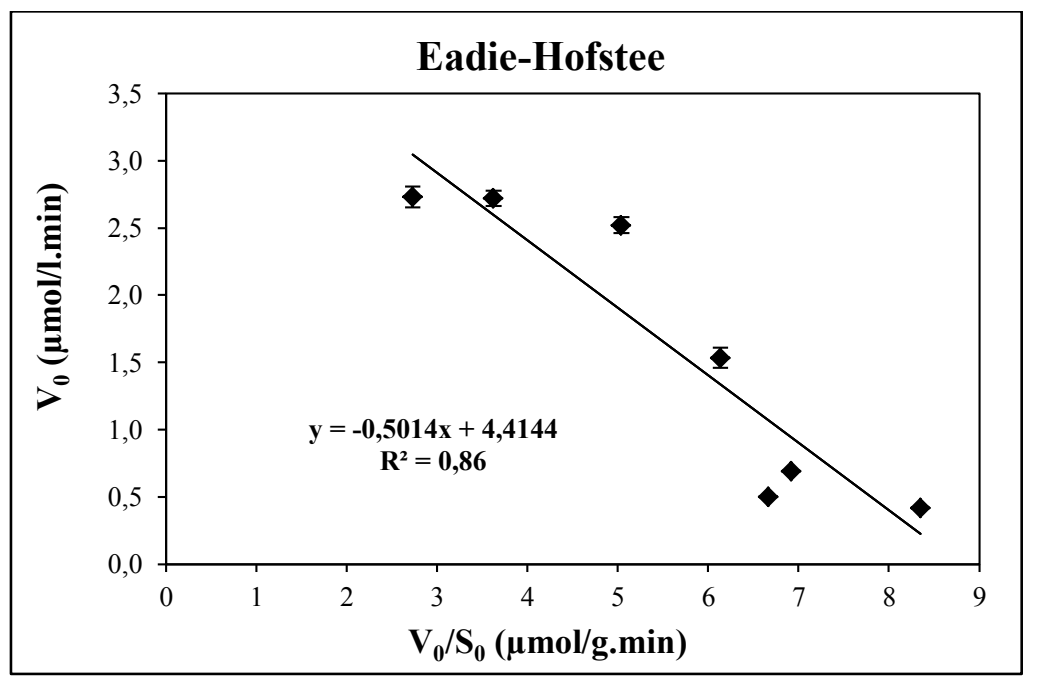

Figura 6.15: Gráfico de Eadie-Hofstee para la $\mathrm{CHasa}_{\mathrm{NI}}$ de $A$. niger AKU 3302.

El valor de $\mathrm{K}_{\mathrm{m}}$ aparente obtenido para la $\mathrm{CHasa}_{\mathrm{NI}}(\sim 0,5 \mathrm{~g} / \mathrm{l})$ fue mayor que el respectivo valor para la enzima libre $(\sim 0,2 \mathrm{~g} / \mathrm{l})$ (ver capítulo 5$)$, ya sea debido a los cambios conformacionales de la enzima que resultan en una menor posibilidad de formar el complejo enzima-sustrato, o bien a una menor accesibilidad del sustrato al sitio activo de la enzima inmovilizada causado por una mayor limitación en la difusión (Tu y col., 2006; Hota y col., 2007).

Por otra parte, el valor de $\mathrm{V}_{\text {máx }}$ para la $\mathrm{CHasa}_{\mathrm{NI}}(\sim 4 \mu \mathrm{mol} / \mathrm{l}$.min) fue mayor que el respectivo valor de la enzima libre $(\sim 1,9 \mu \mathrm{mol} / \mathrm{l}$.min) (ver capítulo 5). Normalmente, las enzimas inmovilizadas tienen valores de $\mathrm{V}_{\text {máx }}$ más bajos que sus contrapartes libres (Petzelbauer y col., 2002; Saville y col., 2004). Se han reportado valores de $\mathrm{V}_{\text {máx }}$ más elevados luego del proceso de inmovilización para otras enzimas, como son los casos de inulinasas (Risso y col., 2010), invertasas (Calixto-Romo y col., 2008) y $\beta$ galactosidasas (Elnashar y Yassin, 2009). Sin embargo, este comportamiento es inusual y la base mecánica de esta característica positiva requiere de mayor investigación (Tu y col., 2006).

Entre otros factores, el mayor valor de $\mathrm{V}_{\text {máx }}$ en comparación con el de la CHasa libre hacen de la $\mathrm{CHasa}_{\mathrm{NI}}$ un mejor biocatalizador que su contraparte libre para llevar a cabo la hidrólisis del ACG. 


\subsubsection{Energía de activación y parámetros termodinámicos:}

La energía de activación $\left(\mathrm{E}_{\mathrm{a}}\right)$ para la $\mathrm{CHasa}_{\mathrm{NI}}$ de A. niger AKU 3302, calculada con la ayuda de la gráfica de Arrhenius, fue de $2,71 \mathrm{kcal} / \mathrm{mol}$ con un coeficiente de determinación de $\mathrm{r}^{2}=0,96$ (Fig. 6.15).

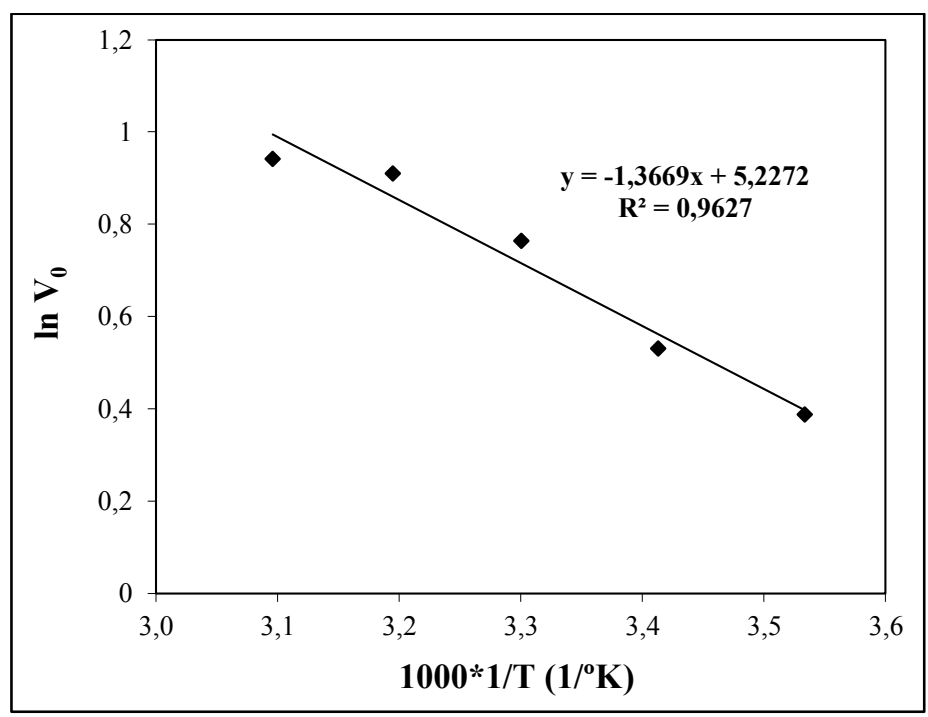

Figura 6.16: Grafico de Arrhenius para la determinación de la energía de activación de la CHasa $_{\mathrm{NI}}$ de $A$. niger AKU 3302.

A $50{ }^{\circ} \mathrm{C}$ la $\mathrm{CHasa}_{\mathrm{NI}}$ exhibió su máxima actividad catalítica en la conversión del sustrato (ACG), utilizando la energía de activación antes mencionada. El valor de $\mathrm{E}_{\mathrm{a}}$ para la $\mathrm{CHasa}_{\mathrm{NI}}$ fue menor que el respectivo valor para la CHasa libre, lo que significa que la enzima inmovilizada fue más insensible a la temperatura.

La entalpía de activación $\left(\Delta H^{*}\right)$ fue positiva y decreció con el aumento de la temperatura de incubación. Un valor de entalpía positivo indica que para formar el estado de transición deben tensionarse o distorsionarse algunos enlaces, consumiendo calor (energía). Los valores positivos para $\Delta G^{*}$ indicaron que se trató de una reacción endergónica. El cambio en la entropía de la reacción enzimática $\left(\Delta S^{*}\right)$ catalizado por la $\mathrm{CHasa}_{\mathrm{NI}}$ fue negativo y disminuyó con el incremento de la temperatura de incubación (Tabla 6.3). El valor del coeficiente $\mathrm{Q}_{10}$ obtenido para la $\mathrm{CHasa}_{\mathrm{NI}}$ de A. niger AKU 3302 fue de 1,15. 
Tabla 6.3: Parámetros termodinámicos de $\mathrm{CHasa}_{\mathrm{NI}}$ de A. niger AKU 3302.

\begin{tabular}{cccc}
\hline Temperatura $\left({ }^{\circ} \mathrm{K}\right)$ & $\Delta \mathrm{G}^{*}(\mathrm{kcal} / \mathrm{mol})$ & $\Delta \mathrm{H}^{*}(\mathrm{kcal} / \mathrm{mol})$ & $\Delta \mathrm{S}^{*}\left(\mathrm{cal} / \mathrm{mol} .{ }^{\circ} \mathrm{K}\right)$ \\
\hline 283 & 16,83 & 2,116 & $-51,981$ \\
293 & 17,35 & 2,096 & $-52,050$ \\
303 & 17,87 & 2,077 & $-52,117$ \\
313 & 18,39 & 2,057 & $-52,181$ \\
323 & 18,91 & 2,037 & $-52,244$ \\
\hline
\end{tabular}

\subsubsection{Influencia de cationes sobre la actividad $\mathrm{CHasa}_{N I}$ :}

Teniendo en cuenta que la $\mathrm{CHasa}_{\mathrm{NI}}$ será utilizada para la hidrólisis enzimática del ACG en extractos de yerba mate, se analizó el efecto de varios cationes presentes en la yerba mate según datos reportados en la bibliografía (Heck y González De Mejía, 2007).

En la Figura 6.17 se puede apreciar que la presencia de $\mathrm{Cu}^{+2} \mathrm{y} \mathrm{Mg}^{+2}$ produjo ligera activación, mientras que la actividad residual de la $\mathrm{CHasa}_{\mathrm{NI}}$ fue del $56 \%$ y $82 \%$, en presencia de los iones $\mathrm{Fe}^{+3}$ y $\mathrm{Zn}^{+2}$, respectivamente. Los iones metálicos divalentes, tales como $\mathrm{Cu}^{+2} \mathrm{y} \mathrm{Mg}^{+2}$ produjeron una ligera activación de la actividad enzimática de $\mathrm{CHasa}_{\mathrm{NI}}$. Este hecho podría explicarse teniendo en cuenta que los iones podrían actuar como sales o puentes iónicos estabilizando a la enzima en su conformación activa y, por lo tanto, podrían proteger a la enzima frente a una posible desnaturalización térmica (Balaji y col., 2008; Sareen y Mishra, 2008).

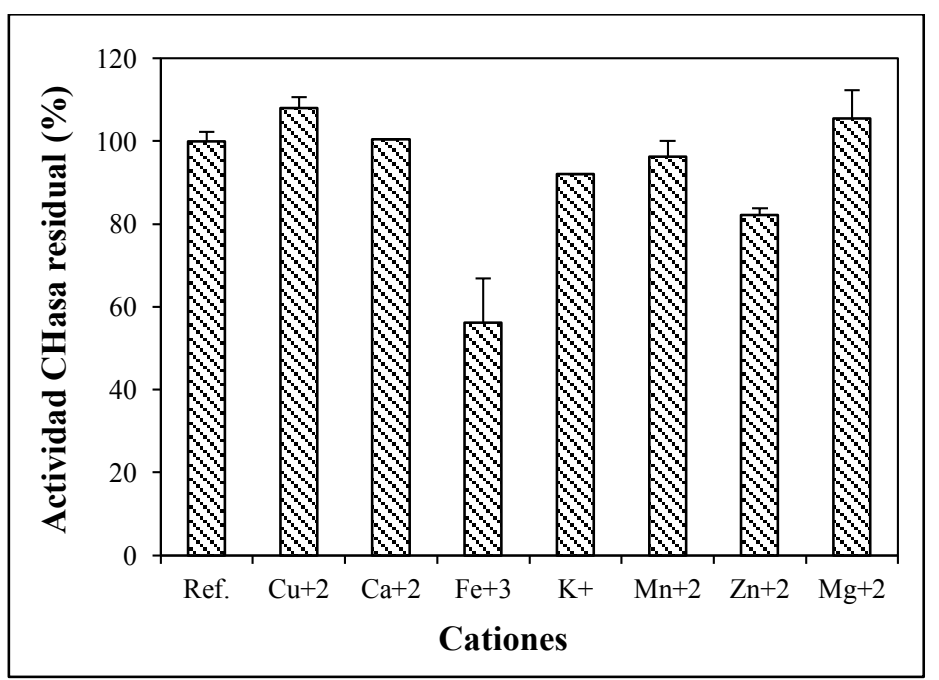

Figura 6.17: Efecto de diferentes cationes sobre la actividad $\mathrm{CHasa}_{\mathrm{NI}}$ de $A$. niger AKU 3302. 
En la Tabla 6.4 se presenta el análisis de varianza para evaluar el efecto de diferentes cationes sobre la actividad CHasa $\mathrm{NI}$.

Tabla 6.4: Tabla de Anova para evaluar la actividad $\mathrm{CHasa}_{\mathrm{NI}}$ en presencia de diferentes cationes.

\begin{tabular}{|l|l|l|l|l|l|}
\hline Fuente de variación & Suma de cuadrados & G.L. & Media Cuad. & $\mathrm{F}_{\text {exp. }}$ & Niv. sig. \\
\hline Entre grupos & 4137,38 & 7 & 519,094 & 25,43 & 0,000 \\
\hline Dentro de grupos & 255,702 & 11 & 23,2456 & & \\
\hline Total (corr.): & 4393,08 & 18 & & & \\
\hline
\end{tabular}

Según el análisis de varianza se puede concluir que hay diferencia estadísticamente significativa en la actividad $\mathrm{CHasa}_{\mathrm{NI}}$ en presencia de distintos cationes, siendo el nivel de significación (p) menor al 0,05 para el $95 \%$ de nivel de confianza. Para determinar las medias que fueron significativamente diferentes unas de otras, se realizó el Test de rangos múltiples (datos no mostrados), el cual determinó que la mayor diferencia se obtuvo en presencia de $\mathrm{Fe}^{+3}$ y $\mathrm{Zn}^{+2}$ mientras que los demás cationes estudiados $\left(\mathrm{Cu}^{+2}\right.$, $\mathrm{Ca}^{+2}, \mathrm{~K}^{+}, \mathrm{Mg}^{+2}$ y $\mathrm{Mn}^{+2}$ ) no tuvieron ningún efecto significativo sobre la actividad $\mathrm{CHasa}_{\mathrm{NI}}$.

\subsubsection{Estabilidad durante el almacenamiento de CHasa ${ }_{N I}$ :}

Los pellets del micelio no viable con actividad $\mathrm{CHasa}_{\mathrm{NI}}$ fueron almacenados en BFS (50 $\mathrm{mM}, \mathrm{pH} 6,5$ ) a $5{ }^{\circ} \mathrm{C}$ y $30{ }^{\circ} \mathrm{C}$ durante un período de 32 días, período durante el cual se llevaron a cabo mediciones periódicas de actividad enzimática (Fig. 6.18).

A $30{ }^{\circ} \mathrm{C}$ los pellets del micelio perdieron aproximadamente el $60 \%$ de su actividad $\mathrm{CHasa}_{\mathrm{NI}}$ dentro de los 14 días y el $70 \%$ de la misma después de 18 días de

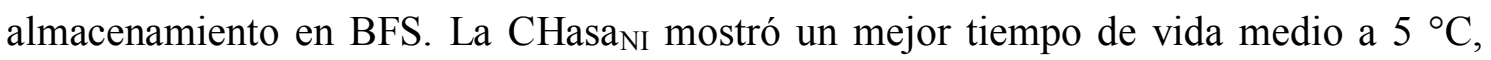
reteniendo el $85 \%$ de su actividad incluso después de 25 días de almacenamiento y protegiendo alrededor del $70 \%$ de su actividad después de 32 días. La disminución en la actividad enzimática se explicó en términos de una pérdida natural dependiente del tiempo de almacenamiento. 


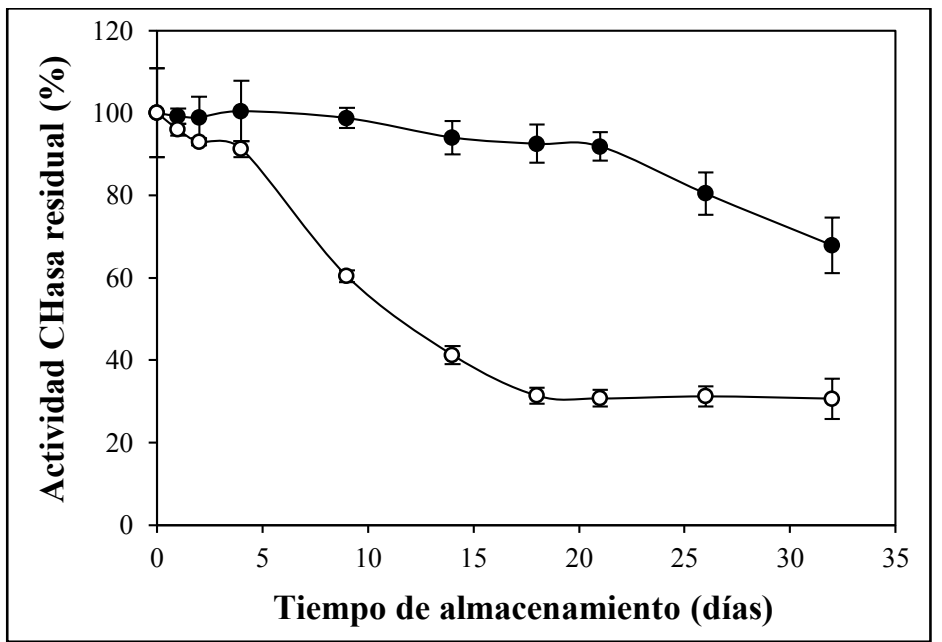

Figura 6.18: Cambio en la estabilidad de la $\mathrm{CHasa}_{\mathrm{NI}}$ con la temperatura de almacenamiento: (o) $30{ }^{\circ} \mathrm{C} \mathrm{y}(\bullet) 5^{\circ} \mathrm{C}$.

\subsubsection{Estabilidad operacional de CHasa $_{N I}$ :}

El uso repetido de enzima inmovilizada puede ayudar a reducir el costo del producto y hacer que el proceso enzimático sea económicamente viable (Ye y col., 2006). La estabilidad operativa o reutilización es de importancia en la determinación de la eficiencia de la enzima inmovilizada. Sin embargo, existen diferentes referencias bibliográfica que reportan que las características de la reacción enzimática cambian cuando una enzima inmovilizada se utiliza repetidamente (Garlapati y col., 2013).

La estabilidad operativa de la CHasa $_{\mathrm{NI}}$ fue determinada durante 22 ciclos de reacción consecutivos a $30^{\circ} \mathrm{C}$ durante 400 min (Fig. 6.19).

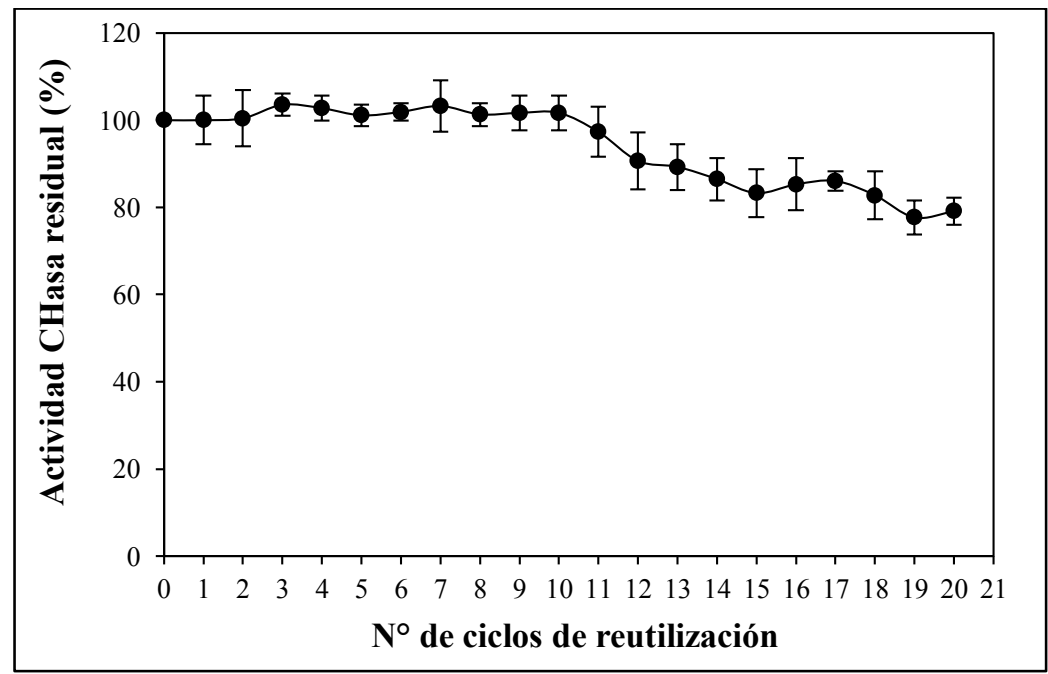

Figura 6.19: Estabilidad operacional de la $\mathrm{CHasa}_{\mathrm{NI}}$. 
No se observó una pérdida aparente en la capacidad de la enzima inmovilizada de hidrolizar el ACG, incluso luego de 11 ciclos consecutivos de reacción. Por otra parte, la enzima retuvo aproximadamente el $80 \%$ de su actividad inicial incluso después de 22 ciclos de uso repetido.

Se investigó la razón de este leve decaimiento de la actividad y se concluyó que el mismo no se debió a la desorción de la enzima del pellet del micelio dado que no se registraron aumentos en la concentración de la enzima en los sobrenadantes de la mezcla de reacción. Como consecuencia, esto podría deberse simplemente a una pérdida intrínseca de la actividad enzimática con los ciclos de reacción.

Los presentes resultados mostraron que la $\mathrm{CHasa}_{\mathrm{NI}}$ contenida en los pellet del micelio no viable de $A$. niger AKU 3302 presentaron una muy buena durabilidad permitiendo su uso repetido en la hidrólisis del ACG.

\subsection{CONCLUSIONES}

Se preparó un biocatalizador inmovilizado de forma natural con elevada actividad CHasa de modo relativamente fácil y económico. La relación óptima entre inactivación térmica del micelio y elevada actividad CHasa fue observada luego de un tratamiento térmico a $55{ }^{\circ} \mathrm{C}$ por $60 \mathrm{~min}$. Bajo estas condiciones, el micelio vegetativo fue inactivado, resultando no viable pero manteniendo cerca del $90 \%$ de la actividad CHasa inicial asociada al micelio. Las condiciones óptimas de operación para la CHasa naturalmente inmovilizada en el micelio de A. niger AKU 3302 fueron: una temperatura de $50^{\circ} \mathrm{C}, \mathrm{pH}$ 6,5 (usando BFS $50 \mathrm{mM}$ ) y una velocidad de agitación de 100 golpes $/ \mathrm{min}$. El modelo cinético de Michaelis-Menten representó satisfactoriamente el comportamiento de la CHasa naturalmente inmovilizada. El valor de $\mathrm{K}_{\mathrm{m}}$ para la enzima auto-inmovilizada $(\sim 0,5 \mathrm{~g} / \mathrm{l})$ fue mayor que el valor obtenido para su contraparte libre $(\sim 0,2 \mathrm{~g} / \mathrm{l})$. Este resultado podría estar relacionado con las limitaciones a la transferencia de masa impuestos por la estructura celular, lo que no ocurre con la CHasa soluble. A pesar de las posibles limitaciones de la difusión a través de la estructura celular, la célula actúa como un soporte para la inmovilización de la enzima protegiéndola del entorno.

El presente trabajo demuestra la aplicación potencial de los pellets del micelio de $A$. niger AKU 3302 como un biocatalizador naturalmente inmovilizado con actividad 
CHasa. Las propiedades y la estabilidad de la enzima exhibieron características interesantes que pueden ser adecuadas para su aplicación futura en la bioconversión del ACG. Además, la alta estabilidad operacional de la CHasa naturalmente inmovilizada propicia su aplicabilidad para la hidrólisis continua de este sustrato presente en extractos naturales. 


\section{$3^{0}$ ETAPA}

Aplicación de la enzima CHasa en la hidrólisis enzimática del $A C G$ contenido en un extracto de yerba mate
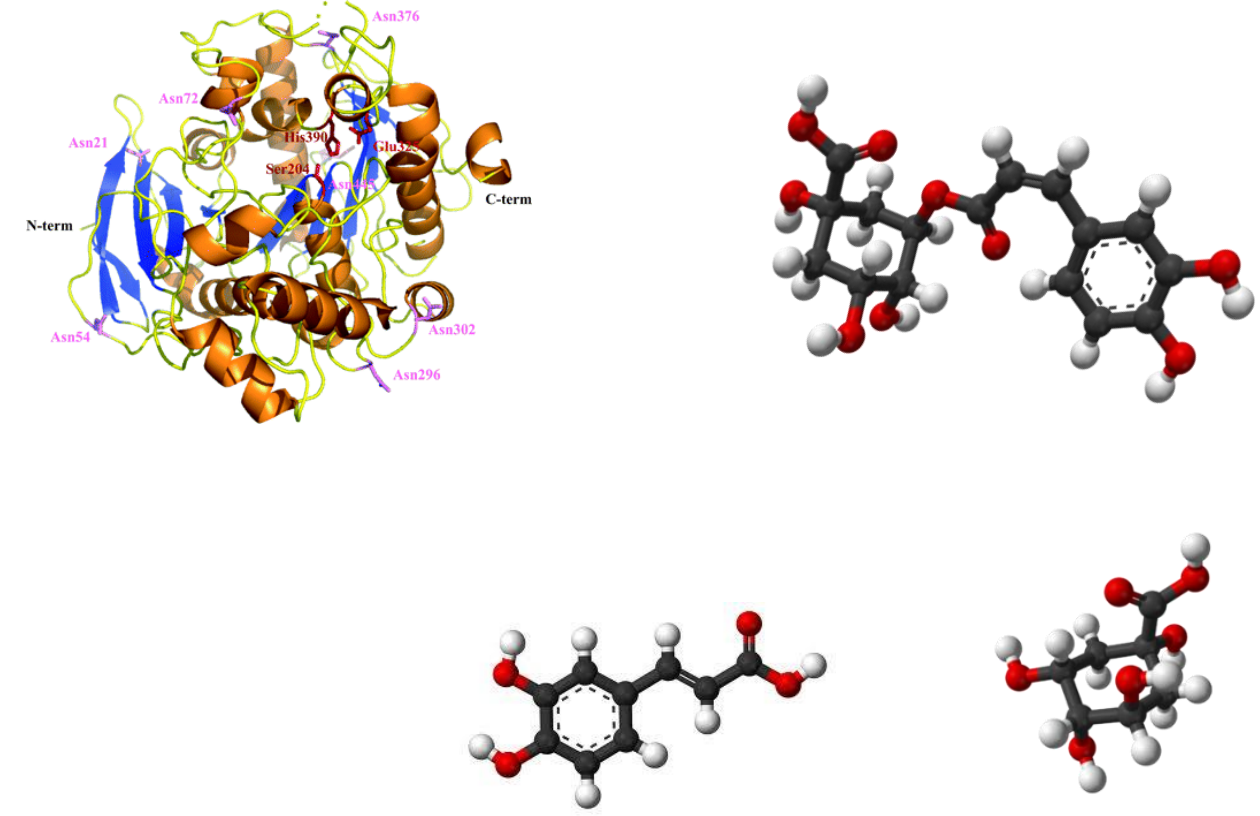


\section{Capítulo 7}

Bioconversión del ácido elorogénico de la yexba mate a ácidos quínico y cafeico en un biorreactor de lecho empaquetado 


\title{
CAPÍTULO 7 BIOCONVERSIÓN DEL ÁCIDO CLOROGÉNICO DE LA YERBA MATE A ÁCIDOS QUIINICO Y CAFEICO EN UN BIORREACTOR DE LECHO EMPAQUETADO
}

\begin{abstract}
Resumen
Los pellets no viables de $A$. niger AKU 3302 con elevada actividad CHasa fueron utilizados como relleno de una columna de vidrio para su operación como biocatalizador en un biorreactor de lecho empaquetado (BLE). Se hizo circular una solución acuosa de palos verdes de yerba mate $\left(\mathrm{PV}_{\mathrm{YM}}\right)$ con elevado contenido de ácido clorogénico (ACG) a través del BLE a diferentes velocidades de flujo. Se determinó tanto el porcentaje de conversión del ACG inicialmente presente en el extracto como las concentraciones y productividades de sus productos de hidrólisis (ácidos cafeico, AC, y quínico, AQ).

El micelio no viable (tratado a $55^{\circ} \mathrm{C}$ por $20 \mathrm{~min}$ ), crecido en la forma de pellets con actividad CHasa intracelular fue obtenido según se describió en los capítulos 4 y 6 . Los pellets fueron conservados en buffer BFS $(50 \mathrm{mM}, \mathrm{pH} 6,5)$ a $4{ }^{\circ} \mathrm{C}$ hasta su utilización y por un período no mayor a 15 días. El extracto de yerba mate con alto contenido de ACG se obtuvo a partir de $\mathrm{PV}_{\mathrm{YM}}$ suministrados por la Cachuera S.A. (Apóstoles, Misiones), materia prima seleccionada en base a los resultados alcanzados en el capítulo 2. Se utilizaron las partículas de menor tamaño (Ø partícula $<500 \mu \mathrm{m})$ que fueron extraídas bajo las condiciones óptimas descritas en el capítulo $3\left(65^{\circ} \mathrm{C}, 5 \mathrm{~min}\right.$, en una relación $\mathrm{S} / \mathrm{L}$ de $\left.1: 20\right)$. El extracto fue mantenido a $4{ }^{\circ} \mathrm{C}$ hasta su utilización, por un tiempo no mayor a los 4 días.

El BLE se construyó con una columna de vidrio con un $\emptyset_{\text {interno }}$ de $1,7 \mathrm{~cm}$, una altura de $14 \mathrm{~cm}$ y un volumen total de $20 \mathrm{ml}$. Para evaluar la bioconversión del ACG en sus respectivos productos de hidrólisis (AQ y AC) se hizo circular una solución de ACG puro o el extracto de yerba mate a través del BLE y se utilizaron métodos espectrofotométricos y cromatográficos (HPLC) para su determinación. El proceso de hidrólisis se llevó a cabo a diferentes caudales de alimentación $(13,6-88,2 \mathrm{ml} / \mathrm{h})$ a fin de evaluar el efecto del tiempo de residencia sobre el porcentaje de conversión del sustrato.

El ACG inicialmente presente en el extracto de yerba mate fue completamente convertido en $\mathrm{AC}$ y $\mathrm{AQ}$ al circular a través de un biorreactor de lecho empaquetado, alcanzándose valores de conversión del $100 \%$ al trabajar a un caudal de $13,6 \mathrm{ml} / \mathrm{h}$.

Se confirmó la eficacia de la $\mathrm{CHasa}_{\mathrm{NI}}$ como biocatalizador inmovilizado estable con actividad CHasa y su biodisponibilidad para usos repetidos por al menos varias veces $(\sim 12 \mathrm{~h})$ sin pérdida apreciable de la actividad catalítica.

Se alcanzaron conversiones de AC y AQ mayores al $100 \%$, lo cual se podría deber a que tanto el AC como el AQ fueron liberados a partir de otros ésteres diferentes al ACG por la acción de otras esterasas intracelulares (además de CHasa) presentes en la CHasa $\mathrm{NI}_{\mathrm{NI}}$.

No se observó formación de gas causada por la respiración del micelio al hacer circular una solución de ACG a través del biorreactor de lecho empaquetado con lo cual se confirma que la viabilidad del micelio ha sido eliminada mediante el tratamiento térmico de los pellets de $A$. niger AKU 3302.
\end{abstract}

\subsection{INTRODUCCIÓN}

Actualmente, existe un gran auge en la aplicación industrial de enzimas como biocatalizadores altamente selectivos para la producción de químicos finos (Koeller y 
col., 2001; Panke y col., 2004). Cuando se trabaja a escala industrial, se favorece la configuración de reactores que operan en forma continua, ya que ofrecen ventajas de altas productividades y bajo requerimiento de trabajo humano. Sin embargo, menos de la cuarta parte de todos los procesos biotecnológicos realizados a escala industrial son procesos continuos (Straathof y col., 2002). Para llegar a ser económicamente viables, en los procesos industriales se debe poner atención a la utilización eficiente del biocatalizador (Kragl y col., 1996; Wandrey, 2004). En los procesos continuos, esto se puede lograr ya sea mediante la retención del catalizador dentro del reactor por medio de una membrana, inmovilizándolo por diferentes mecanismos o bien mediante la utilización de células enteras. Un biocatalizador inmovilizado puede ser fácilmente removido de la mezcla de reacción final, obteniéndose un producto de alta pureza y libre de proteínas y otros potenciales contaminantes (i.e.: restos de reactivos).

El modelo de biorreactor más ligado al uso de enzimas inmovilizados es el biorreactor de lecho empaquetado (BLE). Este es el modelo más simple de construcción y operación en el que la solución de sustrato que se alimenta al reactor circula en una dirección determinada y simultáneamente va teniendo lugar su conversión. El modelo que sigue este reactor en el caso ideal es el de flujo pistón.

Los biorreactores de flujo vertical se han utilizado en numerosos estudios (Dvorak y col., 1992; Cheong y col., 1998; Elliott y col., 1998; Drury, 1999; Tsukamoto y Miller, 1999; Chang y col., 2000; Willow y Cohen, 2003; Tsukamoto y col., 2004; Johnson y Hallberg, 2005; Jong y Parry, 2003). En los BLE las células son inmovilizadas sobre un soporte. Además, en el caso particular de los BLE de flujo descendente, el afluente se alimenta a través de la parte superior mientras que en el modo de flujo ascendente se alimenta a través de la parte inferior del reactor. En general, los biorreactores con flujo vertical pueden generar canales preferenciales por donde percola el líquido afluente. Los biorreactores de flujo ascendente tienden a evitar la compactación y la formación de canales (Neculita y col., 2007).

La enzima clorogenato hidrolasa (CHasa, EC 3.1.1.42) cataliza la hidrólisis de ACG liberando cantidades equimolares de ácidos quínico (AQ) y cafeico (AC), productos de alto valor e interés comercial que no se producen en nuestro país. En estudios previos se obtuvo una clorogenato hidrolasa naturalmente inmovilizada ( $\mathrm{CHasa}_{\mathrm{NI}}$ ) en los pellets de A. niger AKU 3302 (capítulos 4 y 6). Las condiciones óptimas de operación de la 
$\mathrm{CHasa}_{\mathrm{NI}}$, así como sus parámetros cinéticos y termodinámicos fueron determinados utilizando un sistema tipo batch (capítulo 6).

En capítulos anteriores se ha reportado un elevado contenido de ACG en la yerba mate (Ilex paraguariensis), particularmente en los palos verdes de yerba mate (PV $\left.\mathrm{YM}_{\mathrm{YM}}\right)$. Los mismos constituyen una fuente natural de ACG actualmente no explotada y sumamente valiosa por tratarse de un residuo poco valorado de la industria yerbatera.

Por lo tanto, la obtención de un extracto acuoso con elevado contenido de ACG a partir de los $\mathrm{PV}_{\mathrm{YM}}$ y la utilización de la $\mathrm{CHasa}_{\mathrm{NI}}$ como biocatalizador enzimático capaz de hidrolizar el ACG en AC y AQ, constituyen respectivamente la fuente y el proceso necesarios para la obtención de dichos metabolitos de interés.

Con el fin de desarrollar un proceso de producción más práctico de dichos metabolitos, se propone la utilización de un biorreactor del tipo lecho empaquetado conteniendo la $\mathrm{CHasa}_{\mathrm{NI}}$ como relleno a través del cual se haga circular de forma ascendente un extracto obtenido a partir de $\mathrm{PV}_{\mathrm{YM}}$ con alto contenido en ACG.

\subsection{MATERIALES Y MÉTODOS}

\subsubsection{Materiales y reactivos químicos}

Para las extracciones se utilizó agua destilada. Para la determinación del contenido de ACG, AC y AQ se utilizaron los siguientes reactivos de grado analítico o cromatográfico: ACG (Sigma-Aldrich, St. Louis, EE.UU.), AC (Sigma-Aldrich), AQ (Merck, Hohenbrunn, Alemania), agua grado HPLC (Panreac, Barcelona, España), acetonitrilo (J.T. Baker, Phillipsburg, EE.UU.) y ácido acético (Merck).

\subsubsection{Preparación de CHasa naturalmente inmovilizada (CHasa NI $_{\text {) }}$}

El micelio no viable (tratado a $55^{\circ} \mathrm{C}$ por $20 \mathrm{~min}$ ), crecido en la forma de pellets (con un diámetro entre 0,4 y $0,6 \mathrm{~cm}$ ) y con actividad CHasa intracelular, fue obtenido según se describió en los capítulos 4 y 6 . Los pellets con actividad CHasa ${ }_{\mathrm{IN}}$ fueron conservados en BFS $(50 \mathrm{mM}, \mathrm{pH} 6,5)$ a $4{ }^{\circ} \mathrm{C}$ hasta su uso y por un período no mayor a 15 días.

\subsubsection{Obtención del extracto de yerba mate con elevado contenido de ACG}

El extracto acuoso de yerba mate con elevado contenido de ACG se obtuvo a partir de $\mathrm{PV}_{\mathrm{YM}}$ suministrados por la Cachuera S.A., empresa procesadora de yerba mate 
localizada en la ciudad de Apóstoles, Misiones. Los $\mathrm{PV}_{\mathrm{YM}}$ fueron seleccionados como materia prima para la preparación de los extractos ricos en ACG en base a los resultados alcanzados en el capítulo 2. Se utilizaron las partículas de menor tamaño (Ø partícula $<$ $500 \mu \mathrm{m}$ ) en tanto que las extracciones se realizaron bajo las condiciones óptimas descritas en el capítulo $3\left(65^{\circ} \mathrm{C}, 5 \mathrm{~min}\right.$, con una relación $\mathrm{S} / \mathrm{L}$ de 1:20). Luego de la extracción, el extracto obtenido fue filtrado (papel Whatman \# 1), diluido 10 veces en BFS (50 mM, pH: 6,5) de modo de alcanzar una concentración de ACG de $\cong 1,5 \mathrm{mM}$ y mantenido a $4{ }^{\circ} \mathrm{C}$ hasta su utilización, por un tiempo no mayor a los 4 días.

\subsubsection{Determinación de la actividad clorogenato hidrolasa}

La actividad de CHasa $_{\mathrm{NI}}$ se determinó de acuerdo al método de Okamura y Watanabe (1982a) con algunas modificaciones, como se describió en el capítulo 6 de la presente tesis, para adaptarlo al caso del micelio tratado térmicamente en forma de pellets.

\subsubsection{Operación del reactor de lecho empaquetado para la producción de AQ y $\mathrm{AC}$}

El biorreactor de lecho empaquetado (BLE) se construyó con una columna de vidrio con un $\emptyset_{\text {interno }}$ de $1,7 \mathrm{~cm}$, una altura de $14 \mathrm{~cm}$ y un volumen total de $20 \mathrm{ml}\left(\mathrm{V}_{\mathrm{T}}\right)$. La columna posee un puerto superior para la carga del biocatalizador, uno inferior para el ingreso de la corriente de alimentación y otro lateral para la corriente de salida La Figura 7.1 muestra un esquema del montaje experimental utilizado. El BLE se empaquetó con el biocatalizador, ocupando un volumen $\left(\mathrm{V}_{\mathrm{b}}\right)$ de $12 \mathrm{ml}$ de modo que la fracción de espacio vacío $(\varepsilon)$ fue igual a 0,40 (ec. 7.1).

$$
\varepsilon=1-\frac{V_{b}}{V_{T}} \quad(\text { ec. } 7.1)
$$

El BLE se alimentó con una solución pura de ACG 1,5 mM en BFS (50 mM, pH 6,5) a un caudal constante arbitrariamente seleccionado de $13,6 \mathrm{ml} / \mathrm{h}$ por medio de una bomba peristáltica (Masterflex C/L Modelo 77120-62, Barrington, Illinois, EE.UU.). La solución de ACG fue mantenida a $30^{\circ} \mathrm{C}$ mediante un baño termostatizado. 


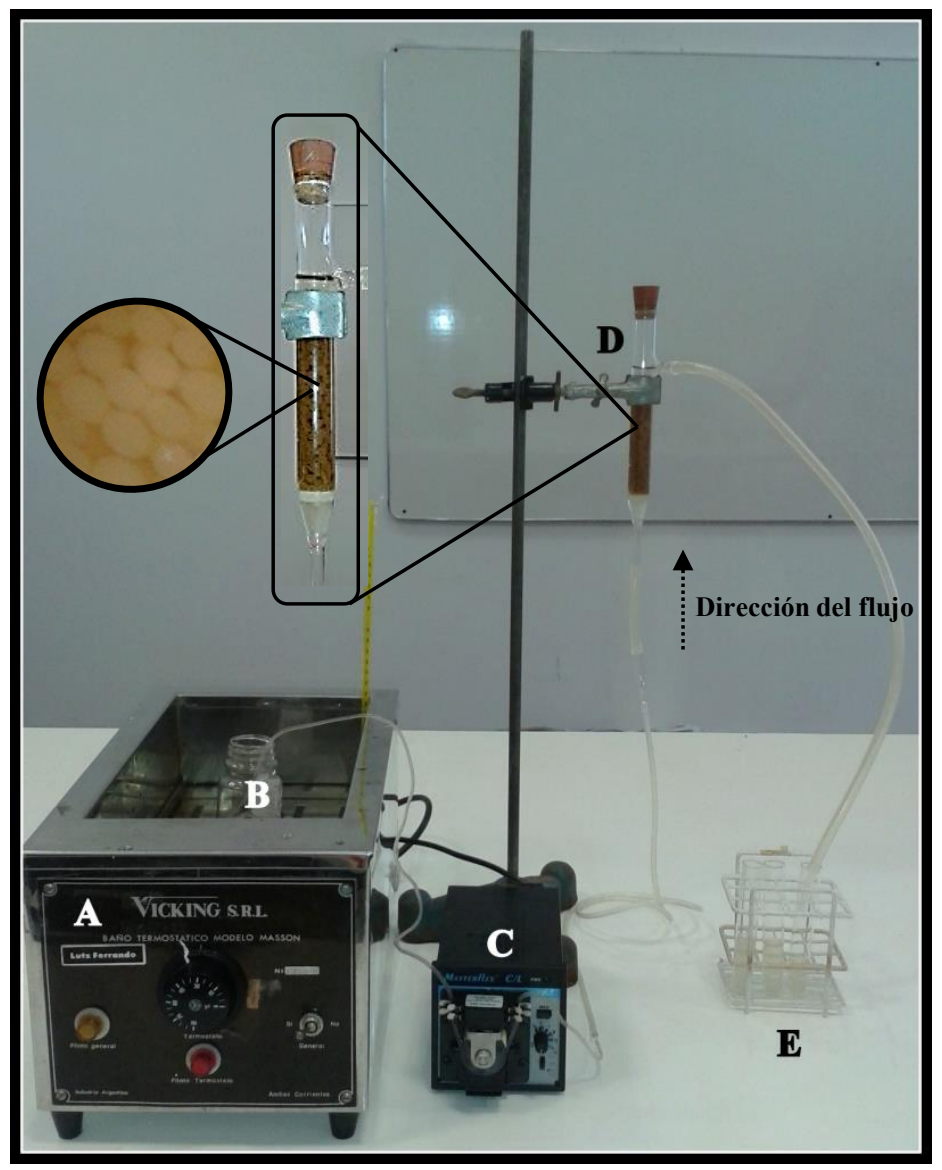

Figura 7.1: Fotografía del sistema de biorreactor de lecho empaquetado de flujo ascendente para la $\mathrm{CHasa}_{\mathrm{NI}}$. A. Baño termostatizado; B. Reservorio con la solución de alimentación; C. Bomba peristáltica; D. Reactor tubular conteniendo la $\mathrm{CHasa}_{\mathrm{NI}}$ como relleno; E. Tubos para recolección del efluente.

A fin de asegurar que se haya alcanzado el estado estacionario, se dejaron transcurrir alrededor de 3 tiempos de retención $\left(\tau_{R}\right)($ ec. 7.2) antes de tomar la primera muestra para realizar las medidas analíticas correspondientes. Transcurrido este tiempo se tomaron tres muestras, separadas al menos un $\tau_{R}$ entre sí, las cuales fueron recogidas en tubos de ensayo. Se midieron las concentraciones de sustrato y sus respectivos productos de hidrólisis en la solución de alimentación y en el efluente.

El $\tau_{R}$ se calculó según:

$$
\tau_{R}=\frac{V_{L}}{F} \quad(\text { ec. } 7.2)
$$

donde el volumen líquido $\left(V_{L}\right)$ se midió como el volumen de líquido drenado por el lecho en tanto que el caudal de alimentación $(F)$ se determinó midiendo el volumen de 
efluente durante un cierto período de tiempo para cada una de las diferentes velocidades de la bomba peristáltica usada.

Posteriormente, se evaluó la hidrólisis del ACG contenido en el extracto de yerba mate y se siguió con el procedimiento descripto anteriormente.

El proceso de hidrólisis se llevó a cabo a diferentes caudales de alimentación $(F=13,6$ $88,2 \mathrm{ml} / \mathrm{h}$ ) a fin de evaluar la relación entre el porcentaje de conversión del sustrato en función del tiempo de residencia. Luego de cada cambio de condición de cultivo se dejó transcurrir al menos $3 \tau_{R}$ a fin de asegurar que se hubiera llegado a un nuevo esta estacionario.

Cabe destacar que aunque la $\mathrm{CHasa}_{\mathrm{NI}}$ presenta una temperatura óptima de $55{ }^{\circ} \mathrm{C}$ (capítulo 6), se decidió realizar este proceso a $30{ }^{\circ} \mathrm{C}$, considerando que a esta temperatura la enzima aún retiene el $85 \%$ de su actividad máxima. En caso de ser necesario el ambiente fue climatizado a la temperatura de trabajo.

\subsubsection{Identificación de los productos de reacción}

Para evaluar la bioconversión del ACG en sus respectivos productos de hidrólisis (AQ y AC) se hizo circular una solución de ACG puro o el extracto de yerba mate a través del BLE y se utilizaron métodos espectrofotométricos y cromatográficos (HPLC), según se describen a continuación.

\subsubsection{Método espectrofotométrico}

Las muestras fueron diluidas y analizadas por espectrofotometría (espectrofotómetro Shimadzu UV-VIS, Modelo UV-2550), realizándose un barrido espectral entre 220-580 $\mathrm{nm}$ de longitud de onda, considerando la longitud de onda de máxima absorción del ACG.

\subsubsection{Cromatografía líquida de alta resolución (HPLC)}

Las concentraciones de ACG, AC y AQ, tanto en la solución de alimentación como en el flujo de salida del biorreactor, fueron determinadas por HPLC utilizando un método adaptado de Adachi y col. (2008). Las respectivas concentraciones se expresaron como $\mathrm{mg} / \mathrm{l}$ de extracto o bien en $\mathrm{mg} / \mathrm{g}_{\text {materia seca }}\left(\mathrm{mg} / \mathrm{g}_{\mathrm{ms}}\right)$. El análisis se llevó cabo utilizando un sistema modular (Waters HPLC) equipado con una bomba (Modelo 510) y un detector 
de índice de refracción (Modelo 481) lo que permitió detectar cualquier compuesto, incluyendo aquellos que no presentaban absorbancia en el UV. Las muestras (20 $\mu 1)$ se inyectaron manualmente en el sistema de HPLC con jeringa Terumo de $25 \mu 1$ y la separación se realizó en una columna de fase reversa C18 (Phenomenex Prodigy ODS3, $250 \mathrm{~mm} \times 4,6 \mathrm{~mm}, 5 \mu \mathrm{m}$ de tamaño de partícula) protegida con un guarda columna de fase reversa C18 de la misma marca. La columna se mantuvo a una temperatura de 30 ${ }^{\circ} \mathrm{C}$, la velocidad del flujo fue de $1,0 \mathrm{ml} / \mathrm{min}$ y la fase móvil estuvo compuesta por una solución $50 \mathrm{mM}$ ácido acético/ $\mathrm{CH}_{3} \mathrm{CN}=8: 2$. Los compuestos fueron identificados por comparación de los tiempos de retención con sus respectivos patrones, $\mathrm{y}$, posteriormente, cuantificados utilizando una curva de calibración de cada compuesto estándar disponible comercialmente.

Todas las determinaciones se realizaron por triplicado y los resultados fueron presentados como promedio \pm desvío estándar.

\subsection{RESULTADOS Y DISCUSIÓN}

\subsubsection{Bioconversión de ACG en AC y AQ mediante un BLE a un caudal fijo}

La Figura 7.2 muestra el espectro de absorción de la solución de ACG puro, antes y después de la circulación a través del BLE a un caudal constante de $13,6 \mathrm{ml} / \mathrm{h}$ y $30^{\circ} \mathrm{C}$.

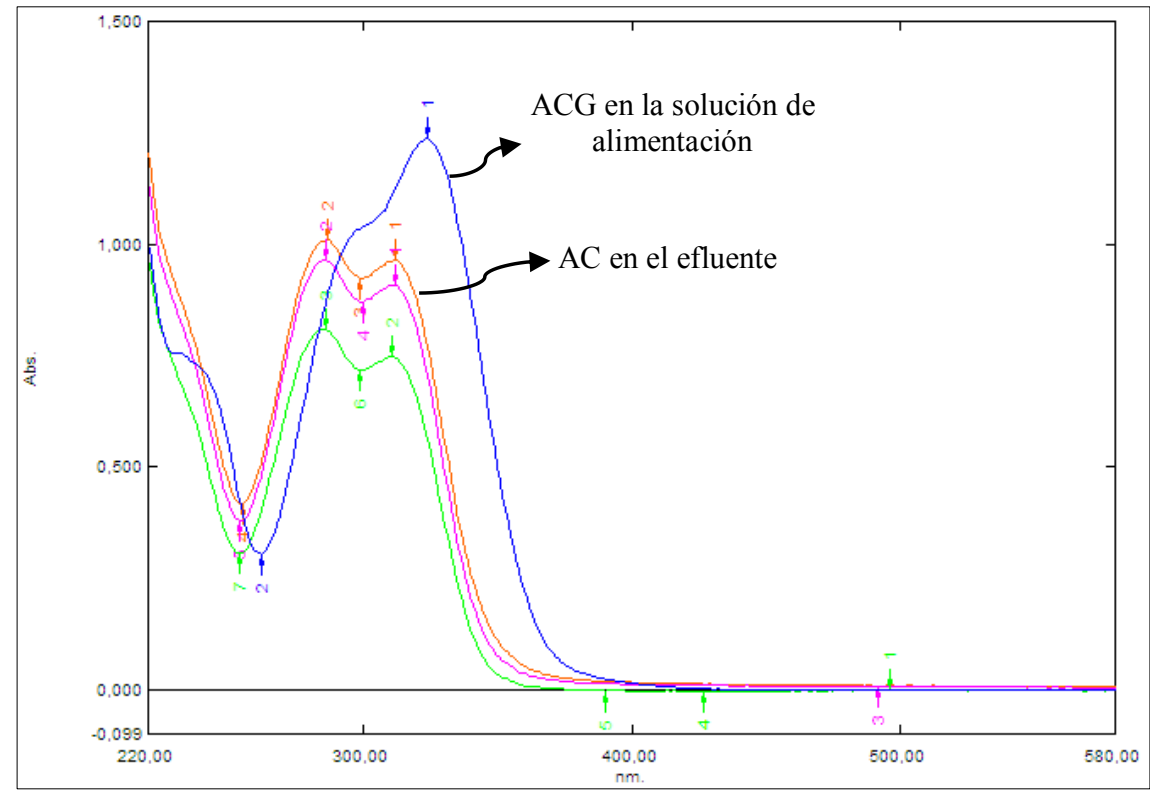

Figura 7.2: Espectro de absorción de la solución de ACG (1,5 mM en BFS $50 \mathrm{mM}, \mathrm{pH}$ 6,5), antes (curva azul) y después de la circulación a través del BLE (curvas roja, rosa y verde) a un caudal constante de $13,6 \mathrm{ml} / \mathrm{h}$ y a $30^{\circ} \mathrm{C}$. 
Se observa el espectro de absorción característico del ACG en la solución de alimentación (curva azul), mientras que el espectro de absorción del efluente luego de alcanzar el estado estacionario $(3 \tau)$ correspondió al del AC (curvas roja, rosa y verde). Esto demuestra que la hidrólisis del ACG se completó en las condiciones de operación del BLE ya que el correspondiente pico desapareció del espectro. No se detectó el espectro correspondiente al AQ ya que este compuesto no absorbe en las longitudes de onda evaluadas (no presenta una fracción fenólica en su estructura).

En base a los prometedores resultados obtenidos al hacer circular una solución de ACG puro a través del BLE conteniendo $\mathrm{CHasa}_{\mathrm{NI}}$ como relleno, se continuaron las experiencias haciendo circular la solución de extracto de yerba mate con elevado contenido de ACG, bajo las mismas condiciones de operación. En la Figura 7.3 se presentan los espectros de absorción del extracto de yerba mate antes y después de la circulación a través del BLE a un caudal constante de $13,6 \mathrm{ml} / \mathrm{h}$ y a $30^{\circ} \mathrm{C}$.

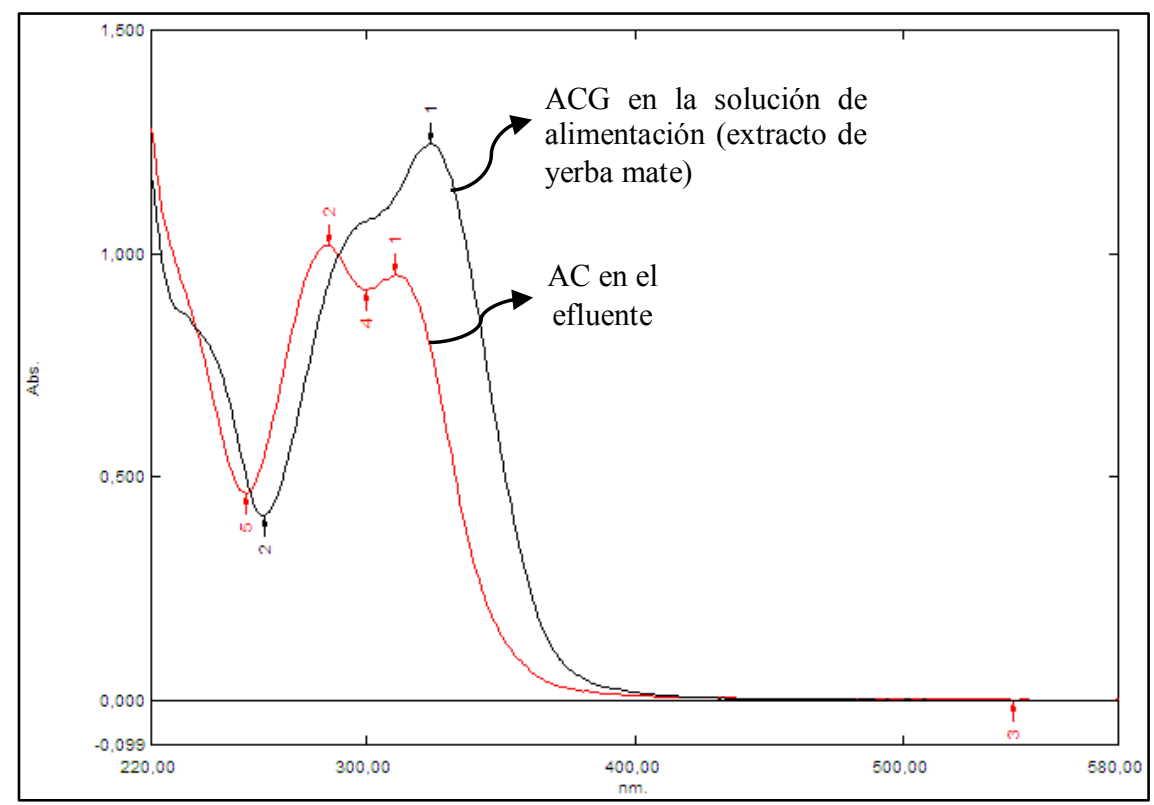

Figura 7.3: Espectro de absorción del ACG contenido en el extracto de yerba mate (curva negra) y de su producto de hidrólisis (AC, curva roja) luego de la bioconversión en el BLE a un caudal constante de $13,6 \mathrm{ml} / \mathrm{h}$ y a $30^{\circ} \mathrm{C}$.

La cantidad de ACG presente en el extracto de yerba mate (curva negra) fue completamente hidrolizada con la correspondiente formación de AC (curva roja). Resulta notable mencionar que el espectro de absorción característico del extracto de yerba mate resulta muy parecido al de la solución pura de ACG (Figs. 7.2 y 7.3). 
Paralelamente, la identificación y cuantificación del ACG, AC y AQ en el extracto de yerba mate antes y después de la circulación a través del BLE, fue monitoreada por HPLC, utilizando un detector de índice de refracción. En la Figura 7.4 se presentan los cromatogramas de los respectivos patrones utilizados para la identificación y cuantificación de los distintos compuestos.
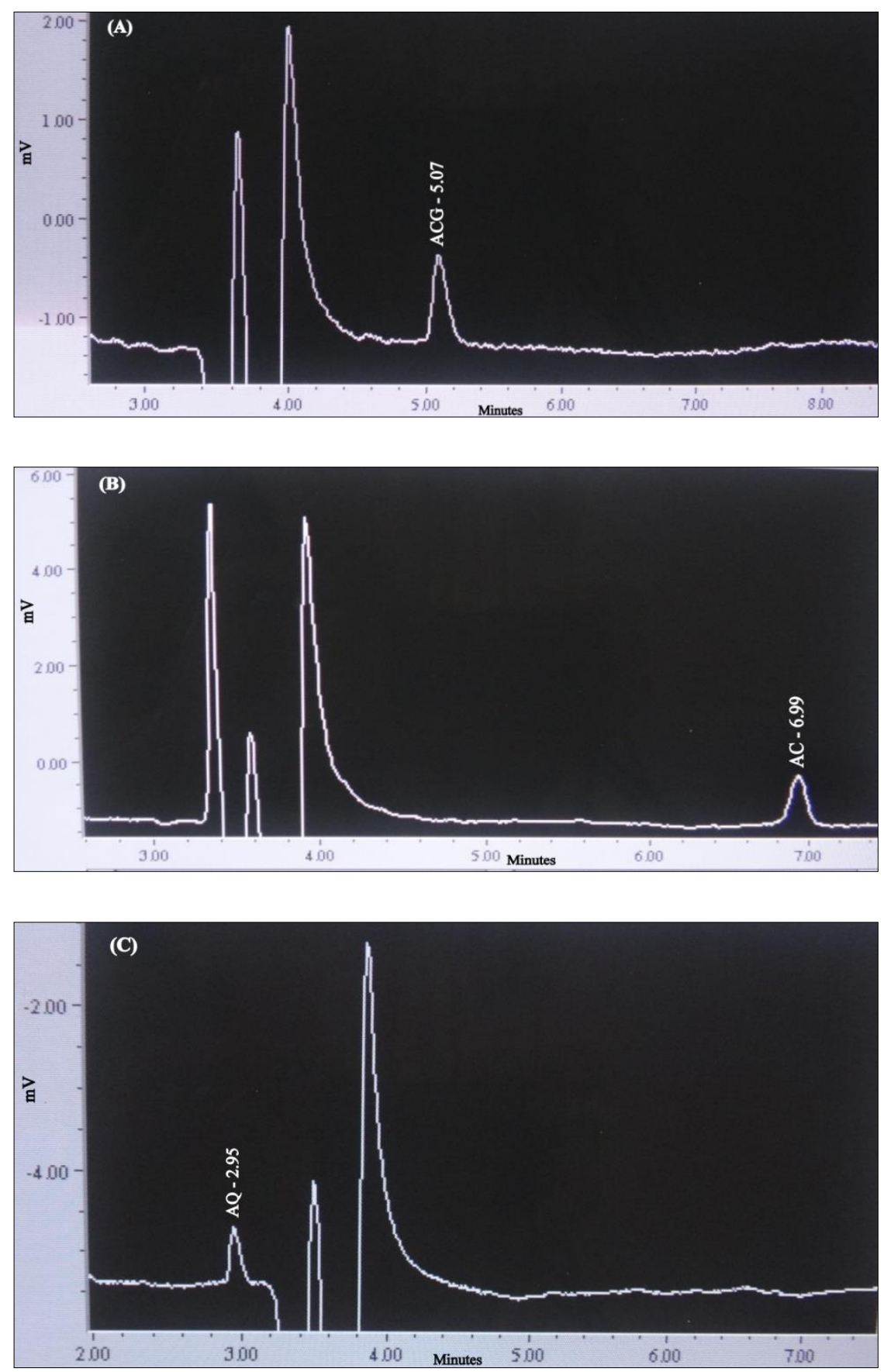

Figura 7.4: Perfil cromatográfico representativo de los respectivos patrones empleando un sistema de HPLC con detector de índice de refracción. (A): ácido clorogénico, ACG; (B): ácido cafeico, AC; (C): ácido quínico, AQ. 
Los tiempos de retención estándar para cada uno de los compuestos fueron 2,95 min para $\mathrm{AQ}, 5,07$ min para $\mathrm{ACG}$ y 6,99 min para $\mathrm{AC}$, bajo las condiciones de ensayo.

Las concentraciones de ACG, AC y AQ en el extracto de yerba mate antes y después de la hidrólisis enzimática fueron calculadas utilizando las siguientes curvas de calibración para cada compuesto estándar:

$$
\begin{array}{lll}
y_{A C G}=2 \times 10^{6} x+2313,8 & R^{2}=0,99 & (\text { ec. } 7.3) \\
y_{A C}=2 \times 10^{6} x-3880,3 & R^{2}=0,99 & (\text { ec. } 7.4) \\
y_{A Q}=2 \times 10^{6} x-4760,4 & R^{2}=0,99 & (\text { ec. } 7.5)
\end{array}
$$

Siendo $y_{A C G}, y_{A C}$ y $y_{A Q}$ las correspondientes áreas y $x$ la concentración de cada compuesto $(\% \mathrm{p} / \mathrm{v})$.

En las Figuras 7.5 y 7.6 se presentan los cromatogramas del extracto de yerba mate antes y después circular a través del BLE, respectivamente, en los cuales se identifican los picos de ACG, AC y AQ.

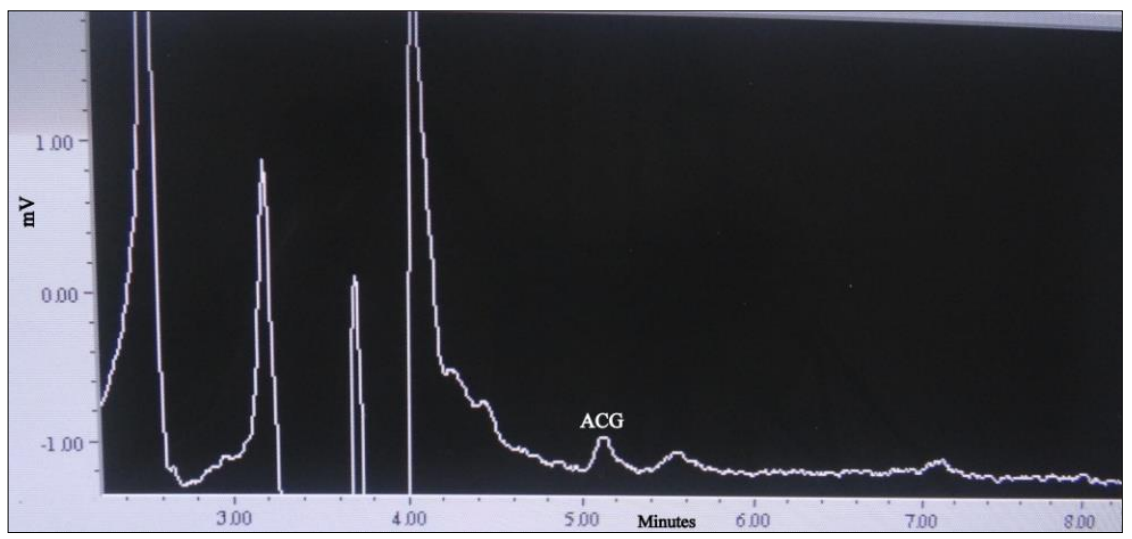

Figura 7.5: Perfil cromatográfico del extracto de palos verdes de yerba mate antes de la hidrólisis con la $\mathrm{CHasa}_{\mathrm{NI}}$, empleando un sistema de HPLC con detector de índice de refracción.

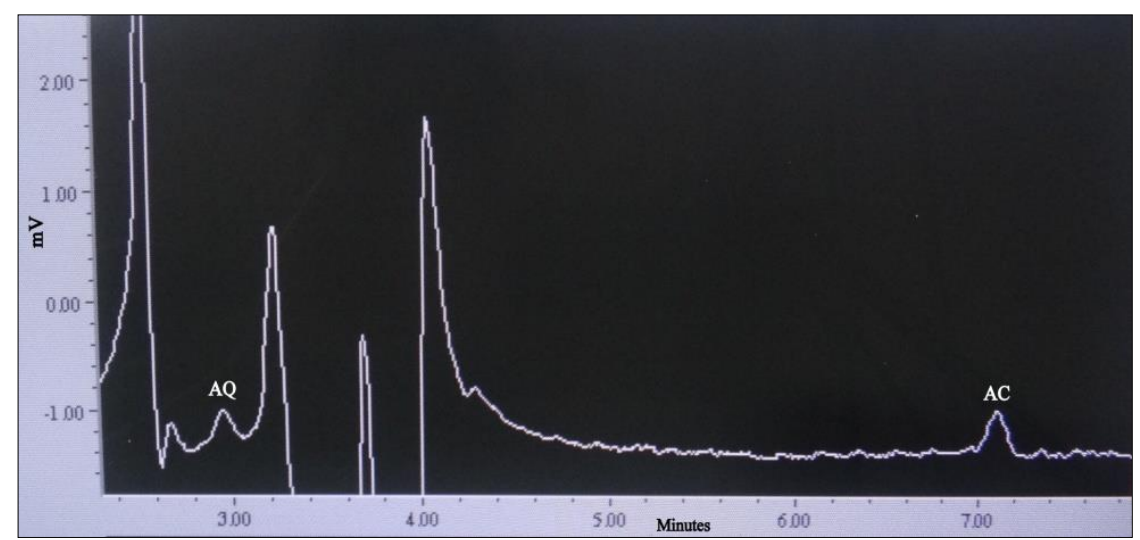

Figura 7.6: Perfil cromatográfico del extracto de palos verdes de yerba mate después de la hidrólisis con la $\mathrm{CHasa}_{\mathrm{NI}}$ en un BLE a un flujo constante de 13,6 ml/h, empleando un sistema de HPLC con detector de índice de refracción. 
Como puede observarse en los cromatogramas, el ACG inicialmente presente en el extracto de yerba mate (Fig. 7.5), es completamente convertido en AC y AQ (Fig. 7.6), comprobándose nuevamente la eficacia de la $\mathrm{CHasa}_{\mathrm{NI}}$ como biocatalizador enzimático al alcanzarse rendimientos del $100 \%$ de conversión al trabajar a un caudal de 13,6 ml/h. En la Tabla 7.1 se muestran las concentraciones de cada compuesto, expresadas en base seca.

Tabla 7.1: Contenido de ACG, AC y AQ antes y después de la hidrólisis enzimática del extracto de yerba mate en el BLE a un flujo constante de $13,6 \mathrm{ml} / \mathrm{h}$.

\begin{tabular}{ccc}
\hline $\begin{array}{c}\text { Compuesto } \\
\left(\mathrm{mg} / \mathrm{g}_{\mathrm{ms}}\right)\end{array}$ & $\begin{array}{c}\text { Antes del tratamiento } \\
\text { (control) }\end{array}$ & $\begin{array}{c}\text { Después del tratamiento } \\
\text { (enzima) }\end{array}$ \\
\hline $\mathrm{ACG}$ & $22,77 \pm 0,48$ & nd \\
$\mathrm{AC}$ & nd & $33,46 \pm 3,35$ \\
$\mathrm{AQ}$ & nd & $25,61 \pm 1,73$ \\
\hline nd: no detectado. & &
\end{tabular}

Se observa que el extracto de $\mathrm{PV}_{\mathrm{YM}}$ contenía inicialmente $22,77 \mathrm{mg}_{\mathrm{ACG}} / \mathrm{g}_{\mathrm{ms}}$, no detectándose cantidades significativas de AC y AQ. Después de la hidrólisis enzimática no se detectó presencia de ACG en el efluente, evidenciándose elevadas concentraciones de AC y AQ. Teniendo en cuenta que la hidrólisis del ACG produce cantidades equimolares de $\mathrm{AC}$ y $\mathrm{AQ}$, en base a la cantidad de $\mathrm{ACG}$ presente en el extracto de $\mathrm{PV}_{\mathrm{YM}}$, se deberían haber obtenido $11,58 \mathrm{mg}_{\mathrm{AC}} / \mathrm{g}_{\mathrm{ms}}$ y $12,35 \mathrm{mg}_{\mathrm{AQ}} / \mathrm{g}_{\mathrm{ms}}$. Sin embargo, las elevadas concentraciones de ambos productos, obtenidas en el efluente ( $\sim$ $\left.33,46 \mathrm{mg}_{\mathrm{AC}} / \mathrm{g}_{\mathrm{ms}} \mathrm{y} \sim 25,61 \mathrm{mg}_{\mathrm{AQ}} / \mathrm{g}_{\mathrm{ms}}\right)$ indicaría que al menos el $67 \%$ del AC y el $54 \%$ del AQ fueron producidos, probablemente, a partir de otros ésteres diferentes al ACG. Resultados similares fueron obtenidos en el capítulo 5 de la presente tesis, al utilizar el EE crudo con actividad CHasa para hidrolizar el ACG contenido en el EYM. Esto se puede deber a la presencia, en los pellets de A. niger AKU 3302, de otras esterasas intracelulares (además de CHasa) que pudieran hidrolizar otros compuestos relacionados al ACG de la yerba mate.

Resultados similares fueron informados por Adachi y col. (2008) quienes obtuvieron un elevado contenido de AC luego de la hidrólisis enzimática de diferentes extractos de café instantáneo, mediante una CHasa inmovilizada en pulpa de café por fermentación tipo koji. 


\subsubsection{Efecto del tiempo de residencia sobre la bioconversión de ACG en el BLE}

La solución de alimentación (extracto de $\mathrm{PV}_{\mathrm{YM}}$ conteniendo $108,9 \pm 11,2 \mathrm{mg}_{\mathrm{ACG}} / \mathrm{l}$ ) fue bombeada a la columna rellena con $\mathrm{CHasa}_{\mathrm{NI}}$ a varias velocidades de flujo. Luego de alcanzar el estado estacionario, se determinó la concentración de ACG, AC y AQ en el efluente. El porcentaje de conversión de ACG se definió como la relación entre la concentración de ACG en el efluente respecto a la concentración inicialmente presente en la solución de alimentación. En la Figura 7.7 se representa la relación entre el porcentaje de conversión de ACG y el tiempo de residencia.

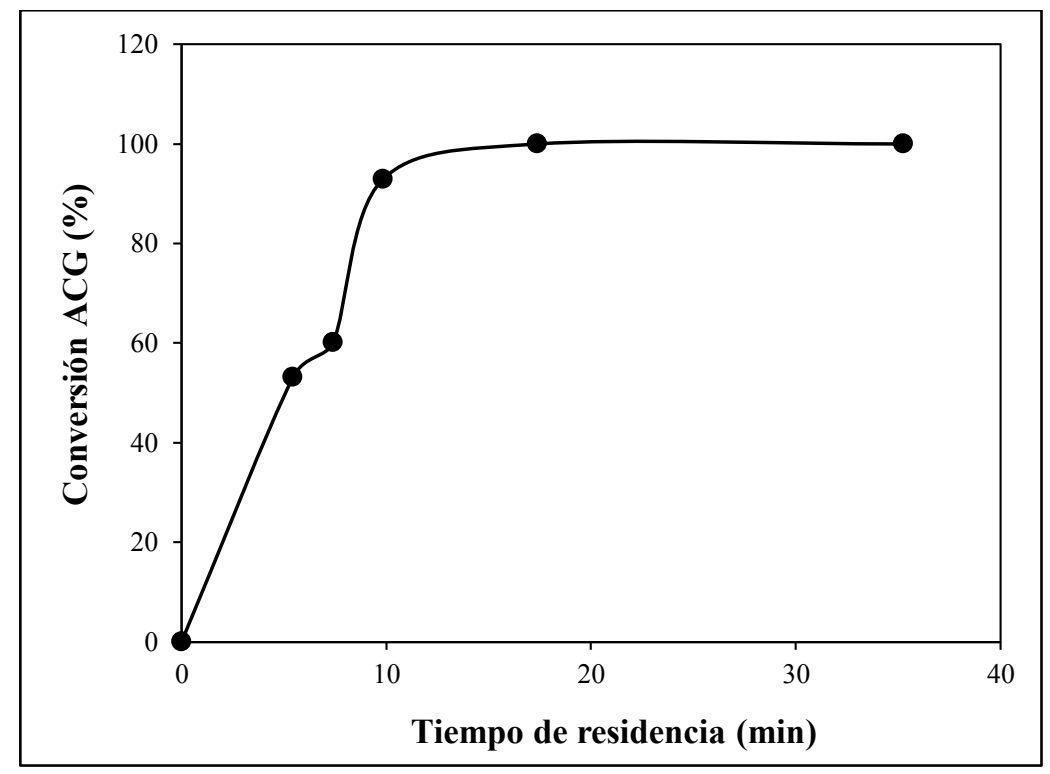

Figura 7.7: Efecto del tiempo de residencia sobre la conversión de ACG.

Como se observa en la Figura 7.7, se obtuvo un $100 \%$ de conversión a valores de $\tau \geq$ 9,83 $\mathrm{min}(48,82 \mathrm{ml} / \mathrm{h})$. A mayores caudales, la conversión disminuyó progresivamente. Las Figuras 7.8 y 7.9 muestran el efecto del tiempo de residencia sobre la concentración y la productividad de $\mathrm{AC}$ y $\mathrm{AQ}$ en el flujo de salida, respectivamente. 


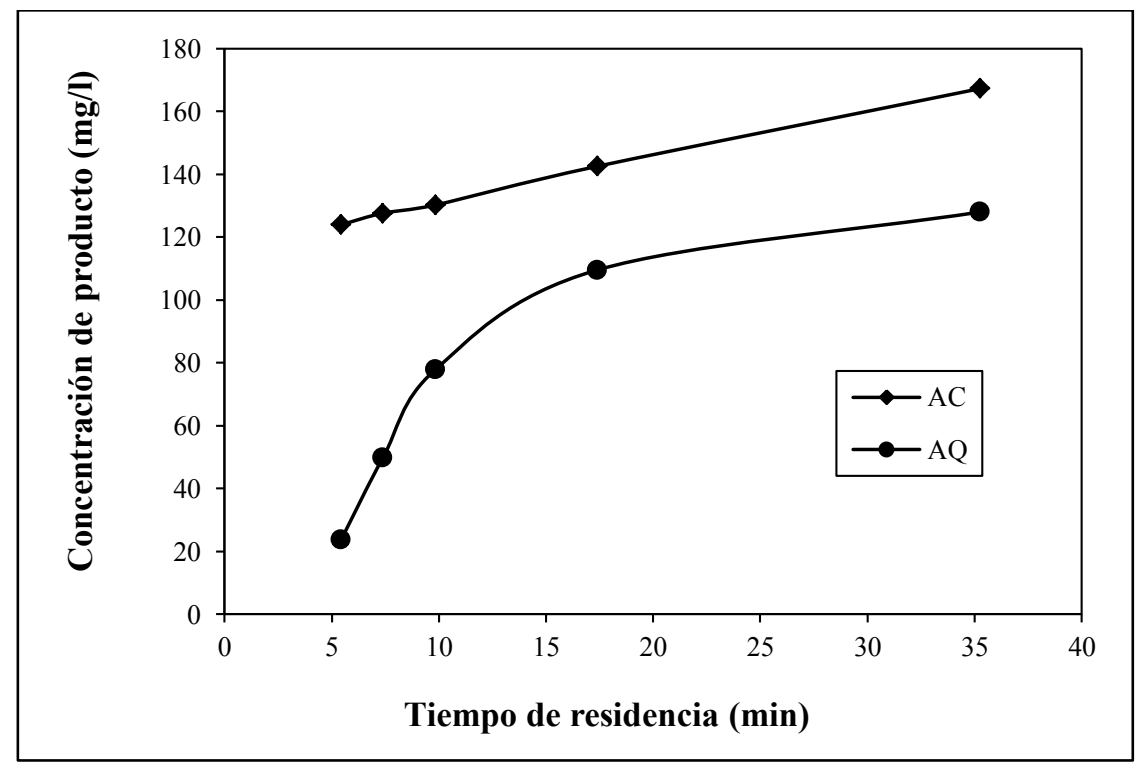

Figura 7.8: Efecto del tiempo de residencia sobre la concentración de AC y AQ en el flujo de salida.

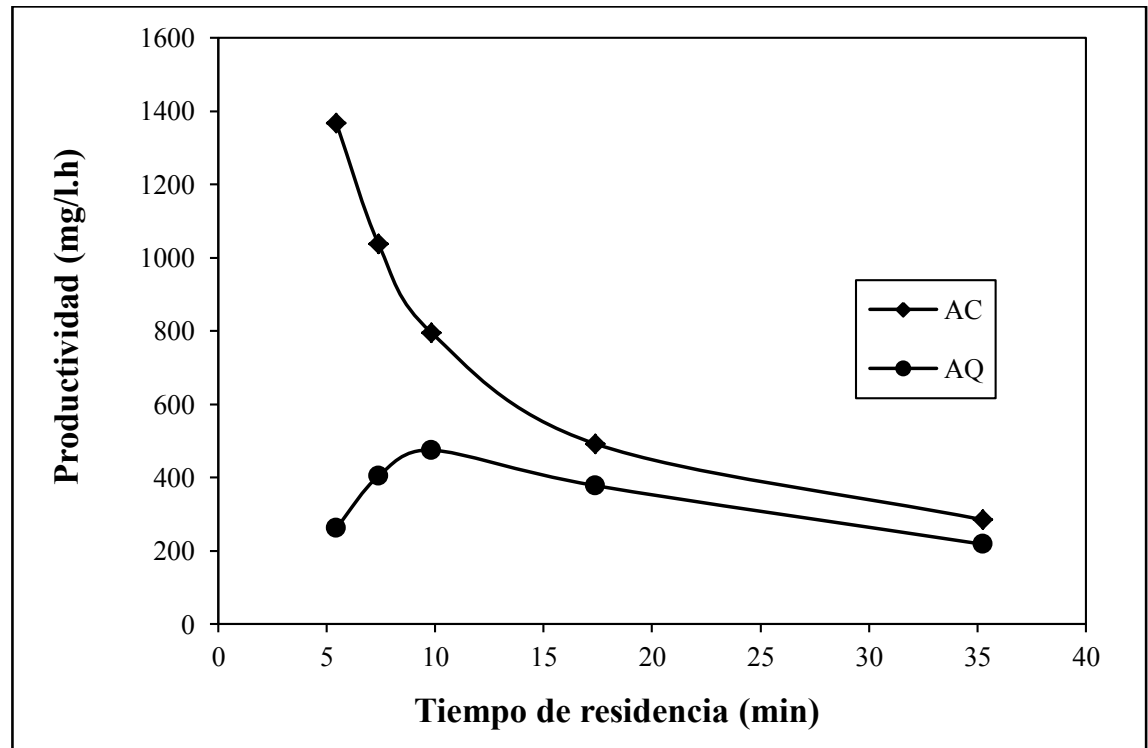

Figura 7.9: Efecto del tiempo de residencia sobre la productividad del AC y AQ en el flujo de salida.

Como se observa en la Figura 7.8, la concentración de $\mathrm{AC}$ obtenida en el efluente aumenta ligeramente al aumentar el $\tau \mathrm{y}$, por lo tanto, la productividad aumenta apreciablemente a bajos valores de $\tau$ (Fig. 7.9). La máxima concentración alcanzada de $\mathrm{AC}$ fue de 167,3 mg/l con un tiempo de residencia de $\tau: 35,3 \mathrm{~min}$, mientras que, la máxima productividad obtenida fue de $1366 \mathrm{mg} / \mathrm{l}$.h con un tiempo de residencia de $\tau$ : 5,4 min. 
En el caso de AQ se obtuvo una mayor concentración a altos valores de $\tau$ y la máxima concentración fue de 128,03 mg/l con un tiempo de residencia de $\tau$ : 35,3 min (Fig. 7.8). La productividad alcanzó un valor máximo de 474,86 mg/l.h con un tiempo de residencia de $\tau$ : 9,83 $\mathrm{min}$ (Fig. 7.9).

Cabe destacar que en función de la concentración de ACG en el extracto de yerba mate ( 108,9 $\left.\mathrm{mg}_{\mathrm{ACG}} / \mathrm{l}\right)$ y según la estequiometría de la hidrólisis de ACG en AC y AQ, se debería obtener en el efluente, una concentración de $\mathrm{AC}$ de $\sim 55,37 \mathrm{mg}_{\mathrm{AC}} / 1$ y de $\mathrm{AQ}$ de $\sim 59,06 \mathrm{mg}_{\mathrm{AQ}} / 1$, considerando una conversión de ACG del $100 \%$. Sin embargo, como se muestra en la Figura 7.8, se alcanzaron valores de AC y AQ muy superiores, lo cual se debería a que tanto el AC como el AQ fueron liberados a partir de otros ésteres diferentes al ACG por la acción de otras esterasas intracelulares (además de CHasa), como fuera previamente mencionado. No obstante, a valores de $\tau \leq 9,83$ min la concentración de AQ disminuyó apreciablemente lo cual indica que a elevados caudales hay una menor conversión de ACG y otros ésteres en AQ.

No se detectó pérdida significativa de la actividad catalítica de $\mathrm{CHasa}_{\mathrm{NI}}$ luego de $\sim 12$ $\mathrm{h}$ de uso repetido con lo cual se verifica la estabilidad de este sistema biocatalítico.

\subsection{CONCLUSIÓN}

El ACG inicialmente presente en el extracto de palos verdes de yerba mate fue completamente convertido en AC y AQ al circular a través de un biorreactor de lecho empaquetado, alcanzándose rendimientos del $100 \%$ de conversión al trabajar a un caudal de $13,6 \mathrm{ml} / \mathrm{h}$.

Se confirmó la eficacia de la $\mathrm{CHasa}_{\mathrm{NI}}$ como biocatalizador inmovilizado estable con actividad CHasa, y su estabilidad para usos repetidos durante alrededor de unas $12 \mathrm{~h}$ sin pérdida apreciable de la actividad catalítica.

Se alcanzaron conversiones de AC y AQ mayores al $100 \%$, lo cual se podría deber a que tanto el AC como el AQ fueron liberados a partir de otros ésteres diferentes al ACG por la acción de otras esterasas intracelulares (además de CHasa).

No se observó formación de gas causada por la respiración del micelio al hacer circular una solución de ACG a través del biorreactor de lecho empaquetado, debido a que el micelio fúngico fue inactivado luego del tratamiento térmico de los pellets de $A$. niger AKU 3302. 
Se espera que la CHasa $_{\mathrm{NI}}$ de $A$. niger AKU 3302, desarrollada en este estudio contribuya a una producción de AQ a mayor escala, a partir de extractos acuosos de palos de yerba mate, un residuo poco valorado en la industria yerbatera. De esta manera, el AQ obtenido podría ser utilizado para su posterior bioconversión en ácido siquímico (precursor directo de la síntesis química de la droga antiviral Oseltamivir, el principio activo del Tamiflú ${ }^{\mathrm{MR}}$ ) y otros metabolitos importantes generados a partir de la ruta metabólica del ácido siquímico (ácidos dehidroquínico y dehidrosiquímico y otros compuestos aromáticos de potencial importancia en las industrias farmacéuticas, bioquímicas y agrícolas). 


\section{Conelusiones Generales}




\section{CONCLUSIONES GENERALES}

En una primera etapa, se analizó el contenido de ácido clorogénico (ACG) en muestras de yerba mate (Ilex paraguariensis) obtenidas de dos plantas de procesamiento ubicadas al Sur de la provincia de Misiones-Argentina, a lo largo de las diferentes etapas de procesamiento y en dos épocas del año. A partir de la muestra seleccionada, se evaluó el método de extracción sólido-líquido más adecuado, la cinética de extracción acuosa de ACG, su ajuste a modelos empíricos y finalmente la optimización mediante la metodología de superficie de respuesta. En una segunda etapa, se analizó la producción de la enzima clorogenato hidrolasa (CHasa) por varias cepas fúngicas utilizando materiales derivados del procesamiento de la yerba mate como inductores de la actividad enzimática. A partir de la cepa seleccionada, se llevó a cabo la producción de la CHasa libre como naturalmente inmovilizada en los mismos pellets fúngicos $\left(\mathrm{CHasa}_{\mathrm{NI}}\right)$. Se estudió el efecto del $\mathrm{pH}$ y la temperatura sobre la actividad y estabilidad de ambas formas de la enzima y sus parámetros cinéticos y termodinámicos, a fin de establecer las condiciones apropiadas para su utilización en la hidrólisis del ACG presente en sustratos naturales. La obtención de un extracto acuoso con elevado contenido de ACG a partir de yerba mate ( $1^{\circ}$ Etapa) y la utilización de la CHasa $\mathrm{NI}_{\mathrm{I}}$ como biocatalizador enzimático para de hidrolizar el ACG en ácidos cafeico (AC) y quínico (AQ) $\left(2^{\circ}\right.$ Etapa), constituyen respectivamente la fuente y el proceso necesarios para la obtención de dichas sustancias de interés comercial. Con el fin de desarrollar una producción más práctica de $\mathrm{AC}$ y $\mathrm{AQ}$, en una tercera etapa se propuso la utilización de un biorreactor del tipo lecho empaquetado conteniendo la $\mathrm{CHasa}_{\mathrm{NI}}$ como relleno del biorreactor a través del cual se hizo circular en forma ascendente el extracto de yerba mate con elevado contenido de ACG.

A partir de los objetivos planteados y los resultados obtenidos es posible arribar a las siguientes conclusiones generales:

\section{Etapa:}

- El análisis cuantitativo-comparativo de todas las muestras de yerba mate analizadas indicó que el contenido de ACG total es ligeramente superior en las muestras correspondientes a la yerba mate recién cosechada (hoja y palo verde). 
Una pérdida sustancial de ACG ocurre durante la etapa de zapecado. El contenido de ACG al inicio de la época de zafra es sustancialmente mayor al obtenido al final de la época de zafra, tanto para las hojas verdes como para los palos verdes.

- La extracción de ACG a partir de PV $\mathrm{YM}_{\mathrm{YM}}$ está influenciada principalmente por la relación sólido/líquido, el tamaño de partícula y la temperatura de extracción.

- Los modelos matemáticos aplicados muestran una buena concordancia con los resultados experimentales, lo que permite su aplicación en el modelado del proceso de extracción sólido-líquido de ACG a partir de $\mathrm{PV}_{\mathrm{YM}}$.

- Los resultados alcanzados constituyen una guía para la obtención de extractos de yerba mate con alto contenido en ACG a partir de uno de los mayores residuos (y menos valorado) derivado de la industria yerbatera: los palos verdes ( $\left.\mathrm{PV}_{\mathrm{YM}}\right)$ obtenidos al inicio de la época de zafra.

\section{$2^{\circ}$ Etapa}

- Se confirmó la naturaleza inducible de la enzima CHasa fúngica. La actividad CHasa se detectó en los micelios de varias cepas de hongos al ser inducida con diferentes materiales derivados del procesamiento de la yerba mate, que contienen ACG en su composición. No se detectó actividad CHasa en ausencia del inductor.

- Aspergillus niger AKU 3302 exhibió la mayor actividad CHasa y el extracto concentrado de yerba mate $(\mathrm{EYM})$ resultó ser el inductor más conveniente entre los diferentes materiales derivados de la yerba mate evaluados. La producción óptima de CHasa se obtuvo a bajas concentraciones del inductor y largos tiempos de inducción.

- Los resultados obtenidos demostraron que el extracto enzimático de A. niger AKU 3302 posee actividad CHasa. No se detectó actividad polifenoloxidasa. La enzima CHasa presentó buena estabilidad térmica y fue estable en un amplio rango de $\mathrm{pH}$.

- Se demostró la capacidad de la CHasa para hidrolizar el ACG contenido en sustratos naturales. Las cantidades de ácidos quínico (AQ) y cafeico (AC) liberadas del EYM fueron mayores que la correspondiente estequiométricamente 
a partir del ACG hidrolizado. Estos resultados sugieren que la CHasa es capaz de actuar sobre otros ésteres del AC presentes en la solución de sustrato.

- La utilización del extracto enzimático crudo con elevada actividad CHasa representa una nueva herramienta clave potencial para la liberación de compuestos fenólicos ( $\mathrm{AC}$ y $\mathrm{AQ}$ ) de interés y aplicación industrial (como antioxidantes, intermediarios clave en la síntesis de nuevos fármacos, etc.).

- La producción de un biocatalizador inmovilizado de forma natural con elevada actividad CHasa resultó relativamente fácil y económicamente viable.

- Se demostró la aplicación potencial de los pellets del micelio de A. niger AKU 3302 como un biocatalizador naturalmente inmovilizado con actividad CHasa. Las propiedades y la estabilidad de la enzima exhibieron características interesantes que pueden ser adecuadas para su aplicación futura en la bioconversión del ACG. Además, la alta estabilidad operacional de la $\mathrm{CHasa}_{\mathrm{NI}}$ propicia su aplicabilidad para la hidrólisis continua de este sustrato presente en extractos naturales.

\section{$3^{\circ}$ Etapa}

- El extracto de yerba mate se hizo circular a través de un biorreactor de lecho empaquetado conteniendo la $\mathrm{CHasa}_{\mathrm{NI}}$ como relleno, obteniéndose rendimientos del $100 \%$ de conversión al trabajar a un caudal de 13,6 ml/h.

- Se confirmó la eficacia de la $\mathrm{CHasa}_{\mathrm{NI}}$ como biocatalizador inmovilizado estable con actividad CHasa, y su estabilidad para usos repetidos por al menos varias veces ( $\sim 12 \mathrm{~h}$ de uso repetido) sin pérdida apreciable de la actividad catalítica.

- Se alcanzaron conversiones de AC y AQ mayores al $100 \%$, lo cual se podría deber a que tanto el AC como el AQ fueron liberados a partir de otros ésteres diferentes al ACG por la acción de otras esterasas fúngicas intracelulares (además de CHasa).

- No se observó formación de gas causada por la respiración del micelio al hacer circular una solución de ACG a través del biorreactor de lecho empaquetado, debido a que la actividad microbiana ha sido eliminada luego del tratamiento térmico de los pellets de A. niger AKU 3302. 
A modo de corolario final para el presente trabajo de Tesis se puede decir que:

Se espera que la CHasa $_{\mathrm{NI}}$ de $A$. niger AKU 3302 desarrollada en este estudio contribuya a una producción de AQ a mayor escala, a partir de extractos acuosos de palos verdes de yerba mate, un residuo poco valorado en la industria yerbatera. De esta manera, el AQ obtenido podría ser utilizado para su posterior bioconversión en ácido siquímico (precursor directo de la síntesis química de la droga antiviral Oseltamivir, el principio activo del Tamiflú ${ }^{\mathrm{MR}}$ ) y otros metabolitos importantes generados a partir de la ruta metabólica del ácido siquímico (ácidos dehidroquínico y dehidrosiquímico y otros compuestos aromáticos de potencial importancia en las industrias farmacéuticas, bioquímicas y agrícolas). 


\section{REFERENCIAS BIBLIOGRÁFICAS}

- Abdel-Naby M. A. (1993). Immobilization of Aspergillus niger NRC 107 xylanase and $\beta$-xylosidase, and properties of the immobilized enzymes. Appl. Biochem. Biotechnol., 38: 69-81.

- Adachi, O., Ano, Y., Akakabe, Y., Shinagawa, E., Matsushita, K. (2008). Coffee pulp koji of Aspergillus sojae as stable immobilized catalyst of chlorogenate hydrolase. Applied Microbiology and Biotechnology, 81: 143-151.

- Adachi, O., Ano, Y., Toyama, H., Matsushita, K. (2006a). High shikimate production from quinate with two enzymatic systems of acetic acid bacteria. Bioscience. Biotechnology and Biochemistry, 70: 2579-2582.

- Adachi, O., Ano, Y., Toyama, H., Matsushita, K. (2006b). Purification and characterization of shikimate dehydrogenase from Gluconobacter oxydans IFO 3244 and its application to enzymatic shikimate production. Bioscience, Biotechnology and Biochemistry, 70: 2786-2789.

- Adachi, O., Ano, Y., Toyama, H., Matsushita, K. (2006c). Enzymatic preparation of metabolic intermediates, 3-dehydroquinate and 3dehydroshikimate, in the shikimate pathway. Bioscience, Biotechnology and Biochemistry, 70: 3081-3083.

- Aguiar Prudêncio A. P., Schwinden Prudêncio E., Castanho Amboni R. D. M., Negrão Murakami A. N., Maraschin M., Cunha Petrusc J. C., Ogliarid P. J., Santos Leite R. (2012). Phenolic composition and antioxidant activity of the aqueous extract of bark from residues from mate tree (Ilex paraguariensis St. Hil.) bark harvesting concentrated by nanofiltration. Food and Bioproducts Processing, 90: 399-405.

- Amable M. A., Dohmann K., Rojas L. M. (1997). La yerba misionera: el árbol de nuestra historia. En: Primer Encuentro del Mercosur: Patrimonio Jesuítico, Buenos Aires.

- Ashihara H., Crozier A. (2001). Caffeine: a well known but little mentioned compound in plant science. Trends in Plant Science, 6: 407-413.

- Ashihara H., Suzuki T. (2004). Distribution and biosynthesis of caffeine in plants. Frontiers in Bioscience, 9: 1864-1876. 
- Asther M., Estrada Alvarado M. I., Haon M., Navarro D., Asther M., LesageMeessen L., Record E. (2005). Purification and characterization of a chlorogenic acid hydrolase from Aspergillus niger catalysing the hydrolysis of chlorogenic acid. J. Biotechnol., 115: 47-56.

- Athayde M. L., Coelho G. C., Schenkel E. P. (2000). Caffeine and theobromine in epicuticular wax of Ilex paraguariensis A. St.-Hil. Phytochemistry, 55(7): 853-857.

- Balaji S., Kumar M. S., Karthikeyan R., Kumar R., Kirubanandan S., Sridhar R., Sehgal P. K. (2008).Purification and characterization of an extracellular keratinase from a hornmeal-degrading Bacillus subtilis MTCC (9102). World J. Microbiol. Biotechnol., 24(11): 2741-2745.

- Balasundram N., Sundram K., Samman S. (2006). Phenolic compounds in plants and agri-industrial by-products: Antioxidant activity, occurrence, and potential uses. Food Chemistry, 99(1): 191-203.

- Barbe C., Dubourdieu D. (1998). Characterization and purification of a cinnamate esterase from Aspergillus niger industrial pectinase preparation. $J$. Sci. Food Agric., 78: 471-478.

- Barchuk R. D. (1998). Aporte nutricional de la yerba mate. M.Sc. Thesis. Facultad de Medicina, Universidad Nacional del Nordeste, Argentina.

- Bassani D. C., Nunes D. S., Granato D. (2014). Optimization of Phenolics and Flavonoids Extraction Conditions and Antioxidant Activity of Roasted YerbaMate Leaves (Ilex paraguariensis A. St.-Hil., Aquifoliaceae) using Response Surface Methodology. Anais da Academia Brasileira de Ciências, 86 (2): 923933.

- Bastos D. H. M., Fornari A. C., Queiroz Y. S., Torres E. A. F. S. (2006). Bioactive compounds content of chimarrão infusions related to the moisture of yerba maté (Ilex paraguariensis) leaves. Brazilian Archives of Biology and Technology, 49: 399-404.

- Bastos D. H. M., Oliveira D. M., Matsumoto R. L. T., Oliveira P. C., Ribeiro M. L. (2007). Yerba mate: Pharmacological properties research and biotechnology. Med. Arom. Plant. Sci. Biotec., 1(1): 37-46. 
- Benoit I., Asther M., Bourne Y., Navarro D., Canaan S., Lesage-Meessen L., Herweijer M., Coutinho P. M., Asther M., Record E. (2007). Gene overexpression and biochemical characterization of the biotechnologically relevant chlorogenic acid hydrolase from Aspergillus niger. Appl. Environ. Microbiol., 73 (17): 5624-5632.

- Benoit I., Asther M., Sulzenbacher G., Record E., Marmuse L., Parsiegla G., Gimbert I., Asther M., Bignon C. (2006). Respective importance of protein folding and glycosylation in the thermal stability of recombinant feruloyl esterase. FEBS Lett., 580: 5815-5821.

- Bergmeyer H. U., Bernt E. (1974). D-Glucose determination with glucose oxidase and peroxidase. Methods of Enzymatic Analysis, 2(3): 1205-1206.

- Bixby M., Spieler L., Menini T., Gugliucci A. (2005). Ilex paraguariensis extracts are potent inhibitors of nitrosative stress: A comparative study with green tea and wines using a protein nitration model and mammalian cell cytotoxicity. Life Sci., 77(3): 345-358.

- Blanch H. W., Clark D. S. (1997). Biochemical Engineering. Second Edition. Chapter 5: Mass Transfer Coupled with Biological Reaction, pp. 431-432.

- Bonpland A. (1897). Notas sobre la utilidad de trabajar los yerbales. En: Revista Farmacéutica T: V: Buenos Aires. Cit. En: María Angélica Amable y Liliana Mirta Rojas, Historia de la yerba mate en Misiones. Posadas, Ediciones Montoya, 1989, pp. 82.

- Bortolussi A., Pascualato R., Gueser G., Cardozo E., Donaluzi C., Mitsui M. (2006). Cuantificacao de metilxantinas e compostos fenólicos en amostras comerciais de erva-mate (Ilex paraguariensis Saint. Hilaire). Actas del IV Congreso Sudamericano de Yerba Mate. Argentina, 5-8/11/2206, pp. 143-147.

- Bracesco N., Sanchez A. G., Contreras V., Menini T., Gugliucci A. (2011). Recent advances on Ilex paraguariensis research: Minireview. J. of Ethnopharmacol., 136(3): 378-384.

- Braun S., Vecht-Lifshitz S. E. (1991). Mycelial morphology and metabolite production. TIBTECH, 9: 63-68.

- Bravo L., Goya L., Lecumberri E. (2006). LC/MS characterization of phenolic constituents of mate (Ilex paraguariensis A. St. Hil) and its antioxidant activity 
compared to commonly consumed beverages. Food Research International, 40: 393-405.

- Bucic'-Kojic' A., Planinic' M., Tomas S., Bilic' M., Velic D. (2007). Study of solid-liquid extraction kinetics of total polyphenols from grape sedes. Journal of Food Engineering, 81: 236-242.

- Cacace J. E., Mazza G. (2003). Mass transfer process during extraction of phenolic compounds from milled berries. Journal of Food Engineering, 59: 379 $-389$.

- Calixto-Romo M. A., Santiago-Hernandez J. A., Vallejo-Becerra V., AmayaDelgado L., Montes- Horcasitas M. C., Hidalgo-Lara M. E. (2008). Expression, purification and immobilization of the intracellular invertase INVA, from Zymomonas mobilison crystalline cellulose and Nylon-6. J. Ind. Microbiol., 35: 1455-1463.

- Cardozo E. L., Ferrarese-Filho O., Cardozo Filho L., Ferrarese M. L. L., Donaduzzi C. M., Sturion J. A. (2007). Methylxanthines and phenolic compounds in mate (Ilex paraguariensis St. Hil.) progenies grown in Brazil. Journal of Food Composition and Analysis, 20: 553-558.

- Carducci C. N., Dabas P. C., Muse J. O. (2000). Determination of Inorganic Cations by Capillary Ion Electrophoresis in Ilex paraguariensis (St. H.), a Plant Used to Prepare Tea in South America. Journal of AOAC International, 83(5): 1167-1173.

- Carini M., Facino R. M., Aldini G., Calloni M., Colombo L. (1998). Characterization of phenolics antioxidants from mate (Ilex paraguariensis) by liquid chromatography mass spectrometry and liquid chromatography tandem mass spectrometry. Rapid Communications in Mass Spectrometry, 12: 18131819.

- Chang S. I., Shin P. K., Kim B. H. (2000). Biological treatment of acid mine drainage under sulphate-reducing conditions with solid waste materials as substrate. Water Research, 34 (4): 1269-1277.

- Changa M. Y., Juangb R. S. (2005). Activities, stabilities, and reaction kinetics of three free and chitosan-clay composite immobilized enzymes. Enzyme Microb. Technol., 36: 75-8. 
- Chen J. H., Ho C. T. (1997). Antioxidant activities of caffeic acid and its related hydroxycinnamic acid compounds. J. Agric. Food Chem., 45: 2374-2378.

- Cheong Y. W., Min J. S., Kwon K. S. (1998). Metal removal efficiencies of substrates for treating acid mine drainage of a Dalsung mine, South Korea. Journal of Geochemical Exploration, 64: 147-152.

- Chu F. K., Trimble R. B., Maley F. (1978) The effect of carbohydrate depletion on the properties of yeast external invertase. J. Biol. Chem., 253:8691-8693

- Chun O. K., Kim D. O. (2004). Consideration on equivalent chemicals in total phenolic assay of chlorogenic acid-rich plums. Food Research International, 37: $337-342$.

- Clifford M. N. (1985). Chemical and physical aspects of green coffee and coffee products. Coffee: botany, biochemistry and production of beans and beverage, 305-374.

- Clifford M. N. (1990). Chlorogenic acids and purine alkaloids contents of mate (Ilex paraguariensis) leaf and beverage. Food Chemistry, 35: 13-21.

- Clifford M. N. (1999). Chlorogenic acids and other cinnamates-nature, occurrence and dietary burden. Journal of the Science of Food and Agriculture, 79: $362-372$.

- Clifford M. N. (2000). Chlorogenic acids and other cinnamates-nature, occurrence, dietary burden, absorption and metabolism. Journal of the Science of Food and Agriculture, 80: 1033-1043.

- Clifford M. N., Wu W., Kuhnert N. (2006). The chlorogenic acids of Hemerocallis. Food Chemistry, 95: 574-578.

- Couteau D., McCartney A. L., Gibson G. R., Williamson G., Faulds C. B. (2001). Isolation and characterization of human bacteria able to hydrolyse chlorogenic acid. J. Appl. Microbiol.; 90: 873-881.

- Da Croce D. M. (2002). Características fisicoquímicas de extractos de erva-mate (Ilex paraguariensis St. Hil) no estado de Santa Catarina. Ciencia Forestal, 12(2): 107-113 (in Portuguese).

- Dalfard A. B., Kajeh K., Soudi M. R., Naderi-Manesh H., Ranjbar B., Sajedi R. H. (2006). Isolation and biochemical characterization of laccase and tyrosinase 
activities in a novel melanogenic soil bacterium. Enzyme Microb. Technol., 39: $1409-1416$.

- Day S. H., Legge R. L. (1995). Immobilization of tyrosinase for use innonaqueous media: enzyme deactivation phenomena. Biotech. Tech., 9: 471476.

- De Bernardi L. A. y Prat Krikum S. D. (2001). Cadena alimentaria de la Yerba Mate. Diagnóstico de la región yerbatera. En www.sagpya.mecon.gov.ar /0-3/in Fusion/diagnóstico/diagnost_YM.htm

- Delage E., Bohuon G., Baron A., Drilleau J. F. (1991). High-performance liquid chromatography of the phenolic compounds in the juice of some French cider apple varieties. Journal of Chromatography A., 555: 125-136.

- Dickel M. L., Rates S. M. K., Ritter M. R. (2007). Plants popularly used for losing weight purposes in Porto Alegre, South Brazil. J. Ethnopharmacol, 109(1): 60-71.

- Doehlert D. H. (1970). Uniform shell designs. Appl. Stat. 231-239.

- Drury W. J. (1999). Treatment of acid mine drainage with anaerobic solid substrate reactors. Water Environment Research, 71: 1244-1250.

- Dvorak D. H., Hedin R. S., Edenborn H. M., McIntire P. E. (1992). Treatment of metalcontaminated water using bacterial sulphate reduction: results from pilotscale reactors. Biotechnology and Bioengineering, 40: 609.

- Elliott P., Ragusa S., Catcheside D. (1998). Growth of sulfate-reducing bacteria under acidic conditions in an upflow anaerobic bioreactor as a treatment system for acid mine drainage. Water Research, 32 (12): 3724-3730.

- Elnashar M. M., Yassin M. A. (2009). Lactose hydrolysis by $\beta$-galactosidase covalently immobilized to thermally stable biopolymers. Appl.Biochem.Biotechnol., 159(2): 426-437.

- Enserink M. (2006). Oseltamivir becomes plentiful-but still not cheap. Science, 312: $382-383$.

- Escalada G., Brumovsky L. A., Hartwig V. G. (2011). Influencia de la zona de cultivo y procesamiento de la yerba mate sobre su contenido de polifenoles totales y capacidad antioxidante. Revista de Ciencia y Tecnología, 13(15): 66-74 (in Spanish). 
- Fang N., Yu S., Prior R. L. (2002). LC/MS/MS characterization of phenolic constituents in dried plums. Journal of Agricultural and Food Chemistry, 50: 3579-3585.

- Fernández P. L., Pablos F., Martin M. J., González A. G. (2002). Study of catechin and xanthine tea profiles as geographical tracers. Journal of Agricultural and Food Chemistry, 50: 1833-1839.

- Filip R., Davicino R., Anesini C. (2010). Antifungal activity of the aqueous extract of Ilex paraguariensis against Malassezia furfur. Phytotherapy Res., 24: 715-719.

- Filip R., López P., Giberti G. C., Coussio J., Ferraro G. (2001). Phenolic compounds in seven South American Ilex species. Fitoterapia, 72: 774-778.

- Filip R., Lotito S. B., Ferraro G., Frag C. G. (2000). Antioxidant activity of Ilex paraguariensis and related species. Nutrition Research, 20(10):1437-1446.

- Freund R. J., Wilson W. J. (1997). Statistical Methods. Ed. Academic Press. USA.

- Furlong G. (1978). Misiones y sus pueblos de guaraníes. Posadas. Lumicop, pp. 416.

- Garlapati V. K., Banerjee R. (2013). Solvent-free synthesis of flavour esters through immobilized lipase mediated transesterification. Enzyme Research.

- Giberti G. C. (1989). Los parientes silvestres de la yerba maté y el problema de su adulteración. Dominguezia, 7(1): 3-21.

- Gnoatto S. C. B., Schenkel E. P., Bassani V. L. (2005). HPLC method to assay total saponins in Ilex paraguariensis aqueous extract. J. Braz. Chem. Soc., 4: 723-726.

- Gorzalczany S., Filip R., Alonso M. R., Mino J., Ferraro G., Acevedo C. (2001), Choleretic effect and intestinal propulsion of "mate" (Ilex paraguariensis) and its substitutes or adulterants. J. Ethnopharmacol., 75: 201-294.

- Gosmann G., Guillaume D., Taketa A. T. C., Schenkel E. P. (1995) Triterpenoid saponins from Ilex paraguariensis. J. Nat. Prod., 58(3): 438-441.

- Gulati A., Ravindranath S. D. (1996). Seasonal variations in quality of kangra tea (Camellia sinensis (L) O Kuntze) in Himachal Pradesh. Journal of the Science of Food and Agriculture, 71: 231-236. 
- Halaouli S., Asther M., Kruus K., Guo L., Hamdi M., Sigoillot J. C., Asther M., Lomascolo A. (2005). Characterization of a new tyrosinase from Pycnoporus species with high potential for food technological applications. J. Appl. Microbiol., 98: 332-343.

- Hallé F., Oldeman R. A. A., Tomlinson P. B. (1978). Tropical trees and forests: an architectural analysis. Berlin: Springer-Verlag.

- Hamada S., Slade H. D. (1980). Biology, immunology and cariogenicity of Streptococcus mutans. Microbiol. Rev., 44: 331-384.

- Heck C. I., González de Mejía, E. (2007). Yerba mate tea (Ilex paraguariensis): A comprehensive review on Chemistry, health implications, and technological considerations. Journal of Food Science, 72(9): 138-150.

- Heck C. I., Schmalko M., González de Mejía, E. (2008). Effect of growing and drying conditions on the phenolic composition of mate teas (Ilex paraguariensis). Journal of Agricultural and Food Chemistry, 56: 8394-8403.

- Heinrichs R., Malavolta E. (2001). Mineral Composition of a Commercial Product from Mate-Herb (Ilex paraguariensis St. Hil.). Ciência Rural, Santa Maria, 31(5): 781-785.

- Hofmann A., Reimold U. W., Koeberl C. (2006). Archean spherule layers in the Barberton Greenstone Belt, South Africa: A discussion of problems related to the impact interpretation, in: W.U. Reimold and R. Gibson (Editors), Processes on the Early Earth. Geological Society of America Special Paper, 405: 33-56.

- Holovatty S. E. (2007). Contenido de polifenoles totales y capacidad antioxidante durante el procesamiento de la yerba mate. Tesis de Magíster en Tecnología de los Alimentos. Universidad Nacional de Misiones. Facultad de Ciencias, Exactas, Químicas y Naturales.

- Hota S. K., Dutta J. R., Banerjee R. (2007). Immobilization of tannase from Rhizopus oryzae and its efficiency to produce gallic acid from tannin rich agroresidues. Indian J. Biotechnol., 6(2): 200-204.

- IRAM Nro. 20503, 1995 - Instituto Argentino de Racionalización de Materiales - Norma 20503: Yerba mate: Determinación de la pérdida de masa a $103{ }^{\circ} \mathrm{C}$. 
- Isolabella S., Cogoi L., López P., Anesini C., Ferraro G., Filip R. (2010). Study of the bioactive compounds variation during yerba mate (Ilex paraguariensis) processing. Food Chemistry, 122: 695-699.

- Jaiswal R., Sovdat T., Vivian F., Kuhnert N. (2010). Profiling and characterization by LC-MSn of the chlorogenic acids and hydroxycinnamoylshikimate esters in mate (Ilex paraguariensis). Journal of Agricultural and Food Chemistry, 58: 5471-5484.

- Jiang B., Zhang Y. (1993). Immobilization of catalase on crosslinked polymeric hydrogels effect of anion on the activity of immobilized. Eur.Polym. J., 29: 1251-1254.

- Jiang Y., Satoh K., Kusama K. (2000). Interaction between chlorogenic acid and antioxidants. Anticancer Research, 20: 2473-2476.

- Jin U. -H., Lee J. -Y., Kang S. -K., Kim J. -K., Park W. -H., Kim J. -G., Moon S. -K., Kim C. -H. (2005). A phenolic compound, 5-caffeoylquinic acid (chlorogenic acid), is a new type and strong matrix metalloproteinase-9 inhibitor: Isolation and identification from methanol extract of Euonymus alatus. Life Science, 77: 2760-2769.

- Johnson D. B., Hallberg K. B. (2005). Biogeochemistry of the compost bioreactor components of a composite acid mine drainage passive remediation system. Science of Total Environment, 338: 81-93.

- Jokić S., Velić D., Bilić M., Bucić-Kojić A., Planinić, M., Tomas, S. (2010). Modelling of the Process of Solid-Liquid Extraction of Total Polyphenols from Soybeans. Czech J. Food Sci., 28 (3): 206 - 212.

- Jong T., Parry D. L. (2003). Removal of sulfate and heavy metals by sulfate reducing bacteria in short-term bench scale upflow anaerobic packed bed reactor runs. Water Research, 37: 3379-3389.

- Koeller K. M., Wong C. H. (2001). Enzymes for chemical synthesis. Nature, 409: 232-240.

- Kragl U., Kruse W., Hummel W., Wandrey C. (1996). Enzyme engineering aspects of biocatalysis: cofactor regeneration as example. Biotechnol. Bioeng., 52: 309-319. 
- Kubo I., Muroi H., Masaki H. (1993). Antibacterial activity against Streptococcus mutans of mate tea flavor components. J. Agr. Food Chem., 41: 107-111.

- Kweon M. H., Hwang H. J., Sung H. C. (2001). Identification and antioxidant activity of novel chlorogenic acid derivatives from bamboo (Phyllo stachys edulis). Journal of Agricultural and Food Chemistry, 49: 4646-4655.

- Légier V., Comeau L. (1992). Continuous synthesis of esters by cell-bound fungal lipases in an organic solvent. Applied Microbiology and Biotechnology, 37: 732-736.

- Li H., Chen B., Yao, S. (2005). Application of ultrasonic technique for extracting chlorogenic acid from Eucommia ulmodies Oliv. (E. ulmodies). Ultrasonics Sonochemistry, 12: 295-300.

- Linares A. R., Hase S. L., Vergara, M. L., Resnik S.L. (2010). Modelling yerba mate aqueous extraction kinetics: influence of temperature. Journal of Food Engineering, 97: 471-477.

- López O., Isolabella S., Anesini C., Ferraro G., Filip R. (2006). Estudio cualicuantitativo por HPLC de los principios activos presentes en los extractos de Ilex paraguarienses (yerba mate) en las diferentes etapas del procesamiento industrial. In Annals of IV South-American Congress on Yerba Mate (1st Ed.). Posadas, Argentina (in Spanish).

- Lunceford N., Gugliucci A. (2005). Ilex paraguariensis extracts inhibit AGE formation more efficiently than green tea. Fitoterapia, 76: 419 - 427.

- Manach C., Scalbert A., Morand C., Remesy C., Jimenez L. (2004). Polyphenols: Food sources and bioavailability. Am. J. Clin. Nutr., 79: 727-747.

- Marques A., Donangelo C. M. (2006). Phenolic compounds in coffee. Brazilian Journal of Plant Phytopatology, 18: 23-36.

- Marques V., Farah A. (2009). Chlorogenic acids and related compounds in medicinal plants and infusions. Food Chemistry, 113: 1370-1376.

- Matheis G. (1983). Enzymatic browning of foods. - Z. Lebensm. Unters. Forsch. 176: 454-462.

- Mazzafera P. (1994). Caffeine, theobromine and theophylline distribution in Ilex paraguariensis. Revista Brasilera de Fisiología Vegetal, 6: 149-151. 
- Mazzafera P., Yamaoka-Yano D. M., Vitoria A. P. (1996). Para que serve a cafeína em plantas? Revista Brasileira de Fisiologia Vegetal, 8(1): 67-74.

- Meyer S., Cerovic Z. G., Goulas Y., Montpied P., Demontes-Mainard S., Bidel L. P. R., Moya I., Dreyer E. (2006). Relationships between optically assessed polyphenols and chlorophyll contents and leaf mass per area ratio in woody plants: A signature of the carbon-nitrogen balance within leaves. Plant Cell Environ, 29: 1338-1348.

- Mosimann A. L. P., Wilhelm-Filho D., Silva E. L. (2006). Aqueous extract of Ilex paraguariensis attenuates the progression of atherosclerosis in cholesterolfed rabbits. BioFactors, 23: 1-12.

- Müller V., Chávez J. H., Reginatto F. H., Zucolotto S. M., Niero R., Navarro D., Yunes R. A., Schenkel E. P., Barardi C. R. M., Zanetti C. R., Simões, C. M. O. (2007). Evaluation of antiviral activity of South American plant extracts against herpes simplex virus type 1 and rabies virus. Phytotherapy Research, 21: 970974.

- Muñoz C., Guillen F., Martinez A., Martinez M. (1997). Laccase isoenzymes of Pleurotus eryngu: characterization, catalytic properties, and participation in activation of molecular oxygen and $\mathrm{Mn}^{+2}$ oxidation. Applied and Environmental Microbiology, 63: 2166-2174.

- Mylonaki S., Kiassos E., Makris D. P., Kefalas P. (2008). Optimisation of the extraction of olive (Olea europaea) leaf phenolics using water/ethanol-based solvent systems and response surface methodology. Analytical and Bioanalytical Chemistry, 392: 977 -985.

- Naczk M., Shahidi F. (2004). Extraction and analysis of phenolics in food. Journal of Chromatography A, 1054: 95-111.

- Navajas Artaza A. (1995). La economía yerbatera Argentina. Erva-Mate: Biología e Cultura no Cone Sul. Universidad Federal do Rio Grande do Sul. Porto Alegre, Brasil: Editora da Universidade (in Portuguese), pp. 23-26.

- Nawaz H., Shi J., Mittal G. S., Kakuda Y. (2006). Extraction of polyphenols from grape seeds and concentration by ultrafiltration. Separation and Purification Technology, 48: 176-181. 
- Neculita C. M., Zagury G. J., Bussière B. (2007). Passive treatment of acid mine drainage in bioreactors using sulfate-reducing bacteria: Critical review and research needs. J. Environ. Qual., 36: 1-16.

- Negrão Murakami A. N., Dias de Mello Castanho Amboni R., Schwinden Prudêncio E., Amante E. R., de Moraes Zanotta L., Maraschin M., Cunha Petrus J. C., Teófilo R. F. (2011). Concentration of phenolic compounds in aqueous mate (Ilex paraguariensis A. St. Hil) extract through nanofiltration. Food Science and Technology, 44: 2211-16.

- Okamura S., Watanabe M. (1982a). Measurement of hydroxycinnamic acid ester hydrolase activity by the change of UV absorption. Agric. Biol. Chem., 46: 297299.

- Okamura S., Watanabe M. (1982b). Purification and properties of hydroxycinnamic ester hydrolase from Aspergillus japonicus. Agric. Biol. Chem., 46: 1839-1848.

- Oliva E. V., Reissmann C. B., Gaiad S., Sturion J. A., De Olivera E. B., Wisniewski C., Miaqui D. P. (2006). Composicao química foliar de macronutrientes em precedencias de erva-mate Ilex paraguariensis St. Hil. In Annals of IV South-American Congress on Yerba Mate (1st Ed.). Posadas, Argentina (in Portuguese).

- Pagliosa C. M., Vieira M. A., Podestá R., Maraschin M., Bertello Zeni A. L., Amante E. R., Dias de Mello Castanho Amboni R. (2010). Methylxanthines, phenolic composition, and antioxidant activity of bark from residues from mate tree harvesting (Ilex paraguariensis A. St. Hil). Food Chemistry, 122: 173-178.

- Panke S., Held M., Wubbolts M. (2004). Trends and innovations in industrial biocatalysis for the production of fine chemicals. Curr. Opin. Biotechnol., 15: $272-279$.

- Pencreac'h G., Baratti J. C. (1997). Activity of Pseudomonas cepacia lipase in organic media is greatly enhanced after immobilization on a polypropylene support. Appl. Microbiol. Biotechnol., 47: 630-635.

- Perry R. H., Green D. W. (1984). Perry's Chemical Engineers Handbook. Sixth Edition. New York: McGraw-Hill, pp 3-287. 
- Petzelbauer I., Kuhn B., Splechtna B., Kulbe K. D., Nidetzky B. (2002). Development of an ultrahigh-temperature process for the enzymatic hydrolysis of lactose. IV. Immobilization of two thermostable b-glycosidases and optimization of a packed-bed reactor for lactose conversion. Biotechnol. Bioeng., 77: 619-631.

- Pilosof A. M. R., Boquet R., Bartholomai G. B. (1985). Kinetics of water uptake by food powders. Journal of Food Science, 50: 278-283.

- Pinelo M., Tress A. G., Pedersen M., Arnous A., Meyer A. S. (2007). Effect of cellulases, solvent type and particle size distribution on the extraction of chlorogenic acid and other phenols from spent coffee grounds. American Journal of Food Technology, 2 (7): 641-651.

- Pittler A., Hostettmann K., Schutz Y. (1999). Thermogenic effects of commercially available plant preparations aimed at treating human obesity. Phytomedicine, 6 (4): 231-238.

- Pittler M. H., Ernst E. (2004). Dietary supplements for body-weight reduction: a systematic review. Am. J. Clin. Nutr., 79(4): 529-536.

- Poenitz E., Poenitz A. (1993). Misiones, Provincia Guaranítica. Posadas, Editorial Universitaria (UNAM), pp. 33.

- Puangpraphant S., Mejia, E. G. (2009). Saponins in yerba mate tea (Ilex paraguariensis A. St.-Hil) and quercetin synergistically inhibit iNOS and COX2 in lipopolysaccharide-induced macrophages through NFKB pathways. $J$. Agric. Food Chem., 57: 8873-8883.

- Rakocevic M., Medrado M. J. S., Lucambio F., Valduga T. A. (2006). Caracterização de crescimento do caule da erva-mate (Ilex paraguariensis St. Hil.) cultivada em dois ambientes luminosos contrastantes. In Annals of IV South-American Congress on Yerba Mate (1st Ed.). Posadas, Argentina (in Portuguese).

- Ramallo L. A., Schmalko M. E., Känzig R. G. (1998). Variación de la concentración de ácido ascórbico (Vitamina C) en el procesamiento de la Yerba Mate. Revista de Ciencia y Tecnología, 1: 25-29.

- Ramírez-Mares M. V., Chandra S., Mejia E. G. (2004). In vitro chemopreventive activity of Camellia sinensis, Ilex paraguariensis and Ardisia 
compressa tea extracts and selected polyphenols. Mutation Research/Fundamental and Molecular Mechanisms of Mutagenesis, 554: 53-65.

- Rice-Evans C. A., Miller N. J., Paganga G. (1996). Structure-antioxidant activity relationships of Xavonoids and phenolic acids. Free Radical Biology and Medicine, 20: 933-956.

- Risso F. V. A., Mazutti M. A., Costa F., Treichel H., Maugeri F., Rodrigues M. I. (2010). Comparative studies of the stability of free and immobilized inulinase from Kluyveromyces marxianus NRRL y-7571 in aqueous-organic solutions. Braz. J. Chem. Eng., 27(4): 507-516.

- Robbins R. J. (2003). Phenolic Acids in Foods: An Overview of Analytical Methodology. Journal of Agricultural and Food Chemistry, 51(10): 2866-2887.

- Romano A., Gandolfi R., Molinari F., Converti A., Zilli M., Borghi M. (2005). Esterification of phenylacetic and 2- phenylpropionic acid by mycelium-bound carboxylesterases. Enzyme Microb. Technol., 36: 432-438.

- Rønsted N., Strandgaard H., Jensen S. R., Mølgaard P. (2002). Chlorogenic acid from three species of Hydrostachys. Biochemical Systematics and Ecology, 30: 1105-1108.

- Rostagno H. S., Albino L. F. T., Donzele J. L., Gomes P. C., de Oliveira R. F., Lopes D. C., Ferreira A. S., Toledo Barreto S. L. (2011). Tabelas Brasileiras para Aves e Suínos: Composição de Alimentos e Exigências Nutricionais. $3^{\mathrm{a}}$ ed. UFV/DZO, 2011, pp. 52.

- Ruiz de Montoya A. (1639). La conquista espiritual. Madrid, Imprenta del Reino, pp. 8.

- Sabatella P., Pokolenko J. J., Schmalko M. E. (2009). Influencia de la composición en la extracción de los solubles de la yerba mate. Revista Ciencia y Técnica, 9: 42-47.

- Sanz T., Torija M. D., Isasa M.E. (1991). Elementos minerales en la yerba mate (Ilex paraguariensis St. H.)/Mineral elements in of mate (Ilex paraguariensis St. H.). Arch. latinoam. Nutr.,41(3): 441-454.

- Sareen R., Mishra P. (2008). Purification and characterization of organic solvent stable protease from Bacillus licheniformisRSP-09-37. Appl.Microbiol.Biotechnol., 79(3): 399-405. 
- Sari F., Turkmen N., Polat G., Sedat, Velioglu, Y. (2007). Total Polyphenol, Antioxidant and Antibacterial Activities of Black Mate Tea. Food Sci. Technol. Res., 13(3): 265-269.

- Saville B. A., Khavkine M., Seetharam G., Marandi B., Zuo Y. L. (2004). Characterization and performance of immobilized amylase and cellulase. Appl. Biochem. Biotechnol., 113-116: 251-259.

- Schmalko M. E., Alzamora S. M. (2001). Color, chlorophyll, caffeine, and water content variation during yerba maté processing. Dry. Technol., 19: 597-608.

- Schöbel B., Pollmann W. (1980a). Further characterization of a chlorogenic acid hydrolase from Aspergillus niger. Z. Naturforsch., 35c: 699-701.

- Schöbel B., Pollmann W. (1980b). Isolation and characterization of a chlorogenic acid esterase from Aspergillus niger. Z. Naturforsch, 35c: 209-212.

- Schubert T., Weiler R., Feigenspan A. (2006). Intracellular calcium is regulated by different pathways in horizontal cells of the mouse retina. $J$ Neurophysiol. 96(3): 1278-1292.

- Scipioni G. P., Ferreyra D. J., Acuña M. G., Schmalko M. E. (2010). Rebaudioside A release from matrices used in a yerba maté infusión. Journal of Food Engineering, 100: 627-633.

- Sepp A. (1974). Jardín de Flores Paracuario. Buenos Aires, Eudeba, pp. 86-87.

- Shahidi F., Naczk M. (2004). Phenolics in Food and Nutraceuticals. Boca Raton: CRC Press, pp. 576. Sidra, Sistema IBGE de Recuperação Automática. Produção da Extração vegetal e da Silvicultura. http://www.sidra.ibge.gov.br/bda/tabela/protabl.asp. Consultado el 02 de enero de 2009.

- Shearer J., Farah A., De Paulis T., Bracy D. P., Pencek R. R., Graham T. E., Wasserman D. H. (2003). Quinides of roasted coffee enhance insulin action in conscious rats. Nutrient Metabolism, 133: 3529-3532.

- Shi J., Yu J., Pohorly J., Young C., Bryan M. (2003). Optimization of the extraction of polyphenols from grape seed meal by aqueous ethanol solution. $J$. Food Agric. Environ, 1(2): 42. 
- Silva E. L., Neiva T. J. C., Shirai M., Terao J., Abdalla D. S. P. (2008). Acute ingestion of yerba mate infusion (Ilex paraguariensis) inhibits plasma and lipoprotein oxidation. Food Research International, 41: 973-979.

- Silva M. H. M., Rakocevic M. (2010). Software for interpolation of vegetative growth of yerba mate plants in 3D. Pesquisa Agropecuária Brasileira, 45: 244251.

- Simoes M. O., Schenkel E. P., Gosmann G., Mello J. C. P., Mentz L. A., Petrovick P. R. (2004). Farmacognosia: da planta ao medicamento. 5. ed. Porto Alegre/Florianópolis: Editora da UFRGS/Editora da UFSC, pp. 1102.

- Sonaglio D., Ortega G. G., Petrovicck P. R., Bassani V. L. (2007). Desenvolvimento tecnológico e produção de fitoterápicos. In C. M. Simões, E. P. Schenkel, G. Gosmann, J. C. P. Mello, L. A. Mentz, P. R. Petrovick (Eds.). Farmacognosia - da Planta ao Medicamento. Porto Alegre, Brazil: Editora da UFRG (in Portuguese), pp. 289-326.

- Spiro M., Jago D. S. (1982). Kinetic and equilibrium of tea infusion. Part 3. Rotatingdisc experiment interpreted by a steady-state model. Journal of Chemical Society, Faraday Transaction, 78: 295-305.

- Stanely Mainzen Prince P., Senthil Kumaran K. (2012). Preventive effects of caffeic acid on lipids, lipoproteins and glycoproteins in isoproterenol induced myocardial infarcted rats. Food Res. Int., 45: 155-160.

- Straathof A. J. J., Panke S., Schmid A. (2002). The production of fine chemicals by biotransformations. Curr. Opin. Biotechnol., 13: 548-556.

- Strassmann B. B, Vieira A. R., Pedrotti E. L., Morais H. N., Dias P. F. (2008). Quantitation of methylxanthinic alkaloids and phenolic compounds in mate (Ilex paraguariensis) and their effects on blood vessel formation in chick embryos. $J$ Agric. Food Chem., 56(18): 8348-8353.

- Suzuki T., Waller G. R. (1984). Biosynthesis and bio-degradation of caffeine, theobromine, and theophylline in Coffea arabica L. fruits. Journal of Agricultural and Food Chemistry, 32: 845-848.

- Taiz L., Zeiger E. (2004). Fisiologia Vegetal, 3. ed. Porto Alegre: Artmed, pp. 719. 
- Taketa A. T. L., Gnoatto S. C. B., Gosmann G., Pires V. S. P., Schenkel E.P., Guillaume D. (2004). Triterpenoids from brazilian Ilex species and their in vitro antitrypanosomal activity. J. Nat. Prod., 67: 1697-1700.

- Tari C., Gogus N., Tokatli F. (2007). Optimization of biomass, pellet size and polygalacturonase production by Aspergillus sojae ATCC 20235 using response surface methodology. Enzyme and Microbial Technology, 40(5): 1108-1116.

- Topakas E., Vafiadi C., Christakopoulos P. (2007). Review: Microbial production, characterization and applications of feruloyl esterases. Process Biochem., 42: 497-509.

- Tsukamoto T. K., Killion H. A., Miller G. C. (2004). Column experiments for microbiological treatment of acid mine drainage: low-temperature, low-pH and matrix investigations. Water Research, 38 (6): 1405-1418.

- Tsukamoto T. K., Miller G. C. (1999). Methanol as a carbon source for microbiological treatment of acid mine drainage. Water Research, 33(6): 13651370.

- Tu M., Zhang X., Kurabi A., Gilkes N., Mabee W., Saddler J. (2006). Immobilization of $\beta$-glucosidase on Eupergit $\mathrm{C}$ forlignocellulose hydrolysis. Biotechnol. Lett., 28(3): 151-156.

- Valduga A. T., Finzer J. R. D., Mosele S. H. (2003). Processamento de ervamate. Erechim: Edifapes, 183.

- Valivety R. H., Halling P. J., Peilow A. D., Macrae A. R. (1994). Relationship between water activity and catalytic activity of lipases in organic media. Effects of supports, loading and enzyme preparation. Eur. J. Biochem., 222: 461-466.

- Vieira M., Maraschin M., Pagliosa C., Podestá R., de Simas K., Rockenbach I., Amboni R., Amante E., (2010). Phenolic acids and methylxanthines composition and antioxidant properties of mate (Ilex paraguariensis) residue. $J$. Food Sci., 75(3): 280-285.

- Wandrey C. (2004). Biochemical reaction engineering for redox reactions. Chem. Rec., 4: 254-265.

- Wang Z. -G., Wang J. -Q., Xu Z. -K. (2006). Immobilization of lipase from Candida rugosa on electrospun polysulfone nanofibrous membranes by adsorption. Journal of Molecular Catalysis B: Enzymatic, 42: 45-51. 
- Willow M. A., Cohen R. R. H. (2003). pH, dissolved oxygen and adsorption effects on metal removal in anaerobic bioreactors. Journal of Environmental Quality, 32: 1212-1221.

- Wrobel K., Colunga, Urbina E. M. (2000). Determination of total aluminum, chromium, copper, iron, manganese, and nickel and their fractions leached to the infusions of black tea, green tea, Hibiscus sabdariffa, and Ilex paraguariensis (mate) by ETA-AAS. Biol. Trace Elem. Res., 78: 271-280.

- Wyss D. F., Wagner G. (1996) The structural role of sugars in glycoprotein. Curr. Opin. Biotechnol., 7: 409-416.

- Yadav G. D., Trivedi A. H. (2003). Kinetic modeling of immobilized-lipase catalysed transesterification of n-octanol with vinyl acetate in non-aqueous media. Enzyme Microb. Technol., 32: 783-789.

- Ye P., Xu Z. K., Wu J., Innocent C., Seta P. (2006). Nanofibrous poly (acrylonitrile-co-maleic acid) membranes functionalized with gelatinand chitosan for lipase immobilization. Biomaterials, 27: 4169-4176.

- Zanoelo E. F., Cardozo Filho L., Cardozo Junior E. L. (2006). Superheated steam-drying of mate leaves and effect of drying conditions on the phenol content. Journal of Food Process Engineering, 29: 253-268. 